\title{
Measurements of NORM in Beach Sand Samples along the Andaman Coast of Thailand after the 2004 Tsunami
}

\author{
by \\ Doendara Malain \\ UNUERSITYF
}

A thesis Submitted at the University of Surrey for the Degree of Doctor of Philosophy

Department of Physics

Faculty of Engineering and Physical Sciences

University of Surrey

July 2011

(C) Doendara Malain 2011 
ProQuest Number: 27607817

All rights reserved

INFORMATION TO ALL USERS

The quality of this reproduction is dependent upon the quality of the copy submitted.

In the unlikely event that the author did not send a complete manuscript and there are missing pages, these will be noted. Also, if material had to be removed, a note will indicate the deletion.

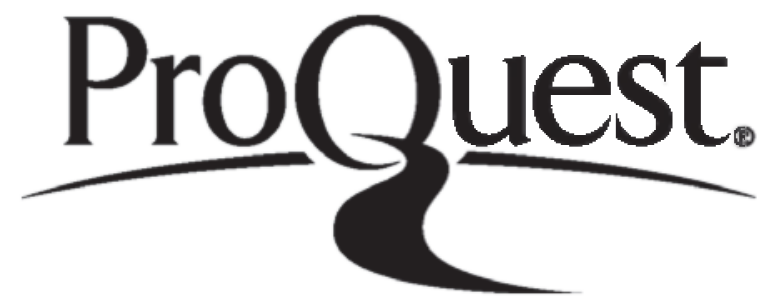

ProQuest 27607817

Published by ProQuest LLC (2019). Copyright of the Dissertation is held by the Author.

All rights reserved.

This work is protected against unauthorized copying under Title 17, United States Code Microform Edition (C) ProQuest LLC.

ProQuest LLC.

789 East Eisenhower Parkway

P.O. Box 1346

Ann Arbor, Ml $48106-1346$ 


\section{Abstract}

A hyper-pure germanium detector-based, gamma-ray spectroscopy, low-background counting system was used to determine the level of natural radioactivity from beach sand samples collected from various locations along the Andaman coast of Thai peninsula following the 2004 tsunami. The activity concentrations of ${ }^{226} \mathrm{Ra},{ }^{232} \mathrm{Th}$ and ${ }^{40} \mathrm{~K}$ were found to lie in the range of $1.6 \pm 0.1 \leftrightarrow 52.5 \pm 0.8,0.3 \pm 0.1 \leftrightarrow 73.9 \pm 1.5$ and $2.8 \pm 0.1 \leftrightarrow 1,111.9 \pm 116.5$ Bq. $\mathrm{kg}^{-1}$ respectively for the west coast and $3.5 \pm 0.1 \leftrightarrow 83.1 \pm 1.2,4.5 \pm 0.1 \leftrightarrow 42.0 \pm 0.9$, and $9.6 \pm 1.1 \leftrightarrow 1,376 \pm 144 \mathrm{~Bq} \cdot \mathrm{kg}^{-1}$ respectively for the east coast. The radioactivity concentrations of ${ }^{226} \mathrm{Ra},{ }^{232} \mathrm{Th}$ and ${ }^{40} \mathrm{~K}$ along the Andaman coast are comparable to that of the east coast, which was not exposed to the tsunami. The activity concentration of artificial radionuclides (ie. ${ }^{137} \mathrm{Cs}$ ) was found to be below the minimum detectable activity. The derived values for external and internal hazard indices for sand samples obtained in this study ranges from $0.01-0.50$ and $0.01-0.72$ respectively while the radium equivalent activity varied from $2.8-184.8 \mathrm{~Bq} \cdot \mathrm{kg}^{-1}$ which are lower than the internationally approved values of $<1$ for $H_{\mathrm{ex}}$ and $H_{\text {in }}$ and $<370 \mathrm{~Bq} \cdot \mathrm{kg}^{-1}$ for $\mathrm{Ra}_{\text {eq }}$. None of beach sand samples which were studied could be considered as a radiological hazard to people who were exposed to them. The monitored areas are at the typical local level of radioactivity from natural background radiation. The gamma absorbed dose rates due to ${ }^{226} \mathrm{Ra},{ }^{232} \mathrm{Th}$ and ${ }^{40} \mathrm{~K}$ in the sand samples varied in the range $1.3 \pm 0.1$ to $86.4 \pm 2.5 \mathrm{nGy} \cdot \mathrm{h}^{-1}$ with an average value of $48 \pm 1 \mathrm{nGy} \cdot \mathrm{h}^{-1}$. Assuming a $20 \%$ outdoor occupancy factor, the corresponding annual effective dose varied from $1.6 \pm 0.1$ to $105.9 \pm 3.1 \mu \mathrm{Sv}^{-y^{-1}}$ with a mean value of $59.1 \pm 0.3$ $\mu S v \cdot y^{-1}$, significantly lower than the worldwide average value of $0.07 \mathrm{mSv}^{-y^{-1}}$ for the annual outdoor effective dose as reported by UNSCEAR(2000). 


\section{Acknowledgments}

I would like to express my sincere gratitude first of all to my supervisor, Prof. Patrick Regan for all his kindness, guidance and advice throughout this research and encouraging me to go ahead with my research with confidence. I also would like to thank Prof. David Bradley and Dr Marcus Matthews who acted as second supervisors, for their valuable discussions.

I am deeply indebted to the laboratory technicians, Mr James Wallbank, Mr John-William Brown and Mr Gary Strudwick for all their technical advice and support. A special thanks to my colleagues for all their substantial suggestion and assistance. The BSc and MSc students whom I have been supervised are also in appreciations for their help in parts of my PhD work.

I also would like to gratefully acknowledge to the Royal Thai Government for providing the fund to the Office of Atoms for Peace (OAP), Ministry of Science and Technology to sponsor my research. I am also very grateful to the Centre for Nuclear and Radiation Physics (CNRP) at the University of Surrey for providing the various facilities and to the Department of Mineral Resources (DMR) in Thailand for allowing me to access the Thai geological data.

Finally, I would like to thank my family for all their love and support during four years as a research student. Even they could not come to visit me in the UK, every call from Thailand is more than valued for me and made me feel less homesick. Apart from these, I would like to thank the Surrey Sport Park and Student Union for their activities that made my life in UK more healthy and enjoyable. I am also grateful for the good times at 18 , St. John Road with my lovely housemates Jariyavadee, Somporn and Patnarin, who had also worked hard together as a committee for the Thai society including all Thai and overseas friends who made every moment in UK unforgetable. 


\section{Contents}

Abstract

Acknowledgements ....................................................................................... ii

Contents

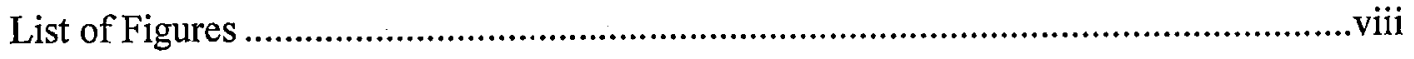

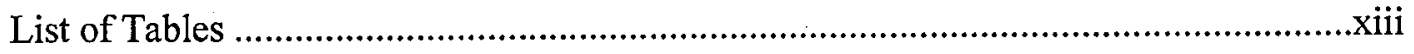

Glossary of Terms

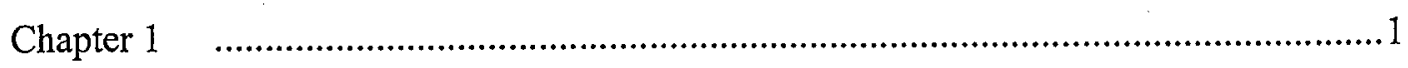

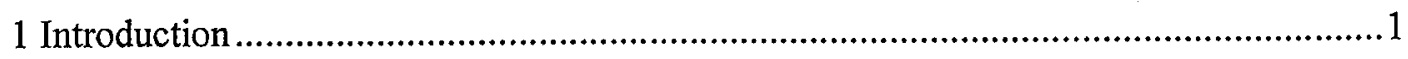

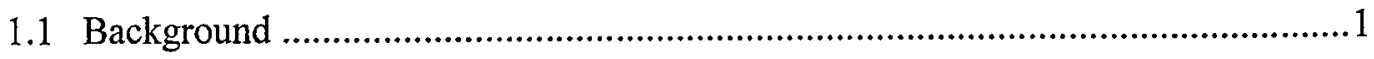

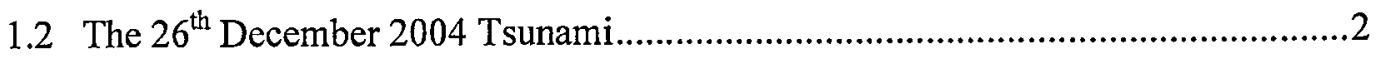

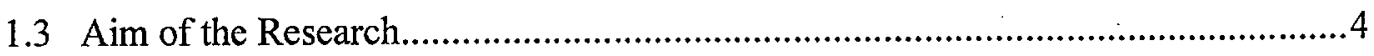

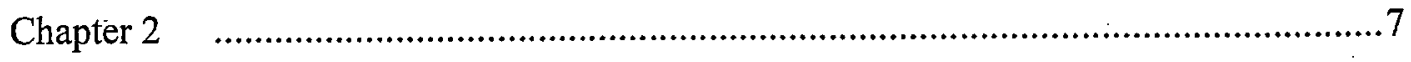

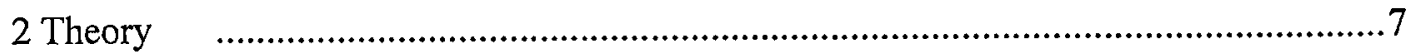

2.1 The Natural Uranium-Thorium Decay Chains ..................................................

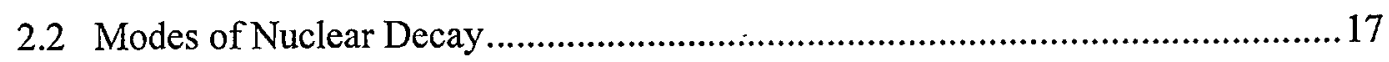

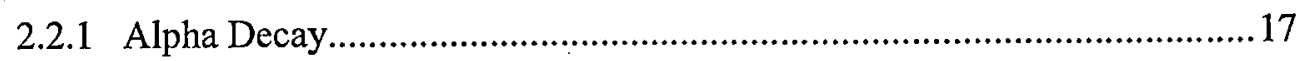

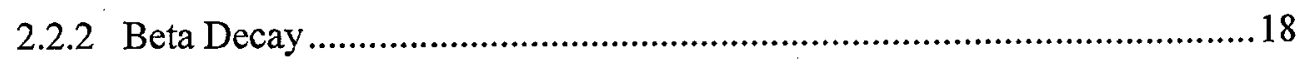

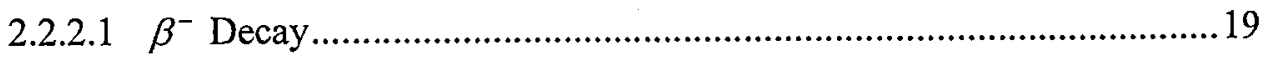

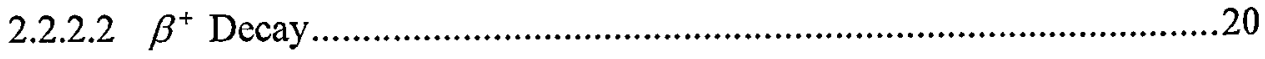

2.2.2.3 Orbital Electron Capture ............................................................21

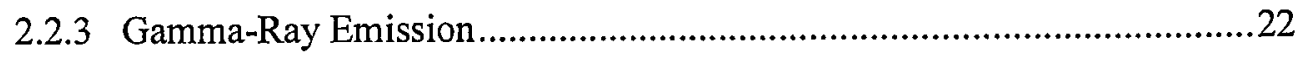

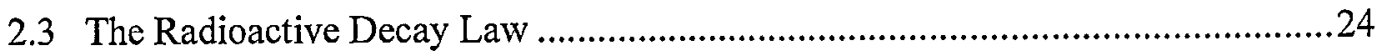




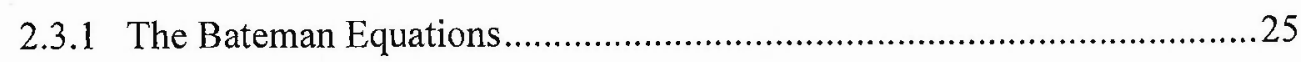

2.3.2 The Genealogically Ordered Exit-only Decay (GOED) Chain ................27

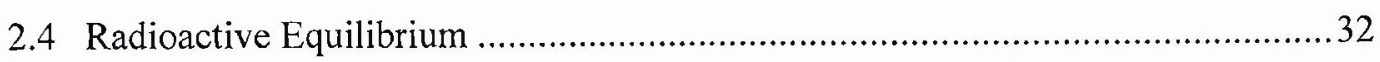

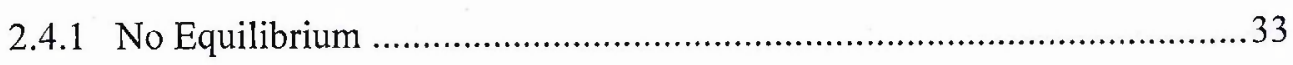

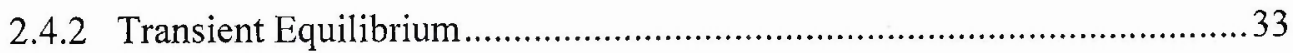

2.4.3 Secular Equilibrium ................................................................ 34

2.5 Gamma-Ray Spectroscopy with Germanium Detectors ....................................34

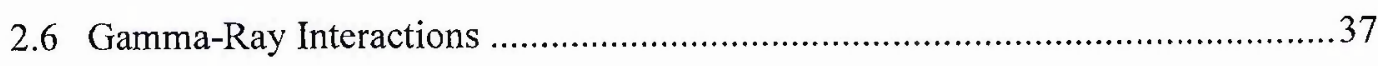

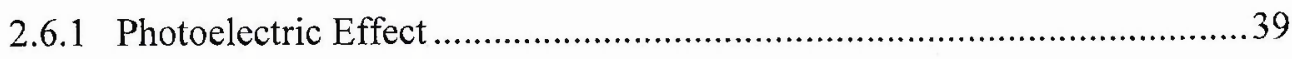

2.6.2 Compton Scattering ................................................................. 41

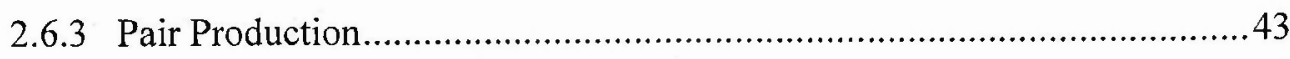

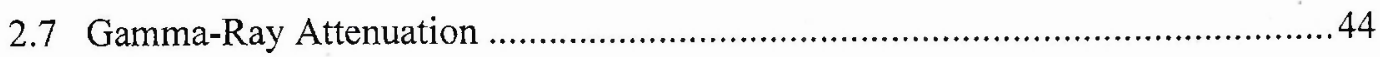

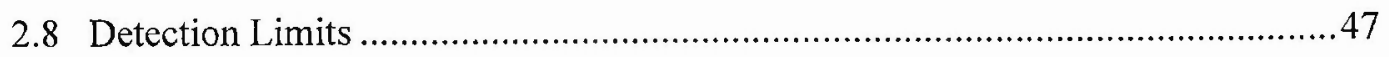

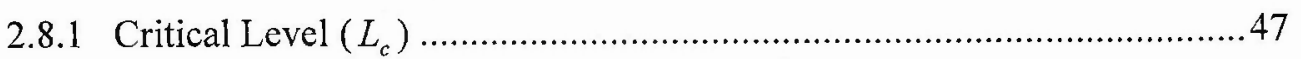

2.8.2 Lower Limit of Detection (LLD) ................................................ 48

2.8.3 Minimum Detectable Activity (MDA) ........................................... 49

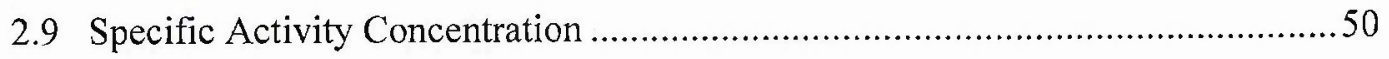

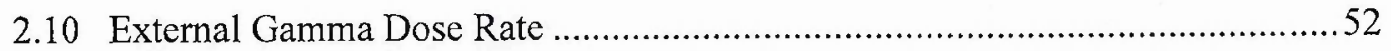

2.10.1 Dose Rate Calculation ..................................................................5 52

2.10.2 Hazard Indices Calculation ..................................................... 53

2.10.3 Annual Effective Dose Calculation ...............................................53

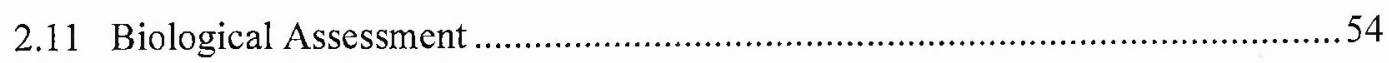

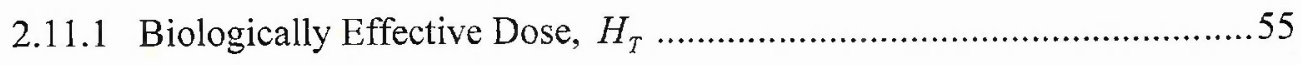

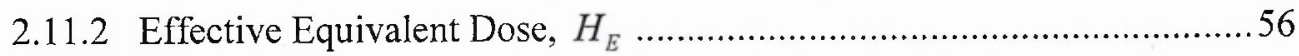


Chapter 3

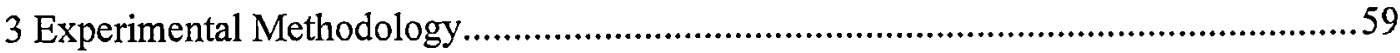

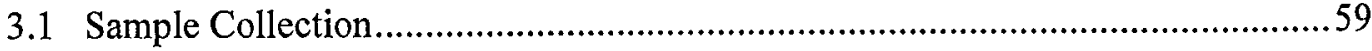

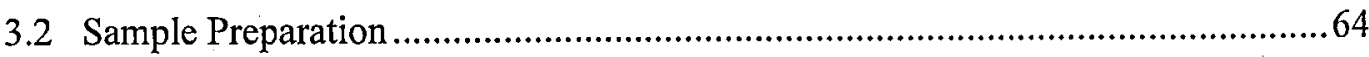

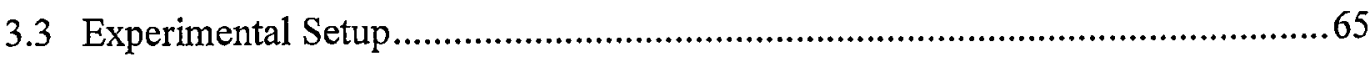

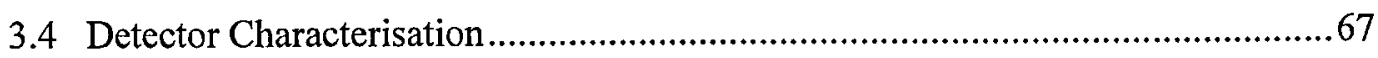

3.4.1 Energy Calibration .........................................................................67

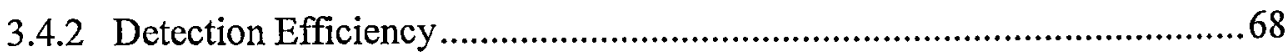

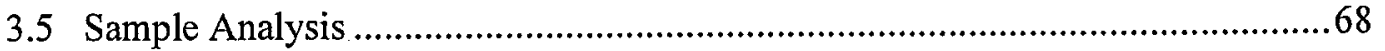

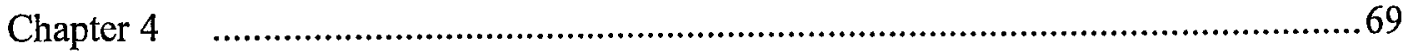

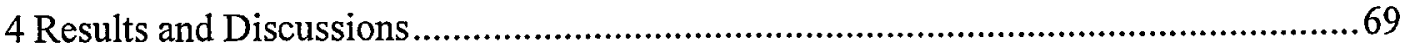

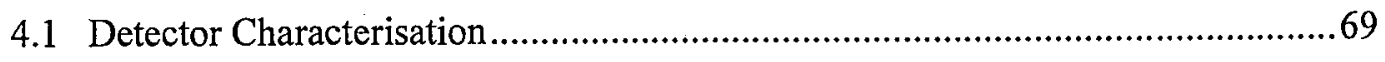

4.1.1 Energy Calibration .....................................................................69

4.1.2 Detection Efficiency ..................................................................... 71

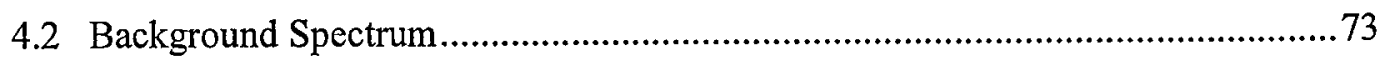

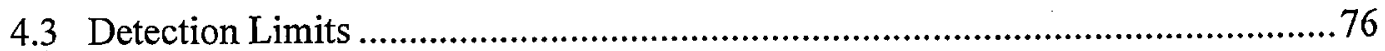

4.3.1 Critical Level $\left(L_{c}\right)$ and Lower limit of detection (LLD).......................76

4.3.2 Minimum Detectable Activity (MDA) .......................................... 77

4.4 Secular Equilibrium in Beach Sand Samples ................................................ 78

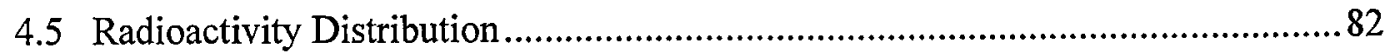

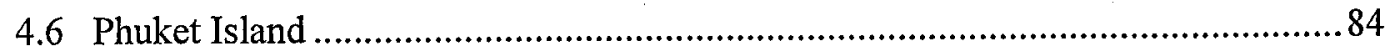

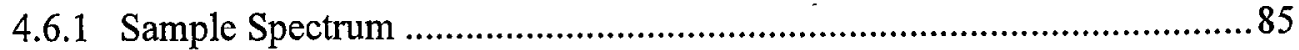

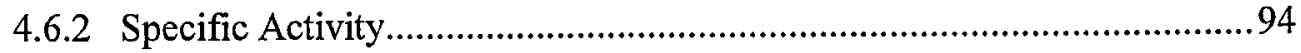


4.6.3 Mutual Interferences.

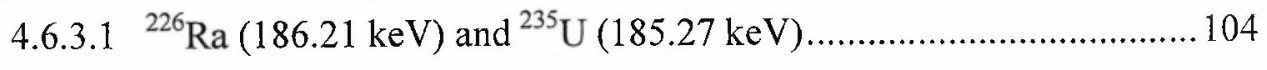

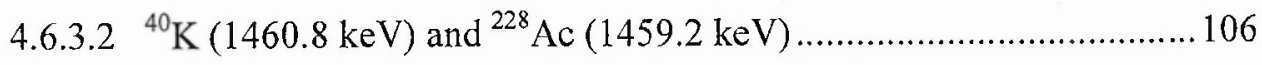

4.6.4 Elemental Concentrations .......................................................... 107

4.7 The West and the East coast of Thailand .................................................. 109

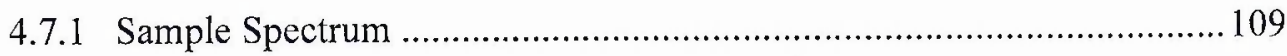

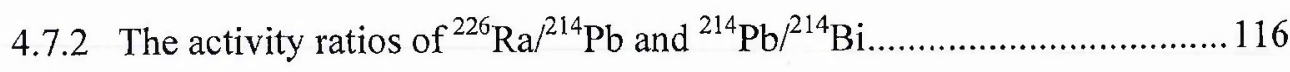

4.7.3 ${ }^{238} \mathrm{U},{ }^{232} \mathrm{Th}(\mathrm{ppm}), \%$ Total $\mathrm{K}$ and the ${ }^{232} \mathrm{Th} /{ }^{238} \mathrm{U}$ ratio ......................... 117

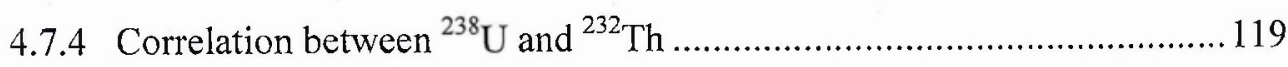

4.7.5 Specific Activity, Radium Equivalent and Hazard Indicies ................... 120

4.7.6 External Gamma Dose Rate.......................................................... 123

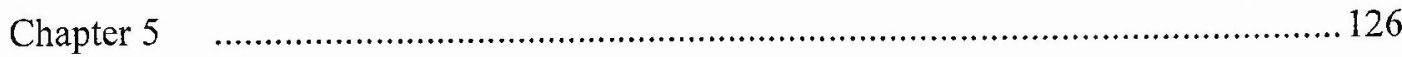

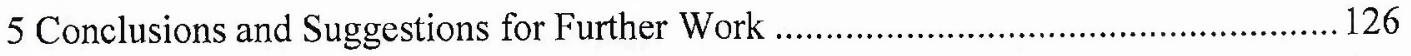

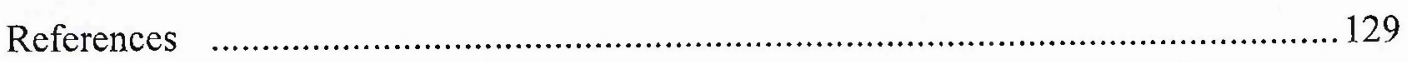

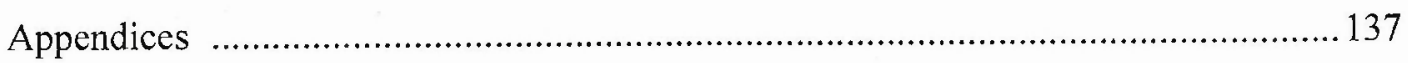

Appendix A - List of Presentations \& Publications................................................. 137

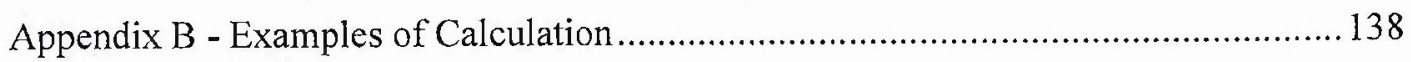

- Source Activity Calculation ............................................................. 138

- Weighted Mean Calculation ............................................................... 139

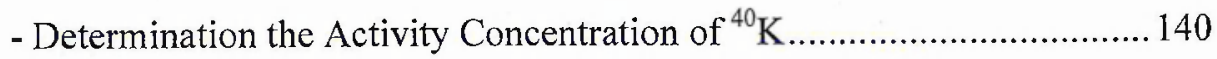

Appendix C - Spectra for ${ }^{32} \mathrm{Th},{ }^{226} \mathrm{Ra},{ }^{152} \mathrm{Eu}$, and NG3 (a mixed radionuclides)........... 142

Appendix D - Geographical Locations and Identification of Sand Samples .................. 143

Appendix E - Paper Publication ...................................................................... 145 


\section{List of Figures}

Figure 1-1: Major tectonic plates and the movent of earth's plates ...............................3

Figure 1-2: Map of southern Thailand and affected areas by tsunami .............................

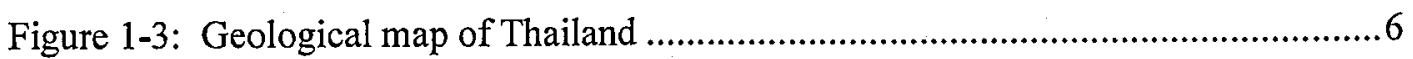

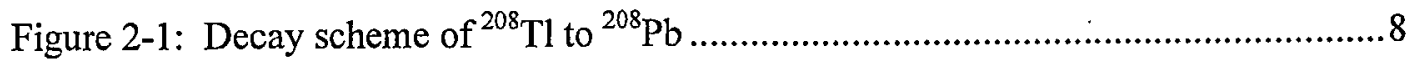

Figure 2-2: The uranium decay series ................................................................

Figure 2-3: The actinium decay series …........................................................... 10

Figure 2-4: The thorium decay series ..................................................................... 11

Figure 2-5: The neptunium decay series ................................................................ 15

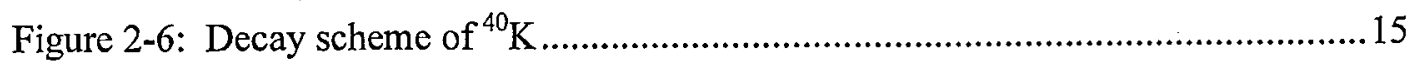

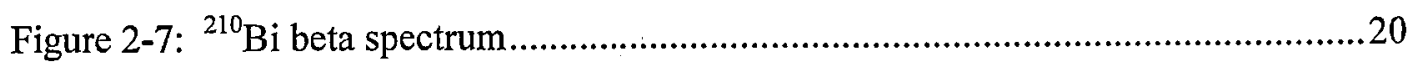

Figure 2-8: Electron capture from the $\mathrm{K}$ shell followed by

characteristic X-ray emission..............................................................22

Figure 2-9: Decay scheme for ${ }^{226} \mathrm{Ra}$ showing the nuclear transitions

from excited level to ground state.

Figure 2-10: Relative activity for the first three members of ${ }^{238} U$ decay

chain as a function of time

Figure 2-11: $T$ The ${ }^{238} \mathrm{U} \rightarrow{ }^{234} \mathrm{U}$ decay chain.

Figure 2-12: Radioactive growth curves for the ${ }^{238} U \rightarrow{ }^{234} U$ decay

chain as a function of time. .32

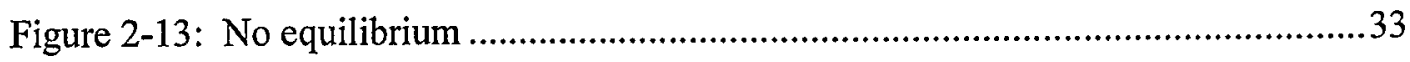

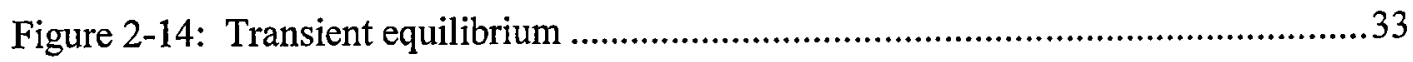

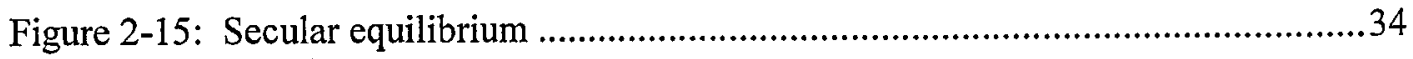

Figure 2-16: Schematic diagram of the band structure in semiconductor ........................35 
Figure 2-17: N-type, p-type and p-n junction in semiconductor. 36

Figure 2-18: Three importances of gamma-ray interaction processes 38

Figure 2-19: Mass attenuation coefficient of germanium and its component parts 39

Figure 2-20: (a) The mechanism of photoelectric absorption, and

(b) the emission of fluorescent X-ray .40

Figure 2-21: The mechanism of Compton scattering 41

Figure 2-22: Schematic diagram of the energy transferred to absorber by single Compton scattering and photoelectric absorption related to scattering angle .43

Figure 2-23: The mechanism of pair production. .43

Figure 2-24: Stopping power of air for an alpha particle as a function of distance travelled

Figure 2-25: The exponential transmission curve for gamma rays measured under good geometry conditions

Figure 3-1: Map showing sampling areas from six provinces along the west and east coast of Thailand

Figure 3-2: Geological map showing sampling points from Phangnga,

Phuket and Krabi provinces along the west coast of Thailand 61

Figure 3-3: Geological map showing sampling points from Chumporn, Suratthani and Nakonsrithammarat provinces along the east coast of Thailand .62

Figure 3-4: Sand sample preparation for the current study 64

Figure 3-5: Low-background shield design and cross-section of materials;
(A) shielded door (B) shielding materials (C) shield penetration
(D) detector preamplifier and dewar and (E) detector .65 
Figure 3-6: Schematic diagram of the high-purity germanium detector system...... .66

Figure 3-7: The high-purity germanium detector system used in the current work.........67

Figure 4-1: Energy calibration response curve using the ${ }^{232}$ Th source .........................69

Figure 4-2: ${ }^{232}$ Th calibration spectrum collected for 86400 s......................................... 70

Figure 4-3: Absolute efficiency curve of detector used in current work........................72

Figure 4-4: Background spectra collected from de-ionised water for

172,800 s (i.e. 2 days)

Figure 4-5: Map showing sampling point from Hat Sai Ri beach in

Chumporn province. .78

Figure 4-6: Growth in curves of some gamma-ray energies associated with the ${ }^{232} \mathrm{Th}$ and ${ }^{238} \mathrm{U}$ decay series from studied sand sample as a function of time . .79

Figure 4-7: Gamma-ray spectrum of the 'Sai Ri' beach sand sample subtracted background collected for $172,800 \mathrm{~s}$

Figure 4-8: Radioactivity distribution in ${ }^{238} \mathrm{U}$ decay series nuclei from studied sand sample as a function of distance from the seashore

Figure 4-9: Radioactivity distribution in ${ }^{232}$ Th decay series nuclei from studied sand sample as a function of distance from the seashore .83

Figure 4-10: Radioactivity distribution in ${ }^{40} \mathrm{~K}$ decay series nuclei from studied sand sample as a function of distance from the seashore .83

Figure 4-11: Geological map showing sampling point around Phuket Island .85

Figure 4-12: Gamma-ray spectrum of the 'Mai Kao' beach sand sample subtracted background collected for 172,800 s (i.e. 48 hours)

Figure 4-13: Gamma-ray spectrum of the 'Nai Ton' beach sand sample subtracted background collected for 172,800 s (i.e. 48 hours)

Figure 4-14: Gamma-ray spectrum of the 'Surin' beach sand sample 
subtracted background collected for 172,800 s (i.e. 48 hours)

Figure 4-15: Gamma-ray spectrum of the 'Patong' beach sand sample subtracted background collected for 172,800 s (i.e. 48 hours)

Figure 4-16: Gamma-ray spectrum of the 'Kata Noi' beach sand sample subtracted background collected for 172,800 s (i.e. 48 hours)

Figure 4-17: Gamma-ray spectrum of the 'Rawai' beach sand sample subtracted background collected for 172,800 s (i.e. 48 hours)

Figure 4-18: Gamma-ray spectrum of the 'Chalong Bay' beach sand sample subtracted background collected for 172,800 s (i.e. 48 hours)

Figure 4-19: Gamma-ray spectrum of the 'Ao Po' beach sand sample subtracted background collected for 172,800 s (i.e. 48 hours) 93

Figure 4-20: Radionuclide activity for the 'Mai Kao' beach sand sample.

The dotted line represents the weighted mean value equal of $23.9 \pm 0.4$ and $26.7 \pm 0.4 \mathrm{~Bq} \cdot \mathrm{kg}^{-1}$ for the ${ }^{238} \mathrm{U}$ and ${ }^{232} \mathrm{Th}$ series respectively ....95

Figure 4-21: Radionuclide activity for the 'Nai Ton' beach sand sample.

The dotted line represents the weighted mean value equal of $16.6 \pm 0.3$ and $32.1 \pm 0.5 \mathrm{~Bq} \cdot \mathrm{kg}^{-1}$ for the ${ }^{238} \mathrm{U}$ and ${ }^{232} \mathrm{Th}$ series respectively ...96

Figure 4-22: Radionuclide activity for the 'Surin' beach sand sample.

The dotted line represents the weighted mean value equal of $9.0 \pm 0.1$ and $11.4 \pm 0.2 \mathrm{~Bq} \cdot \mathrm{kg}^{-1}$ for the ${ }^{238} \mathrm{U}$ and ${ }^{232} \mathrm{Th}$ series respectively $\ldots . .97$

Figure 4-23: Radionuclide activity for the 'Patong' beach sand sample.

The dotted line represents the weighted mean value equal of 13.4 \pm 0.2 and $22.6 \pm 0.4 \mathrm{~Bq} . \mathrm{kg}^{-1}$ for the ${ }^{238} \mathrm{U}$ and ${ }^{232} \mathrm{Th}$ series respectively $\ldots 98$

Figure 4-24: Radionuclide activity for the 'Kata Noi' beach sand sample.

The dotted line represents the weighted mean value equal of $9.8 \pm 0.2$ and $13.8 \pm 0.2 \mathrm{~Bq} \cdot \mathrm{kg}^{-1}$ for the ${ }^{238} \mathrm{U}$ and ${ }^{232} \mathrm{Th}$ series respectively .....99 
Figure 4-25: Radionuclide activity for the 'Rawai' beach sand sample.

The dotted line represents the weighted mean value equal of $14.6 \pm 0.2$ and $19.0 \pm 0.3 \mathrm{~Bq} \cdot \mathrm{kg}^{-1}$ for the ${ }^{238} \mathrm{U}$ and ${ }^{232} \mathrm{Th}$ series respectively...... 100

Figure 4-26: Radionuclide activity for the 'Chalong Bay' beach sand sample.

The dotted line represents the weighted mean value equal of 22.0 \pm 0.3 and $24.5 \pm 0.4 \mathrm{~Bq} \cdot \mathrm{kg}^{-1}$ for the ${ }^{238} \mathrm{U}$ and ${ }^{232} \mathrm{Th}$ series respectively.... 101

Figure 4-27: Radionuclide activity for the 'Ao Po' beach sand sample.

The dotted line represents the weighted mean value equal of $6.0 \pm 0.1$ and $11.1 \pm 0.2 \mathrm{~Bq} \cdot \mathrm{kg}^{-1}$ for the ${ }^{238} \mathrm{U}$ and ${ }^{232} \mathrm{Th}$ series respectively....... 102

Figure 4-28: The concentrations of ${ }^{238} \mathrm{U},{ }^{232} \mathrm{Th}$ in $\mathrm{ppm}$ and \%total $\mathrm{K}$ in beach sand samples collected from eight different beaches around Phuket island...... 108

Figure 4-29: Gamma-ray spectrum of the 'Mai Kao' beach sand sample (background subtracted) collected for 172,800 s (i.e. 48 hours)

Figure 4-30: Gamma-ray spectrum of the 'Thai Mueng' beach sand sample

(background subtracted) collected for 172,800 s (i.e. 48 hours)

Figure 4-31: Gamma-ray spectrum of the 'Nopparat Thara' beach sand sample (background subtracted) collected for 172,800 s (i.e. 48 hours)

Figure 4-32: Gamma-ray spectrum of the 'Laem Son' beach sand sample (background subtracted) collected for 172,800 s (i.e. 48 hours)

Figure 4-33: Gamma-ray spectrum of the 'Chaiya' beach sand sample

(background subtracted) collected for 172,800 s (i.e. 48 hours)

Figure 4-34: Gamma-ray spectrum of the 'Khanom' beach sand sample subtracted background collected for 172,800 s (i.e. 48 hours)

Figure 4-35: The concentrations of ${ }^{238} \mathrm{U},{ }^{232} \mathrm{Th}(\mathrm{ppm})$ and \%Total $\mathrm{K}$ from all of the beach sand samples measured in the current study

Figure 4-36: Correlation between ${ }^{238} U$ and ${ }^{232} \mathrm{Th}$ in beach sand samples 


\section{List of Tables}

Table 1-1: Typical concentrations of long-lived cosmogenic radionuclides in air, rainwater, and ocean water . .5

Table 1-2: Short-lived cosmogenic radionuclides in rainwater ..................................5

Table 2-1: Most significant gamma-rays emitted by the NORM nuclides..................... 12

Table 2-2: Additional naturally occurring radioactive nuclides ................................. 13

Table 2-3: Ranges and averages of the concentrations of ${ }^{40} \mathrm{~K},{ }^{232} \mathrm{Th}$, and ${ }^{238} \mathrm{U}$ in typical rocks and soils........................................................ 16

Table 2-4: Natural concentration of some terrestrial radionuclides ..............................16

Table 2-5: The isotopic characteristic of the ${ }^{238} \mathrm{U}^{234} \mathrm{U}$ decay chain ................................

Table 2-6: Radiation weighting factors, $W_{R}$ for various radiations ...............................55

Table 2-7: Tissue weighing factors, $W_{T}$ and $\sum W_{T}$ for different organs .......................56

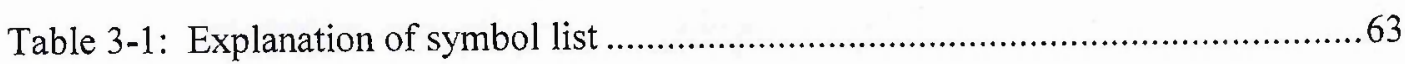

Table 4-1: Main X-ray and $\gamma$-ray energy peaks observed in background spectrum.......73

Table 4-2: Critical level $\left(\mathrm{L}_{c}\right)$ and lower limit of detection (LLD)

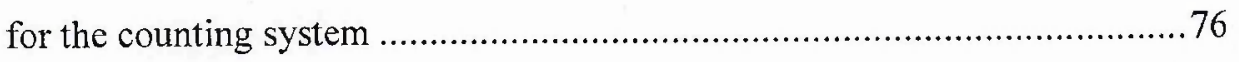

Table 4-3: The minimum detectable activity (MDA) for the counting system ...............77

Table 4-4: The summary of the activity concentrations of measured radionuclides in sand samples from eight different beaches around Phuket Island

Table 4-5: The activity ratio of ${ }^{226} \mathrm{Ra} /{ }^{214} \mathrm{~Pb}$ and ${ }^{214} \mathrm{~Pb} /{ }^{214} \mathrm{Bi}$ in beach sand samples ...... 116

Table 4-6: Elemental concentrations of the ${ }^{238} \mathrm{U},{ }^{232} \mathrm{Th}$ in $\mathrm{ppm}$ and the ratio of ${ }^{232} \mathrm{Th} /{ }^{238} \mathrm{U}$... 118 
Table 4-7: Activity concentrations, the radium equivalent activity, the external $\left(H_{\mathrm{e}}\right)$ and internal $\left(H_{\mathrm{in}}\right)$ hazard indicies of ${ }^{226} \mathrm{Ra},{ }^{232} \mathrm{Th}$ and ${ }^{40} \mathrm{~K}$ in sand samples

Table 4-8: The specific activities of ${ }^{238} \mathrm{U},{ }^{226} \mathrm{Ra},{ }^{232} \mathrm{Th},{ }^{40} \mathrm{~K}$ and ${ }^{137} \mathrm{Cs}$ in beach sand and soil samples ..... 122

Table 4-9: The absorbed dose rate and annual effective dose rate caused by ${ }^{226} \mathrm{Ra},{ }^{232} \mathrm{Th},{ }^{40} \mathrm{~K}$ from the sand samples in the current study. 124 


\section{Glossary of Terms}

ADC-Analogue to Digital Converter

DEP-Double Escape Peak

EC-Electron Capture

FWHM-Full Width at Half Maximum

HPGe-High Purity Germanium

IAEA-The International Atomic Energy Agency

ICRM-International Committee for Radionuclide Metrology

ICRP-International Commission on Radiological Protection

LLD-Lower Limit of Detection

MCA-Multichannel Analyser

MDA-Minimum Detectable Activity

NCRP-National Council on Radiation Protection and Measurements

NIM-Nuclear Instrumentation Module

NORM-Naturally Occurring Radioactive Material

SEP-Single Escape Peak

TCS-True Coincidence Summing

TENORM-Technically Enchanted Naturally Occurring Radioactive Material

UNSCEAR-United Nations Scientific Committee on the Effects of Atomic Radiation VDU-Visual Display Unit 


\section{Chapter 1}

\section{Introduction}

\subsection{Background}

Humans are subjected to low levels of natural radioactivity from their surroundings every day of their lives. Most of these exposures come from naturally occurring radionuclides, including those created directly from cosmic radiation. Natural materials containing these radionuclides are often referred to by the acronym NORM (Naturally Occurring Radioactive Materials) [NCRP87] and can be described as two groups of radionuclides, namely cosmogenic and primordial. Cosmogenic radionuclides are continuously produced following the bombardment from high-energy cosmic rays on atoms in the atmosphere (usually oxygen or nitrogen), whereas primordial radionuclides have been present on earth since its creation and are present in the wider environment such as foods, soil, water, air, building materials and the human body (e.g. ${ }^{40} \mathrm{~K}$ in bones) [WIL94]. Only 4 of 22 identified cosmogenic radionuclides $\left({ }^{14} \mathrm{C},{ }^{3} \mathrm{H},{ }^{22} \mathrm{Na}\right.$ and $\left.{ }^{7} \mathrm{Be}\right)$ are considered to contribute significantly to human dose rate. The list of long-lived cosmogenic radionuclides present in air, rain water and ocean water (in units of Bq. $\mathrm{kg}^{-1}$ ) is shown in Table 1-1 followed by the short-lived cosmogenic radionuclides appearing in rain water (Table 1-2) [CHO02, EIS97]. Since the largest contribution (about $87 \%$ ) [UNSCEAR00] towards the radiation dose received by the world's population is due to natural radiation sources, it is important to assess such doses with the aim of preventing potentially adverse health effects on humans.

Primordial radionuclides typically have a very long half-life, similar to the estimated age of the Earth (4.5 $\times 10^{9}$ years) [NCRP87] and have accompanied the Earth since its formation. These radionuclides and their decay progeny are contained in terrestrial materials and are widespread throughout the land and oceans. From a radiological point of view, the most important primordial radionuclides are ${ }^{238} \mathrm{U}$ (half-life $4.47 \times 10^{9}$ years), 
${ }^{232} \mathrm{Th}$ (half-life $1.41 \times 10^{10}$ years) and ${ }^{40} \mathrm{~K}$ (half-life $1.28 \times 10^{9}$ years) [UNSCEAR93]. Other terrestrial radionuclides, including those of the ${ }^{235} \mathrm{U}$ series, ${ }^{87} \mathrm{Rb},{ }^{138} \mathrm{La},{ }^{147} \mathrm{Sm}$, and ${ }^{176} \mathrm{Lu}$ are also known, but since relatively low levels of dose arise in the natural background from such radionuclides, their effects are normally discounted [UNSCEAR00]. Manmade radionuclides such as ${ }^{137} \mathrm{Cs},{ }^{90} \mathrm{Sr},{ }^{241} \mathrm{Am}$ and ${ }^{239} \mathrm{Pu}$ are also found in nature as a result of nuclear atmospheric weapons testing and nuclear accidents (e.g. Chernobyl and most recently Fukushima). The primary source of ${ }^{137} \mathrm{Cs}$ in the biosphere is from atmospheric nuclear weapons testing by the United States and the former Soviet Union from the 1940 s to the $1960 \mathrm{~s}$. About $90 \%$ of ${ }^{137} \mathrm{Cs}$ was produced by atmospheric testing, 6 $\%$ was created by the Chernobyl accident and $4 \%$ by nuclear fuel reprocessing facilities [NCRP07]. Although natural radionuclides result in a relatively small amount of radiation dose, dust particles contaminated by ${ }^{137} \mathrm{Cs}$ may become air-borne and inhalation of contaminated dust can result in an internal exposure. In general, there is no regulation for limiting the exposure dose received by populations from the natural background radiation because the NORM concentration is generally rather low. Nonetheless, NORM concentrations can be increased above average natural background levels through some industrial activities, for example, waste products from the oil and gas industry such as sludge and scale [BER95]. They accumulate in pipes and storage tanks and contribute a high activity concentration of NORM. The isotopes of the inert gas radon i.e. ${ }^{219} \mathrm{Rn},{ }^{220} \mathrm{Rn}$ and ${ }^{222} \mathrm{Rn}$ from the actinium, thorium and uranium series respectively are also diffused into the wider environment. When enclosed houses with inadequate ventilation are built, the radon levels indoors can be raised [THO98]. In addition, many radioisotopes are used in medical, educational and industrial applications. An accidental discharge from these radioisotopes can cause radioactive contamination into the natural environment. At elevated levels, NORM may be redefined as Technologically Enhanced Naturally Occurring Radioactive Material (TENORM) [WIL94].

\subsection{The $26^{\text {th }}$ December 2004 Tsunami}

A large earthquake (followed by the tsunami) took place on $26^{\text {th }}$ December 2004 below Sumatra, measuring approximately 9.3 on the Richter scale and hit the 17 countries of Sri Lanka, India, Indonesia, Thailand, Malaysia, Myanmar, Maldives, Bangladesh, Somalia, Seychelles, Madagascar, Mozambique, Mauritius, South Africa, Australia, Tanzania, and Kenya [DMRT05]. This earthquake was generated by the movement of Indo-Australian 
plate below the Eurasian plate. Normally these plates move by about $70 \mathrm{~mm}$ every year but they were unable to move for several years. The pressure built up, leading to an enormous accumulation of the pressure under the earth's crust. The rapid release of this pressure can result in a massive rise (or drop) in sea level. A sudden replacement of a large volume of water due to this earthquake created destructive tsunami waves (Figure 1-1).
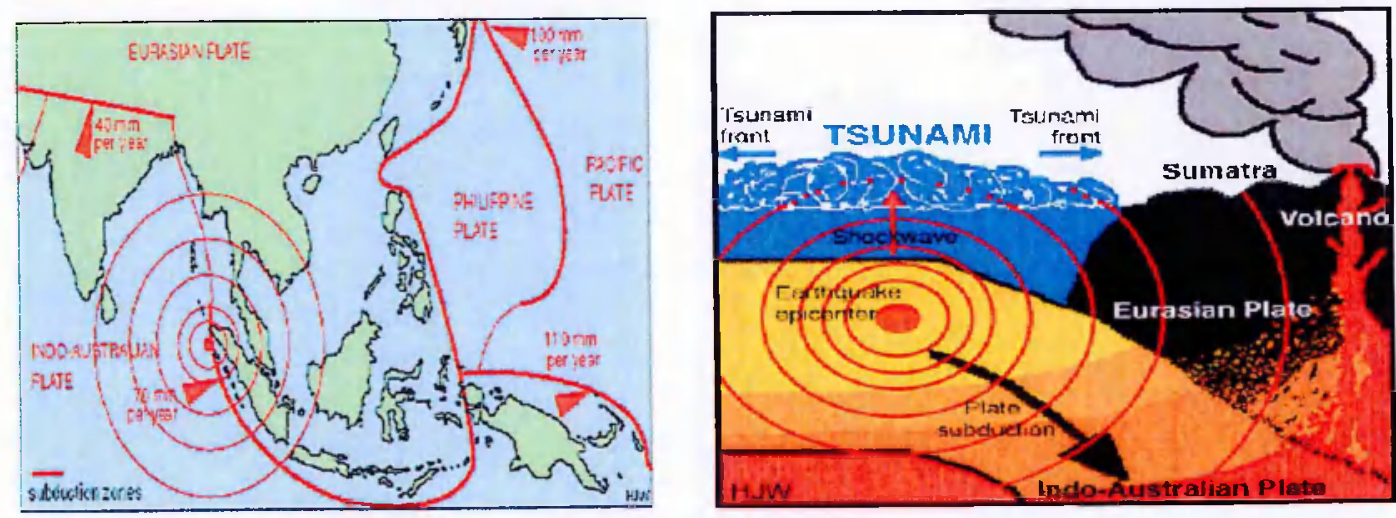

Figure 1-1: Major tectonic plates and the movement of earth's plates [DMRT05].

In Thailand, a series of large waves hit the Andaman Coast, affecting seriously the six coastal provinces along the Andaman Sea in southern of Thailand, namely; Ranong, Phang Nga, Phuket, Krabi, Trang and Satun. The most impacted area was the Khao Lak district in Phang Nga province as shown in Figure 1-2. The underlying geomorphic features on both coastal plains of Thai peninsula are different and affected by the variety of quaternary deposits in the Southern Region [DHE95] as illustrated in Figure 1-3.
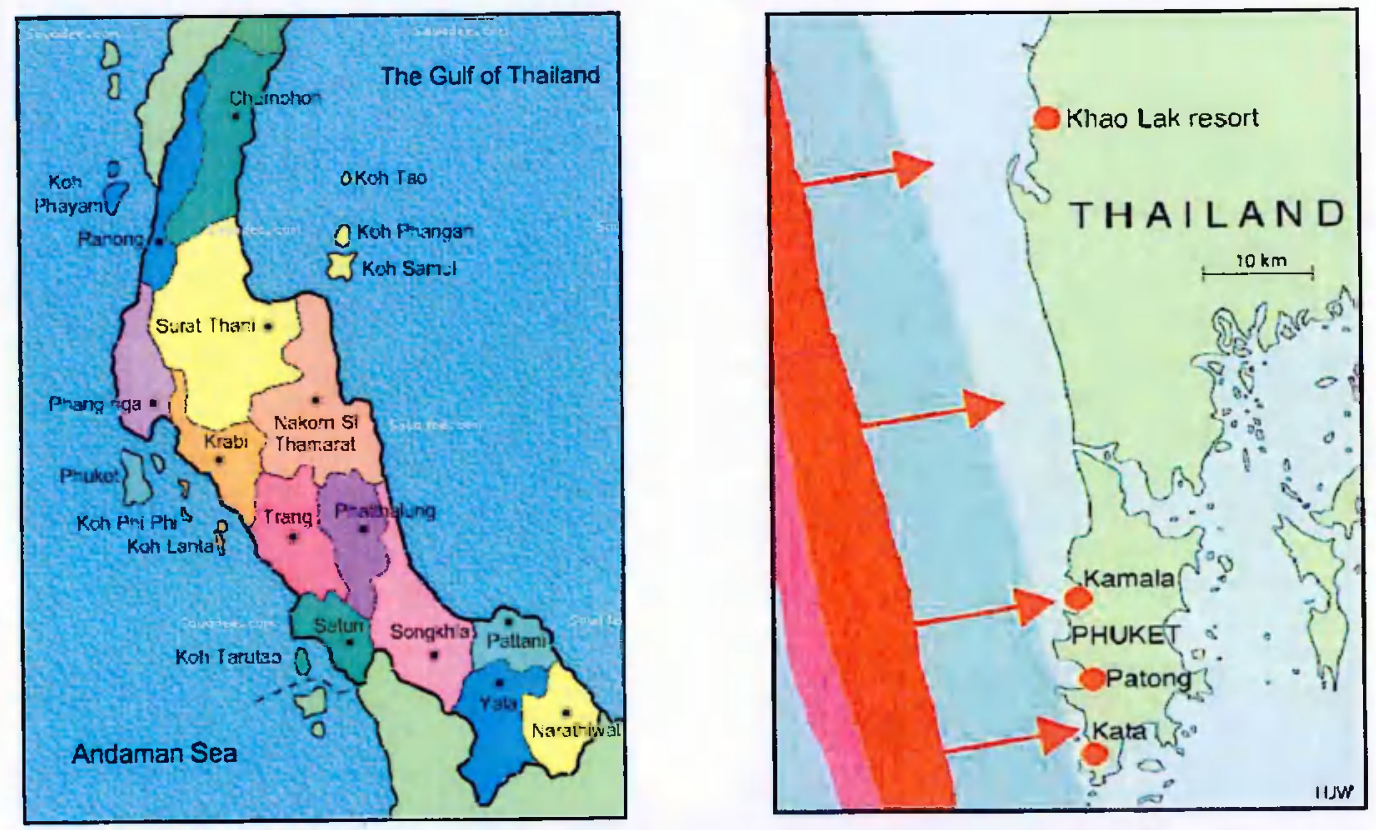

Figure 1-2: Map of southern Thailand and affected areas by tsunami [AVI05, THA11]. 


\subsection{Aim of the Research}

According to Gonzalez [GON00], some natural processes such as volcanic eruptions, mineral water springs, erosion and movements of sand can bring proportions of the earth's radioactive inventory into the human habitat. This $\mathrm{PhD}$ thesis project investigates whether the movement of sea water and sand caused by the tsunami resulted in the transfer of significant amounts of radioactivity from other areas (for example the ocean floors) onto the beaches of western Thailand, thereby increasing the environmental dose rate due to NORM in these areas. Approximately 60 beach sand samples were collected along both the western and eastern sides of Thailand coast in August 2008 and were analysed for the activity concentrations of ${ }^{226} \mathrm{Ra},{ }^{232} \mathrm{Th}$ and ${ }^{40} \mathrm{~K}$. Use was made of a $\mathrm{HPGe}$ detector-based gamma-ray spectroscopy low background counting system to allow estimates of the equivalent dose rate in air $1 \mathrm{~m}$ above the ground surface present along the Andaman coast of Thailand following the 2004 tsunami. The results from the western coast were then compared to the measurements on the eastern coast of the Thai peninsula, which was not exposed in the tsunami. These data will also be used to help establish a radiological baseline map in Thailand and as a reference to assess any alterations in the radioactivity background level due to the changes in the topography of the location, other developments around the area (i.e. the use of fertilisers for agricultural purposes) or any artificial influences on the environment.

An introduction to the natural uranium-thorium decay chains is presented in Chapter 2 including the concepts of the radioactive decay law, modes of nuclear decay, radioactive equilibrium and gamma-ray features which are divided into three parts: (i) gamma-ray spectroscopy with germanium detectors, (ii) gamma-ray interactions with matter and (iii) gamma-ray attenuation. The detection limits, specific activity concentration, external gamma dose rate determination and biological effects are also discussed in this Chapter. The experimental methodology involving sample collection and preparation, experimental setup, detector characterisation and sample analysis are presented in Chapter 3, followed by the experimental results of this study in Chapter 4 . The conclusions of this study and suggestions for further analysis are outlined in the final chapter. 
Table 1-1 Typical concentrations of long-lived cosmogenic radionuclides in air, rainwater, and ocean water [CHO02, EIS97].

\begin{tabular}{cccccc}
\hline Nuclide & $\begin{array}{c}\text { Half-life } \\
\text { (years) }\end{array}$ & $\begin{array}{c}\text { Decay Mode } \\
\text { and Particle } \\
\text { Energy (MeV) }\end{array}$ & \multicolumn{2}{c}{ Typical Concentrations (Bq.kg-1) } \\
\cline { 4 - 6 } (troposphere) & Rainwater & Ocean water \\
\hline${ }^{3} \mathrm{H}$ & 12.32 & $\beta^{-} 0.0186$ & $1.2 \times 10^{-3}$ & & $7 \times 10^{-4}$ \\
${ }^{10} \mathrm{Be}$ & $1.52 \times 10^{6}$ & $\beta^{-} 0.555$ & & & $2 \times 10^{-8}$ \\
${ }^{14} \mathrm{C}$ & 5715 & $\beta^{-} 0.1565$ & & & $5 \times 10^{-3}$ \\
${ }^{22} \mathrm{Na}$ & 2.605 & $\beta^{+} 0.545$ & $1 \times 10^{-6}$ & $2.8 \times 10^{-4}$ & \\
${ }^{26} \mathrm{Al}$ & $7.1 \times 10^{5}$ & $\beta^{+} 1.16$ & & & $2 \times 10^{-10}$ \\
${ }^{32} \mathrm{Si}$ & 160 & $\beta^{-} 0.213$ & & & $4 \times 10^{-7}$ \\
${ }^{35} \mathrm{~S}$ & 0.239 & $\beta^{-} 0.167$ & $1.3 \times 10^{-4}$ & $7.7-107 \times 10^{-3}$ & \\
${ }^{36} \mathrm{Cl}$ & $3.01 \times 10^{5}$ & $\beta^{-} 0.709$ & & & $1 \times 10^{-5}$ \\
${ }^{39} \mathrm{Ar}$ & 268 & $\beta^{-} 0.565$ & & & $6 \times 10^{-8}$ \\
${ }^{53} \mathrm{Mn}$ & $3.7 \times 10^{6}$ & $\mathrm{EC}(0.596)$ & & & \\
${ }^{80} \mathrm{Kr}$ & $2.2 \times 10^{5}$ & $\mathrm{EC}(0.28)$ & & & \\
\hline
\end{tabular}

Values in parenthesis are decay energies

Table 1-2 Short-lived cosmogenic radionuclides in rainwater [CHO02].

\begin{tabular}{ccc}
\hline Nuclide & Half-life & $\begin{array}{c}\text { Decay Mode and } \\
\text { Particle Energy } \\
\text { (MeV) }\end{array}$ \\
\hline${ }^{7} \mathrm{Be}$ & $53.28 \mathrm{~d}$ & $\mathrm{EC}(0.477)$ \\
${ }^{24} \mathrm{Na}$ & $14.96 \mathrm{~h}$ & $\beta^{-} 1.389$ \\
${ }^{28} \mathrm{Mg}$ & $21.0 \mathrm{~h}$ & $\beta^{-} 0.459$ \\
${ }^{32} \mathrm{P}$ & $14.28 \mathrm{~d}$ & $\beta^{-} 1.710$ \\
${ }^{33} \mathrm{P}$ & $25.3 \mathrm{~d}$ & $\beta^{-} 0.249$ \\
${ }^{39} \mathrm{Cl}$ & $55.6 \mathrm{~min}$ & $\beta^{-} 1.91$ \\
\hline \multicolumn{3}{c}{ Value in parenthesis is decay energy } \\
\hline
\end{tabular}




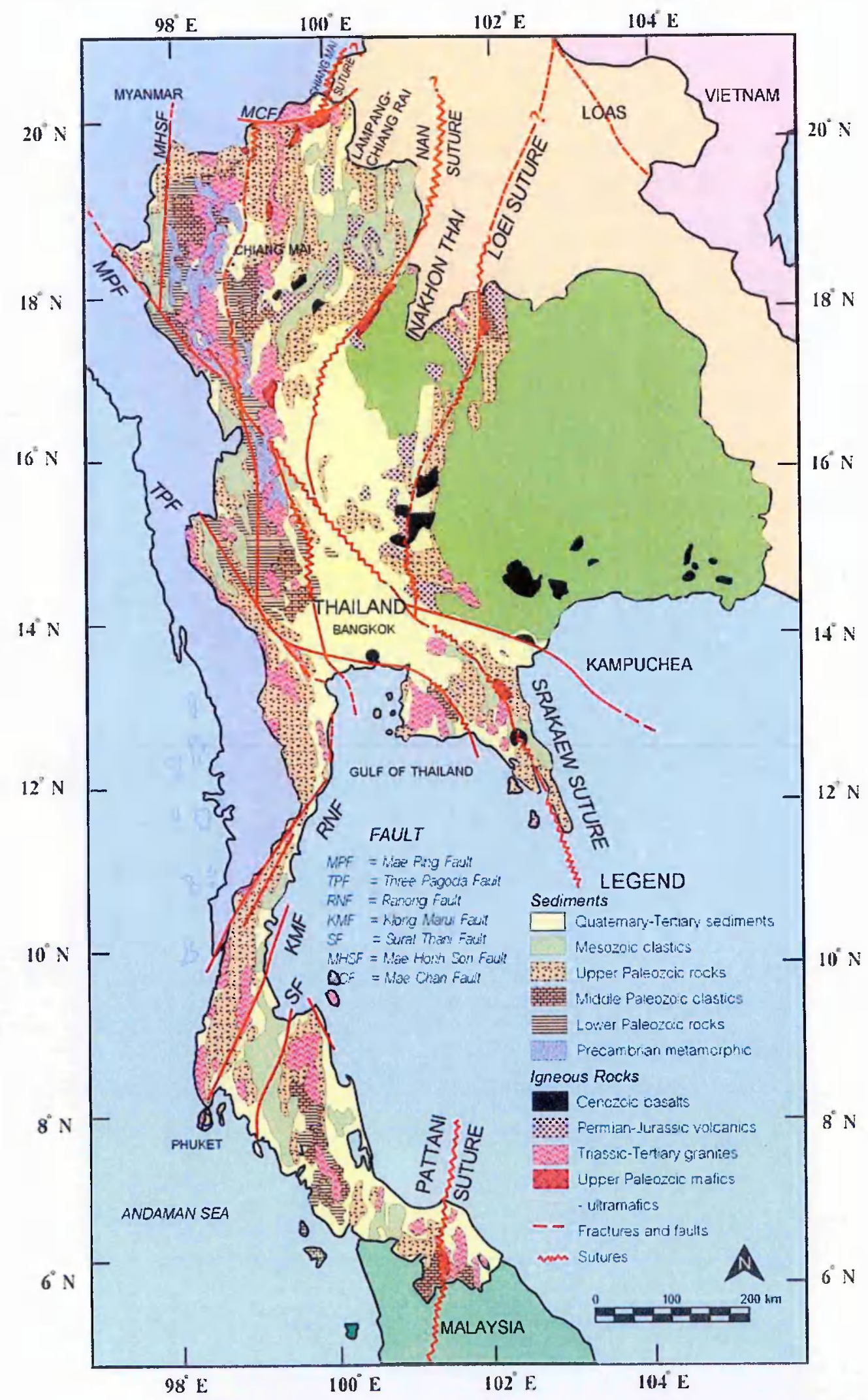

Figure 1-3: Geological map of Thailand [DMRA05]. 


\section{Chapter 2}

\section{Theory}

\subsection{The Naturally Occurring Radionuclides}

The naturally occurring radionuclides can be divided into two categories that occur: single decays and those comprised of the three main radioactive decay series. Decay chains from terrestrial radionuclides have been present since the birth of the earth, headed by the radionuclides ${ }^{235} \mathrm{U}$ (half-life $7.04 \times 10^{8}$ years), ${ }^{238} \mathrm{U}$ (half-life $4.47 \times 10^{9}$ years), and

${ }^{232} \mathrm{Th}$ (half-life $1.41 \times 10^{10}$ years) [UNSCEAR93]. Naturally occurring uranium consists of three separate radioisotopes with present day isotopic abundances of $99.3 \%$ for ${ }^{238} \mathrm{U}$ and about $0.7 \%$ for ${ }^{235} \mathrm{U}$, plus a small amount of ${ }^{234} \mathrm{U}\left(5 \times 10^{-3} \%\right)$ [CEM09]. The ${ }^{238} \mathrm{U}$ and ${ }^{234} \mathrm{U}$ isotopes are part of the same series (the "uranium" series), while ${ }^{235} \mathrm{U}$ is the first radionuclide of another family called the actinium series. Uranium has been found in all rocks and soils with an average concentration in the range of 1-3 parts per million (ppm) by weight, which corresponds to a specific activity of $\sim 74 \mathrm{mBq} \cdot \mathrm{g}^{-1}$ soil [WIL94, CEM09]. The relationship between uranium and $\mathrm{P}_{2} \mathrm{O}_{5}$ content of fertilizer has been investigated in various studies and it has been concluded that the concentration of uranium is directly proportional to the concentration of phosphorous [BOU78, SPA72]. Therefore, higher concentrations of uranium than normal are encountered in phosphaterich soil (about 7-125 ppm), while the uranium content in medium-grade and high-grade ore are about 1,000-5,000 ppm, and 10,000-40,000 ppm respectively [CEM09].

In nature, natural thorium is about 4 times more abundant than uranium and contains $100 \%$ of ${ }^{232} \mathrm{Th}$ isotope [GIL08, CEM09]. High concentrations of thorium are commonly found in monazite minerals, (which can have thorium contents of up to $26.5 \%$ ) and in zircon (up to about 13\%) [UNSCEAR93]. A member of these three families can be simply distinguished by dividing its mass number by 4 . Those nuclides which have mass numbers that can be formed by $4 n+2,4 n+3$ and $4 n$ (where $n$ is an integer) belong to uranium, actinium and thorium series respectively. In the uranium series, there are 14 decay stages until reaching the stable ${ }^{206} \mathrm{~Pb}$ while in actinium, the transformation process 
involves 12 radionuclides with the stable end product, ${ }^{207} \mathrm{~Pb}$. Another 11 radionuclides make up the thorium chain, ending with the stable nuclide, ${ }^{208} \mathrm{~Pb}$. The decay stages of these three decay series are illustrated in Figures 2-2, 2-3, and 2-4. The daughter nuclides generated during the decay of the very long-lived natural radionuclides are also radioactive and therefore they continue to decay until a final (stable) daughter nuclide is formed, leading to the termination of the decay chains.

After an unstable nuclide emits an $\alpha$ or $\beta$ particle, the residual nucleus may be populated in an excited state. In order to de-excite the nucleus to its ground state, a single gamma ray or a cascade of gamma rays can be expelled. This phenomenon is associated with the energy difference between the initial state and the final state. For example, there are five main $\gamma$-ray energies emitting from a source of ${ }^{208} \mathrm{Tl}$ (in the ${ }^{232} \mathrm{Th}$ decay chain) at $277,511,583,860$ and $2614 \mathrm{keV}$. A schematic diagram of the gamma-ray decay scheme from ${ }^{208} \mathrm{Tl}$ to ${ }^{208} \mathrm{~Pb}$ is depicted in Figure $2-1$. Other gamma-ray emission from ${ }^{238} \mathrm{U},{ }^{232} \mathrm{Th}$, ${ }^{235} \mathrm{U}$ decay series and their daughters are shown in Table 2-1. A listed of the main sources of naturally occurring radioactive nuclides are given in Table 2-2 along with some of their properties [CHO02].

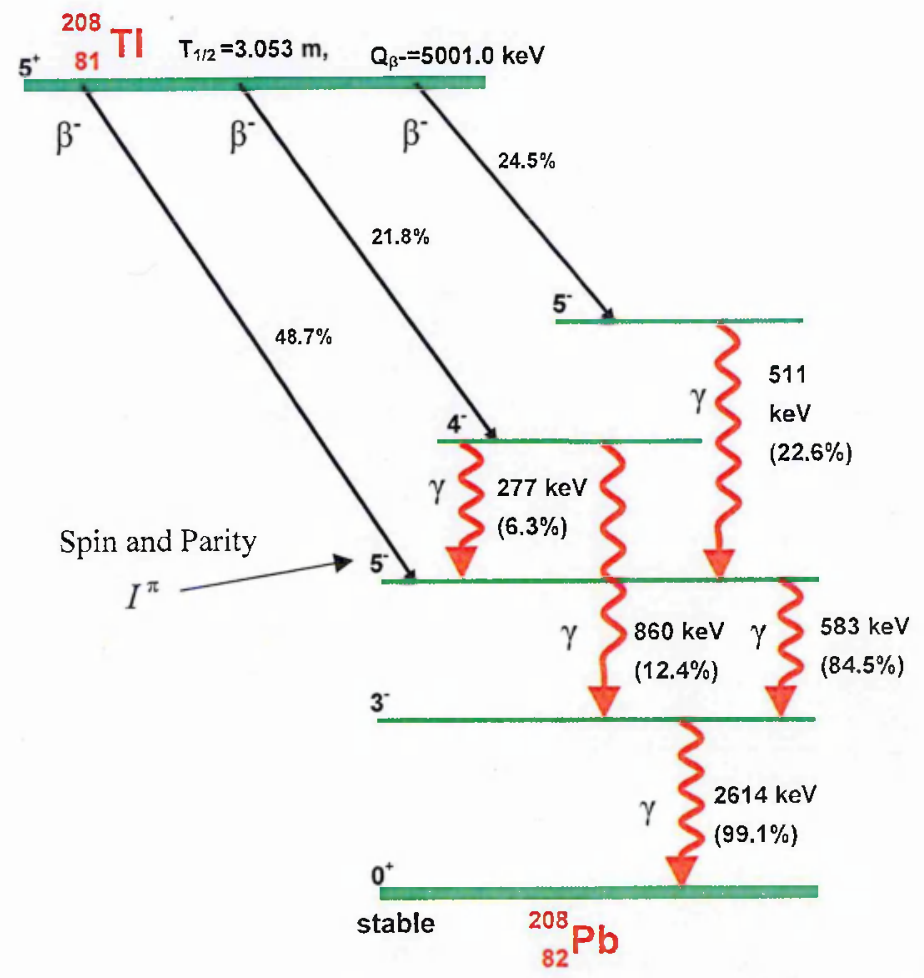

Figure 2-1: Decay scheme of ${ }^{208} \mathrm{Tl}$ to ${ }^{208} \mathrm{~Pb}$, (these data are taken from [F[R98]). 


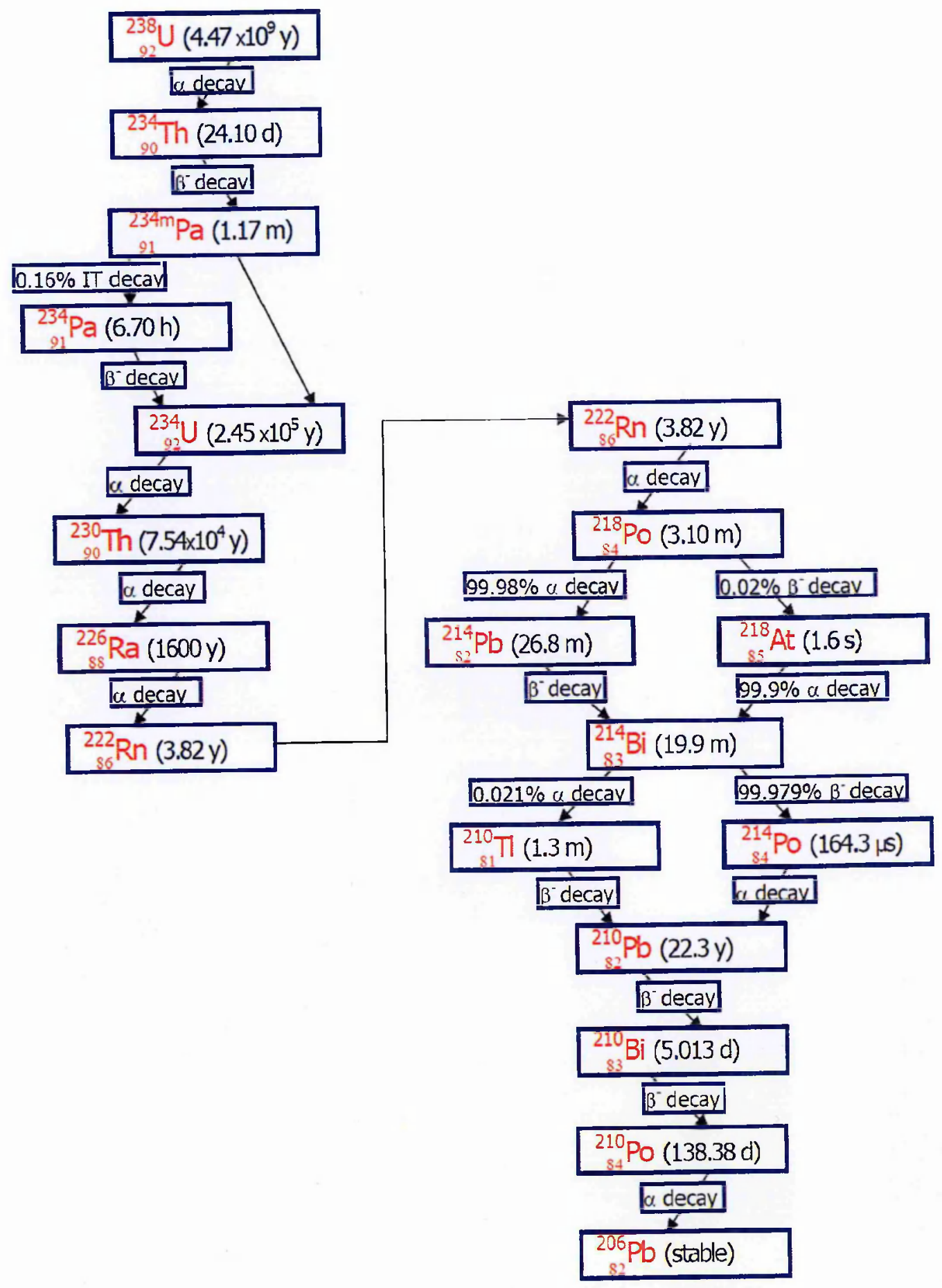

Figure 2-2: The uranium decay series. 


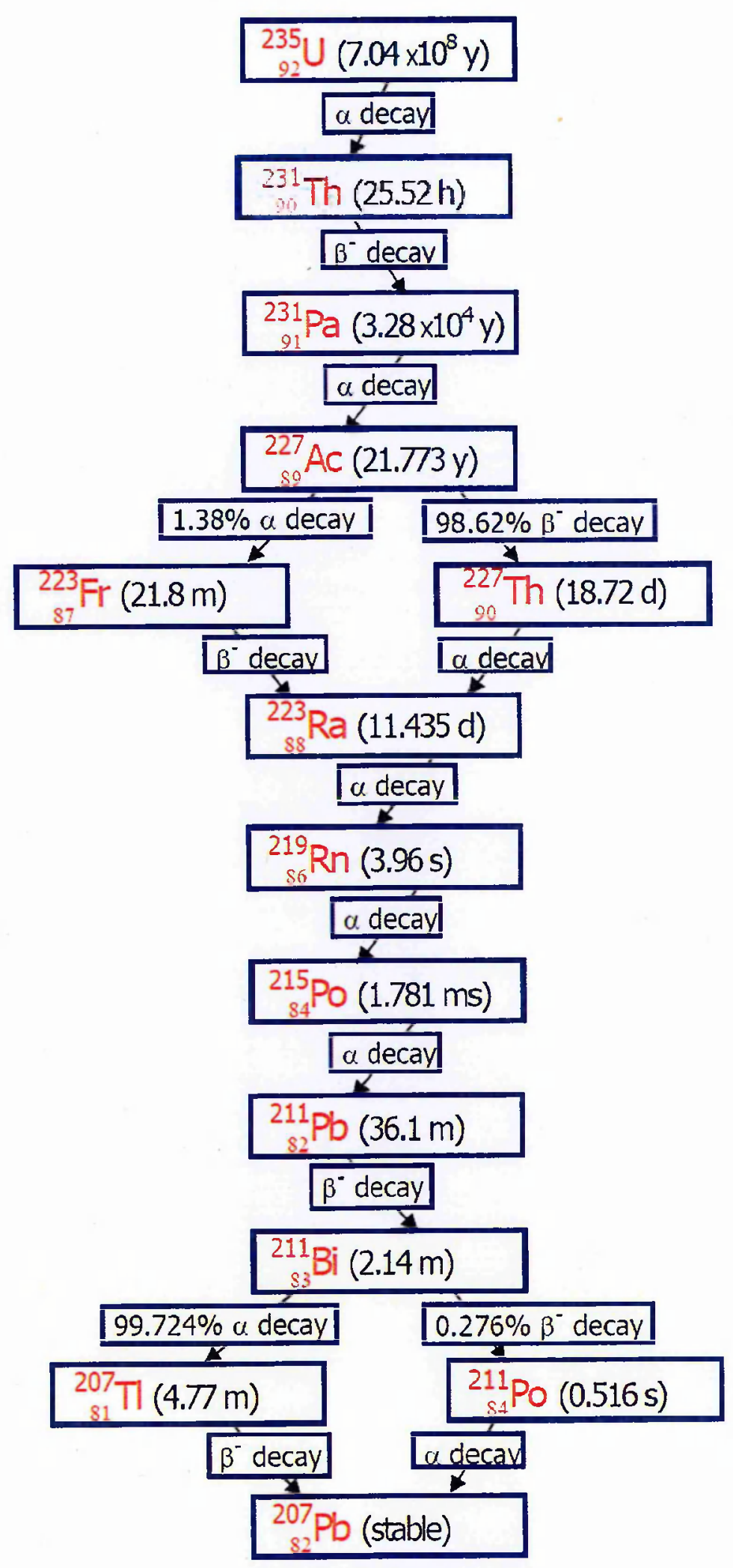

Figure 2-3: The actinium decay series. 


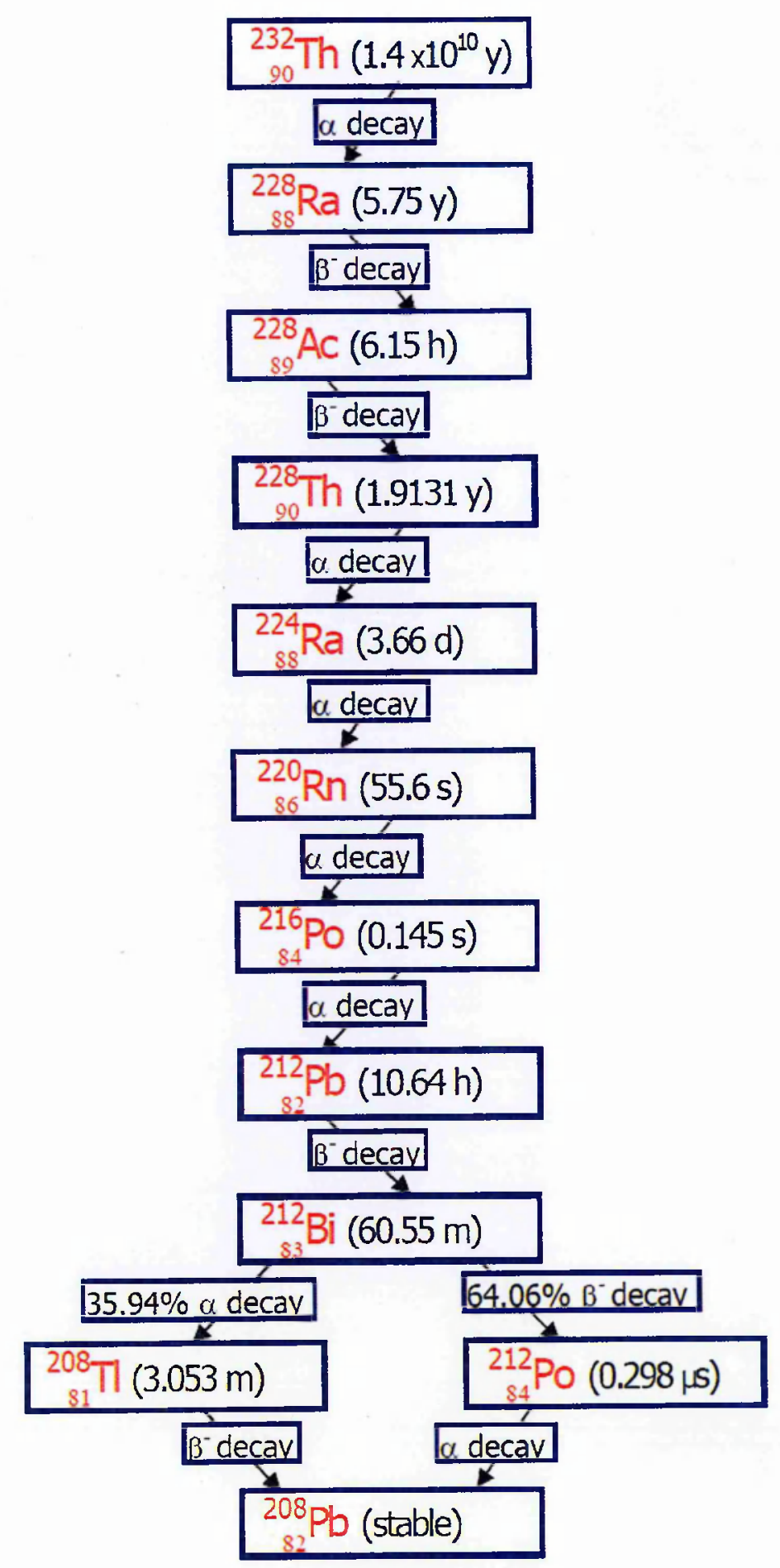

Figure 2-4: The thorium decay series. 
Table 2-1 The most significant gamma rays emitted by the NORM nuclides [WAH07, FIR98].

\begin{tabular}{|c|c|c|c|c|}
\hline Nuclide & Half-life & $\begin{array}{l}\text { Decay } \\
\text { mode }\end{array}$ & $\begin{array}{c}\text { Gamma-ray energy } \\
(\mathrm{keV})\end{array}$ & $\begin{array}{c}\text { Emission probability } \\
(\%)\end{array}$ \\
\hline${ }^{238} \mathrm{U}$ series & & & & \\
\hline${ }^{234} \mathrm{O}$ & $4.468(3) \times 10^{9} \mathrm{y}$ & $\alpha$ & $\begin{array}{l}49.55(6) \\
63283(6)\end{array}$ & $\begin{array}{l}0.063(7) \\
41(7)\end{array}$ \\
\hline & $24.10(3) \mathrm{d}$ & $\beta$ & $\begin{array}{l}0.283(0) \\
92.370(10)\end{array}$ & $2.42(15)$ \\
\hline & & & $92.793(10)$ & $2.39(15)$ \\
\hline${ }^{234 \mathrm{~m}} \mathrm{~Pa}$ & $1.17(3) \mathrm{m}$ & $\beta^{-}$ & $1001.03(3)$ & $0.837(10)$ \\
\hline & & & $766.38(2)$ & $0.294(12)$ \\
\hline & & & $742.81(3)$ & $0.080(4)$ \\
\hline${ }^{234} \mathrm{U}$ & $2.455(6) \times 10^{3} \mathrm{y}$ & $\alpha$ & $53.20(2)$ & $0.123(2)$ \\
\hline${ }^{230} \mathrm{Th}$ & & $\alpha$ & $67.672(2)$ & $0.373(21)$ \\
\hline${ }^{226} \mathrm{Ra}$ & $1600(7) y$ & $\alpha$ & $186.211(13)$ & $3.59(6)$ \\
\hline${ }^{222} \mathrm{Rn}$ & 3.8235 (3) d & & $511(2)$ & 0.076 \\
\hline${ }^{218} \mathrm{Po}$ & $3.10(1) \mathrm{m}$ & $\alpha, \beta^{-}$ & no $\gamma$-rays & \\
\hline${ }^{214} \mathrm{~Pb}$ & $26.8(9) \mathrm{m}$ & & $351.932(2)$ & $35.1(4)$ \\
\hline & & & $\begin{array}{l}295.224(2) \\
241.997(3)\end{array}$ & $\begin{array}{l}18.2(2) \\
7.12(11)\end{array}$ \\
\hline${ }^{218} \mathrm{At}$ & $1.6 \mathrm{~s}$ & & no $\gamma$-rays & \\
\hline${ }^{214} \mathrm{Bi}$ & $19.9(4) \mathrm{m}$ & $\alpha, \beta^{-}$ & $609.312(7)$ & $44.6(5)$ \\
\hline & & & $1764.494(14)$ & $15.1(2)$ \\
\hline & & & $1120.287(10)$ & $14.7(2)$ \\
\hline & & & $1238.110(12)$ & $5.78(8)$ \\
\hline${ }^{214} \mathrm{Po}$ & $164.3(20) \mu \mathrm{s}$ & $\alpha$ & $799.7(1)$ & $0.0104(35)$ \\
\hline${ }^{210} \mathrm{Tl}$ & $1.3 \mathrm{~m}$ & $\beta^{-}$ & no $\gamma$-rays & - \\
\hline${ }^{210} \mathrm{~Pb}$ & $22.3(2) \mathrm{y}$ & $\beta$ & $46.539(1)$ & $4.25(4)$ \\
\hline${ }^{210} \mathrm{Bi}$ & $5.013(5) \mathrm{d}$ & $\alpha, \beta^{-}$ & no $\gamma$-rays & \\
\hline${ }^{210} \mathrm{Po}$ & $138.376(2) \mathrm{d}$ & $\alpha$ & $803.10(5)$ & $0.00122(4)$ \\
\hline${ }^{206} \mathrm{~Pb}$ & stable & - & - & - \\
\hline${ }^{232}$ Th series & & & & \\
\hline${ }^{232} \mathrm{Th}$ & $1.405(6) \times 10^{10} y$ & $\alpha$ & $63.81(2)$ & $0.263(13)$ \\
\hline${ }^{228} \mathrm{Ra}$ & $5.75(3) \mathrm{y}$ & $\beta^{-}$ & $13.52(2)$ & \\
\hline${ }^{228} \mathrm{Ac}$ & $6.15(2) h$ & $\beta^{-}$ & $911.204(4)$ & $25.8(4)$ \\
\hline & & & $968.971(17)$ & $15.8(3)$ \\
\hline & & & $338.320(3)$ & $11.27(12)$ \\
\hline & & & $964.766(10)$ & $4.99(9)$ \\
\hline & & & $463.004(6)$ & $4.40(7)$ \\
\hline${ }^{228} \mathrm{Th}$ & $1.9116(16) \mathrm{y}$ & $\alpha$ & $84.373(3)$ & $1.22(2)$ \\
\hline${ }^{224} \mathrm{Ra}$ & $3.66(4) d$ & $\alpha$ & $240.986(6)$ & $4.10(5)$ \\
\hline${ }^{220} \mathrm{Rn}$ & $55.6(1) \mathrm{s}$ & $\alpha$ & $549.76(4)$ & $0.114(17)$ \\
\hline${ }^{216} \mathrm{Po}$ & $0.145(2) \mathrm{s}$ & $\alpha$ & $804.9(5)$ & $0.0019(3)$ \\
\hline${ }^{212} \mathrm{~Pb}$ & $10.64(1) \mathrm{h}$ & $\beta^{-}$ & $\begin{array}{l}238.632(2) \\
300.087(10)\end{array}$ & $\begin{array}{l}43.3(3) \\
3.28(3)\end{array}$ \\
\hline${ }^{212} \mathrm{Bi}$ & $60.55(6) \mathrm{m}$ & $\alpha, \beta^{-}$ & $727.330(9)$ & $6.58(6)$ \\
\hline${ }^{212} \mathrm{p}_{0}$ & $0209(0)$ & & $1620.50(10)$ & $1.49(4)$ \\
\hline${ }^{208} \mathrm{Tl}$ & $\begin{array}{l}0.299(2) \mu \mathrm{s} \\
3.053(4) \mathrm{m}\end{array}$ & $\begin{array}{l}\alpha \\
\beta^{-}\end{array}$ & $\begin{array}{l}\text { no } \gamma \text {-rays } \\
2614.533(13)\end{array}$ & $35.64(6)$ \\
\hline & & & $583.191(2)$ & $30.4(2)$ \\
\hline & & & $510.77(10)$ & $8.13(2)$ \\
\hline${ }^{208} \mathrm{~Pb}$ & stable & - & $860.564(5)$ & $\begin{array}{l}4.47(4) \\
-\end{array}$ \\
\hline
\end{tabular}


Table 2-1 The most significant gamma rays emitted by the NORM nuclides (continued).

\begin{tabular}{|c|c|c|c|c|}
\hline Nuclide & Half-life & $\begin{array}{l}\text { Decay } \\
\text { mode }\end{array}$ & $\begin{array}{c}\text { Gamma-ray energy } \\
(\mathrm{keV})\end{array}$ & $\begin{array}{c}\text { Emission probability } \\
(\%)\end{array}$ \\
\hline \\
\hline${ }^{235} \mathrm{U}$ & $7.038(5) \times 10^{8} y$ & $\alpha$ & $185.715(5)$ & $57.2(5)$ \\
\hline & & & $143.764(2)$ & $10.96(8)$ \\
\hline & & & $163.358(2)$ & $5.08(4)$ \\
\hline & & & $205.309(2)$ & $5.01(5)$ \\
\hline \multirow[t]{2}{*}{${ }^{231} \mathrm{Th}$} & 25.52 (1) h & $\beta^{-}$ & $25.646(4)$ & $14.5(3)$ \\
\hline & & & $84.216(3)$ & $6.6(3)$ \\
\hline \multirow[t]{3}{*}{${ }^{231} \mathrm{~Pa}$} & $3.276(11) \times 10^{4} \mathrm{y}$ & $\alpha$ & $27.36(1)$ & $10.3(4)$ \\
\hline & & & $300.07(1)$ & $2.47(6)$ \\
\hline & & & $302.65(2)$ & $2.87(27)$ \\
\hline${ }^{227} \mathrm{Ac}$ & $21.773(3) y$ & $\alpha, \beta^{-}$ & $99.6(1)$ & $0.0056(17)$ \\
\hline \multirow[t]{4}{*}{${ }^{227} \mathrm{Th}$} & $18.72(2) \mathrm{d}$ & $\alpha$ & $235.971(20)$ & $12.3(13)$ \\
\hline & & & $50.13(1)$ & $8.0(9)$ \\
\hline & & & $256.25(2)$ & $7.0(4)$ \\
\hline & & & $329.851(20)$ & $2.69(27)$ \\
\hline \multirow[t]{4}{*}{${ }^{223} \mathrm{Ra}$} & $11.435(4) \mathrm{d}$ & $\alpha$ & $269.459(10)$ & $13.7(3)$ \\
\hline & & & $154.21(1)$ & $5.62(14)$ \\
\hline & & & $323.871(10)$ & $3.93(7)$ \\
\hline & & & $144.232(10)$ & $3.22(7)$ \\
\hline \multirow[t]{2}{*}{${ }^{219} \mathrm{Rn}$} & $3.96(1) \mathrm{s}$ & $\alpha$ & $271.23(1)$ & $10.8(3)$ \\
\hline & & & $401.81(41)$ & $6.4(2)$ \\
\hline${ }^{215} \mathrm{Po}$ & $1.781(4) \mathrm{ms}$ & $\alpha, \beta^{-}$ & $438.8(3)$ & $0.04(2)$ \\
\hline \multirow[t]{3}{*}{${ }^{211} \mathrm{~Pb}$} & $36.1(2) \mathrm{m}$ & $\beta^{-}$ & $404.853(10)$ & $3.78(5)$ \\
\hline & & & $832.01(3)$ & $3.52(5)$ \\
\hline & & & $427.088(10)$ & $1.76(4)$ \\
\hline${ }^{21 l} \mathrm{Bi}$ & $2.14(2) \mathrm{m}$ & $\alpha, \beta^{-}$ & $351.059(20)$ & $12.91(11)$ \\
\hline \multirow[t]{2}{*}{${ }^{211} \mathrm{Po}$} & $0.516(3) \mathrm{s}$ & $\alpha$ & $897.80(5)$ & $0.561(11)$ \\
\hline & & & $569.70(22)$ & 0.545 \\
\hline${ }^{207} \mathrm{Tl}$ & $4.77(2) \mathrm{m}$ & $\beta^{*}$ & $897.80(5)$ & $0.260(9)$ \\
\hline${ }^{207} \mathrm{~Pb}$ & stable & - & - & - \\
\hline
\end{tabular}

Table 2-2 Additional Naturally Occurring Radioactive Nuclides [FRI81, CHO02, NCRP87].

\begin{tabular}{|c|c|c|c|c|}
\hline Nuclide & Half-life (y) & $\begin{array}{l}\text { Decay } \\
\text { mode }\end{array}$ & Isotopic Abundance (\%) & $\begin{array}{c}\text { Typical crustal } \\
\text { concentration }\left(\mathrm{Bq} \cdot \mathrm{kg}^{-1}\right)\end{array}$ \\
\hline${ }^{40} \mathrm{~K}$ & $1.26 \times 10^{5}$ & $\beta^{-}, \mathrm{EC}$ & 0.0117 & 630 \\
\hline${ }^{50} \mathrm{~V}$ & $>1.4 \times 10^{17}$ & $\beta^{-}, \mathrm{EC}$ & 0.250 & $2 \times 10^{-5}$ \\
\hline${ }^{87} \mathrm{Rb}$ & $4.8 \times 10^{10}$ & $\beta^{-}$ & 27.83 & 70 \\
\hline${ }^{113} \mathrm{Cd}$ & $9 \times 10^{15}$ & $\beta^{-}$ & 12.2 & $<2 \times 10^{-6}$ \\
\hline${ }^{115} \mathrm{In}$ & $5.1 \times 10^{14}$ & $\beta^{-}$ & 95.7 & $2 \times 10^{-5}$ \\
\hline${ }^{123} \mathrm{Te}$ & $1.3 \times 10^{13}$ & $\mathrm{EC}$ & 0.905 & $2 \times 10^{-7}$ \\
\hline${ }^{138} \mathrm{La}$ & $1.1 \times 10^{\mathrm{Il}}$ & $\mathrm{EC}, \beta^{-}$ & 0.089 & $2 \times 10^{-2}$ \\
\hline${ }^{144} \mathrm{Nd}$ & $2.1 \times 10^{15}$ & $\alpha$ & 23.8 & $3 \times 10^{-4}$ \\
\hline${ }^{147} \mathrm{Sm}$ & $1.06 \times 10^{11}$ & $\alpha$ & 15.1 & 0.7 \\
\hline${ }^{152} \mathrm{Gd}$ & $1.1 \times 10^{14}$ & $\alpha$ & 0.20 & $7 \times 10^{-6}$ \\
\hline${ }^{176} \mathrm{Lu}$ & $3.6 \times 10^{10}$ & $\beta^{-}$ & 2.61 & 0.04 \\
\hline${ }^{174} \mathrm{Hf}$ & $2.0 \times 10^{15}$ & $\alpha$ & 0.16 & $2 \times 10^{-7}$ \\
\hline${ }^{187} \mathrm{Re}$ & $4 \times 10^{10}$ & $\beta^{-}$ & 62.60 & $1 \times 10^{-3}$ \\
\hline${ }^{190} \mathrm{Pt}$ & $6 \times 10^{11}$ & $\alpha$ & 0.013 & $7 \times 10^{-8}$ \\
\hline
\end{tabular}

Pink colour: Data from [CHO02], Blue colour: Data from [NCRP87] 
The similarity of the three families is that each series contains one gaseous member from the element, radon; these are called radon $\left({ }^{222} \mathrm{Rn}, \mathrm{T}_{1 / 2}=3.825 \mathrm{~d}\right)$, thoron $\left({ }^{220} \mathrm{Rn}, \mathrm{T}_{1 / 2}=55.6 \mathrm{~s}\right)$, and actinon $\left({ }^{219} \mathrm{Rn}, \mathrm{T}_{1 / 2}=3.96 \mathrm{~s}\right)$ for the uranium, thorium and actinium series respectively. Since ${ }^{220} \mathrm{Rn}$ and ${ }^{219} \mathrm{Rn}$ decay away rapidly, the health hazard from ${ }^{222} \mathrm{Rn}$ gas is the most important of these to be considered. Inhalation of contaminated dust particles causes deposition of radioactive radon progeny in the lung and brings about an internal exposure. Non-gaseous radioactive daughter nuclei produced by ${ }^{222} \mathrm{Rn}$ when accumulating in the lungs give rise to a health effect of about 500 times larger than that from ${ }^{222} \mathrm{Rn}$ itself [CEM09] and ${ }^{214} \mathrm{Po}$ and ${ }^{218} \mathrm{Po}$ which are the decay products of radon can also catalyse cancer and damage cell tissue. Radon gas is an inert radioactive gas which is both colourless and odourless. It is easily spread through the air relying on various factors such as diffusion, convection processes, surface conditions, temperature and wind speed [VAN01]. The concentration in indoor air depends on several factors such as underlying soil and rocks, ventilation in the buildings, and meteorological factors affecting the flow rate into buildings [THE96]. Radon is not only contained in some natural gas and oils supplies but is also present in confined spaces and ground water. It can enter buildings from soil and rocks, from building materials and tap water. High radon exposure is found in many places around the world, particularly in areas with geothermal or volcanic activity and also in caves and mines. A relationship between the weather conditions and radon levels had been discovered by various British researchers. In the cold season with high pressure conditions (i.e. cave system) the radon levels tend to increased by orders-of-magnitude [UND96]. The average of ${ }^{222} \mathrm{Rn}$ concentration in outdoor air reported from several countries may be taken normally to be in the range of $0.1-0.5 \mathrm{pCi} \cdot \mathrm{L}^{-1}\left(4-19 \mathrm{~Bq} \cdot \mathrm{m}^{-3}\right)$ [EIS97].

There is a fourth decay series which is headed by ${ }^{241} \mathrm{Pu}$, called the neptunium series. ${ }^{241} \mathrm{Pu}$ is an artificial radionuclide made in the laboratory by neutron irradiation of the reactor-produced ${ }^{239} \mathrm{Pu}$ [CEM09]. Even the longest half-life of the member in this series, ${ }^{237} \mathrm{~Np}\left(\mathrm{~T}_{1 / 2}=2.2 \times 10^{6} \mathrm{yrs}\right)$ is short enough to have decayed away since the birth of the earth and no longer found in nature, apart from residues from atomic weapons testing. The neptunium decay series are displayed in Figure 2-5. 


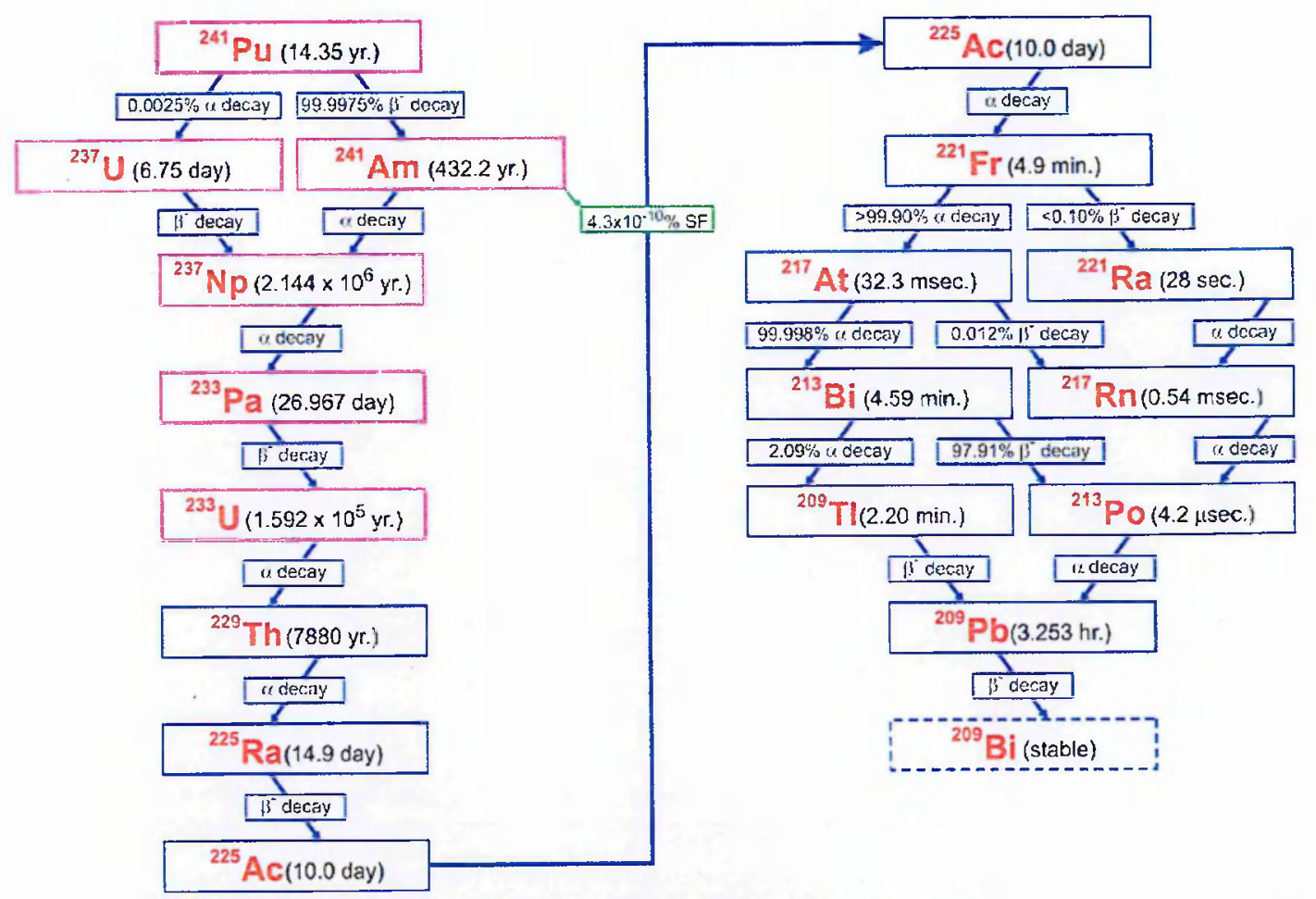

Figure 2-5: The neptunium decay series [HEA98].

In addition, ${ }^{40} \mathrm{~K}$, a non-series natural radionuclide with a half-life of $1.28 \times 10^{9}$ years, is common in all types of rock, with a variation of concentrations related to those in the underlying rock. In nature, natural potassium contains only $0.0118 \%$ of ${ }^{40} \mathrm{~K}$ [THE96]. However, with an elemental abundance more than $10^{4}$ times that of uranium and thorium by weight in soil and rock, ${ }^{40} \mathrm{~K}$ contributes to the dose received by NORM at a level comparable to that from the ${ }^{238} \mathrm{U}$ and ${ }^{232} \mathrm{Th}$ decay chains. The decay process of ${ }^{40} \mathrm{~K}$ involves $\beta^{-}$emission $(89 \%)$ and electron capture (EC) $(11 \%)$. The $\beta^{-}$end-point energy is $1.312 \mathrm{MeV}$ and a gamma ray at energy of $1.461 \mathrm{MeV}$ is emitted following the electron capture decay branch, as shown in Figure 2-6.

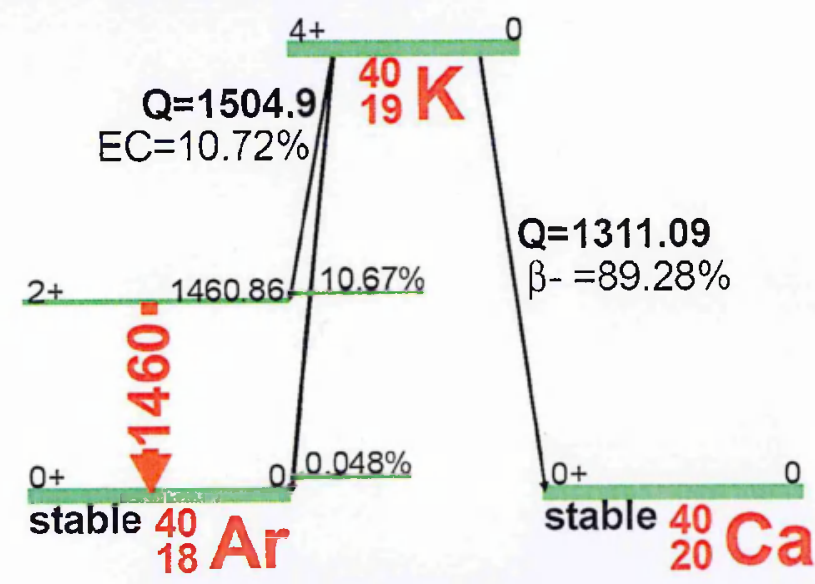

Figure 2-6: Decay scheme of ${ }^{40} \mathrm{~K}$ [HEA98]. 
The concentration of ${ }^{238} \mathrm{U},{ }^{232} \mathrm{Th},{ }^{226} \mathrm{Ra}$ and ${ }^{40} \mathrm{~K}$ in typical rocks and soils reported by NCRP and in other media are given in Table 2-3 and Table 2-4 respectively.

Table 2-3 Ranges and averages of the concentrations of ${ }^{40} \mathrm{~K},{ }^{232} \mathrm{Th}$, and ${ }^{238} \mathrm{U}$ in typical rocks and soils [NCRP87].

\begin{tabular}{|c|c|c|c|c|c|c|}
\hline \multirow{2}{*}{ Rock type } & \multicolumn{2}{|c|}{${ }^{s 0} \mathrm{~K}$} & \multicolumn{2}{|c|}{${ }^{232} \mathrm{Th}$} & \multicolumn{2}{|c|}{${ }^{238} \mathbf{U}$} \\
\hline & $\%$ total K & $\mathrm{Bq} / \mathbf{k g}$ & ppm & $\mathrm{Bq} / \mathrm{kg}$ & ppm & $\mathrm{Bq} / \mathrm{kg}$ \\
\hline \multicolumn{7}{|l|}{ Igneous rocks } \\
\hline Basalt (crustal ave.) & 0.8 & 300 & $3-4$ & $10-15$ & $0.5-1$ & $7-10$ \\
\hline Mafic & $0.3-1.1$ & $70-400$ & $1.6,2.7$ & 7,10 & $0.5,0.9$ & 7,10 \\
\hline Salic & 4.5 & $1100-1500$ & 16,20 & 60,80 & $3.9,4.7$ & 50,60 \\
\hline Granite (crustal ave.) & $>4$ & $>1000$ & 17 & 70 & 3 & 40 \\
\hline \multicolumn{7}{|l|}{ Sedimentary rocks } \\
\hline Shale sandstones & 2.7 & 800 & 12 & 50 & 3.7 & 40 \\
\hline Clean quartz & $<1$ & $<300$ & $<2$ & $<8$ & $<1$ & $<10$ \\
\hline Dirty quartz & $2^{a}$ & $400^{a}$ & $3-6^{a}$ & $10-25^{a}$ & $2-3^{a}$ & $40^{a}$ \\
\hline Arkose & $2-3$ & $600-900$ & $2^{a}$ & $<8$ & $1-2^{a}$ & $10-25^{a}$ \\
\hline Beach sands & $<1$ & $<300^{a}$ & 6 & 25 & 3 & 40 \\
\hline Carbonate rocks & 0.3 & 70 & 2 & 8 & 2 & 25 \\
\hline \multicolumn{7}{|l|}{ All Rock (range) } \\
\hline Continental crust (ave.) & 2.8 & 850 & 10.7 & 44 & 2.8 & 36 \\
\hline Soil (ave.) & 1.5 & 400 & 9 & 37 & $1-8$ & 66 \\
\hline
\end{tabular}

$a$ indicates estimate in the absence of measured values.

Table 2-4 Natural concentration of some terrestrial radionuclides [VAN01].

\begin{tabular}{lcccc}
\hline \multirow{2}{*}{ Media } & \multicolumn{4}{c}{ Acitivity concentration $(\mathbf{B q} / \mathrm{kg})$} \\
\cline { 2 - 5 } & ${ }^{\mathbf{4 0}} \mathbf{K}$ & ${ }^{226} \mathbf{R a}$ & ${ }^{232} \mathbf{T h}$ & ${ }^{238} \mathbf{U}$ \\
\hline Soils & 400 & 40 & 25 & 25 \\
Granite & 1000 & 100 & 80 & 60 \\
Coal & $<40$ & $<20$ & $<20$ & - \\
Fertilizers & $<4000$ & $<400$ & $<20$ & - \\
Ground water & $<1$ & $<1$ & $<1$ & $<1$ \\
Seawater & 10 & $<1$ & $<1$ & 0.04 \\
Drinking-water & 0.2 & $<1$ & - & 0.004 \\
Milk & 47 & 0.003 & - & - \\
Foodstuffs & $40-300$ & $0.01-100$ & - & - \\
Man & -60 & 0.03 & - & 0.1 \\
\hline
\end{tabular}

Natural radioactivity has also been investigated in seawater with the total amounts estimated to be $4.3 \times 10^{12} \mathrm{~kg}(53 \mathrm{EBq})$ for ${ }^{238} \mathrm{U}$, and $6.9 \times 10^{10} \mathrm{~kg}(0.3 \mathrm{EBq})$ for ${ }^{232} \mathrm{Th}$. The amount of ${ }^{40} \mathrm{~K}$ is deduced to be $7.4 \times 10^{13} \mathrm{~kg}$ corresponding to the activity of $1.94 \times 10^{4} \mathrm{EBq}$ which is the major contribution from radioactive source in the oceans [CHOO2]. 


\subsection{Modes of Nuclear Decay}

Nuclear disintegration is the decay process that allows an unstable nuclide to transform to a new nuclide which has a lower total mass/energy. Alpha or beta radiation is the result of the decay process and can be emitted individually or in competition with each other. In some cases more than one manner of the decay process is energetically allowed for a given radionuclide. In addition, following decays from beta or alpha emission there can be an additional release of energy from the excited-state of daughter nucleus, which is called gamma-ray emission. Several gamma rays may be emitted in a cascade, each with different and characteristic energies.

\subsubsection{Alpha Decay}

An alpha particle is an ${ }^{4} \mathrm{He}$ nucleus, with the symbol, $\alpha$. The emission of an $\alpha$ particle generally occurs for heavy radionuclides with atomic number, $Z>83$. Alpha emission is the preferential decay mode for such heavy nuclei, resulting from the Coulomb repulsion effect between protons which increases with the square of the atomic number. After undergoing the alpha emission, the mass number of the final nucleus is less than the initial nucleus by four atomic mass units and the nuclear charge less by two units. The emission of an $\alpha$ particle can be represented by the following process [KRA88]:

${ }_{Z}^{A} X_{N} \rightarrow{ }_{Z-2}^{A-4} X_{N-2}^{\prime}+\alpha+Q$

where $X$ and $X^{\prime}$ are the parent and the daughter nuclide respectively. The $Q$ value is the net energy released in the decay due to the difference in mass/energy between the parent and the daughter nuclide.

The law of conservation of mass/energy gives [KRA88],

$m_{x}=m_{x}+m_{\alpha}+Q$

where the masses are in atomic mass units (u), expressing $c^{2}$ as $931.502 \mathrm{MeV} / \mathrm{u}$ gives the $Q$ value directly in $\mathrm{MeV}$. 
For example, in the case of an alpha decay of the radium isotope: ${ }_{88}^{226} R a \rightarrow{ }_{86}^{222} R n+{ }_{2}^{4} \mathrm{He}+Q$

from Eq. (2.2) the $Q$ value can be expressed by:

$Q=m_{x}-m_{x^{\prime}}-m_{\alpha}$

where

$Q=226.025406-222.017574-4.002603$

$=0.005229 \mathrm{amu}$ (atomic mass unit)

In energy units,

$Q=\left(m_{x}-m_{x}-m_{\alpha}\right) c^{2}$

$Q=0.005229 \times 931 \mathrm{MeV} / \mathrm{amu}=4.86 \mathrm{MeV}$

The $Q$ value is transferred to the total kinetic energy of the decay fragments and typically divided between the $\mathrm{Rn}$ and the He in a specific proportion to conserve linear momentum. Normally, about $98 \%$ of the $Q$ value is given to the alpha particle, while the much heavier nuclear fragment $X^{\prime}$ carries the rest of the energy (only about $2 \%$ ). For a typical $Q$ value of $5 \mathrm{MeV}$, the final heavy particle has energy of the order of $100 \mathrm{keV}$ [KRA88]. This energy is generally more than enough to overcome the binding energy of atoms. Therefore both alpha particles and the heavy fragments can be released from a radioactive source if it is close to the surface. For the radionuclide in one of the decay chains e.g. ${ }^{238} \mathrm{U}$ or ${ }^{232} \mathrm{Th}$, the recoiling daughter nucleus is often radioactive.

\subsubsection{Beta Decay}

Beta decay is the decay process that results from the conversion of a proton to neutron or of a neutron into a proton to maximize the binding energy and so produce the most stable nuclide in a given isobaric chain. There are three processes involved with beta decay, as follows [KRA88]: 
$n \rightarrow p+e^{-} \quad$ negative beta decay $\left(\beta^{-}\right)$

$p \rightarrow n+e^{-} \quad$ positive beta decay $\left(\beta^{+}\right)$

$p+e^{-} \rightarrow n \quad$ orbital electron capture $(\varepsilon)$

\subsubsection{1 $\beta^{-}$decay}

A beta particle, $\beta^{-}$, is an electron which is similar to any other electron and can not be physically distinguished from the atomic electrons in its structure. The beta particle has a single electric negative charge $\left(-1.6 \times 10^{-19} \mathrm{C}\right)$ and a relatively small mass compared to a proton or neutron $(0.00055 \mathrm{amu})$ [CEM09]. Since a neutron is converted to a proton within the nucleus, the beta particle is emitted from the nucleus and thus the atomic number of the nuclide increases by one. In order to conserve angular momentum and total mass energy the process produces another (neutrally charged) particle, the anti-neutrino [KRA88]. The process can be written as,

${ }_{0}^{1} n \rightarrow{ }_{1}^{1} H+{ }_{-1}^{0} \beta+\bar{v}$

In the case of mono-energetic beta particle [CEM09]:

$m_{n}=m_{p}+m_{\beta}+Q$

However, beta particles are found to be emitted with a continuous distribution of energies ranging from zero up to the endpoint energy which can be theoretically estimated based on mass-energy considerations for the particular beta transition. The average energy of the beta radiation is about $30-40 \%$ of the maximum ('end point') energy for most beta emitters [CEM09]. As an example, the beta-particle spectrum from ${ }^{210} \mathrm{Bi}$ (which is a member of the uranium decay chain) is shown in Figure 2-7. This has maximum (end point) energy for the beta particle of $1.16 \mathrm{MeV}$, but the kinetic energies of the most of the betas are significantly smaller than the average energy of $\sim 390 \mathrm{keV}$ or about $33 \%$ of the maximum energy [NEA40]. 


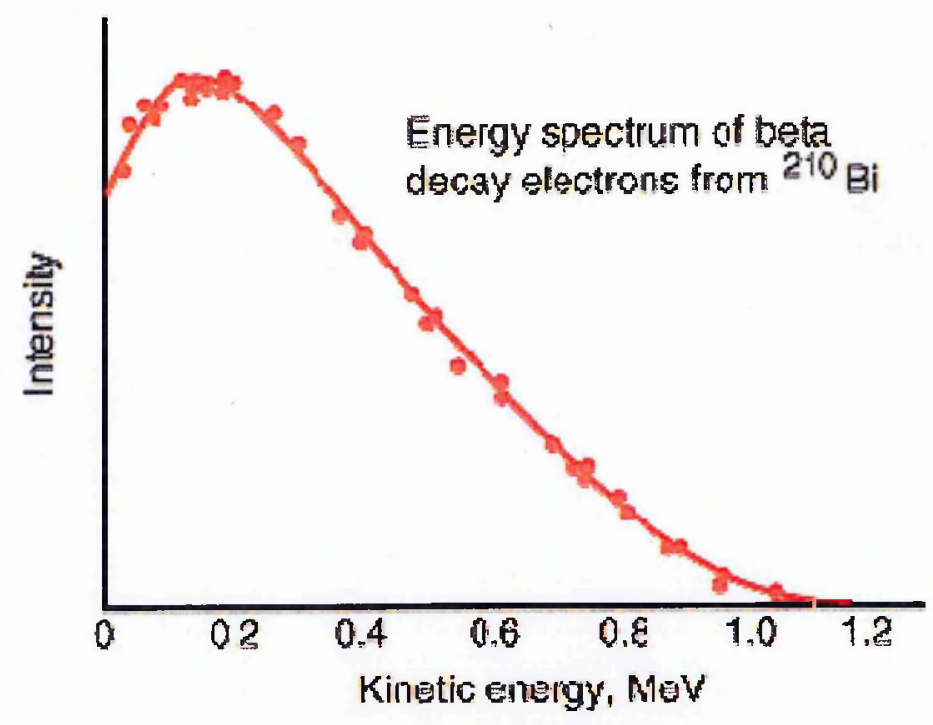

Figure $2-7:{ }^{210} \mathrm{Bi}$ beta spectrum [NEA40].

\subsubsection{2 $\beta^{+}$decay}

The $\beta^{+}$particle or positron is a beta particle which has a positive charge $\left(+1.6 \times 10^{-19} \mathrm{C}\right)$ and the same mass of $0.00055 \mathrm{amu}\left(9.1094 \times 10^{-31} \mathrm{~kg}\right)$ as the electron. Positron emission is the result of the conversion of a proton to a neutron within the nucleus and it arises when the ratio of neutrons to protons in the nucleus is low relative to the stable isobar of that particular mass chain. The daughter product has one atomic number less than the parent and also produces a neutrino according to equation:

${ }_{1}^{1} H \rightarrow{ }_{0}^{1} n+{ }_{+1}^{0} \beta+v$

where $v$ represents the neutrino.

Losing one proton from the nucleus also leads to another loss of an orbital electron from the daughter nucleus which happens rapidly after the nuclear transition. In terms of atomic masses, therefore the conservation equation is given by [CEM09]:

$$
m_{p}=m_{n}+m_{\beta^{+}}+m_{\beta^{-}}+Q
$$

where $m_{p}, m_{n}, m_{\beta^{+}}$and $m_{\beta^{-}}$are the masses of the parent nucleus, daughter nucleus, positron, and electron respectively and $Q$ is the net energy released from the reaction. 
After the positron is emitted from the nucleus, it can combine with an atomic electron and both the positron and electron can annihilate resulting in two gamma-rays whose energies are equal to the mass equivalent of those positron and electron $(511 \mathrm{keV})$.

\subsubsection{Orbital Electron Capture}

Electron capture is a decay process that competes with $\beta^{+}$emission. $\beta^{+}$emission is allowed from nucleus with neutron to proton ratios lower than the stable isobar of that particular mass chain. The mass of the parent nucleus is larger than that of the daughter by at least two electron masses. If this mass/energy requirement cannot be met, the proton can instead decay by the capture of orbital electron in order to create a neutron. This alternative decay process is known as electron capture (or $\mathrm{K}$ capture when the orbital electron is from the $\mathrm{K}$-shell) and can be written schematically as [CEM09]:

${ }_{1}^{1} H+{ }_{-1}^{0} e \rightarrow{ }_{0}^{1} n+v$

Capturing electrons from the $\mathrm{K}$ shell is the most likely in such a mechanism since the electrons are much closer to the nucleus than those in any other higher angular momentum shell. As a result, the possibility of capturing the electron in the $\mathrm{K}$ shell is much higher than that for any other shell. The mass/energy conservation equation for $\mathrm{K}$ shell electron capture can be expressed by [CEM09]:

$$
m_{p}+m_{e}=m_{n}+E_{b}+Q
$$

where $m_{p}$ and $m_{n}$ are the atomic masses of the parent and the daughter respectively, $m_{e}$ is the mass of the captured electron, $E_{b}$ is the binding energy of the electron, and $Q$ is the net energy released from the reaction.

A characteristic X-ray is commonly emitted from the daughter element following the orbital electron capture since an electron de-excites from the outer orbit to the lower energy level that had been occupied by the captured electron (Figure 2-8). 


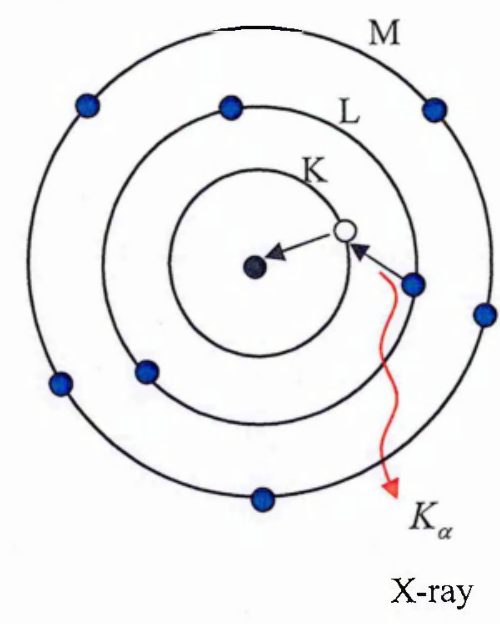

Figure 2-8: Electron capture from the $\mathrm{K}$ shell followed by characteristic X-ray emission.

\subsubsection{Gamma-Ray Emission}

Gamma rays are electromagnetic radiation whose energies typically are in the range of 0.1 to $10 \mathrm{MeV}$ with the corresponding wavelengths between $10^{4}$ and $100 \mathrm{fm}$ [KRA88]. The emission of gamma rays is caused by radiative transformations from the excited-state of daughter nuclides and does not effect or change the atomic number or neutron number of the atom. Figure 2-9 shows a gamma-ray decay scheme for ${ }^{226} \mathrm{Ra}$ (in the ${ }^{238} \mathrm{U}$ chain) which involves three excited states of the daughter ${ }^{222} \mathrm{Rn}$ nucleus and the emission of four different gamma-ray energies at 186, 262, 415, and $601 \mathrm{keV}$. There are no directly observed gamma transitions from the highest excited state to the lower state (601 $\mathrm{keV} \rightarrow 448 \mathrm{keV})$ and from the latter state to the ground state $(448 \mathrm{keV} \rightarrow 0 \mathrm{keV})$ as they are significantly hindered by the gamma-ray selection rules to large angular momentum change between the initial and final states which such a transition would represent. 


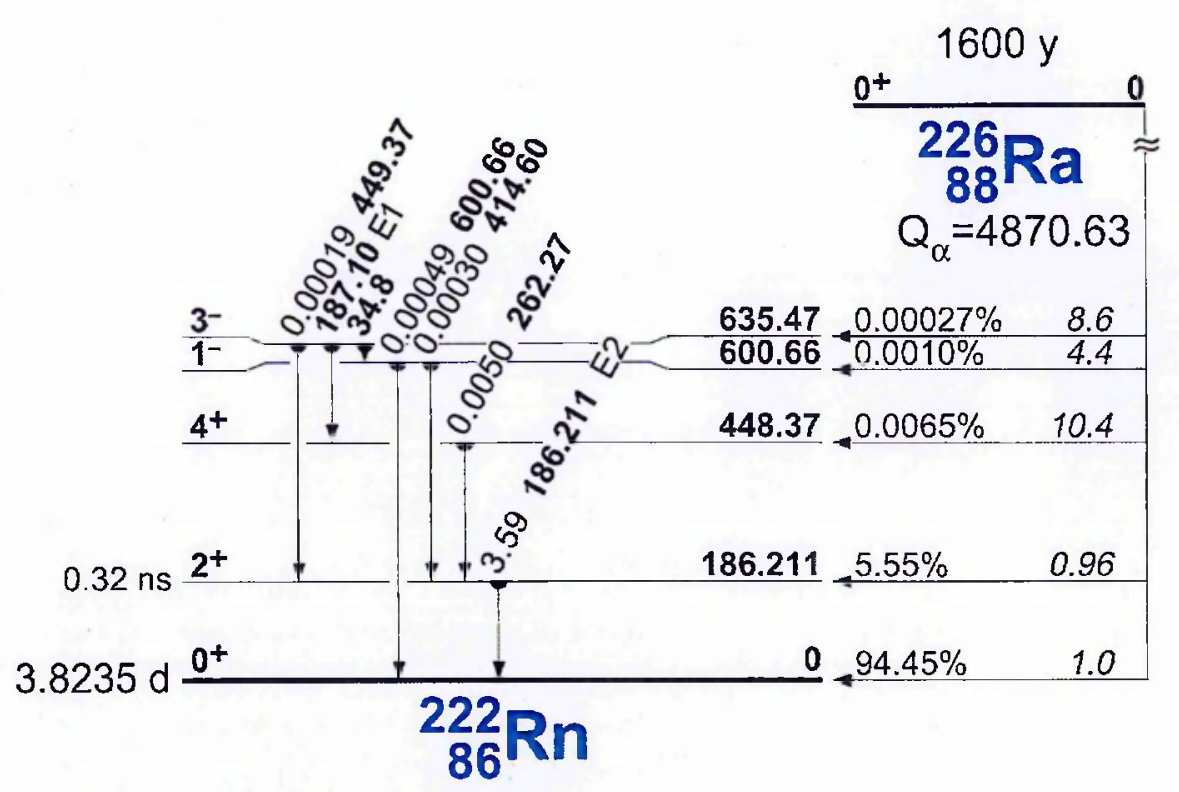

Figure 2-9: Decay scheme for ${ }^{226}$ Ra showing the nuclear transitions from excited levels to the ground state.

Electromagnetic transitions between $I_{i}=1^{-}$and $I_{f}=4^{+}$and $I_{i}=4^{+}$to $I_{f}=0^{+}$where $I_{i}$ and $I_{f}$ are the initial excited state and the final state angular momentum, are hindered in their decay and would need to decay by electric octapole (E3) and electric hexadecupole (E4) type transitions respectively. Such decays are very hindered compared to lowerorder multipole decays. Therefore, only the E2 (electric quadrupole) and E1 (electric dipole) transitions play a significant role in the observed NORM gamma rays associated with decays in the ${ }^{226} \mathrm{R}$ a nucleus.

Internal conversion is an alternative decay mechanism for excited states in nuclei and competes with gamma emission. The energy of an excited nuclear state is transferred to an atomic electron, (usually a $\mathrm{K}$ - or L- shell electron) which is then ejected from the atom. The kinetic energy, $T_{e}$, of the ejected electron is equal to the difference between the excitation energy $E$ of the nucleus and the binding energy $B$ of the electron in its atomic shell according to the equation [KRA88]:

$T_{e}=E-B$

After the internal conversion, a vacancy is left by the ejected electron in one of the deeper bound energy levels. As a result, characteristic X-rays are emitted when this vacancy is 
filled by an outer electron in the same atom. These characteristic X-rays may themselves be absorbed in the atom and then eject electrons, called Auger electrons.

\subsection{The Radioactive Decay Law}

Nuclides with unfavourable neutron-to-proton ratios relative to the stable isobar are referred as "unstable". The process that allows unstable nuclides to form isotopes which are more stable is called radioactive decay. As discussed in the earlier sections, such spontaneous nuclear transformations can occur via the emission of an $\alpha$ - or $\beta$-ray (or by electron capture). Radioactive properties can be characterised without any influences from physical or chemical circumstances such as temperature, pressure, or dissolution. The fundamental law of radioactive decay can be written as [KRA88]:

$$
A=-\frac{d N}{d t}=\lambda N
$$

where $A$ is the activity of a radioisotope source (i.e. the number of nuclei decaying per unit time)

$N$ is the number of radioactive nuclei

$\lambda$ is a constant called the disintegration or decay constant

Assuming that there are $N_{0}$ atoms of the parent at $t=0$ and no decay products are initially populated, then:

$$
\begin{aligned}
& N_{1}(t=0)=N_{0} \\
& N_{2}(t=0)=N_{3}(t=0)=\ldots=0
\end{aligned}
$$

For the common case of radioactive decay, the parent nuclei only decay into a single radioactive daughter. The number of parent nuclei will decrease as a function of time given by:

$$
d N_{1}=-\lambda_{1} N_{1} d t
$$

During this time that the number of daughter nuclei can increase because of the decays of the parent; however if the daughter is also radioactive, it is also decreasing due to its own decay, i.e;

$$
d N_{2}=\lambda_{1} N_{1} d t-\lambda_{2} N_{2} d t
$$


Integrating Equation 2.15 brings about the exponential law of radioactive decay:

$$
N(t)=N(0) e^{-\lambda t}
$$

where $N(0)$ is a constant number showing the number of nuclei present at $t=0$.

From Eq. (2.17), the activity of the radioactive parent nuclide $A(t)$ as a function of time is

$$
A(t)=\lambda N(t)=\lambda N(0) e^{-\lambda t}=A(0) e^{-\lambda t}
$$

By substituting $N\left(t_{1 / 2}\right)=N(0) / 2$ in Equation 2.17, the half-life $\left(t_{1 / 2}\right)$, after which one half of the initial nuclei have decayed is given by [LIL01]

$$
t_{1 / 2}=\frac{\ln 2}{\lambda}=\frac{0.693}{\lambda}
$$

The mean lifetime (or simply the 'lifetime'), $\tau$, can be described as the mathematical mean or arithmetical average time before the nuclide decays and is equal to the reciprocal of the decay constant. The mean lifetime derived in terms of the half-life is given by [KRA88]

$$
\tau=\frac{1}{\lambda}=\frac{t_{1 / 2}}{0.693}=1.443 t_{1 / 2}
$$

A serial transformation can be generated when the daughter of a radioactive nucleus become radioactive and decays to a third radioactive nucleus and so on.

$$
N_{1} \rightarrow N_{2} \rightarrow N_{3} \rightarrow \text { etc. }
$$

For instance, the ${ }^{235} \mathrm{U}$ series which decays through 11 decay stages combines $\alpha$ and $\beta^{-}$ decay and ends at ${ }^{207} \mathrm{~Pb}$.

\subsubsection{The Bateman Equations}

The general equation giving the number of atoms of the $i^{\text {th }}$ isotope in the decay chain at time $t$ in terms of the decay constants of all the other isotopes in the chain was developed by H. Bateman [BAT10]. If $N_{i}(0)$ is the number of atoms of the $i^{\text {th }}$ isotope of the series at time $t=0$ and assuming zero concentrations of all daughters at time zero [CET06], then

$$
N_{1}(0) \neq 0 \text { and } N_{i}(0)=0 \text { when } i>1
$$


and the Bateman equation takes the form:

$$
N_{i}(t)=\lambda_{1} \lambda_{2} \ldots \lambda_{i-1} N_{1}(0) \sum_{j=1}^{i} \frac{e^{-\lambda_{j} t}}{\prod_{k \neq j}\left(\lambda_{k}-\lambda_{j}\right)}
$$

Applying the Bateman equation for the second and third isotope in a series [TSO95], we have

$$
N_{2}(t)=\lambda_{1} N_{1}(0)\left(\frac{e^{-\lambda_{1} t}}{\lambda_{2}-\lambda_{1}}+\frac{e^{-\lambda_{2} t}}{\lambda_{1}-\lambda_{2}}\right)=\frac{\lambda_{1} N_{1}(0)}{\left(\lambda_{2}-\lambda_{1}\right)}\left(e^{-\lambda_{1} t}-e^{-\lambda_{2} t}\right)
$$

and

$$
\begin{aligned}
A_{2}(t)= & \lambda_{2} N_{2}(t)=N_{1}(0) \frac{\lambda_{2} \lambda_{1}}{\left(\lambda_{2}-\lambda_{1}\right)}\left(e^{-\lambda_{1} t}-e^{-\lambda_{2} t}\right)=A_{1}(0) \frac{\lambda_{2}}{\lambda_{2}-\lambda_{1}}\left(e^{-\lambda_{1} t}-e^{-\lambda_{2} t}\right) \\
& =A_{1}(0) \frac{1}{1-\frac{\lambda_{1}}{\lambda_{2}}}\left(e^{-\lambda_{1} t}-e^{-\lambda_{2} t}\right)=A_{1}(t) \frac{\lambda_{2}}{\lambda_{2}-\lambda_{1}}\left(1-e^{-\left(\lambda_{2}-\lambda_{1}\right) r}\right)
\end{aligned}
$$

$$
N_{3}(t)=\lambda_{1} \lambda_{2} N_{1}(0)\left[\frac{e^{-\lambda_{1} t}}{\left(\lambda_{2}-\lambda_{1}\right)\left(\lambda_{3}-\lambda_{1}\right)}+\frac{e^{-\lambda_{2} t}}{\left(\lambda_{1}-\lambda_{2}\right)\left(\lambda_{3}-\lambda_{2}\right)}+\frac{e^{-\lambda_{3} t}}{\left(\lambda_{1}-\lambda_{3}\right)\left(\lambda_{2}-\lambda_{3}\right)} \mid\right]
$$

$$
\begin{aligned}
A_{3}(t)= & \lambda_{3} N_{3}(t)=\lambda_{3} \lambda_{1} \lambda_{2} N_{1}(0)\left[\frac{e^{-\lambda_{1} t}}{\left(\lambda_{2}-\lambda_{1}\right)\left(\lambda_{3}-\lambda_{1}\right)}+\frac{e^{-\lambda_{2} t}}{\left(\lambda_{1}-\lambda_{2}\right)\left(\lambda_{3}-\lambda_{2}\right)}+\frac{e^{-\lambda_{3} t}}{\left(\lambda_{1}-\lambda_{3}\right)\left(\lambda_{2}-\lambda_{3}\right)} \mid\right] \\
& =\lambda_{3} \lambda_{2} A_{1}(t)\left[\frac{1}{\left(\lambda_{2}-\lambda_{1}\right)\left(\lambda_{3}-\lambda_{1}\right)}+\frac{e^{-\left(\lambda_{2}-\lambda_{1}\right) t}}{\left(\lambda_{1}-\lambda_{2}\right)\left(\lambda_{3}-\lambda_{2}\right)}+\frac{e^{-\left(\lambda_{3}-\lambda_{1}\right) t}}{\left(\lambda_{1}-\lambda_{3}\right)\left(\lambda_{2}-\lambda_{3}\right)}\right]
\end{aligned}
$$

The Bateman equations were used to estimate the number of the atoms and the activity concentrations of ${ }^{238} \mathrm{U},{ }^{234} \mathrm{Th}$ and ${ }^{234 \mathrm{~m}} \mathrm{~Pa}$ atoms which are the first three members of ${ }^{238} \mathrm{U}$ decay chain where zero initial concentrations of ${ }^{238} U$ daughters were assumed. Figure 210 shows the growth curve of the ${ }^{234} \mathrm{Th}$ and ${ }^{234 \mathrm{~m}} \mathrm{~Pa}$ in the ${ }^{238} \mathrm{U}$ as a function of time. The half-life of ${ }^{238} \mathrm{U}\left(t_{1 / 2}=4.47 \times 10^{9}\right.$ years $)$ is very long compared to ${ }^{234} \mathrm{Th}\left(t_{1 / 2}=24.10\right.$ days $)$ and ${ }^{234 \mathrm{~m}} \mathrm{~Pa}\left(t_{1 / 2}=1.17\right.$ minutes $)$. As a result, ${ }^{238} \mathrm{U}$ decays at an almost constant rate i.e. $e^{-\lambda_{1} t} \approx 1$, while ${ }^{234} \mathrm{Th}$ and ${ }^{234 \mathrm{~m}} \mathrm{~Pa}$ take approximately 170 days and 10 minutes to reach equilibrium with their parents respectively. 


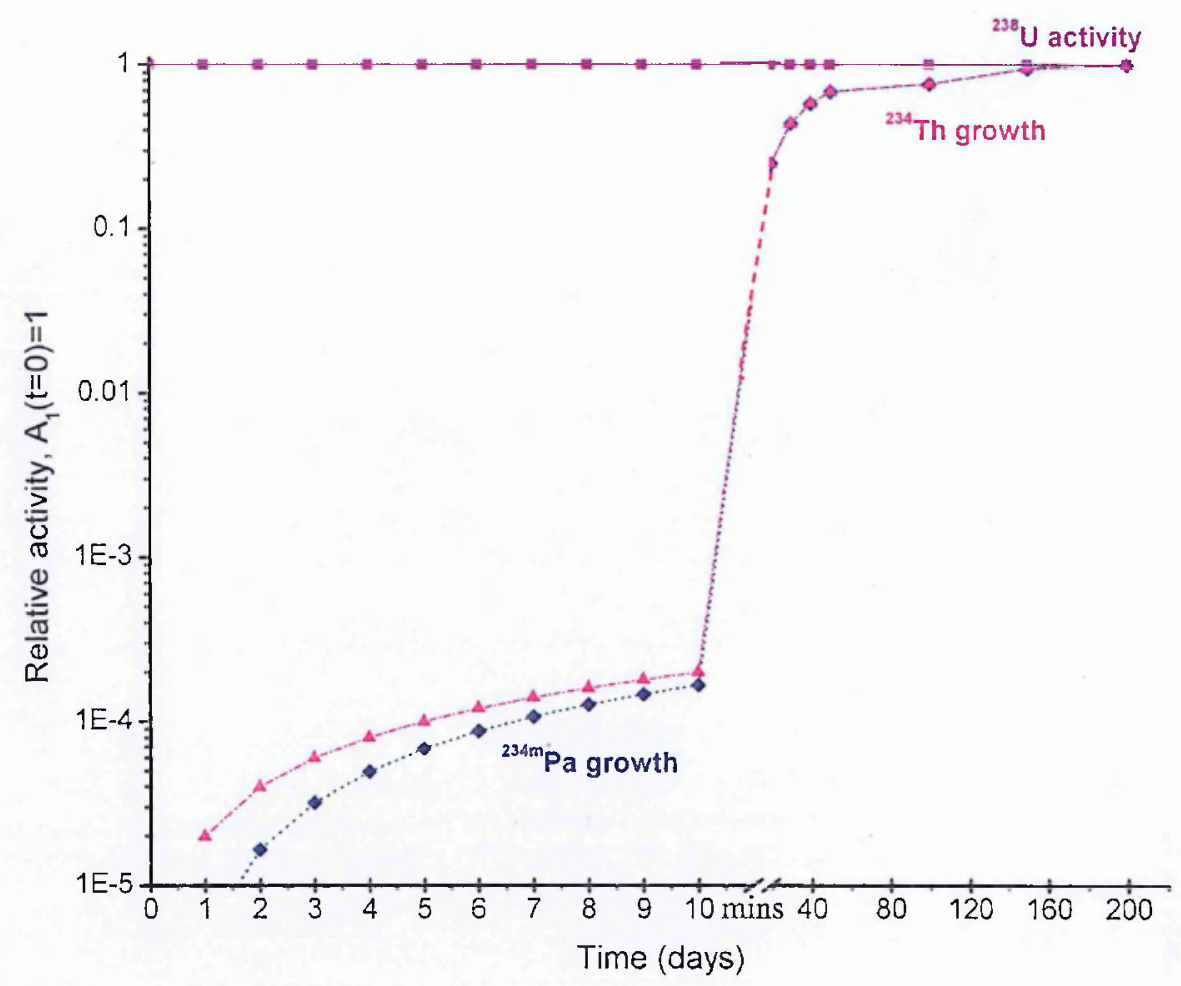

Figure 2-10: Relative activity for the first three members of ${ }^{238} \mathrm{U}$ decay chain as a function of time.

\subsubsection{The Genealogically Ordered Exit-Only Decay (GOED) Chain}

Since the Bateman equations are a solution that can be applied only to a simple decay chain from which there is no branching for each radioactive state, the Genealogically Ordered Exit-only Decay (GOED) chain is used to derive explicit solutions for solving radioactive decay chains under given initial-value conditions [YUA07]. In term of "exitonly decay chains", there are no external sources producing a daughter nuclide into a chain, i.e. only a nuclide inside the system may produce a daughter nuclide. The analytic solution of GOED chain which is the extended version of Bateman equations can be classified into several cases but only three cases are discussed in the current work.

The ordinary linear differential equations of a GOED chain are identical to its decay constants according to the equation [YUA07]:

$N_{i}(t)=C_{i, 1} e^{-\lambda_{1} t}+C_{i, 2} e^{-\lambda_{2} t}+\ldots .+C_{i, i-1} e^{-\lambda_{i-1} t}+C_{i, i} e^{-\lambda_{i} t}$ 


$$
=\sum_{j=1}^{i} C_{i, j} e^{-\lambda_{j} t}, \quad i=1,2, \ldots m,
$$

where $C_{i, j}$ are constant matrix elements determined by initial conditions

Case I: Single-child chain

A single child chain has only one ancestor and every nuclide also has only one child. Therefore, the coefficient for a single-child chain can be expressed by [YUA07]:

$C_{i, j}=C_{j, j} \prod_{k=j+1}^{i} \frac{\lambda_{k-1}}{\lambda_{k}-\lambda_{j}} \quad$ for $j<i, \quad i=2,3, \ldots, m$

where nuclide $i$ is a child of nuclide $j$ for $1 \leq j<i$

\section{Case II: Dominant-child chain}

A dominant-child chain is a GOED chain that has only one ancestor while the nuclides in the chain (except the ancestor) have more than one child but only one dominant child is kept in the chain. The coefficient for a dominant-child chain can be expressed by [YUA07]:

$C_{i, j}=C_{j, j} \prod_{k=j+1}^{i} \frac{\rho_{k-1, k} \lambda_{k}}{\lambda_{k}-\lambda_{j}} \quad$ for $j<i, \quad i=2,3, \ldots, m$

In this case, the branching factor $\rho$ is under the following conditions:

$$
\begin{aligned}
& 0<\rho_{i, i+1} \leq 1 \quad \text { for } i=1,2, \ldots, m-1 \\
& \rho_{i, j} \equiv 0 \quad \text { for } j \neq i+1
\end{aligned}
$$

Case III: Simple multi-parent converging chain

A simple multi-parent converging chain is a GOED chain which multiple nuclide parents decay to only one single child [YUA07]:

$$
\begin{array}{ll}
C_{i, j}=\frac{1}{\lambda_{i}-\lambda_{j}} \sum_{k=j}^{i-1} \rho_{k, i} \lambda_{k} C_{k, j}=0 & j<i, \quad i=1,2, \ldots, m-1 \\
C_{i, i}=N_{i, 0}-\sum_{j=1}^{i-1} C_{i, j}=N_{i, 0}, & i=1,2, \ldots, m-1 \\
C_{m, j}=\frac{1}{\lambda_{m}-\lambda_{j}} \sum_{k=j}^{m-1} \rho_{k, m} \lambda_{k} C_{k, j}, &
\end{array}
$$




$$
\begin{array}{r}
=\frac{\rho_{j, m} \lambda_{j} C_{j, j}}{\lambda_{m}-\lambda_{j}}=\frac{\rho_{j, m} \lambda_{j} N_{j, 0}}{\lambda_{m}-\lambda_{j}}, \quad j<m \\
C_{m, m}=N_{m, 0}-\sum_{j=1}^{m-1} C_{m, j}=N_{m, 0}-\sum_{j=1}^{m-1} \frac{\rho_{j, m} \lambda_{j} N_{j, 0}}{\lambda_{m}-\lambda_{j}}
\end{array}
$$

In this case, the branching factors are:

$\rho_{i, m}>0 \quad$ for $i=1,2, \ldots, m-1$

$\rho_{i, j} \equiv 0 \quad$ for $j \neq m$

The GOED formulae were used to solve the ${ }^{238} \mathrm{U} \rightarrow{ }^{234} \mathrm{U}$ decay chain (Figure 2-11) which can be divided into three small decay chains; (i) a single-child chain $\left({ }^{238} \mathrm{U} \rightarrow{ }^{234} \mathrm{Th} \rightarrow{ }^{234 \mathrm{~m}} \mathrm{~Pa}\right)$, (ii) a dominant-child chain from the decay of ${ }^{234 \mathrm{~m}} \mathrm{~Pa}$ to ${ }^{234} \mathrm{~Pa}$ and ${ }^{234} \mathrm{U}$, and (iii) a simple multi-parent converging chain from the decay of ${ }^{234 \mathrm{~m}} \mathrm{~Pa}$ and ${ }^{234} \mathrm{~Pa}$ to ${ }^{234} \mathrm{U}$.

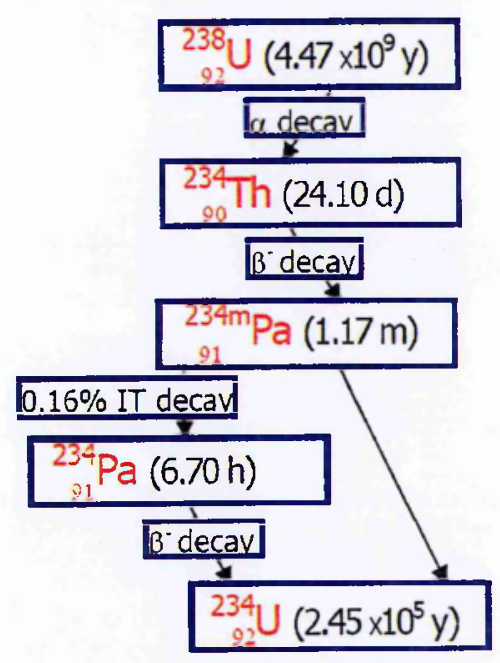

Figure 2-11: $T \mathrm{The}^{238} \mathrm{U} \rightarrow{ }^{234} \mathrm{U}$ decay chain.

The ${ }^{238} \mathrm{U} \rightarrow{ }^{234} \mathrm{U}$ Decay Chain can be considered as two parallel chains as follows:

Route $1:{ }^{238} \mathrm{U} \rightarrow{ }^{234} \mathrm{Th} \rightarrow{ }^{234 \mathrm{~m}} \mathrm{~Pa}^{\rho_{3,4}} \stackrel{0.0013}{\rightarrow}{ }^{234} \mathrm{~Pa} \rightarrow{ }^{234} \mathrm{U}$

Route $2:{ }^{238} \mathrm{U} \rightarrow{ }^{234} \mathrm{Th} \rightarrow{ }^{234 \mathrm{~m}} \mathrm{~Pa} \stackrel{\rho_{3,5}=0.9987}{\rightarrow}{ }^{234} \mathrm{U}$.

For the first three radionuclides, the coefficients for a single-child chain can be expressed by [YUA07]: 
$C_{1,1}=N_{1,0}$,

$C_{2,1}=C_{1,1} \frac{\lambda_{1}}{\lambda_{2}-\lambda_{1}}$

$C_{2,2}=N_{2,0}-C_{2,1}$

$C_{3,1}=C_{1,1} \frac{\lambda_{1} \lambda_{2}}{\left(\lambda_{2}-\lambda_{1}\right)\left(\lambda_{3}-\lambda_{1}\right)}$,

$C_{3,2}=C_{2,2} \frac{\lambda_{2}}{\lambda_{3}-\lambda_{2}}$,

$C_{3,3}=N_{3,0}-C_{3,1}-C_{3,2}$

For nuclide $4\left({ }^{234} \mathrm{~Pa}\right)$, the coefficient for a dominant-child decay chain can be described by [YUA07].

$$
\begin{aligned}
& C_{4,1}=C_{1,1} \frac{\lambda_{1} \lambda_{2} \lambda_{3} \rho_{3,4}}{\left(\lambda_{2}-\lambda_{1}\right)\left(\lambda_{3}-\lambda_{1}\right)\left(\lambda_{4}-\lambda_{1}\right)}, \\
& C_{4,2}=C_{2,2} \frac{\lambda_{2} \lambda_{3} \rho_{3,4}}{\left(\lambda_{3}-\lambda_{2}\right)\left(\lambda_{4}-\lambda_{2}\right)}, \\
& C_{4,3}=C_{3,3} \frac{\lambda_{3} \rho_{3,4}}{\lambda_{4}-\lambda_{3}}, \\
& C_{4,4}=N_{4,0}-C_{4,1}-C_{4,2}-C_{4,3}
\end{aligned}
$$

For nuclide $5\left({ }^{234} \mathrm{U}\right)$, the coefficients can be determined from accumulations from the first route as following:

$$
\begin{aligned}
& C_{5,1}^{1}=C_{1,1} \frac{\lambda_{1} \lambda_{2} \lambda_{3} \lambda_{4} \rho_{3,4}}{\left(\lambda_{2}-\lambda_{1}\right)\left(\lambda_{3}-\lambda_{1}\right)\left(\lambda_{4}-\lambda_{1}\right)\left(\lambda_{5}-\lambda_{2}\right)} \\
& C_{5,2}^{1}=C_{2,2} \frac{\lambda_{2} \lambda_{3} \lambda_{4} \rho_{3,4}}{\left(\lambda_{3}-\lambda_{2}\right)\left(\lambda_{4}-\lambda_{2}\right)\left(\lambda_{5}-\lambda_{2}\right)}, \\
& C_{5,3}^{1}=C_{3,3} \frac{\lambda_{3} \lambda_{4} \rho_{3,4}}{\left(\lambda_{4}-\lambda_{3}\right)\left(\lambda_{5}-\lambda_{3}\right)}, \\
& C_{5,4}^{1}=C_{4,4} \frac{\lambda_{4}}{\left(\lambda_{5}-\lambda_{4}\right)}, \\
& C_{5,5}^{1}=-\left(C_{5,1}^{1}-C_{5,2}^{1}-C_{5,3}^{1}-C_{5,4}^{1}\right)
\end{aligned}
$$


For nuclide $5\left({ }^{234} \mathrm{U}\right)$, the coefficients can be determined from accumulations from the second route as following:

$$
\begin{aligned}
& C_{5,1}^{2}=C_{1,1} \frac{\lambda_{1} \lambda_{2} \lambda_{3} \rho_{3,5}}{\left(\lambda_{2}-\lambda_{1}\right)\left(\lambda_{3}-\lambda_{1}\right)\left(\lambda_{5}-\lambda_{2}\right)} \\
& C_{5,2}^{2}=C_{2,2} \frac{\lambda_{2} \lambda_{3} \rho_{3,5}}{\left(\lambda_{3}-\lambda_{2}\right)\left(\lambda_{5}-\lambda_{2}\right)}, \\
& C_{5,3}^{2}=C_{3,3} \frac{\lambda_{3} \rho_{3,5}}{\left(\lambda_{5}-\lambda_{3}\right)}, \\
& C_{5,5}^{2}=-\left(C_{5,1}^{2}+C_{5,2}^{2}+C_{5,3}^{2}\right)
\end{aligned}
$$

Combining from these two routes yield the following coefficients:

$$
\begin{aligned}
& C_{5,1}=C_{5,1}^{1}+C_{5,1}^{2}, \\
& C_{5,2}=C_{5,2}^{1}+C_{5,2}^{2}, \\
& C_{5,3}=C_{5,3}^{1}+C_{5,3}^{2}, \\
& C_{5,4}=C_{5,4}^{1} \\
& C_{5,5}=N_{5,0}+C_{5,5}^{1}+C_{5,5}^{2},
\end{aligned}
$$

\begin{tabular}{|c|c|c|c|c|c|}
\hline No. & Nuclide & Half-life & $\begin{array}{c}\text { Decay constant } \\
\left(\text { day }^{-1}\right)\end{array}$ & $\begin{array}{c}\text { Branching ratio } \\
\rho_{i, j}\end{array}$ & $\begin{array}{c}\text { Initial value } \\
\qquad N_{i, 0} \\
\end{array}$ \\
\hline 1 & ${ }^{238} \mathrm{U}$ & $4.468 \times 10^{9} \mathrm{yr}$ & $4.25 \times 10^{-13}$ & $\rho_{1,2}=1$ & $N_{1,0}$ \\
\hline 2 & ${ }^{234} \mathrm{Th}$ & 24.10 days & $2.876 \times 10^{-2}$ & $\rho_{2,3}=1$ & $N_{2.0}$ \\
\hline 3 & ${ }^{234 \mathrm{~m}} \mathrm{~Pa}$ & $1.175 \mathrm{~min}$ & $8.496 \times 10^{2}$ & $\begin{array}{l}\rho_{3,4}=0.0013 \\
\rho_{3,5}=0.9987\end{array}$ & $N_{3,0}$ \\
\hline 4 & ${ }^{234} \mathrm{~Pa}$ & $6.75 \mathrm{~h}$ & 2.467 & $\rho_{4,5}=1$ & $N_{4,0}$ \\
\hline 5 & ${ }^{234} \mathrm{U}$ & $2.45 \times 10^{5} \mathrm{yr}$ & $7.753 \times 10^{-9}$ & & $N_{5,0}$ \\
\hline
\end{tabular}

The radioactive properties of the radionuclides in the ${ }^{238} \mathrm{U} \rightarrow{ }^{234} \mathrm{U}$ decay chain used to calculate the decay coefficients are summarized in Table 2-5. At time $t=0$, the number of the ${ }^{238} \mathrm{U}$ daughter products is assumed to be zero, thus the growth curves of ${ }^{234} \mathrm{Th},{ }^{234 \mathrm{~m}} \mathrm{~Pa}$, ${ }^{234} \mathrm{~Pa}$ and ${ }^{234} \mathrm{U}$ in ${ }^{238} \mathrm{U}$ using the decay coefficients as mentioned above can be plotted in Figure 2-12.

Table 2-5 The isotopic characteristic of the ${ }^{238} \mathrm{U} \rightarrow{ }^{234} \mathrm{U}$ decay chain. 


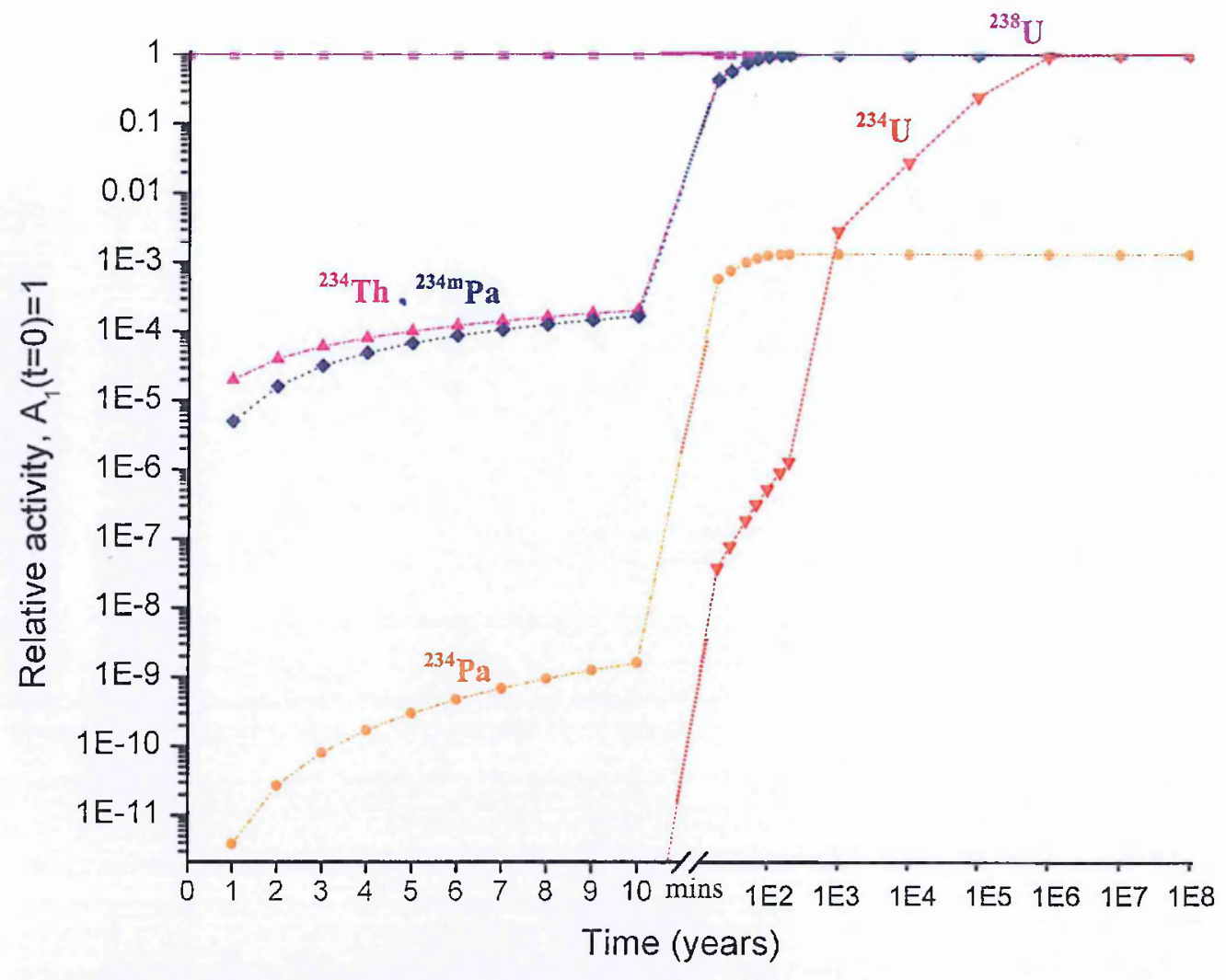

Figure 2-12: Radioactive growth curves for the ${ }^{238} U \rightarrow{ }^{234} U$ decay chain as a function of time.

The growth curves created by the use of GOED formulae are identical to that by the Bateman equations where the initial values are set to be zero. The exit-only decay chain also covers Bateman's original case including under given initial conditions and other common branching cases. As the decay GOED chains can be divided into a number of smaller decay chains, it is much easier to handle and solve the radioactive decay chains.

\subsection{Radioactive Equilibrium}

The quantitative relationship among the various members of the series is associated with the half-life of the parent and its daughter. The activity of radionuclides in radioactive decay chains that will be present at each stage can be estimated by understanding the "equilibrium conditions". Radioactive equilibrium can be classified into three particular cases as follows: 


\subsubsection{No equilibrium}

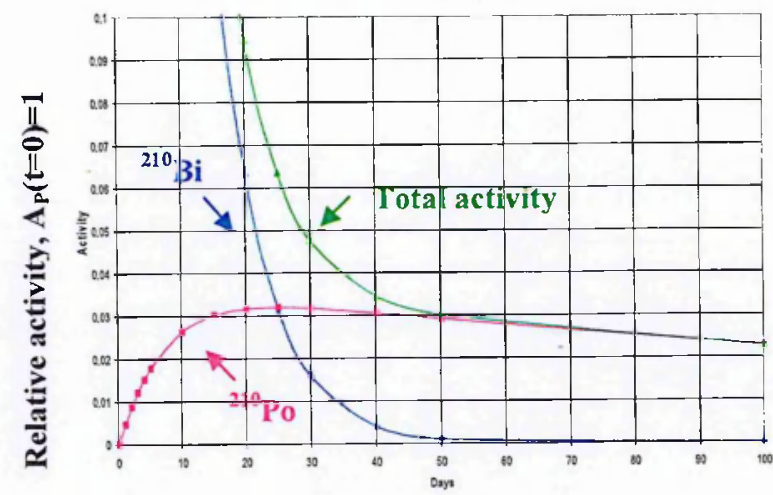

$$
\begin{aligned}
& \text { For } \lambda_{D}<\lambda_{P} \text { or }\left(t_{1 / 2}\right)_{D}>\left(t_{1 / 2}\right)_{P} \quad \text { e.g. } \\
& { }^{210} \mathrm{Bi}\left(\mathrm{t}_{1 / 2}=5.013 \mathrm{~d}\right) \rightarrow{ }^{210} \mathrm{Po}\left(\mathrm{t}_{1 / 2}=138.37 \mathrm{~d}\right) \\
& \frac{A_{D}}{A_{P}}=\frac{\lambda_{D}}{\lambda_{D}-\lambda_{P}}\left(1-e^{-\left(\lambda_{D}-\lambda_{P}\right) t}\right)
\end{aligned}
$$

Figure 2-13: No equilibrium.

When ${ }^{210} \mathrm{Bi}$ with half-life of 5.013 days decays to ${ }^{210} \mathrm{Po}$ with half-life of 138.37 days in the uranium series, the half-life of the parent is less than that of the daughter. In this case there is no equilibrium. Figure 2-13 shows that the activity of the decay product reaches a maximum at a finite time and then gradually declines while the parent decays away. The ratio of parent and daughter activities can be determined from Eq. (2.59).

\subsubsection{Transient equilibrium}

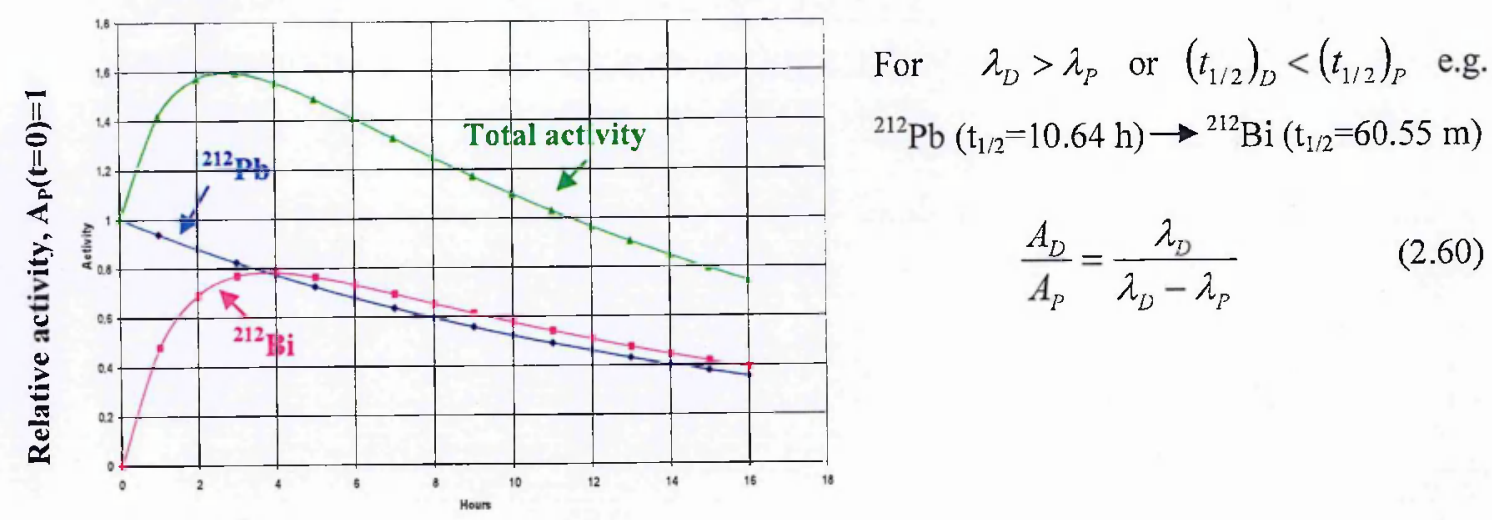

Figure 2-14: Transient equilibrium.

For instance, ${ }^{212} \mathrm{~Pb}$ with half-life of 10.64 hours decays to ${ }^{212} \mathrm{Bi}$ with a half-life of 60.55 minutes in the thorium series, i.e. the parent half-life is slightly longer than that of the daughter. The daughter activity rises to a maximum, and after the equilibrium is approached, the rate of decay of the daughter is at the same rate as it is being formed. The activity of the daughter nuclide becomes greater than that of the parent (see Figure 2-14). The relationship between the parent and daughter activities is estimated by Eq. (2.60). 


\subsubsection{Secular equilibrium}

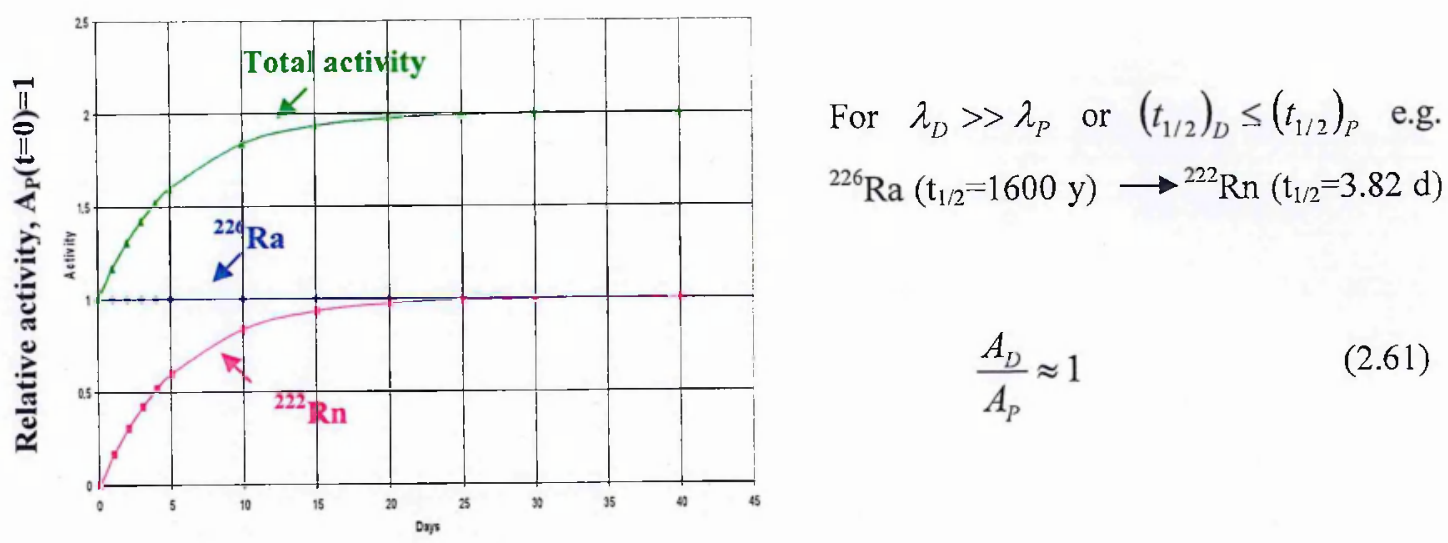

Figure 2-15: Secular equilibrium.

In cases where the half-life of the parent is much longer than any of the daughter nuclides in the chain, the equilibrium state is referred as secular equilibrium. From Figure 2-15, ${ }^{226} \mathrm{Ra}$ with a half-life of 1600 years decays to ${ }^{222} \mathrm{Rn}$ with a half-life of 3.82 days (from the uranium series). The daughter decays much more rapidly than the mother and according to a standard 'rule of thumb', it takes about 7 half lives of the daughter to obtain near equilibrium with its parent. At this point, the daughter activity approximated to the same as its parent activity [TRA07]. This phenomenon normally occurs in long lived primordial radionuclides decay chains i.e. ${ }^{238} \mathrm{U}$, and ${ }^{232} \mathrm{Th}$. When the growth and decay rates of each radionuclide in the decay chain are equal, radioactive equilibrium has been established in the whole chain. As a result, in the current research secular equilibrium is considered to be present. Therefore, if the activity of one radionuclide in a decay chain can be measured, then the same activity can be assigned to the radionuclides in that chain if equilibrium is assumed.

\subsection{Gamma-ray Spectroscopy with Germanium Detectors}

A gamma-ray spectrometer is a non-destructive instrument that provides information on both the energy and intensity of radiation that is emitted from $\gamma$-ray (or energetic X-ray) sources. The detectors widely used with gamma-ray measurements are NaI(Tl) scintillators, high-purity $\mathrm{Ge}$ and $\mathrm{Si}(\mathrm{Li})$ semiconductor detectors. In comparison to $\mathrm{NaI}(\mathrm{Tl})$ scintillation detectors, germanium detectors have a better ability to resolve the energy with a typical energy resolution of a few tenths of a percent compared with $5-10 \%$ for 
sodium iodide [KNO00]. For this reason, the full-energy peaks obtained from the sodium iodide detector may have an interference from other transitions. A system which uses germanium is better able to distinguish precisely between the different, discrete $\gamma$-ray energy peaks within a full spectrum. Hence, the use of germanium detector becomes more technically suitable when analysing complicated gamma-ray spectra with potentially hundreds of different full energy peaks.

Semiconductor detectors are solid-state devices characterised by bands of energy states in a crystal of the material from which they have been made such as silicon or germanium. In general, these energy bands in semiconductors are divided into two distinct groups, namely the valence and conduction bands. The valence band is occupied by electrons binding to specific lattice sites, whereas in the conduction band the electrons are capable of moving through the crystal. The conduction bands have higher energy than the valence bands and these are separated by a band gap where no electron energies are allowed. The width of the band gap classifies a material into three types, depending on their electrical conductivity i.e. insulators, conductors, and semiconductors. In an insulator, the band gap is relative large (about $\geq 5 \mathrm{eV}$ ) meaning that no electrons excite across the gap, whereas for semiconductors the size of energy gap is smaller $(\sim 1 \mathrm{eV})$ and thus the electrons that gain enough energy (for example from thermal excitations) can pass over the band gap to the conduction band [GIL08] (see Figure 2-16).

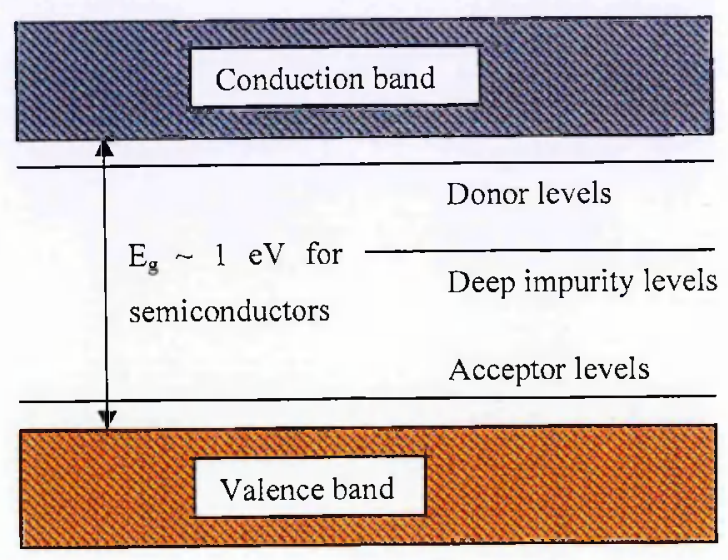

Figure 2-16: Schematic diagram of the band structure in semiconductor [ELE08]. 
There are two types of semiconductor to be considered; p-type and n-type, based on its having either the high concentration of electrons or holes respectively. $P$-type or positive semiconductors can accept electrons since they have an excess of holes. The solid materials from which p-type semiconductors are made contain three valence electrons which is one less than the semiconductor atoms such as boron, aluminum, gallium or indium. In contrast, for $n$-type or negative semiconducting material, the impurities have five valence electrons, one more than the Ge semiconductor atoms (such as phosphorus, arsenic and antimony). Since these types of semiconductor have an excess of electrons, they act as a donor (see Figure 2-17). A p-n junction can be created by joining an n-type and a p-type semiconductor together. The region where the excess holes meet with the excess electrons and have been cancelled out is called the depletion zone (see Figure 2-17). When the voltage is applied in the reverse bias direction (the $n$ region is connected to the positive terminal and the $p$ region to the negative terminal) to a $\mathrm{p}-\mathrm{n}$ junction, there will be no current flow because a very high resistivity is created (minority carriers crossing the junction) and therefore its leakage current is very small.
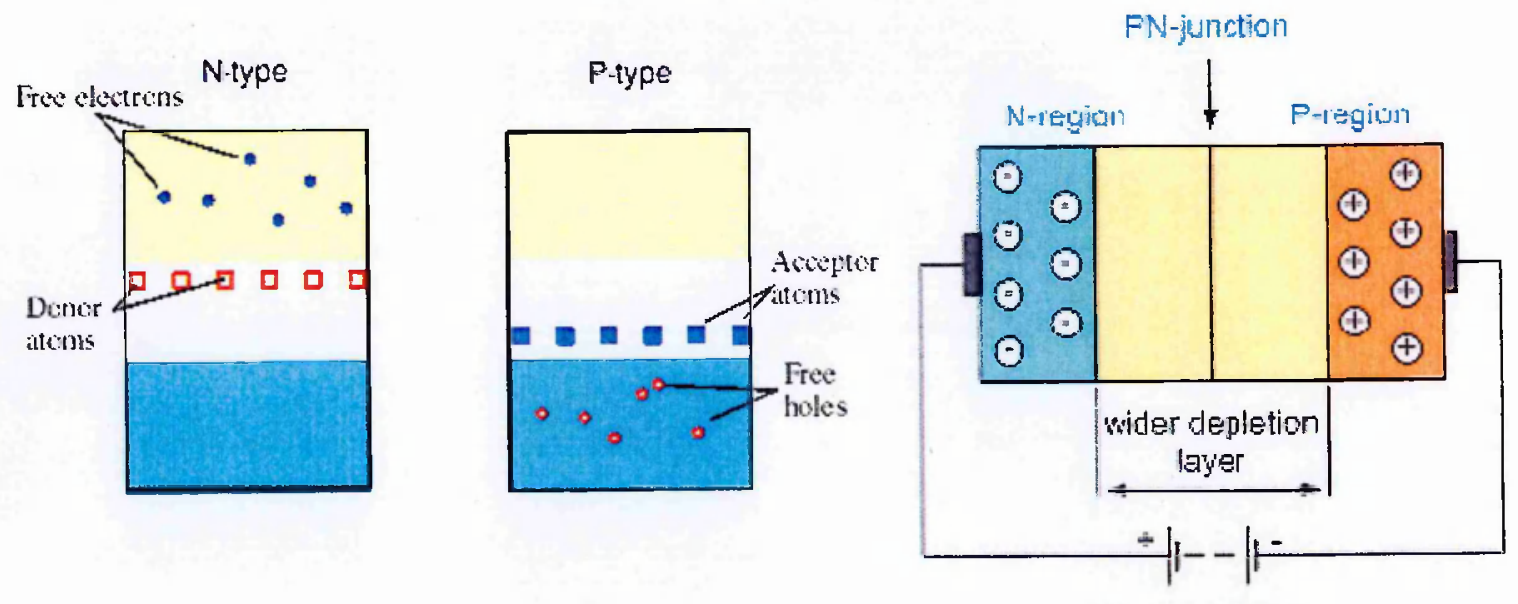

Bissing Voltage

Figure 2-17: N-type, p-type and p-n junction in semiconductor [ELE08].

When a photon interacts in the crystal, bound electrons are excited to the conduction band and if the energy is sufficient to create the cascade of electrons, many electron-hole pairs will be produced and migrate to their respective electrodes of the device. The average energy needed to create one electron-hole pair is about $3 \mathrm{eV}$ for germanium and $3.6 \mathrm{eV}$ for silicon [FRI81]. An external electric field of about 1000 Volts per centimetre of the detector thickness is applied to collect these charges [KNO00]. The 
optimum bias voltage is normally specified by manufacturers for each detector. Otherwise, applying relatively low voltages leads to poor performances for charge collection and peak shape configuration whereas very high voltage can cause a voltage breakdown. The resultant charges are then integrated by a charge sensitive preamplifier and converted to a voltage pulse with amplitude proportional to the original photon energy deposited in the crystal. Since the thickness of the depletion layer is inversely proportional to the impurity concentration which resulting in recombining or trapping of electrons and holes, large volumes of extremely high-purity material are desired for obtaining high efficiency when irradiated with high energy photons.

In 1962, a construction of semiconductor detectors was developed by infusing lithium ions on one surface of the p-type material known as germanium lithium-drifted $(\mathrm{Ge}(\mathrm{Li}))$ detector and silicon lithium-drifted $(\mathrm{Si}(\mathrm{Li}))$ detector [DEB88]. These lithium ions compensate for impurity atoms during the production of $\mathrm{n}$ - and p-type semiconductors. $\mathrm{Ge}(\mathrm{Li})$ detectors have now been widely replaced by high-purity germanium (HPGe) detectors due to an advance techniques of refining Ge crystals. These detectors can have an impurity concentration as low as $10^{10}$ atoms $/ \mathrm{cm}^{3}$ [KNO00] allowing storage at room temperature. However, due to the relatively small band gap for germanium $(\sim 0.7 \mathrm{eV})$ thermal excitation of electrons across the band gap can produce a significant electrical noise background [GIL08]. Therefore, the use of liquid nitrogen as a refrigerant (the boiling temperature of liquid nitrogen at $77 \mathrm{~K}$ or $-200{ }^{\circ} \mathrm{C}$ ) is required for the high-purity germanium detectors operation. [KNO00].

\subsection{Gamma-ray Interactions}

Gamma rays can be defined as an electromagnetic radiation with both particle and wavelike characteristics, travelling with the speed of light and having no charge. Often, $\gamma$-rays are produced after $\alpha$ and $\beta$ decays that leave an excited nucleus behind. These excited states decay rapidly to the nuclear ground state following the emission of one or more $\gamma$ rays. The photon energies for gamma rays are typically in the range of $\sim 100 \mathrm{keV}$ to $\sim 10$ $\mathrm{MeV}$ [KNO00]. There are three main fundamental mechanisms which describe the interaction of photons with matter. These processes are energy dependent: 
- The photoelectric effect, where the primary photon energy is completely absorbed after undergoing an interaction with a tightly bound atomic electron

- Compton scattering, where the photon interacts with a weakly bound atomic electron and only part of the energy of the photon is transferred to this electron;

- Pair production in which the incoming photon has high enough energy (1.022 $\mathrm{MeV}$ ) to create an electron-position pair in the Coulomb field

The photoelectric process is predominantly observed at low energy, i.e., below 50 $\mathrm{keV}$ for silicon and below $150 \mathrm{keV}$ for germanium [VET07]. In the mid-energy range, between several hundred $\mathrm{keV}$ and about $30 \mathrm{MeV}$ for silicon and between 0.15 and 8 $\mathrm{MeV}$ for germanium, the main interaction likely contribute to the attenuation coefficient comes from Compton scattering. At higher energies, pair production becomes the most significant process. The dominant processes of gamma rays interacting with $\mathrm{Ge}$ and $\mathrm{Si}$ are shown in Figure 2.18. The mass attenuation coefficient in germanium due to photoelectric absorption, Compton scattering and pair production as a function of gamma-ray energy is illustrated in Figure 2.19. A sharp rise at low energy in the curve corresponds to the $\mathrm{K}$ absorption edge equal to the binding energy of the $\mathrm{K}$-shell electron $(11.1 \mathrm{keV}$ for germanium [GIL08]). L-edges also can be seen at lower energies.

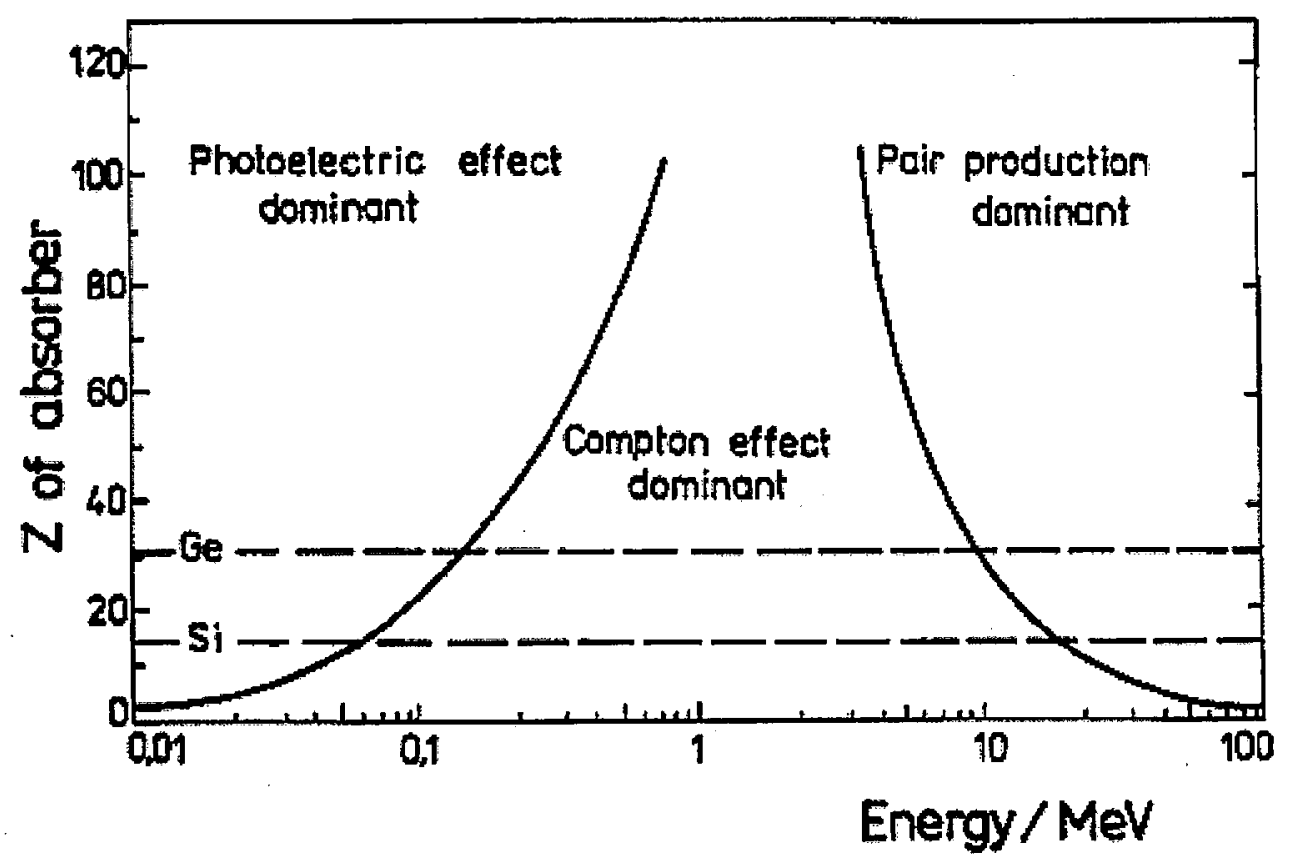

Figure 2-18: Three importances of gamma-ray interaction processes [SAK94]. 


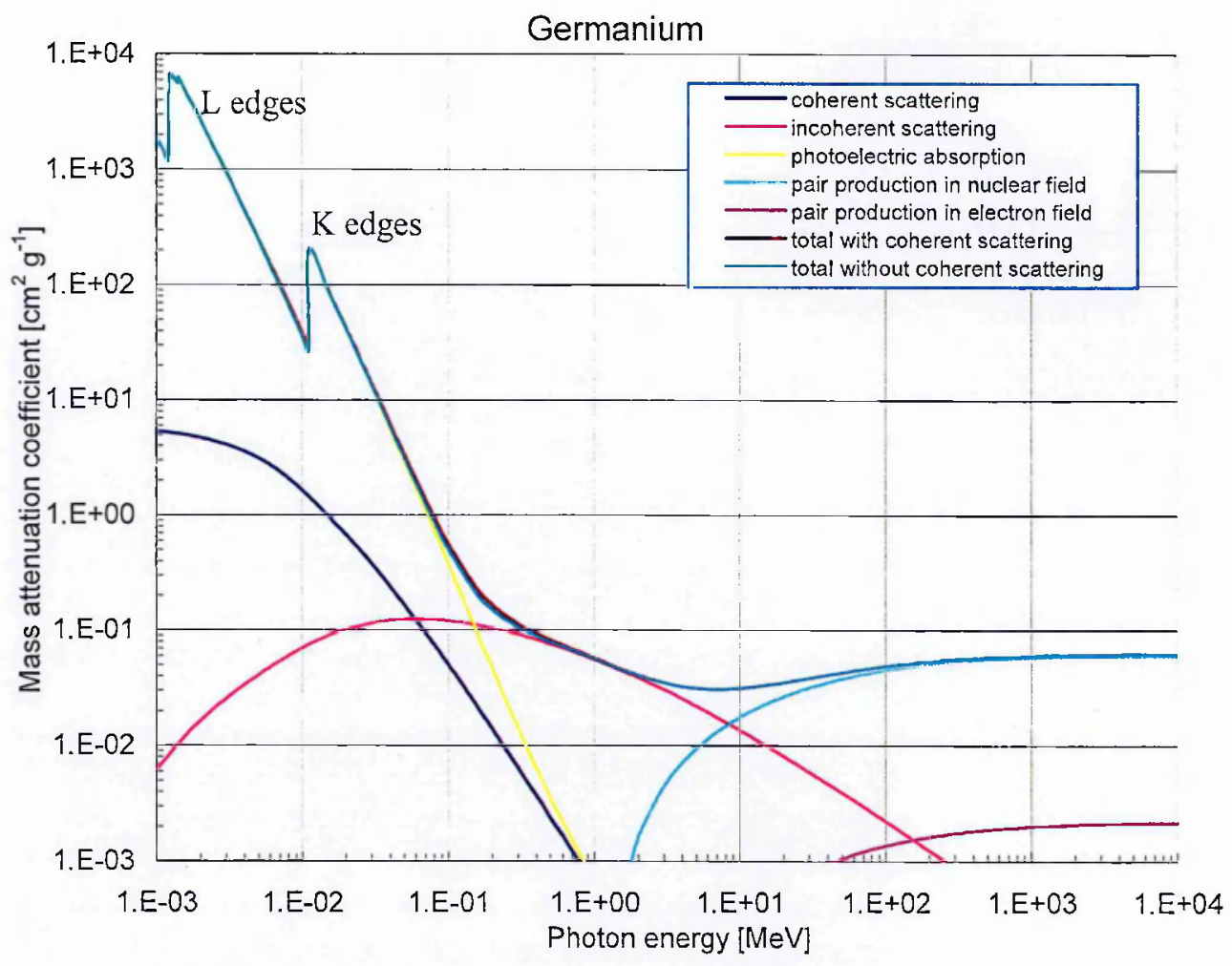

Figure 2-19: Mass attenuation coefficient of germanium and its component parts [LER09].

\subsubsection{Photoelectric Effect}

In the photoelectric process, the incident photon is completely absorbed after undergoing an interaction with an atom and all of its energy is transferred to a bound electron. The electron is ejected with energy $E_{e}$ equal to the difference between the photon energy, $E_{\gamma}$ and the binding energy, $E_{b}$ of the electron (Figure 2-20(a)). The kinetic energy of the electron after leaving the atom is given by:

$$
E_{e}=E_{\gamma}-E_{b}
$$

A vacancy is created after the ejection of the photoelectron and quickly filled by an electron from one of the other atomic shells, followed by the emission of a characteristic X-ray or Auger electrons (Figure 2-20(b)). Further re-absorption from photoelectric processes continues until ideally, all of the energy of the gamma ray is absorbed within the detector, which contributes to the total energy peak. 

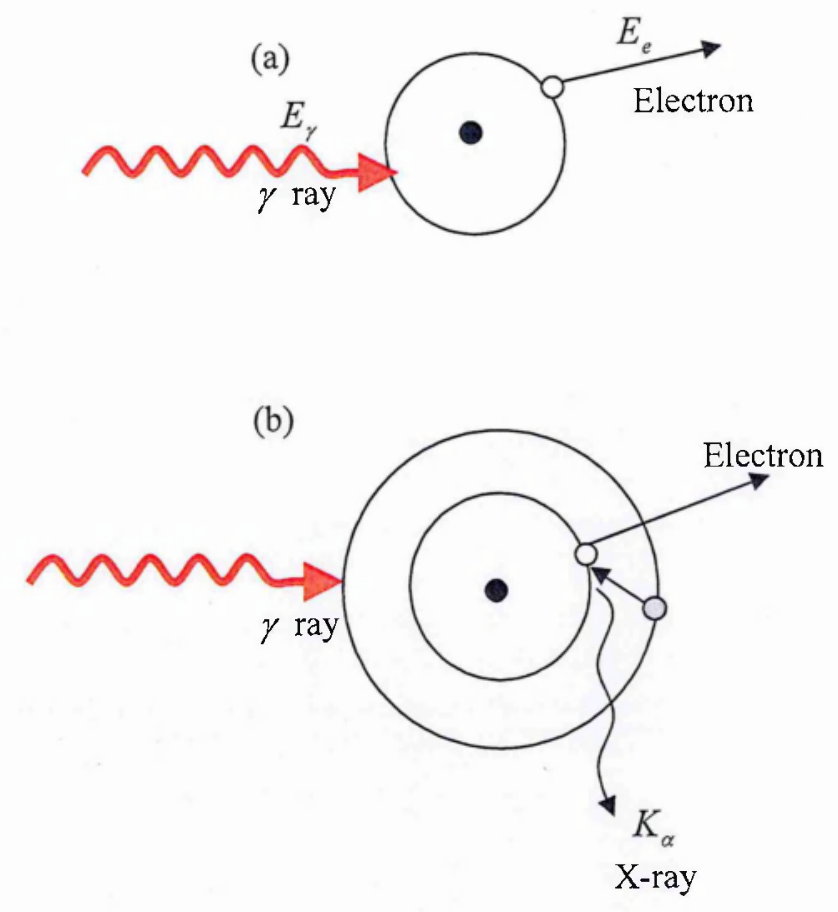

Figure 2-20: (a) The mechanism of photoelectric absorption, and (b) the emission of fluorescent X-ray [GIL08].

The energy level from which the atomic electron is ejected depends upon the energy of the incoming gamma ray. The ejection of electrons primarily take place in the $\mathrm{K}$ shell but if the energy is not sufficient enough to eject the $\mathrm{K}$ electron, then electrons in the $\mathrm{L}$ or $\mathrm{M}$ shell will be ejected instead. The probability of photoelectric absorption, $\tau$, can be expressed by a rough approximation over all ranges of the atomic number $(Z)$ of the absorber material and photon energy $\left(E_{\gamma}\right)$, according to [KNO00]:

$$
\tau \propto \frac{Z^{n}}{E_{\gamma}^{3.5}} \quad \text { where } n=4-5 \text { depending on the energy }
$$

Normally, the gamma-ray energy is assumed to be completely absorbed in the photoelectric effect. Nevertheless, for the case of those events which undergo interactions near the surface of the detector, there are some florescent $(\mathrm{K}) \mathrm{X}$-rays that can escape from the detector volume. The net energy absorbed in the detector would then be [GIL08]:

$$
E_{e}=E_{\gamma}-E_{K_{\alpha}}
$$


where $E_{K_{\alpha}}$ is the energy of the $K_{\alpha} \mathrm{X}$-ray of the detector material. This process is known as X-ray escape.

\subsubsection{Compton Scattering}

In the Compton effect, an incident gamma-ray photon interacts with an electron in the absorbing material and transfers a portion of its energy to the electron. This results in a Compton scattered photon with energy $E_{\gamma}^{\prime}=h v^{\prime}$ and a so called Compton (recoil) electron with energy $E_{e}$. The energy distribution depends on the angle $\theta$ between the direction of the original photon and the scattered one (Figure 2-21). The energy difference between the incident and scattered photon is transferred to the electron as kinetic energy.

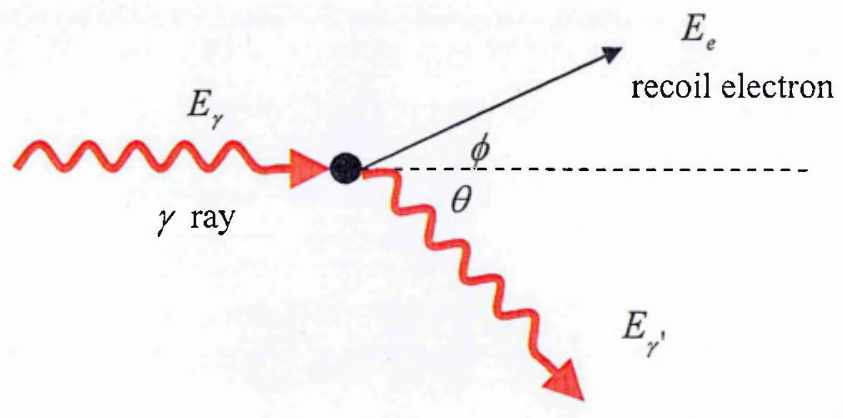

Scattered $\gamma^{\prime}$-ray

Figure 2-21: The mechanism of Compton scattering [GIL08].

From conservation of total mass-energy and linear momentum, for a single Compton scattered event, [KNO00]:

$E_{e}=E_{\gamma}-E_{\gamma}^{\prime}$

where

$$
E_{\gamma}^{\prime}=\frac{E_{\gamma}}{1+\frac{E_{\gamma}}{m_{0} c^{2}}(1-\cos \theta)}
$$

Using Eq. 2.65 and 2.66, the kinetic energy of the electron is therefore given by

$$
E_{e}=\frac{E_{\gamma}(1-\cos \theta)}{m_{0} c^{2}+E_{\gamma}(1-\cos \theta)}
$$


where $E_{\gamma}$ is the incident $\gamma$-ray energy

$E_{\gamma}^{\prime}$ is the scattered $\gamma$-ray energy

$\theta$ is the angle of the scattered photon that respect to the direction of the incident photon

$E_{e}$ is the kinetic energy of the electron; the rest mass of the electron, $\mathrm{m}_{0} \mathrm{c}^{2}=0.511$ $\mathrm{MeV}$ [THE96]

In normal circumstances, all scattering angles may be observed in the detector. Therefore, the recoil electron energy can range from 0 for $\theta=0^{\circ}$ to $2 E_{\gamma}^{2} /\left(m_{0} c^{2}+2 E_{\gamma}\right)$ for a scattering angle of $\theta=180^{\circ}$. The minimum energy of recoil electron is zero which means that there is no energy transferred to the detector while the maximum value is obtained when photon is backscattered. Figure 2-22 shows an idealised schematic diagram for a single interaction of the continuum of energies corresponding to Compton scattered electrons known as the Compton continuum, which range from zero up to the maximum, which is called the Compton edge. In this schematic diagram, the incident gamma ray does not have a high enough energy $(>1.022 \mathrm{MeV})$ to allow pair production occur. As a result, this schematic spectrum only shows the effects of Compton scattering and photoelectric absorption. The narrow peak represents the photoelectric absorption designated as the full-energy peak. The probability of Compton scattering depends mainly on the number of electrons per atom of the interacting matter. The Klein and Nishina equation describes the differential scattering cross section, $d \sigma / d \Omega$ for photon scattering from electrons at an angle $\theta$ [KRA88]:

$$
\frac{d \sigma}{d \Omega}=r_{0}^{2}\left[\left.\frac{1}{1+\alpha(1-\cos \theta)}\right|_{]} ^{3}\left[\frac{1+\cos \theta}{2}\right]\left[1+\frac{\alpha^{2}(1-\cos \theta)^{2}}{\left(1+\cos ^{2} \theta\right)[1+\alpha(1-\cos \theta)]}\right]\right.
$$

where $\alpha$ is the photon energy in units of the electron rest energy $\left(\alpha=\mathrm{E}_{\gamma} / m c^{2}\right)$

$r_{0}$ is the classical electron radius $\left(r_{0}=e^{2} / 4 \pi \varepsilon_{0} m c^{2}=2.818 \mathrm{fm}\right)$

$d \Omega$ is the solid angle increment in Steradians 


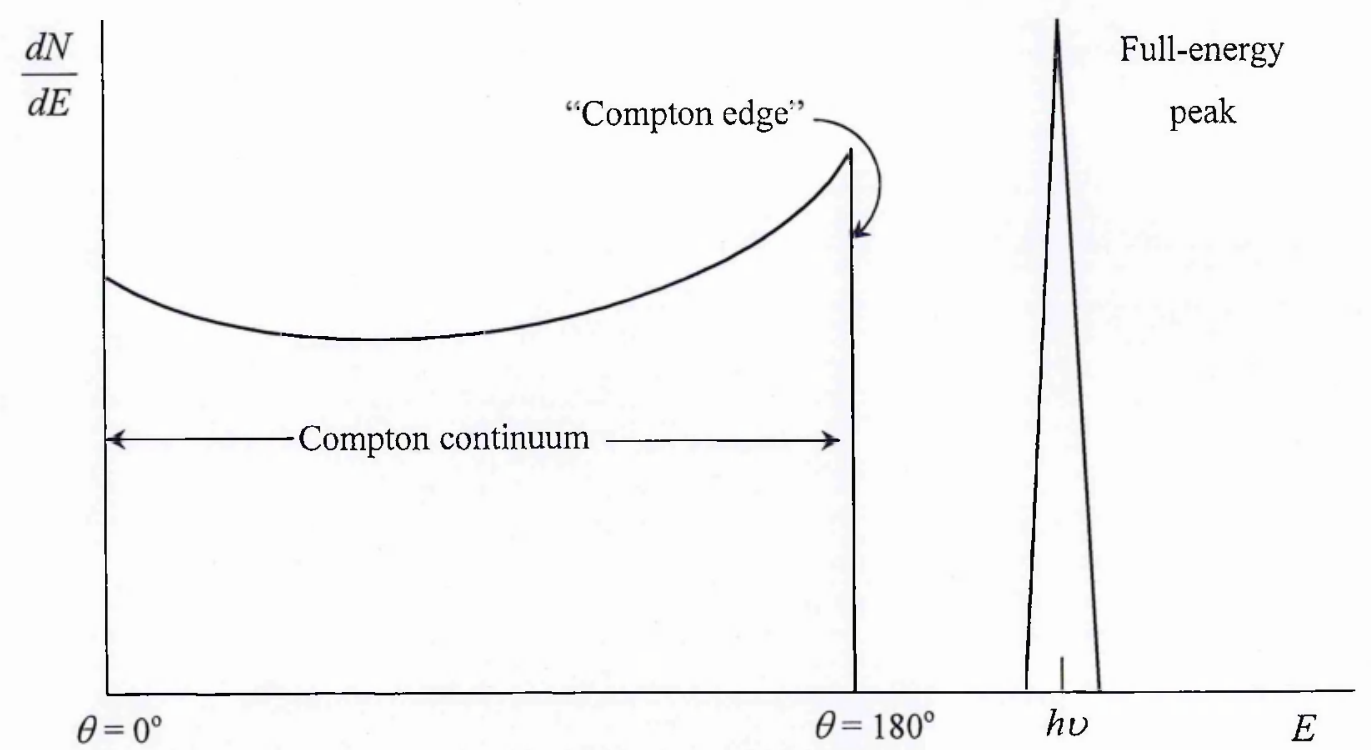

Figure 2-22: Schematic diagram of the energy transferred to an absorber by single Compton scattering and photoelectric absorption for a monoenergetic gamma-ray source [GIL08].

\subsubsection{Pair Production}

At higher gamma-ray energies $(>4 \mathrm{MeV})$ pair production becomes increasingly significant. This interaction process takes place when the incoming photon has an energy greater than twice the electron rest mass, i.e.., $2 \mathrm{~m}_{0} \mathrm{c}^{2}=1.022 \mathrm{MeV}$ [KNO00]. As a result of the interaction, the photon converts in the nuclear Coulomb field to an electronpositron pair. The incident gamma-ray energy can be split into positron and electron kinetic energies according to the following expression:

$$
E_{\gamma}=2 m_{0} c^{2}+E_{e}^{k i n}+E_{e^{+}}^{k i n} \quad\left(E_{\gamma}>1.022 \mathrm{MeV}\right)
$$

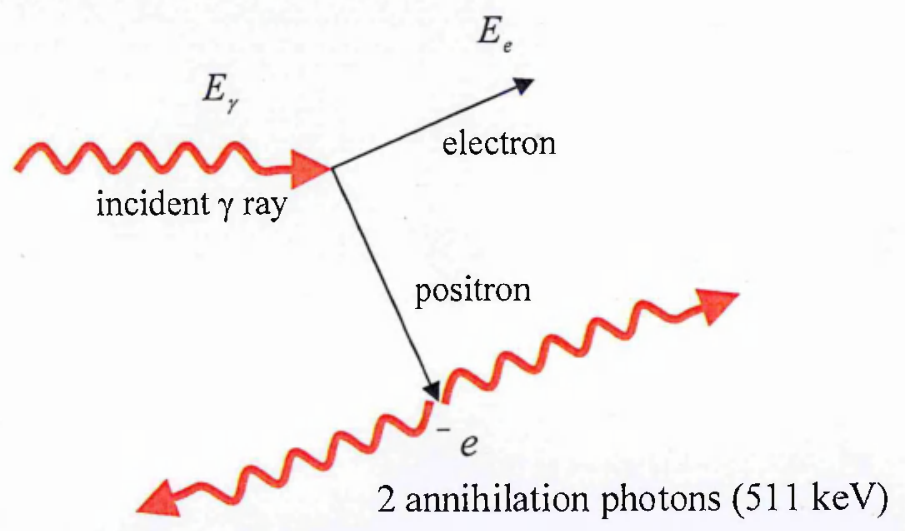

Figure 2-23: The mechanism of pair production [GIL08]. 
The positron will be slowed down in the absorbing medium and interact with an atomic electron and subsequently annihilate. Two photons with energies of $0.511 \mathrm{MeV}$ are produced and emitted in opposite directions to conserve linear momentum (see Figure 223). The probability of pair production depends on $Z^{2}$ [DEB88]. The original pair production interaction and the annihilation radiations are in virtual coincidence because the time required for the positron to slow down prior to annihilation is only of the order of 1 ns [GIL08]. For a standard size of detector, the electron and positron kinetic energies are typically fully deposited whereas the annihilation photons may either escape the detector volume, or undergo further interactions within the detector. These additional interactions may lead to either partial or complete energy absorption of the residual gamma-ray energy. When one of the two annihilation gamma rays escapes from the detector volume without further interaction, $0.511 \mathrm{MeV}$ will be lost from the detector. Therefore, a separate peak will present in the spectrum with an energy level of $E_{\gamma}-0.511$ $\mathrm{MeV}$, called the single-escape peak, where $E_{\gamma}$ is the gamma-ray energy characterised by the full-energy peak. If both of annihilation gamma rays escape from the detector without interaction, this contributes to the double escape peak at the energy level of $E_{y}-1.02 \mathrm{MeV}$ [ELB03].

\subsection{Gamma-Ray Attenuation}

The term "attenuation" describes the process by which photons are removed from a "pencil photon beam" through a defined thickness of material [DEB88]. The attenuation of heavy particles in the material is different from that of gamma radiation. The specific energy loss or the stopping power of a uniform medium for heavy charged particles i.e. protons, alpha, heavy ions as can be described by the Bethe-Bloch formula [LIL01]:

$-\frac{d E}{d x}=\left(\frac{z e^{2}}{4 \pi \varepsilon_{0}}\right)^{2} \frac{4 \pi Z \rho N_{A}}{A m_{0} c^{2} \beta^{2}}\left[\ln \frac{2 m_{0} c^{2} \beta^{2}}{I\left(1-\beta^{2}\right)}-\beta^{2}\right]$

where $\beta=v / c=$ speed of the particle relative to $c$,

$E$-energy of the particle,

$x$-distance travelled by the particle, 
$e$-magnitude of the electron charge,

$v$-velocity of the particle,

$c$-speed of light,

$m_{0}$-rest mass of the electron,

$n$-electron density of the absorber,

$I$-average excitation and ionisation potential of the absorber,

$z$-atomic number of the particle,

$\varepsilon_{0}$-vacuum permittivity,

$A$-atomic mass number,

$Z$-atomic number,

$\rho$-density of stopping material,

$N_{A}$-Avogardro's number

Figure 2-24 shows the stopping power of air in $\mathrm{MeV} \mathrm{cm}^{-1}$ for an alpha particle of 5.49 $\mathrm{MeV}$ versus the distance of penetration. As the particle loses energy, the stopping power increases with distance travelled until it reaches a maximum (the Bragg peak) close to the end of the path, after which it drops abruptly to zero as the particle comes to rest [LIL01].

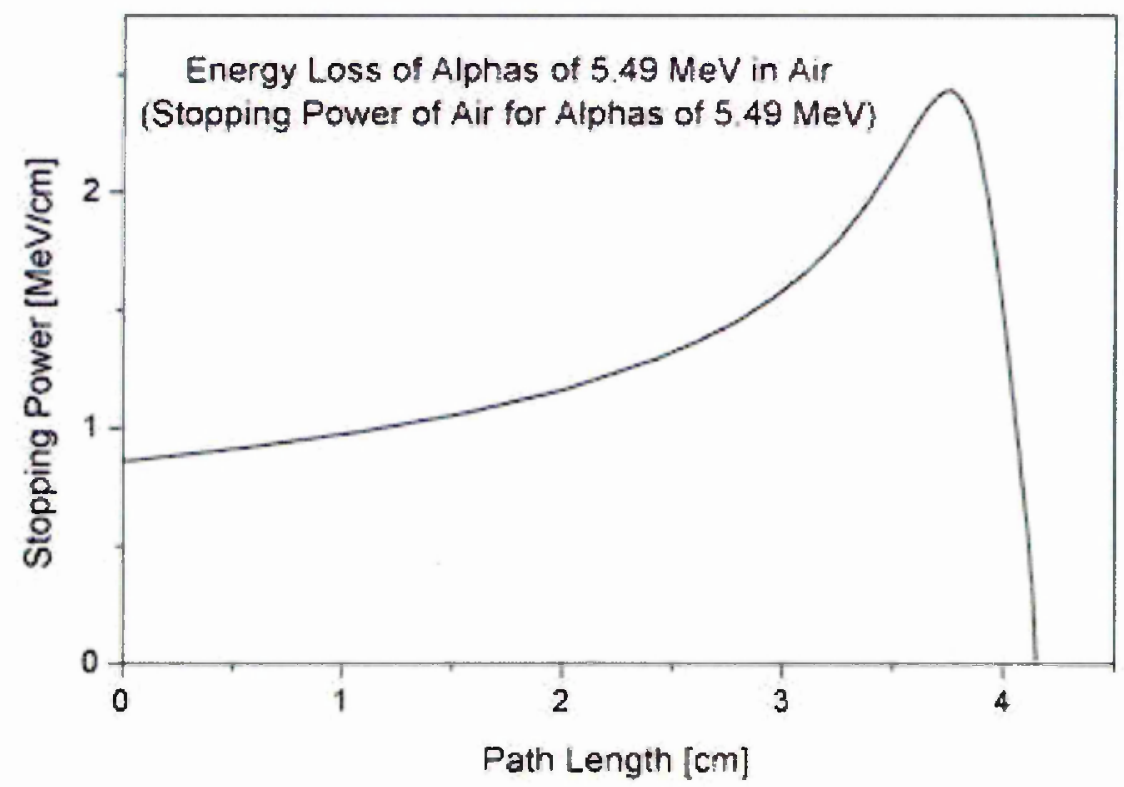

Figure 2-24: Stopping power of air for an alpha particle as a function of distance travelled.

For gamma radiation, increasing the thickness of the absorber only give a higher probability of the loss of gamma radiation through the interaction processes (i.e. by either 
absorption or scattering). For a well defined geometry, (e.g. Figure 2-25) the gamma-rays can be collimated into a narrow beam passing through the various absorber thicknesses before they strike a detector. An exponential fall off with distance results from the gamma-ray attenuation as also shown in Figure 2-25. The basic attenuation of photons in matter is described by Beers law which states [KNO00]:

$$
\ln I=-\mu t+\ln I_{0}
$$

Taking the inverse logs of both sides of Eq. (2.70), we have,

$$
I=I_{0} e^{-\mu t}
$$

where $I=$ transmitted photon intensity,

$I_{0}=$ incident photon intensity,

$e=$ base of the natural logarithm system

$\mu=$ the linear attenuation coefficient, and

$t=$ thickness of the absorber material.

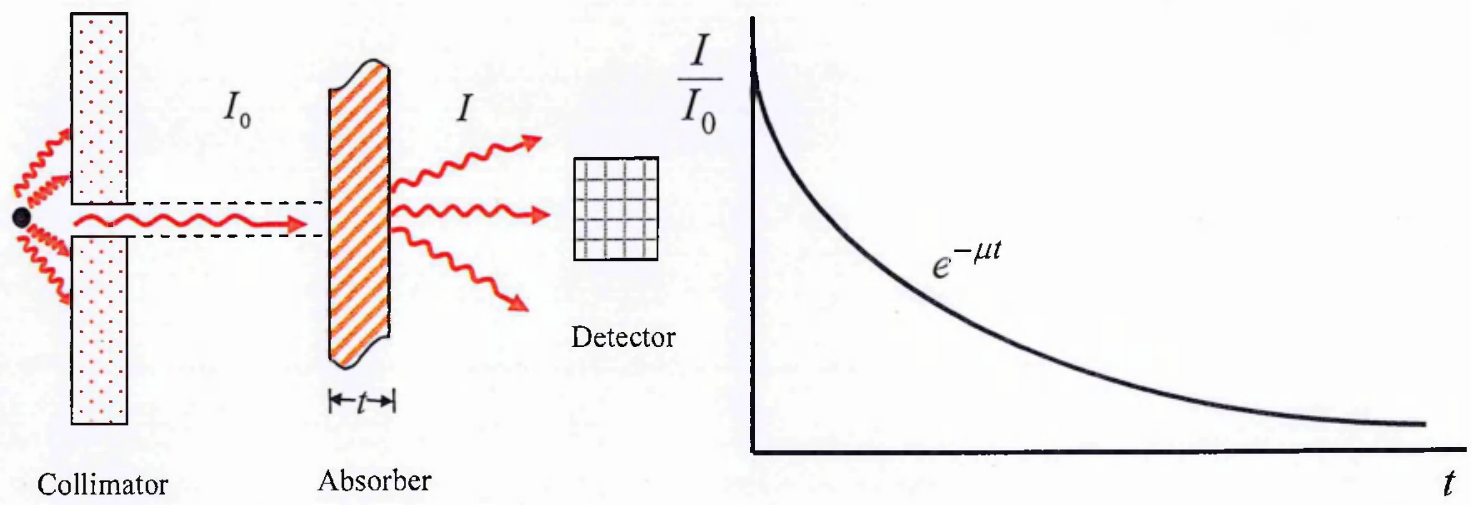

Figure 2-25: Schematic diagram of the exponential transmission curve for gamma rays measured under well-defined geometric conditions [KNO00].

The attenuation coefficient is defined as the fractional decrease or attenuation of the gamma-ray beam intensity per unit thickness of absorber as defined by equation below [CEM09]:

$\lim _{\Delta t \rightarrow 0} \frac{\Delta I / I}{\Delta t}=-\mu$

where $\Delta I / I$ is the fraction of the gamma-ray beam attenuated by an absorber of thickness $\Delta t$. 
The total probability per unit length (e.g., $\mathrm{cm}^{-1}$ ) for removal of a photon is called the total linear attenuation coefficient $\mu_{l}$ and is determined by the sum of respective probabilities for photoelectric absorption, Compton scattering and pair production. If the absorber thickness is measured in units of $\mathrm{g} / \mathrm{cm}^{2}$, then the absorber coefficient is called the mass attenuation coefficient $\mu_{m}$. The numerical relationship between $\mu_{l}$ and $\mu_{m}$ in a material which has density of $\rho\left(\mathrm{g} / \mathrm{cm}^{3}\right)$, is given by [CEM09]:

$\mu_{l}\left(\mathrm{~cm}^{-1}\right)=\mu_{m}\left(\frac{\mathrm{cm}^{2}}{\mathrm{~g}}\right) \times \rho\left(\frac{\mathrm{g}}{\mathrm{cm}^{3}}\right)$

In terms of the mass attenuation coefficient, the attenuation law for gamma rays takes the form:

$I=I_{0} e^{-\left(\mu_{t} / \rho\right) \rho t} \quad$ or $\quad I=I_{0} e^{-\mu_{m} \rho t}$

where $\rho t$ is the mass thickness of the absorber in units of $\mathrm{g} / \mathrm{cm}^{2}$.

In radiation measurements, the mass attenuation coefficient is more usually used rather than the linear attenuation coefficient..

For low-level radioactivity measurements, an environmental sample is usually prepared in a significant volume which may give rise to significant gamma-ray attenuation within the sample volume itself. This effect depends on several factors such as the gamma-ray energy, the geometry and the type/density of the samples. In order to achieve a statistically significant analysis when measuring environmental samples, a correction factor needs to be added for self-attenuation. This can have values up to tens of percent for gamma-ray energies below $200 \mathrm{keV}$. By restricting the sample size and concentrating on gamma-ray energies above $200 \mathrm{keV}$, the extent of self-attenuation effects can be minimised [SAT84, QUI06].

\subsection{Detection Limits}

\subsubsection{Critical Level Limit $\left(L_{c}\right)$}

A critical level $\left(L_{c}\right)$ is set to be the activity level used to compare with the net counts resulting from the unknown sample. If the net counts are less than $L_{c}$, it is concluded that the sample does not contain any measureable activity; alternatively if the net counts exceed $L_{c}$, it 
is assumed that some real "excess" activity is present [CUR68]. The critical level, $L_{c}$, is calculated using the expression,

$$
L_{c}=1.645 \sigma_{N_{s}} \quad(95 \% \text { confidence limit })
$$

where $\sigma_{N_{S}}=$ the standard deviation (or uncertainty) of the net background count

The standard deviation of the net signal is derived from [CUR68]:

$$
\sigma_{N_{S}}^{2}=\sigma_{N_{T}}^{2}+\sigma_{N_{B}}^{2}
$$

where $\sigma_{N_{\mathrm{T}}}^{2}$ represents the variance of the unknown sample and $\sigma_{N_{B}}^{2}$ represents the variance of the blank. If there is no activity present in the sample, then $\sigma_{N_{\mathrm{T}}}=\sigma_{N_{B}}$ therefore [KNO00]:

$$
\sigma_{N_{S}}^{2}=\sigma_{N_{\mathrm{T}}}^{2}+\sigma_{N_{B}}^{2}=2 \sigma_{N_{B}}^{2}
$$

If the significant fluctuations in the measurements only arise from counting statistics, then $\sigma_{N_{B}}=\sqrt{N_{B}}$ and the critical limit is given by:

$$
L_{c}=1.645 \sqrt{\left(2 \sigma_{N_{B}}^{2}\right)=} 2.326 \sigma_{N_{B}}
$$

where $\sigma_{N_{B}}=$ the standard deviation of counts in the blank sample

\subsubsection{Lower Limit of Detection (LLD)}

The lower limit of detection (LLD) or the detection limit $\left(\mathrm{L}_{\mathrm{D}}\right)$ can be defined as the minimum number of net counts that give confidence of detecting a real radiation source based on consideration of the uncertainties ("error") for both alpha and beta type errors. An alpha error refers to an error of saying that there is activity in the sample when in fact there is none; this is often also called a "false positive". By contrast, a beta error refers to an error of saying that there is no activity when there is actual activity present, which is called false negative. For a $5 \%$ value of the alpha and beta errors (i.e. false positive and false negative 5 times out of 100 ), if the sample and background counting times are equal, the LLD is given by [KNO00]: 


\subsubsection{Minimum Detectable Activity (MDA)}

In gamma spectrometry, the minimum detection limit refers to the minimum detectable activity (MDA) which describes the smallest amount of radioactivity that can be measured with a certain degree of confidence. The MDA depends on various factors such as the sample composition, the energy of the radiation, the source-detector distance, the detector efficiency, the background radiation level and the time available for the measurements [DEB88]. The definition of MDA was first introduced by Currie and it is based on a binary (yes or no) decision as to whether a given sample contains activity [CUR68].

To convert the $L L D$ in counts to a minimum detectable activity (MDA), additional factors of photon emission probability per disintegration of the selected gamma line $(f)$ and absolute efficiency $(\varepsilon)$ must be taken into account [CUR68]:

$$
M D A=\frac{4.653 \sigma_{N_{B}}+2.706}{f \varepsilon T}
$$

where $T$ is the counting time per sample.

The minimum detectable activity per mass of the samples can be calculated from:

$$
M D A=\frac{4.653 \sigma_{N_{B}}+2.706}{f m \varepsilon T}
$$

where $m$ is the mass of the sample in $\mathrm{kg}$.

Equations 2.80 and 2.81 can be used only if the counting times for the blank are the same as that of the sample. In the condition where both are different, the following equations must be used [CEM09]:

$$
L L D=3.29 \sqrt{r_{b} t_{g}\left(1+\frac{t_{g}}{t_{b}}\right)}+2.706
$$


$M D A=\frac{3.29 \sqrt{r_{b} t_{g}\left(1+\frac{t_{g}}{t_{b}}\right)}+2.706}{f \varepsilon T}$

where $r_{b}$ is the background counting rate

$r_{g}$ is the sample counting rate

$t_{b}$ is the background counting time

$t_{g}$ is the sample counting time

\subsection{Specific Activity Concentration}

The activity concentration, $A$, for radionuclides in a measured sample is calculated using the relation [DOV04]:

$A=\frac{N}{\varepsilon f t_{s} m K_{1} K_{2} K_{3} K_{4} K_{s}}$

where $N$ is the corrected net peak area of the corresponding photopeak given by

$N=N_{S}-\frac{t_{s}}{t_{b}} N_{b}$

$N_{S}$ is the net peak area in the sample spectrum,

$N_{b}$ is the corresponding net peak area in the background spectrum,

$\varepsilon$ is the absolute detection efficiency at photopeak energy,

$t_{s}$ is the live time of the sample spectrum collection, in seconds,

$t_{b}$ is the live time of the background spectrum collection, in seconds,

$m$ is the mass of the measured sample, in $\mathrm{kg}$,

$f$ is the emission probability of the gamma line corresponding to the peak energy,

$K_{1}$ is the correction factor for the nuclide decay from the time the sample was collected to the start of the measurement, given by [DOV04]: 
$K_{1}=\exp \left(-\frac{\ln 2 \cdot \Delta t}{T_{1 / 2}}\right)$

where $\Delta t$ is the elapsed time from when the sample was taken to the beginning of the measurement and $T_{1 / 2}$ is the radionuclide half life.

$K_{2}$ is the correction factor for the nuclide decaying during counting period, given by [DOV04]

$K_{2}=\frac{T_{1 / 2}}{\ln 2 \cdot t_{r}}\left(1-\exp \left(-\frac{\ln 2 \cdot t_{r}}{T_{1 / 2}}\right)\right)$

where $t_{r}$ is the elapsed (real clock) time during the measurement.

$K_{3}$ is the correction factor for a self-attenuation in the measured sample compared with the calibration sample [EGG99]:

$K_{3}=\frac{1-e^{-\mu x}}{\mu x}$

where $x$ is the thickness of the measured sample and $\mu$ is the photon linear attenuation coefficient for the $\gamma$-ray energy of interest.

If the matrix of materials which contains both the calibration sample and the measured sample are the same, then $K_{3}=1$ [DOV04].

If more than one photon is absorbed by the detector during a pulse sampling cycle, the sum of the energies of two (or more) is recorded in the spectrum instead of two (or more) individual signals. Any full-energy photon that is summed with another pulse is not recorded in the single photon peak and represents a loss of counts or efficiency. This loss is count rate dependent.

$K_{4}$ is the correction factor for pulses loss due to random summing, where

$K_{4}=\exp (-2 R \tau)$

where $\tau$ is the resolution time of the measurement system and $R$ is the mean count rate.

For low count rates (i.e. $<100 \mathrm{~Hz}$ ) this correction factor can be taken as 1 . 
$K_{5}$ is the coincidence correction factor for those nuclides decaying through a cascade of successive photon emissions. If the photon decay is a single step cascade, then $K_{5}=1$. Also if the efficiency calibration sample and measured sample contain the same nuclide (e.g. ${ }^{232} \mathrm{Th}$ or ${ }^{226} \mathrm{Ra}$ ), then $K_{5}=1$.

$$
K_{5}=\frac{\varepsilon_{a p}(E)}{\varepsilon(E)}
$$

where $\varepsilon_{a p}(E)=$ the corresponding apparent efficiency at the specific energy, $\varepsilon(E)=$ the full energy peak efficiency at the specific energy

\subsection{External Gamma Dose Rate}

Humans have exposure to gamma radiation everyday of their life directly from all soils and sands. Radioactivity from terrestrial radionuclides is normally present at trace amounts. Higher radiation levels can be found in igneous rock, phosphate sedimentary rocks, dark shale and metamorphic rocks derived from these [UNSCEAR00]. It can be noted that the specific levels of radioactivity depend on the types of rock from which the soils or sands originated. The decay products from the ${ }^{238} \mathrm{U}$ and ${ }^{232} \mathrm{Th}$ series, plus ${ }^{40} \mathrm{~K}$ play a major role in the external sources due to NORM radiation on the human body. The total absorbed gamma dose rate due to the naturally-occurring radionuclides ${ }^{226} \mathrm{Ra},{ }^{232} \mathrm{Th}$ and ${ }^{40} \mathrm{~K}$ can be calculated from the specific activity of each radionuclide. The biological effects on humans from such external and internal irradiation are described in the next section.

\subsubsection{Dose Rate Calculation}

The gamma dose rate $(D)$ in $n G y \cdot h^{-1}$ in the outdoor air is calculated using the following equation reported by [UNSCEAR00]:

$$
D=0.462 A_{R a}+0.604 A_{T h}+0.0417 A_{K}
$$

where $D$ is the dose rate in $\mathrm{nGy} \cdot \mathrm{h}^{-1}$ and $A_{\mathrm{Ra}}, A_{\mathrm{Th}}$, and $A_{\mathrm{K}}$ are the specific activities in Bq. $\mathrm{kg}^{-1}$ of ${ }^{226} \mathrm{Ra},{ }^{232} \mathrm{Th}$ and ${ }^{40} \mathrm{~K}$, respectively. 


\subsubsection{Hazard Indices Calculation}

The radium equivalent activity, $\mathrm{Ra}_{\mathrm{eq}}$, can be expressed as [BER95]:

$$
R a_{c q}=A_{R a}+\left(A_{T h} \times 1.43\right)+\left(A_{K} \times 0.077\right)
$$

where $A_{\mathrm{Ra}}, A_{\mathrm{Th}}$, and $A_{\mathrm{K}}$ are the specific activities (in $\mathrm{Bq} \cdot \mathrm{kg}^{-1}$ ) of ${ }^{226} \mathrm{Ra},{ }^{232} \mathrm{Th}$ and ${ }^{40} \mathrm{~K}$, respectively. This calculation is based on the assumption that $370 \mathrm{~Bq} \cdot \mathrm{kg}^{-1}$ of ${ }^{226} \mathrm{Ra}$ or 259 Bq. $\mathrm{kg}^{-1}$ of ${ }^{232} \mathrm{Th}$ or $4,810 \mathrm{~Bq} \cdot \mathrm{kg}^{-1}$ of ${ }^{40} \mathrm{~K}$ produces the same gamma dose rate. The maximum radium-equivalent activity is $370 \mathrm{~Bq} \cdot \mathrm{kg}^{-1}$.

The external hazard index, $H_{\mathrm{ex}}$, is defined by [BER95]:

$$
H_{e x}=\frac{A_{R a}}{370}+\frac{A_{T h}}{259}+\frac{A_{K}}{4810}
$$

where $A_{\mathrm{Ra}}, A_{\mathrm{Th}}$, and $A_{\mathrm{K}}$ are the specific activities (Bq.kg ${ }^{-1}$ ) of ${ }^{226} \mathrm{Ra},{ }^{232} \mathrm{Th}$ and ${ }^{40} \mathrm{~K}$, respectively. The value of this index must be less than unity in order to keep the radiation hazard insignificant. A value of $H_{\mathrm{ex}}$ equal to unity corresponds to the upper limit of radium equivalent activity $\left(370 \mathrm{~Bq} \cdot \mathrm{kg}^{-1}\right)$ [SAK94].

The internal hazard index, $H_{\text {in }}$, is defined by [BER95]:

$$
H_{\text {in }}=\frac{A_{R A}}{185}+\frac{A_{T h}}{259}+\frac{A_{K}}{4810}
$$

where $A_{\text {Ra }}, A_{\mathrm{Th}}$, and $A_{\mathrm{K}}$ are the specific activities $\left(\mathrm{Bq} \cdot \mathrm{kg}^{-1}\right)$ of ${ }^{226} \mathrm{Ra},{ }^{232} \mathrm{Th}$ and ${ }^{40} \mathrm{~K}$, respectively. The internal hazard index should be less than unity if the radiation hazard from internal exposure to radon and its daughter products in human body are to be considered as safe.

\subsubsection{Annual Effective Dose Calculation}

The annual effective dose can be calculated by the following equation [DOV04, ONJ06]:

Annual effective dose $\left(\mathrm{mSv} \cdot \mathrm{y}^{-1}\right)=D\left(\frac{10^{-9} G y}{h}\right) \times 24 \frac{h}{d a y} \times 365 \frac{d a y}{y} \times \frac{10^{-6} m G y}{10^{-9} G y} \times 0.7 \frac{S v}{G y} \times 0.2$

$$
=D \times 1.23 \times 10^{-3} m S v \cdot y^{-1}
$$


where the conversion factor from the absorbed dose rate in air to the effective dose received by adults is $0.7 \mathrm{~Sv} \cdot \mathrm{Gy}^{-1}$ [UNSCEAR00]. This assumes on outdoor occupancy factor of $20 \%$, this being the average worldwide reported in [UNSCEAR93].

\subsection{Biological Assessment}

The biological severity on humans varies with the type of radiation, the depth of deposition within organic tissue and the composition of the absorbing material. Therefore, living organisms will not necessarily experience the same biological effect, even if the same amount of energy is deposited. The more complex the organ cell structure, the higher its sensitivity to radiation. A quantitative measure of radiation energy absorption is known as the "dose". In the SI system, the unit of dose is the gray (Gy) which is defined

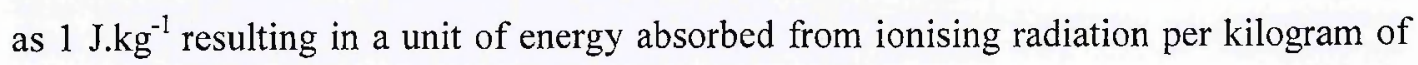
matter [FRI81].

One exposure unit $(\mathrm{X})$ is described as that quantity of $\mathrm{X}$ - or gamma radiation that generates ions containing one Coulomb of charge per kilogram in air. The exposure unit can be converted to the units of energy absorption per unit mass of air (i.e. air dose) by using the fact that (i) the charge on a single ion is $1.6 \times 10^{-19} \mathrm{C}$ and (ii) the average energy dissipated in the production of a single ion pair in air is $33.8 \mathrm{eV}$. Therefore,

$$
\begin{aligned}
1 \mathrm{X} \text { unit } & =1 \frac{\mathrm{C}}{\mathrm{kg}} \text { air } \times \frac{1 \mathrm{ion}}{1.6 \times 10^{-19} \mathrm{C}} \times 33.8 \frac{\mathrm{eV}}{\mathrm{ion}} \times 1.6 \times 10^{-19} \frac{\mathrm{J}}{\mathrm{eV}} \times 1 \frac{\mathrm{Gy}}{\mathrm{J} / \mathrm{kg}} \\
& =33.8 \mathrm{~Gy} \text { (in air) }
\end{aligned}
$$

Thus, a gamma-ray exposure of 1 Coulomb/kilogram equals to 33.8 joules/kilogram, or $33.8 \mathrm{~Gy}[\mathrm{KNO} 00]$. The energy deposition in air can be converted to the absorbed dose in organic tissue by considering the electronic density of the absorber. For example, a tissue have a specific gravity of 1 and have an elementary composition of $5.98 \times 10^{22}$ hydrogen atoms per gram, $2.75 \times 10^{22}$ oxygen atoms per gram, $0.172 \times 10^{22}$ nitrogen atoms per gram, and $6.02 \times 10^{21}$ carbon atoms per gram, then the electronic density is $3.28 \times 10^{23}$ electrons per gram. For air, whose density is $1.293 \times 10^{-3} \mathrm{~g} / \mathrm{cm}^{3}$, the electronic density is 
$3.01 \times 10^{23}$ electrons/gram. Therefore, the energy absorption in $\mathrm{J} / \mathrm{kg}$ of tissue subjecting to an exposure of $1 \mathrm{C} / \mathrm{kg}$ air is [CEM09]:

$$
\frac{3.28}{3.01} \times 33.8 \frac{\mathrm{J}}{\mathrm{kg}} \text { air }=37 \frac{\mathrm{J}}{\mathrm{kg}} \text { tissue }
$$

As a result, the energy absorbed in the air does not give the same dose rate when absorbing in the living tissue.

\subsubsection{Biological Effective Dose, $H_{T}$}

Since the probabilities for the damage to the cell are dissimilar for different types of radiation. Radiation weighing factors, $W_{R}$ have been recommended to account for this (see Table 2-6). The biologically effective dose $H_{T}$ can then be calculated by using equation [ICRP06].

$$
H_{T}(S v)=\sum_{R} H_{T, R}=\sum_{R} w_{R} \cdot D_{T, R}
$$

where $D_{T, R}$ is the absorbed dose in the units of gray (Gy) average over the tissue organ $T$, due to radiation $R . H_{T}$ is the total effective dose given by a sum over all radiation types irradiating the target, and has units of sieverts (Sv).

Table 2-6 Radiation weighting factors, $W_{R}$ for various radiations [ICRP2006].

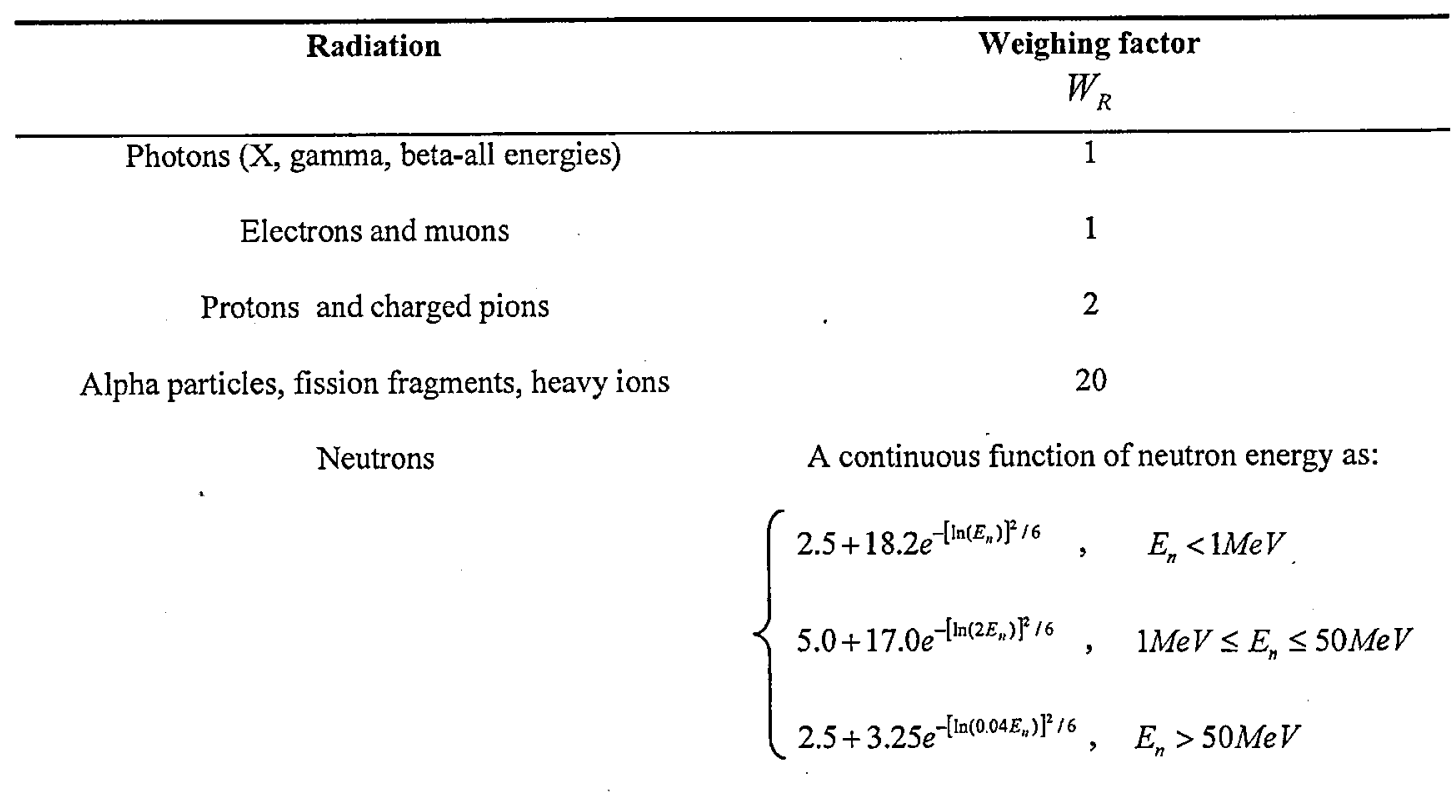

All values relate to the radiation incident on the body or, for internal radiation sources, emitted from the source. 


\subsubsection{Effective Equivalent Dose $H_{E}$}

It is not only the type of radiation which results in different levels of biological effect in human tissue but also the differing composition of the different cell types and their radiation sensitivities. Thereby, a tissue weighing factor is also introduced to explain the variation of sensitivities of different types of cells for different radiation. The effective equivalent dose $H_{E}$ which is the sum of the weighted equivalent doses in all tissues is estimated by Eq. (2.100)

$$
H_{E}(S v)=\sum w_{T} H_{T}
$$

where $W_{T}$ is the tissue weighting factor for tissue, $T$ and with $\sum W_{T}=1$.

The most recent values for $W_{T}$ that have been recommend by the ICRP for different tissues are given in Table 2-7.

Table 2-7 Tissue weighing factors, $W_{T}$ and $\sum W_{T}$ for different organs [ICRP06].

\begin{tabular}{ccc}
\hline Tissue & $W_{T}$ & $\sum W_{T}$ \\
\hline Gonads & 0.08 & 0.08 \\
Lung, Bone-marrow, Stomach, Colon, & 0.12 & 0.72 \\
Breast, Remainder Tissues* & & 0.16 \\
Thyroid, Liver, Oesophagus, Bladder & 0.04 & 0.04 \\
Skin, Bone surface, Salivary glands, & 0.01 & \\
Brain & &
\end{tabular}

*Remainder Tissues: Adrenals, Extrathoracic (ET) region, Gall bladder, Heart, Kidneys, Lymphatic nodes, Muscle, Oral mucosa, Pancreas, Small intestine, Spleen, Thymus, Uterus/cervix.

Internal exposure from ionising radiation can be caused by consuming primordial radionuclides into the body by ingestion or inhalation. Eating food or drinking water contaminated with ${ }^{40} \mathrm{~K},{ }^{238} \mathrm{U}$ and ${ }^{232} \mathrm{Th}$ series radionuclides gives rise to internal irradiation. Doses from inhalation typically arise from breathing dust particles containing radionuclides from the ${ }^{238} \mathrm{U}$ and ${ }^{232} \mathrm{Th}$ decay chains in air. Usually, terrestrial radionuclides are present only in trace amount. However, if radioactive materials are released to the environment in significant amounts, this could result in significant 
biological damage. To determine an internal dose rate, both physical and biological factors must be taken into account. The physical factors involve the type and energy of the radiation and the radiological half-life. The biological factors rely on the distribution of the radioisotope within the body and the kinetic behaviour, such as absorption rate, turnover rates and retention times in the various organs and tissues.

\subsubsection{Effective Half-Life $T_{E}$}

The concentration of a radionuclide in an organism is directly related to the difference between the intake of the radionuclide and its removal from the organism by excretion and/or radioactive decay. The number of radioactive nuclides within an organ at time $t$, is $Q(t)$, after deposition of a quantity $Q_{0}$ is given by [CEM09];

$$
Q=Q_{0} e^{-\left(\lambda_{R}+\lambda_{B}\right) t}
$$

where $\lambda_{R}$ is the radioactive decay constant and $\lambda_{B}$ is the biological elimination constant.

If

$$
\lambda_{E}=\lambda_{R}+\lambda_{B}
$$

then

$$
Q=Q_{0} e^{-\lambda_{E} t}
$$

where $\lambda_{E}$ is called the effective elimination constant. The effective half-life is then

$$
T_{E}=\frac{0.693}{\lambda_{E}}
$$

From the relationship between $\lambda_{\mathrm{B}}, \lambda_{\mathrm{R}}$ and $\lambda_{E}$

$$
\frac{1}{T_{E}}=\frac{1}{T_{R}}+\frac{1}{T_{B}}
$$

or

$$
T_{E}=\frac{T_{R} \times T_{B}}{T_{R}+T_{B}}
$$

where $T_{E}$ is effective half-life, $T_{B}$ is biological half-life, and $T_{R}$ is radiological half-life 
The number of radionuclides declines therefore due to both radioactive decay processes and their biological ejection from the human body. Therefore, the effective half-life is smaller than either the biological or radiological half-lives [CEM09]. The biological effects of radiation are very complicated since they are linked to the physical constituents and the metabolism processes which are impacted by several factors such as body size, age, sex, physical activity, physical condition, metabolic rate and the overall deposition of the radionuclide in the body [RON84]. 


\section{Chapter 3}

\section{Experimental Methodology}

\subsection{Sample Collection}

Approximately 60 beach sand samples were collected by random selection from different locations along the west and the east coast of southern Thailand during August 2008 covering six provinces, namely Phang-nga, Phuket, Krabi, Chumporn, Suratthani and Nakonsrithammarat, as shown in Figure 3-1.

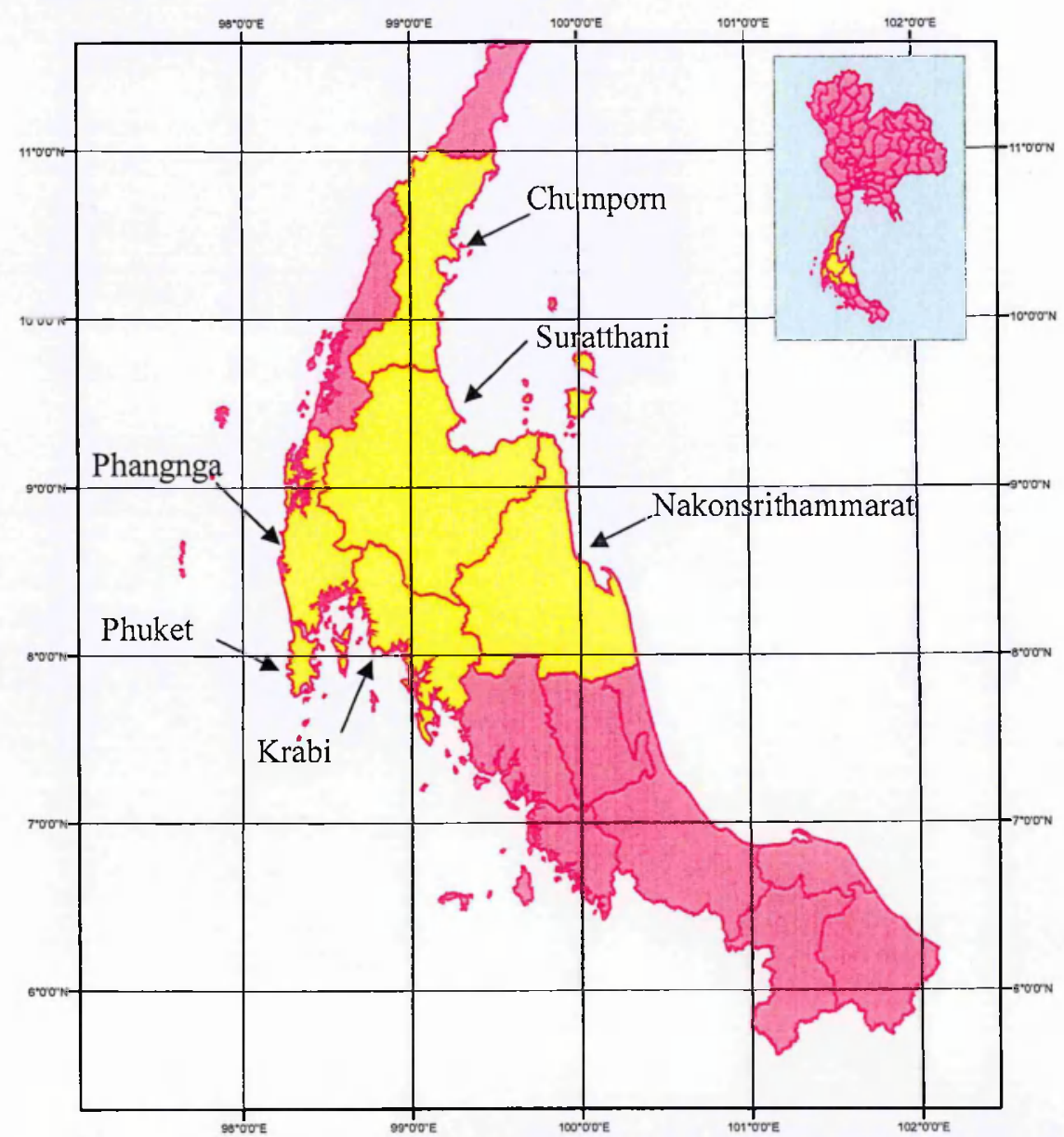

Figure 3-1: Map showing sampling areas from six provinces along the west and east coast of Thailand. 
Beach sand samples were collected from different beaches and at different distances from the seashore (i.e. at the beachfront, 10 and 20 metres from the beach line) along the west and east coast of Thailand at the following provinces:

- Phang-Nga province; Hat Khoa Lak, Hat Thai Mueng

- Phuket province; Hat Nai Ton, Hat Surin, Hat Patong, Hat Kata Noi, Hat Rawai, Ao Chalong and Ao Po

- Krabi province; Hat Nopparat Thara, Ao Tonsai, PhiPhi Don, Ao Lohdalam and Bamboo Island

- Chumporn province; Hat Sai Ri and Hat Laem Son

- Suratthani province; Hat Chaweng, Hat Lamai, Hat Taling Ngam, Hat Lipanoi and Ao Bo Phut in Samui Island, Hat Rin Nok, Hat Kho Ma in Phangan Island and Hat Chaiya

- Nakornsrithammarat province; Hat Khanom

The geological maps of the west and the east coast of Thailand using ArcView software showing the sampling points are depicted in Figure 3-2, and 3-3, respectively, followed by the explanation of the symbol list in Table 3-1. The quaternary coastal deposits cover the main part of southern Thailand for a distance of about $1,840 \mathrm{~km}$ in the Gulf of Thailand and occur periodically along the $865 \mathrm{~km}$ west coast of Thai Peninsular [DHE92]. 


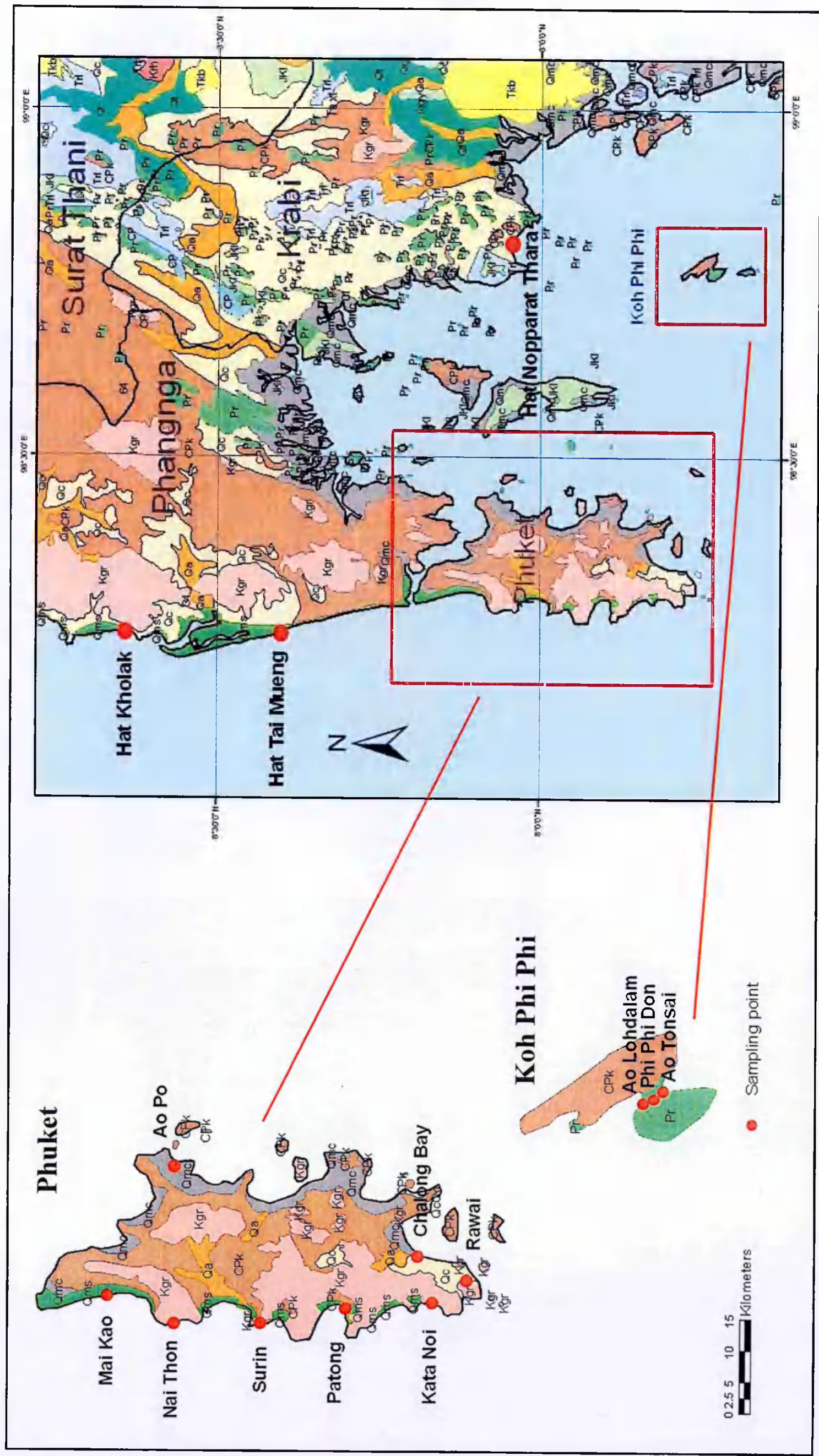




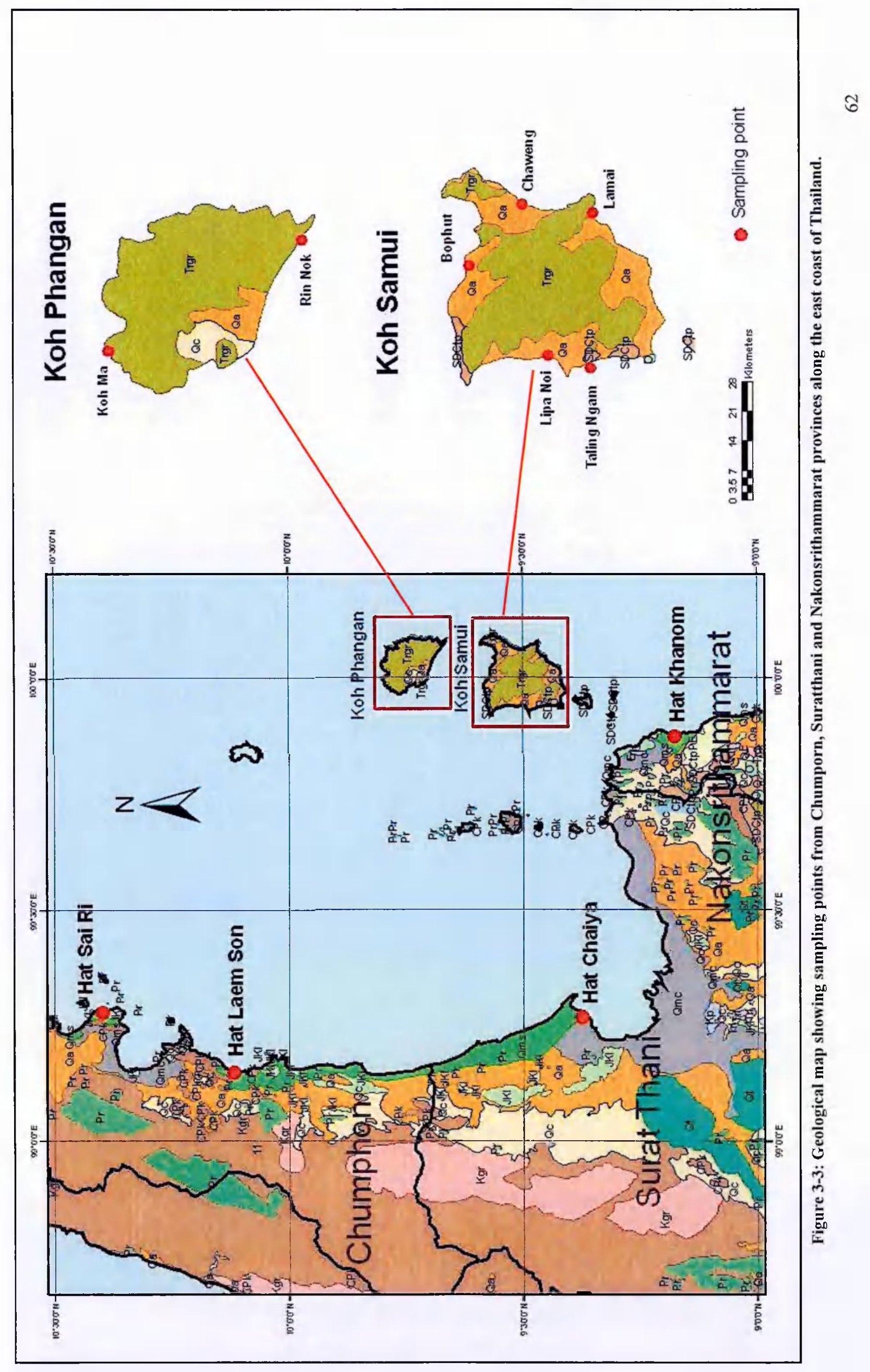




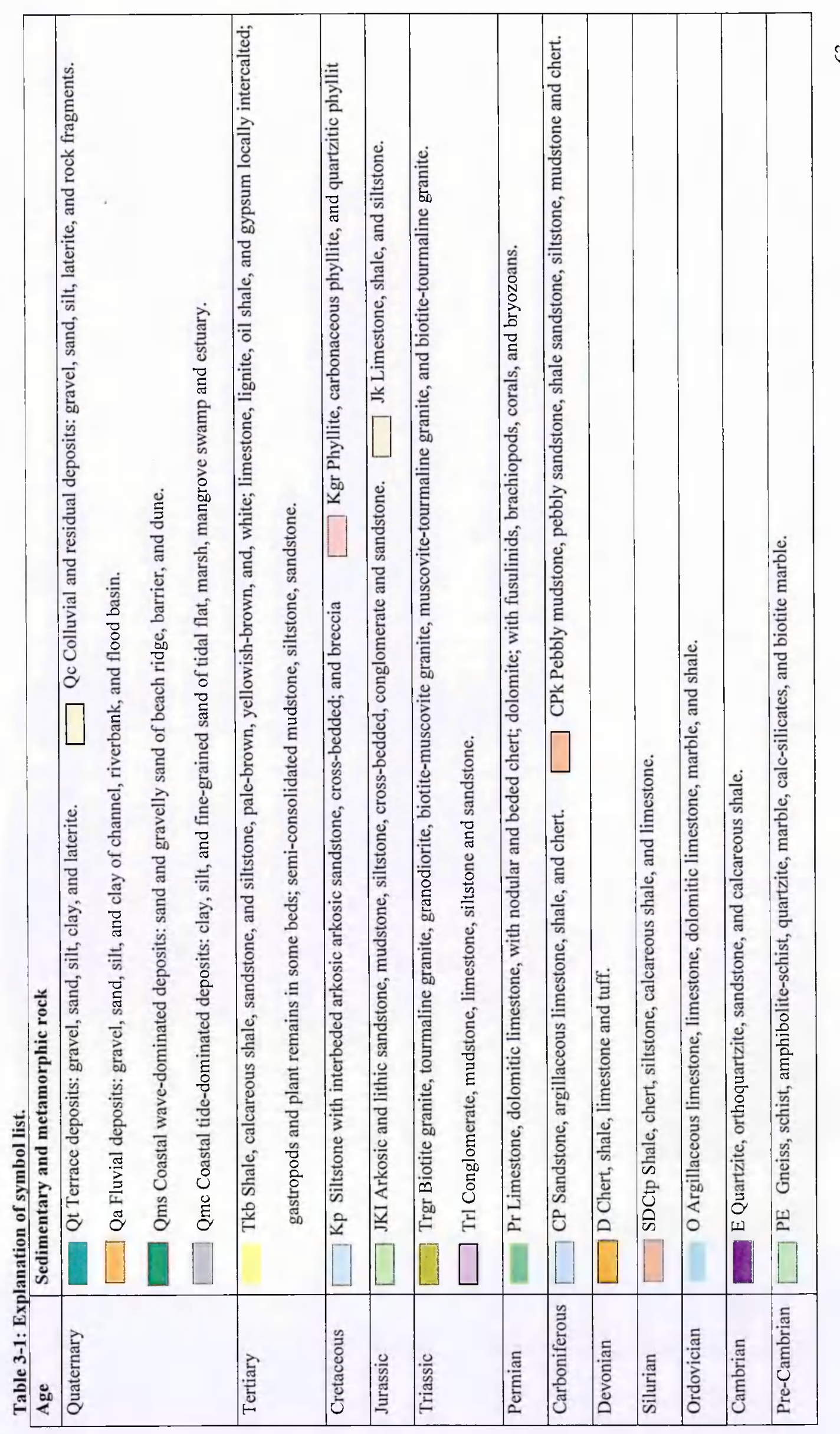




\subsection{Sample Preparation}

Approximately $2 \mathrm{~kg}$ for each sand sample was collected from the ground surface down to a depth of $5 \mathrm{~cm}$. After collection, sample preparation was then carried out by: (i) drying of the samples at room temperature to remove excess moisture; (ii) oven drying the samples at a temperature of $50^{\circ} \mathrm{C}$ for 24 hours to obtain a constant weight; (iii) passing through a $500 \mu \mathrm{m}$ sieve to ensure homogeneity of the sample; (iv) placing in $550 \mathrm{ml}$ polyethylene plastic marinelli beakers which were sealed with PVC tape and; (v) dry weighing and storing for approximately 4 weeks to allow radioactive equilibrium of ${ }^{222} \mathrm{Rn}$ with it parent $\left({ }^{226} \mathrm{Ra}\right)$ in the uranium chain. The processes of sample preparation are shown in Figure 3-4.

(a) experimental apparatus

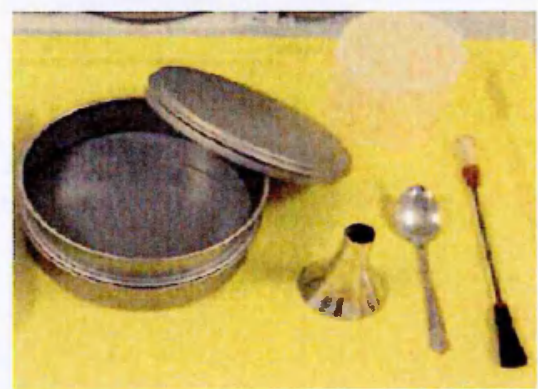

(c) oven drying at $50^{\circ} \mathrm{C}$ for 24 hours

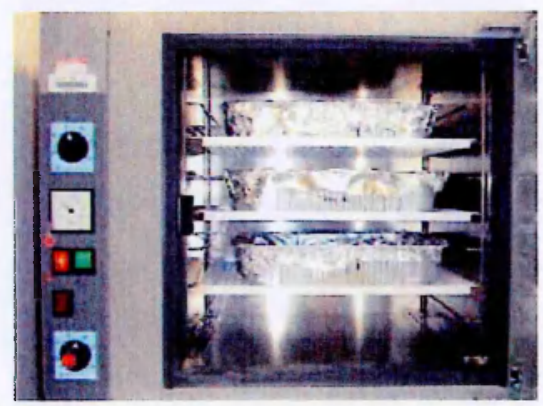

(e) placing in $550 \mathrm{ml}$ marinelli beakers

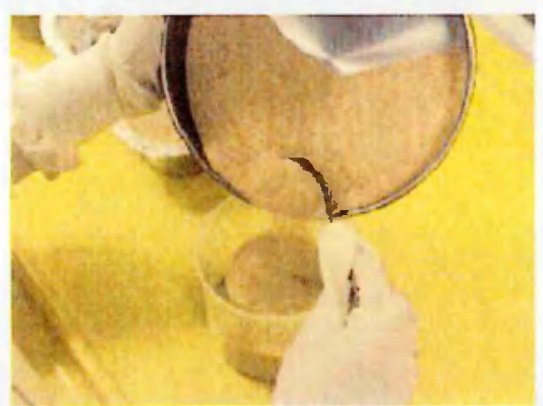

(b) drying at room temperature

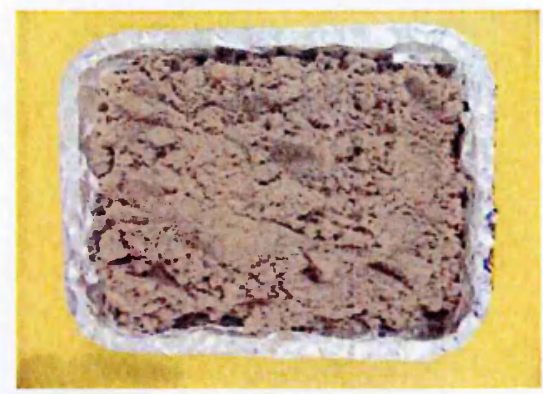

(d) passing through $500 \mu \mathrm{m}$ sieve

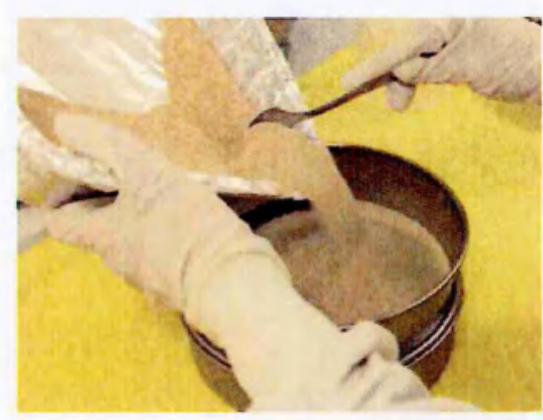

(f) sealed and stored for 4 weeks

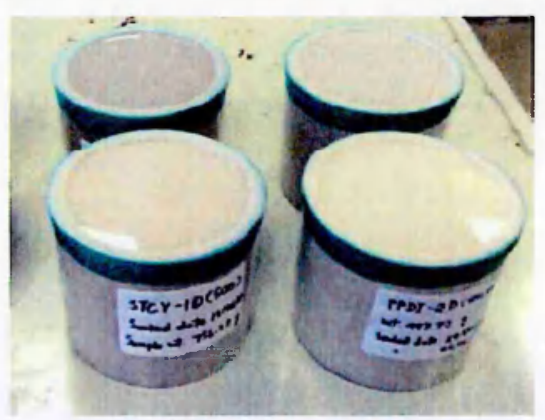

Figure 3-4: Sand sample preparation for the current study. 


\subsection{Experimental Setup}

Gamma-ray spectrometry analysis of the beach sand samples was carried out using a HPGe coaxial detector which had the following specifications:

a) Canberra coaxial germanium detector

\begin{tabular}{|l|l|}
\hline Detector Model & GCW2021 \\
\hline Serial number & b 06308 \\
\hline Geometry & Coaxial one open end, open end facing window \\
\hline Diameter & $62 \mathrm{~mm}$ \\
\hline Length & $48 \mathrm{~mm}$ \\
\hline Distance from window & $10 \mathrm{~mm}$ \\
\hline Bias voltage $(\mathrm{V} \mathrm{dc})$ & $(+) 3000 \mathrm{~V} \mathrm{dc}$ \\
\hline
\end{tabular}

b) Detector with shielding system

To reduce the external gamma-ray background in the measured spectrum, a cylindrical lead shield with a fixed bottom and a movable cover shielded the detector. The detector shield contained a $10 \mathrm{~cm}$ thick low background lead, internally lined with $1.5 \mathrm{~mm}$ copper and $1 \mathrm{~mm}$ tin sheets as shown in schematically in Figure 3-5 below.

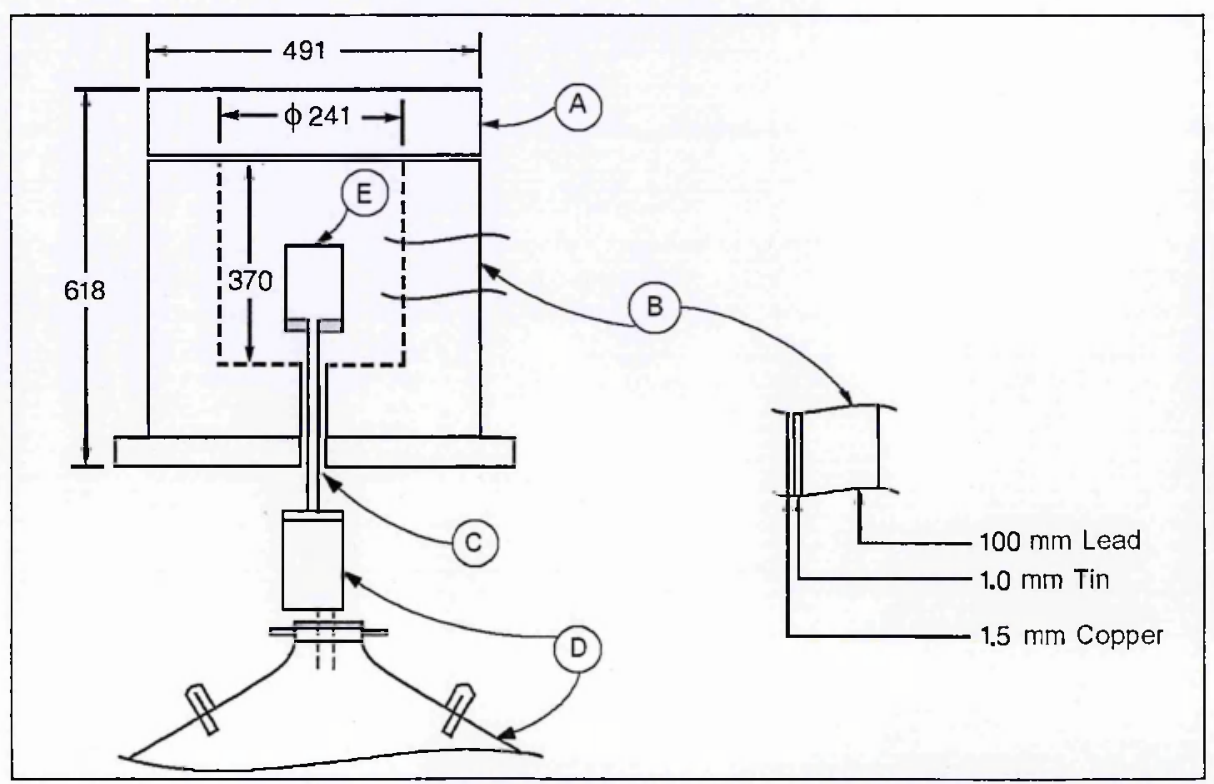

Figure 3-5: Low-background shield design and cross-section of materials; (A) shielded door (B) shielding materials (C) shield penetration (D) detector preamplifier and dewar and (E) detector. 
Shielding of the germanium detector is very important for counting low-level environmental samples because it decreases the amount of background radiation which reaches the detector. The material that is most widely used to construct the passive detector shields is lead, which is used because of its high density. An optimum thickness of lead shielding is about $10 \mathrm{~cm}$ in order to reduce the cosmic- ray components [LIN90] and typical gamma ray of the background (i.e. ${ }^{40} \mathrm{~K}$ from concrete walls). Smaller thickness of shields may not absorb sufficient gamma rays from external background sources efficiently enough, while higher thickness of shields leads to an excess of production of secondary radiations due to cosmic-ray interactions within the lead shield. In the current work, the bulk shield of lead is covered on the inside with a graded coppertin liner comprising of $1.5 \mathrm{~mm}$ and $1 \mathrm{~mm}$ thick sheets of copper and tin respectively. The sheets of copper are used to absorb the characteristic fluorescence $K_{\alpha}$ and $K_{\beta} X$-rays created in the lead that are excited by background or source radioactivity, while the tin sheets are used to attenuate the copper K X-rays from the fluorescence of the copper sheet liner.

\section{c) HPGe detector system}

Gamma-spectrometric analysis of the samples was performed with a computer-based gamma-ray spectrometry system for qualitative and quantitative determination of gammaemitting radionuclides. The system included a high-resolution HPGe coaxial detector, high-voltage power supply, preamplifier, amplifier and a multi channel analyzer (MCA) (see Figures 3-6 and 3-7). The HPGe coaxial detector used had a measured energy resolution of $2.08 \mathrm{keV}$ (FWHM), an absolute full-energy peak gamma-ray efficiency of approximately $0.5 \%$ and relative efficiency of $28.8 \%$ at $1332 \mathrm{keV}$.

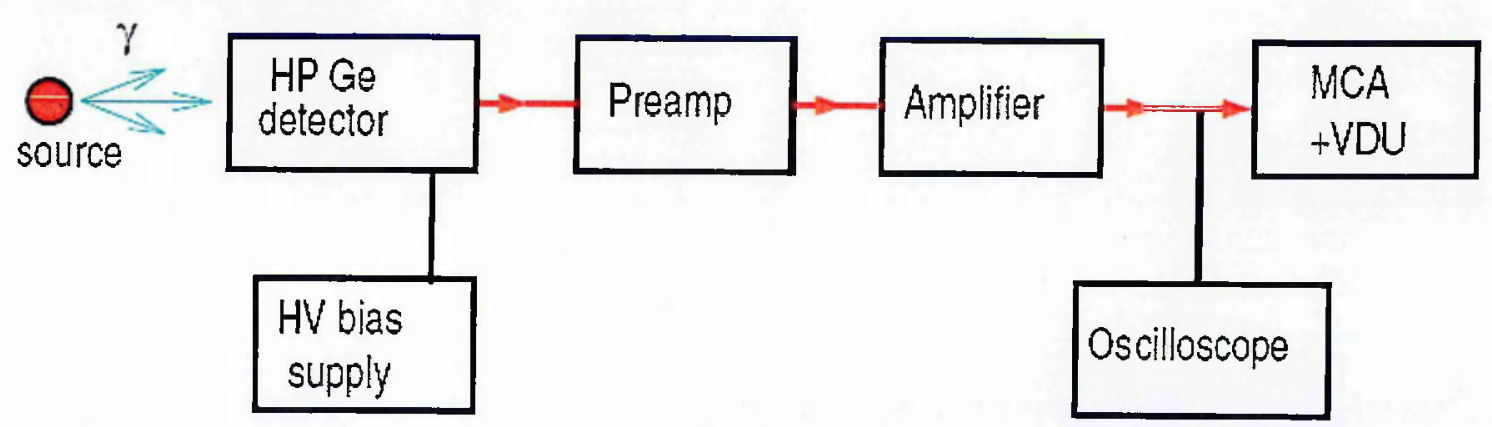

Figure 3-6: Schematic diagram of the high-purity germanium detector system [PPR08]. 


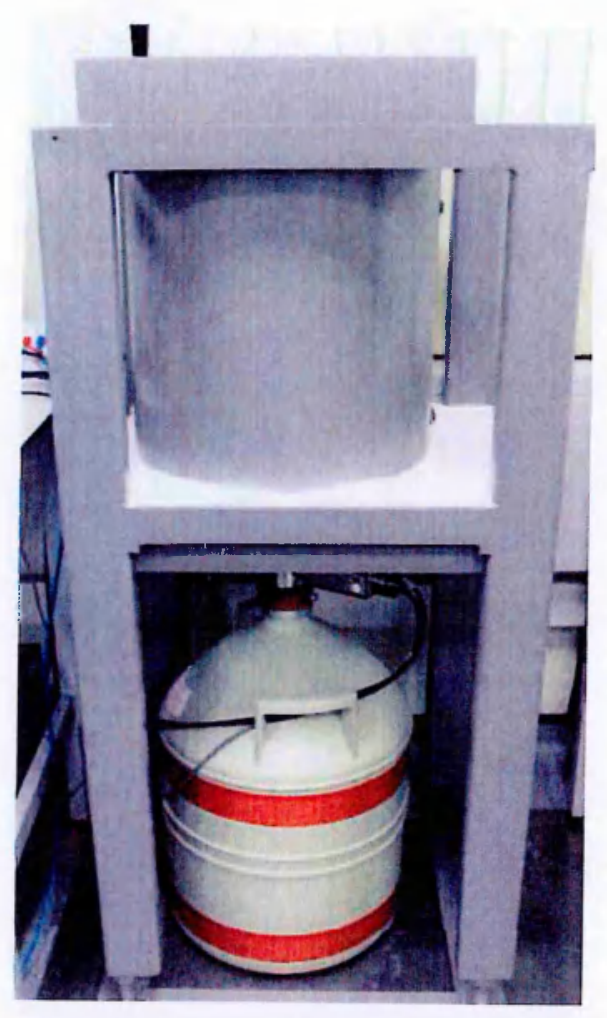

(a) HPGe detector

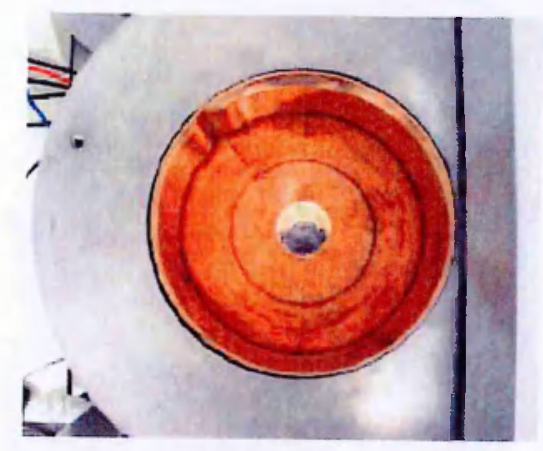

(b) Top view of HPGe detector and shielding

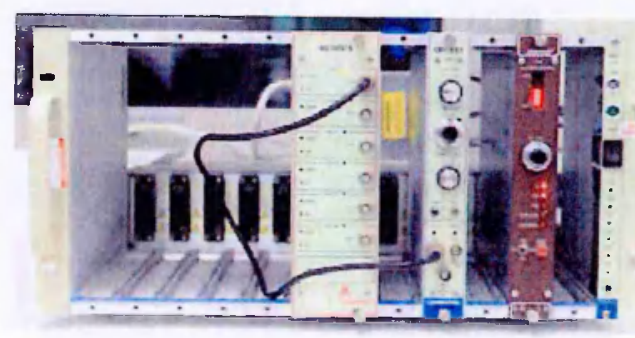

(c) NIM bin with high voltage, Amplifier and ADC units

Figure 3-7: The high-purity germanium detector system used in the current work.

\subsection{Detector Characterisation}

\subsubsection{Energy Calibration}

A pre-prepared source standard of ${ }^{232} \mathrm{Th}$ and its decay chain members, with energies up to $2.6 \mathrm{MeV}$ was used to perform an energy calibration which covered the entire range over which the gamma-ray spectrometer was used. The list of gamma-ray energy emitted by ${ }^{232} \mathrm{Th}$ source is shown in Table 2-1. The ${ }^{232} \mathrm{Th}$ standard source was held in a marinelli beaker with an activity of approximately $1 \mathrm{kBq}$ and was placed around the top of the detector and an energy spectrum collected for 86,400 s (i.e. one day). The energy calibration was normally performed before measuring the sample, and then repeated every week to check for any drift in the detector gain, thus maintaining the quality of the measurements. 


\subsubsection{Detection Efficiency}

Four independent reference sources containing (i) ${ }^{232} \mathrm{Th}$, (ii) ${ }^{226} \mathrm{Ra}$, (iii) ${ }^{152} \mathrm{Eu}$, and (iv) NG3 (a mixed radionuclide source containing ${ }^{241} \mathrm{Am},{ }^{109} \mathrm{Cd},{ }^{139} \mathrm{Ce},{ }^{137} \mathrm{Cs},{ }^{60} \mathrm{Co},{ }^{57} \mathrm{Co}$, ${ }^{203} \mathrm{Hg},{ }^{113} \mathrm{Sn},{ }^{85} \mathrm{Sr}$, and ${ }^{88} \mathrm{Y}$ ) in the same marinelli beaker geometry as used for the samples were employed for the absolute efficiency calibration of the system. With the same geometry and the same range in density between reference sources $\left(1.1 \mathrm{~g} / \mathrm{cm}^{3}\right.$ for the ${ }^{232} \mathrm{Th}$ and ${ }^{226} \mathrm{Ra}$ sources; $1.6 \mathrm{~g} / \mathrm{cm}^{3}$ for the ${ }^{152} \mathrm{Eu}$ and NG3 sources) and sand samples (which had typical measured densities of $\sim 1.3-1.5 \mathrm{~g} / \mathrm{cm}^{3}$ ), differences in the selfattenuation for gamma rays for the sources and samples was then assumed to be a negligible contribution to the overall experimental uncertainties in the radiometric evaluations discussed in this thesis.

\subsection{Sample Analysis}

The measurement time for the sand samples and the background was set to 172,800 s (i.e. 48 hours). This was chosen in order to gain sufficient counting statistics for each sample. The background spectra, collected with de-ionised water filled blanks, were used to correct the net peak area of gamma rays of the measured isotopes. The spectrum analysis was performed by the computer software Genie 2000 obtained from CANBERRA [CAN04]. Decays associated with defined radionuclides were then identified by measuring their literature gamma-ray energies. The gamma-ray lines used to determine the radionuclide activities were carefully chosen based on high intensity decay branches and peak energies which were generally free of mutual spectral interferences (i.e. gammaray energy doublets associated with different radionuclides). 


\section{Chapter 4}

\section{Results and Discussions}

\subsection{Detector Characterisation}

\subsubsection{Energy Calibration}

A pre-prepared source standard of ${ }^{232} \mathrm{Th}$ and its decay chain members with gamma-ray energies up to $2.6 \mathrm{MeV}$ and an activity of $1.08 \mathrm{kBq}$, was used to calibrate the germanium detector's energy and full-energy-peak efficiency responses. An example of calibration spectrum, collected for 86,400 s is shown in Figure 4-2. Energy calibration represents the relationship between the MCA channel number and the photon energies. Once energy calibration points have been established over the energy range of interest, a calibration curve relating energy to channel number is derived. Although the calibration curve can be described by the least-square fitting of a polynomial of the form $E_{i}=\sum_{n=0}^{N} a_{n} C_{i}^{n}$, where $E_{i}$ is the energy corresponding to the channel number $C_{i}$ because of the small degree of nonlinearity, the channel number versus energy plot is well described by a linear relationship (see Figure 4-1) over this range.

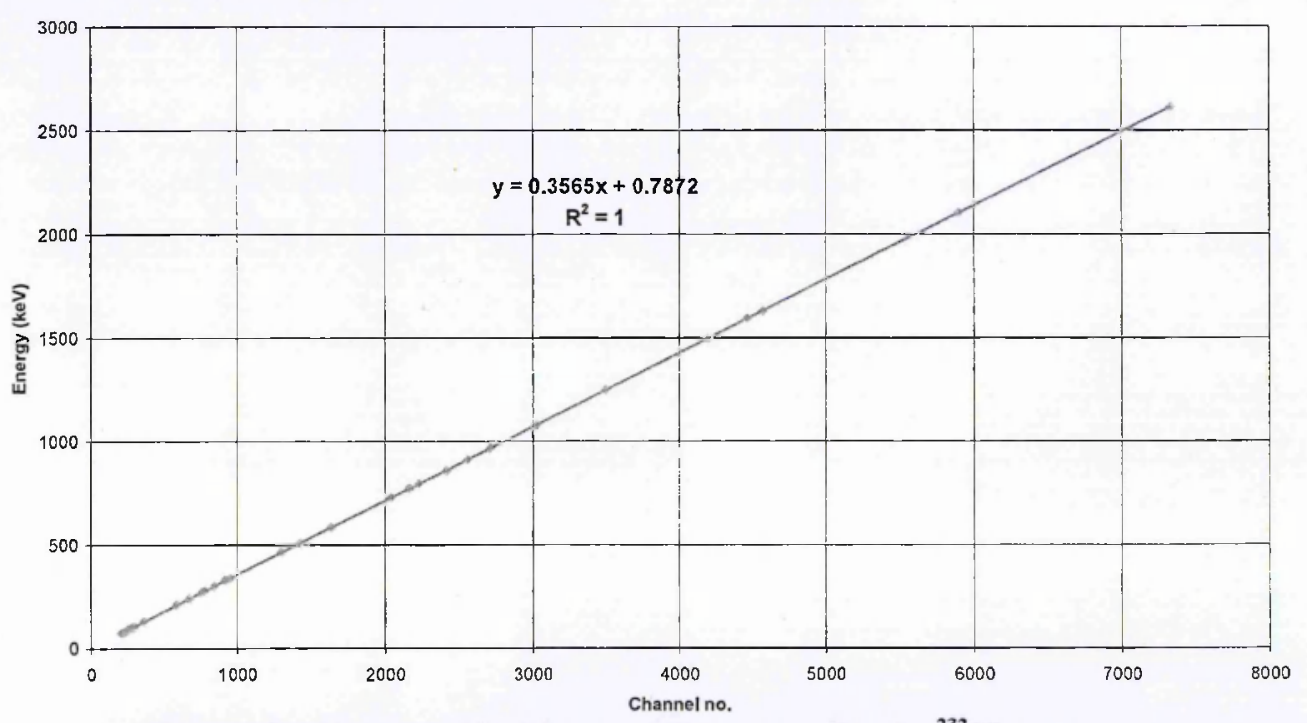

Figure 4-1: Energy calibration response curve using the ${ }^{232} \mathrm{Th}$ source. 


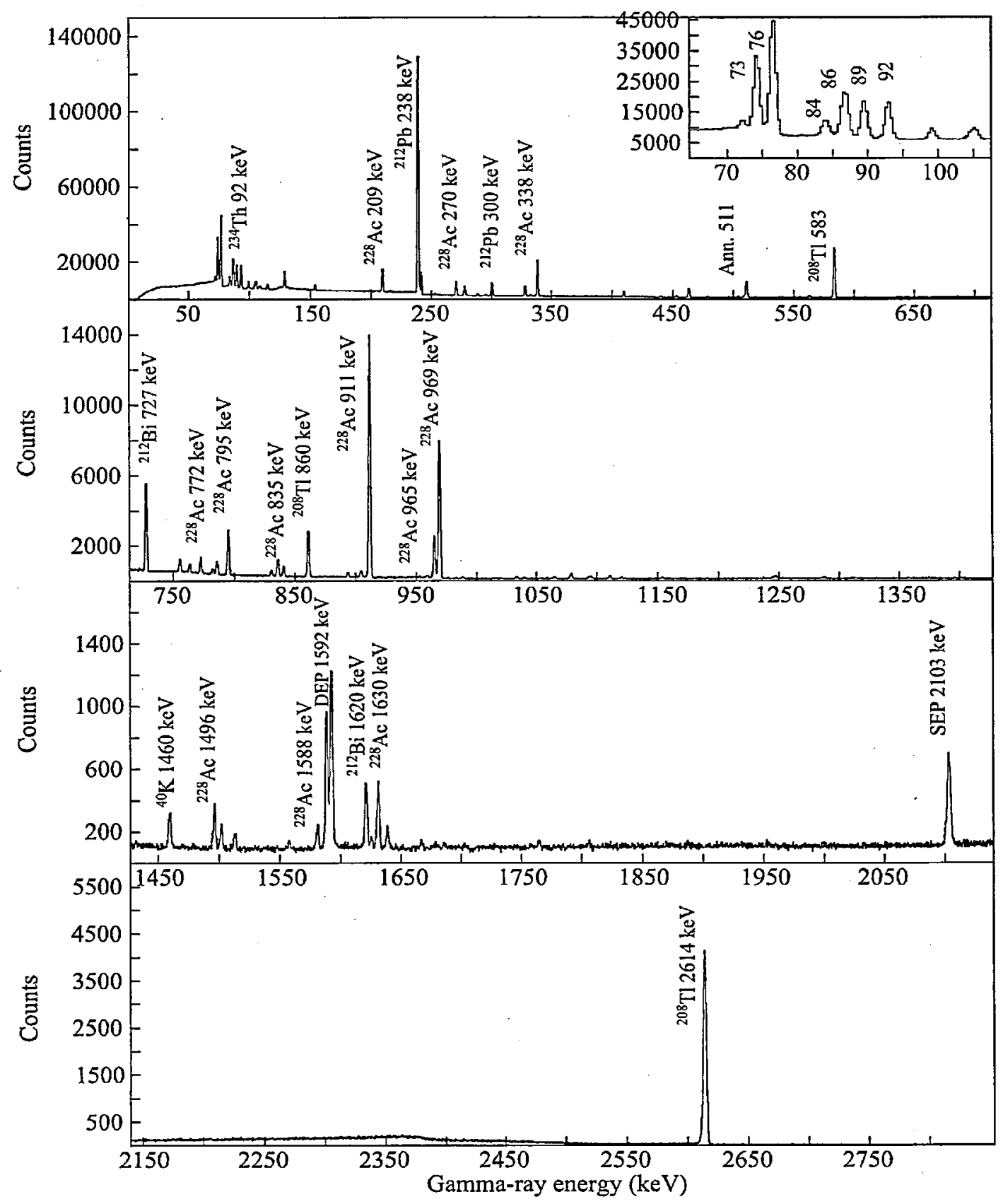

Figure 4-2: ${ }^{232}$ Th calibration spectrum collected for 86400 s.

By measuring the spectrum of the ${ }^{232} \mathrm{Th}$ standard source emitting gamma rays of known, precise energy and comparing these to the measured peak centroid position in channel numbers, the point energies ( $\sim 20$ points) were calibrated. These covered the entire energy range over which the HPGe spectrometer was used. The measured energies are then used to identify the radionuclides in the background and sand samples. The energy calibration has to be recalculated periodically to maintain the correct energy-channel relationship. 


\subsubsection{Detection Efficiency}

Gamma rays must first undergo an interaction in the detector before detection is possible. Since electromagnetic radiation can travel significant distances between successive interactions, germanium detectors are less than 100\% efficient [KNO00]. It thus becomes necessary to have a precise figure for the detector gamma-ray detection efficiency in order to relate the number of pulses counted to the number of photons emitted by the source. In this study, the absolute photopeak efficiency was evaluated using four independent reference sources containing ${ }^{232} \mathrm{Th},{ }^{226} \mathrm{Ra},{ }^{152} \mathrm{Eu}$, and NG3 (a mixed radionuclide containing ${ }^{241} \mathrm{Am},{ }^{109} \mathrm{Cd},{ }^{139} \mathrm{Ce},{ }^{137} \mathrm{Cs},{ }^{60} \mathrm{Co},{ }^{57} \mathrm{Co},{ }^{203} \mathrm{Hg},{ }^{113} \mathrm{Sn},{ }^{85} \mathrm{Sr}$, and $\left.{ }^{88} \mathrm{Y}\right)$.

The absolute photopeak efficiency $\left(\varepsilon_{\imath}\right)$ is defined as [KNO00]:

$\varepsilon_{t}=\frac{C_{t} \times 100 \%}{N_{\gamma}}$

where $C_{t}=$ total number of counts recorded per unit time in the full-energy peak, integrated over the recorded spectrum subtracted by the corresponding background count rate. $N_{\gamma}=$ number of gamma quanta emitted by the source per unit time.

$N_{\gamma}=D_{s} I_{\gamma}\left(E_{\gamma}\right)$

where $D_{s}=$ disintegration rate of the source and $I_{\gamma}\left(E_{\gamma}\right)=$ the fractional number of gammas emitted per disintegration.

In the current work, linear classes of efficiency functions constructed from several sets of independent efficiency data sets were used to fit the absolute full-energy peak efficiency response curve to the polynomial function described by Gray and Ahmed [GRA85]. i.e.,

$$
\left.\varepsilon(E, p)=\left[p_{1}+p_{2} \ln (E)+p_{3} \ln ^{2}(E)+p_{4} \ln ^{3}(E)+p_{5} \ln ^{5}(E)+p_{6} \ln ^{7}(E)\right]\right] / E
$$

where $\varepsilon$ is the absolute full-energy peak efficiency, $E$ represents the gamma-ray energy in $\mathrm{MeV}$ and $p_{1}-p_{6}$ are the function parameters. 
The majority of the data sets which were used to test the series and poly-log classes were obtained by Debertin [DEB79], in the course of an intercomparison of gamma-ray emission-rate measurements, organised by the $\alpha$-, $\beta$-, $\gamma$-ray spectrometry group of the International Committee for Radionuclide Metrology (ICRM). The remaining data sets were obtained from the literature. 38 samples data sets were collected which 32 data sets consisted of measurements made independently on different detector. The remaining six data sets consisted of three unrelated pair; each pair consisted of measurements made on the same detector, over the same energy range, but at different distance. The absolute fullenergy peak efficiency curve as a function of photon energy using this fitting function is shown in Figure 4-3. The spectra for the four standard sources used to detcrmine the absolute full-energy peak efficiency are shown in Appendix C.

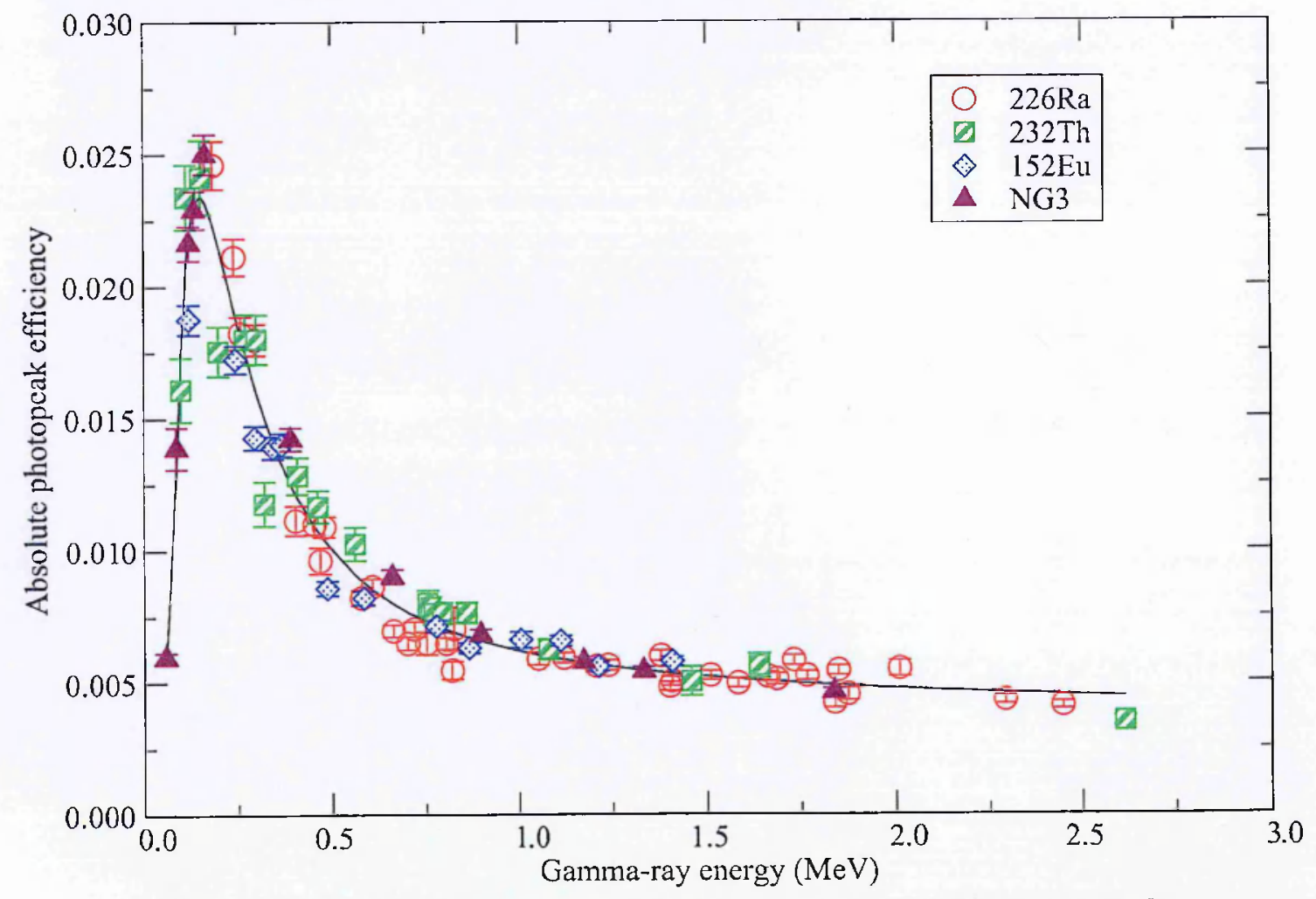

Figure 4-3: Absolute efficiency curve of the detector response used in current work.

From Figure 4-3, it can be seen that the detector has an absolute full-energy peak efficiency less than $2.5 \%$ when the sample was placed directly over the detector (i.e. in the Marinelli beaker geometry). This can be explained by the relative importance of the three gamma-ray major interaction processes in Figure 2-18 and Figure 2-19. The crosssections for the predominant interactions of gamma rays are functions of photon energy 
and the absorber atomic number. At low gamma-ray energies (less than $100 \mathrm{keV}$ ), photoelectric absorption process is dominant when gamma-ray energies interact with the Ge detector $(Z=32)$. In this process, the incident photons transfer all of their energy to bound electrons and are completely absorbed. Between energies of about $100 \mathrm{keV}$ to 1 $\mathrm{MeV}$ for gamma rays, the Compton effect is dominant which caused gamma-ray photons scattered and escape from the detector. At higher gamma-ray energies ( $>5 \mathrm{MeV})$, pair production processes play a significant role.

\subsection{Background Spectrum}

The analysis of a $\gamma$-spectrum is based on an evaluation of the full energy peaks; the analysis software locates the peaks, determines the peak areas (counts) and thereafter calculates peak emission rates (counts per second corrected for detector efficiency), associates peaks with radionuclides, and calculates their activities. It is important to know if the activity of a radionuclide is above a statistical detection threshold. Therefore, the detection limits are also usually determined during the analysis phase [TO100]. Deciding which radionuclides are present involves qualitative analysis and thereafter determining their activities related to quantitative analysis.

The radiation background collected from de-ionised water filled Marinelli beaker 'blanks' was observed for two days to meet the required statistical uncertainty. Identification procedures start by matching the observed peak energies with energies of photon transitions by known radionuclides. The radionuclide types are identified in Table 4-1 and the background spectra observed are shown in Figure 4-4.

Table 4-1: Main X-ray and $\gamma$-ray energy peaks observed in background spectrum.

\begin{tabular}{ccl}
\hline Energy $(\mathrm{keV})^{[\mathrm{GL} 08]}$ & Mother Nuclide Decay & \multicolumn{1}{c}{ Source of Radiation } \\
\hline 63.3 & ${ }^{234} \mathrm{Th}$ & ${ }^{238} \mathrm{U}$ series \\
139.7 & ${ }^{75 \mathrm{~m}} \mathrm{Ge}$ & ${ }^{74} \mathrm{Ge}(\mathrm{n}, \gamma)$ in detector crystal \\
198.4 & ${ }^{7{ }^{7 m} \mathrm{Ge}}$ & ${ }^{70} \mathrm{Ge}(\mathrm{n}, \gamma)$, sum $175.0+23.4$, in detector crystal \\
511.0 & Annihilation & Annihilation radiation $\left(\beta^{+}\right)$ \\
1460.8 & ${ }^{40} \mathrm{~K}$ & Primordial \\
1764.5 & ${ }^{214} \mathrm{Bi}$ & ${ }^{238} \mathrm{U}\left({ }^{226} \mathrm{Ra}\right)$ series \\
2223.3 & ${ }^{2} \mathrm{H}$ & ${ }^{1} \mathrm{H}(\mathrm{n}, \gamma)$, reactions with hydrogenous \\
& & material in the vicinity of the detector \\
2614.5 & ${ }^{208} \mathrm{Tl}$ & ${ }^{232} \mathrm{Th}$ series \\
\hline
\end{tabular}




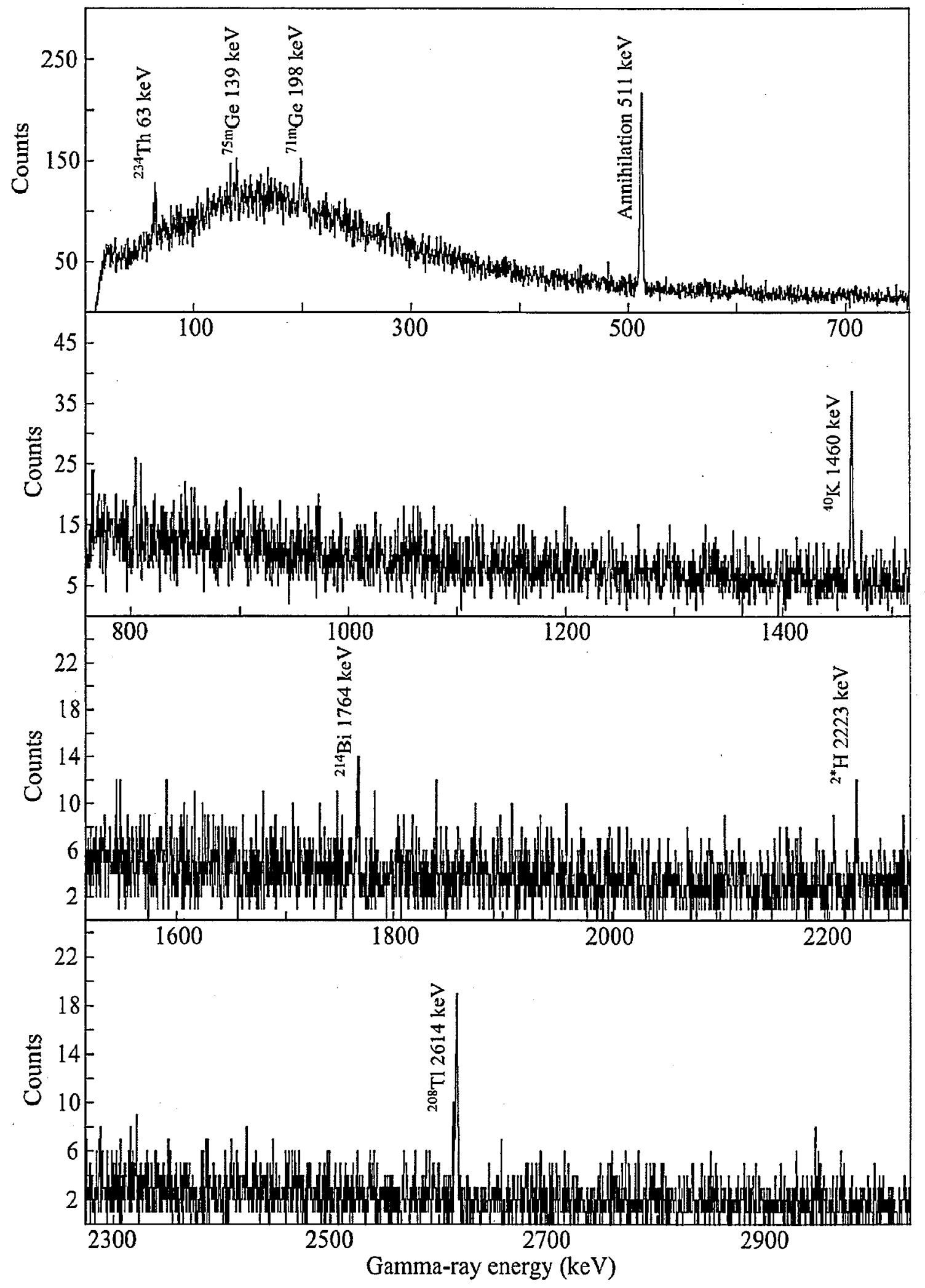

Figure 4-4: Background spectra collected from de-ionised water for 172,800s (i.e. 2 days). 
Figure 4-4 shows the radionuclides observed in the background spectra (i.e., from the deionised water sample) after performing a background count with the new detector set up. The radionuclides as listed in Table 4-1 are mainly from natural occurring radioactive material (NORM). These radionuclides are the progeny of the decay chains headed by ${ }^{238} \mathrm{U},{ }^{232} \mathrm{Th}$ (Figure $2-2$ and 2-3) and the non-series radioisotopes that decay directly to a stable isotope, including ${ }^{40} \mathrm{~K}$. It is therefore a smaller contributor to the natural background dose. The source of the background radionuclides can be classified into three groups: (i) arising from natural occurring radioactive material; (ii) coming from the interaction between cosmic-ray products and component surrounding the detector e.g. water, detector crystal; and (iii) from annihilation radiation when interaction gamma-ray energy is more than $1,022 \mathrm{keV}$.

(i) The $\gamma$-ray lines at energies of 63.3 and $1,764.5 \mathrm{keV}$ arise from ${ }^{234} \mathrm{Th}$ and ${ }^{214} \mathrm{Bi}$ decay $\left({ }^{238} \mathrm{U}\right.$ ) respectively whereas the $\gamma$-ray line at energy $2,614.5 \mathrm{keV}$ comes from ${ }^{208} \mathrm{Tl}$ decay $\left({ }^{232} \mathrm{Th}\right)$. The $\gamma$-ray line at energy of $1,460.8 \mathrm{keV}$ comes from very long-lived ${ }^{40} \mathrm{~K}$ isotope which is present in the cement or concrete block walls surrounding the detector.

(ii) The decay $\gamma$-rays from short half-life isomeric levels (i.e. $139.7 \mathrm{keV}$ in ${ }^{75 \mathrm{~m}} \mathrm{Ge}$ and $198.4 \mathrm{keV}$ in ${ }^{71 \mathrm{~m}} \mathrm{Ge}$ ) are produced by Ge atoms excited by collisions between high-energy neutrons as cosmic-rays reaction products and the components surrounding the detector and even the detector itself [GEH05]. The background spectrum was also observed the reaction ${ }^{1} \mathrm{H}(\mathrm{n}, \gamma){ }^{2} \mathrm{H}$ with a $2,223 \mathrm{keV}$ gamma ray (which is the deuteron binding energy) produced by the neutron reactions with hydrogenous material (i.e. de-ionised water in the Marinelli beaker) in the proximity of the detector [ANSI99].

(iii) Annihilation radiations at $\gamma$-ray energy of $511 \mathrm{keV}$ are created from the pairproduction process when a $\gamma$-ray with an energy of $>1,022 \mathrm{keV}$ interacts with the active volume of a HPGe detector. The resulting positron from positron-electron pair can then combine with a negative electron in the absorbing material. The original positron and electron disappear (i.e. annihilate) and are replaced by two oppositely directed photons.

In this study, no detectable characteristic X-rays above the MDA were found in the background spectrum. A graded shield of a $10 \mathrm{~cm}$ thick lead wall lining with a sheet of copper and tin both on top and the bottom of the castle prevent the characteristic Xrays from the lead-shield excited by background radioactivity being observed. Contaminations of shielding materials, even in small amounts, can cause fluctuations in 
the background when low-level activities are measured (e.g. if the background activity is the same order of magnitude as the source strength). Therefore, refined lead with a graded shield or other special constructions of the shielding are required for the low-level radioactivity measurements [KNO00].

The terrestrial nuclear radiations on the earth since its origin are present in materials like soil, rock, brick, tiles, etc. A 'zero' background radiation level is therefore not possible. The variation of background radiation depends on the mineral content in the ground and the cosmic-ray intensity (which in turn depends on the altitude and latitude). Normally, the external background dose rate varies from about 700-1500 $\mu$ Gy per year [CEM08]. However, significantly higher natural radiation backgrounds than average also found in numerous other places. For example, in Brazil, there are beaches where the background dose rate is as high as $430,000 \mu$ Gy per year [SAK94] and in such a case the shielding is more important in any measurements for reducing the natural gamma-ray background in the area.

\subsection{Detection Limits}

\subsubsection{Critical level $\left(\mathrm{L}_{\mathrm{c}}\right)$ and lower limit of detection (LLD)}

The critical level $\left(\mathrm{L}_{\mathrm{c}}\right)$ or "trigger point" for the counting system calculated by Equation 2.79 is shown in Table 4-2 below. This value represents no actual additional activity present in the sample or no source being present.

Table 4-2 Critical level $\left(\mathrm{L}_{c}\right)$ and lower limit of detection (LLD) for the counting system.

\begin{tabular}{ccccc}
\hline $\begin{array}{c}\text { Radionuclide } \\
\text { (mother) }\end{array}$ & $\begin{array}{c}\text { Energy } \\
\text { (keV) }\end{array}$ & $\begin{array}{c}\text { Lc } \\
\text { (Counts } \pm \text { ) }\end{array}$ & $\begin{array}{c}\text { LLD above } \\
\text { background } \\
\text { (Counts) }\end{array}$ & $\begin{array}{c}\text { LLD gross net } \\
\text { count } \\
\text { (Counts) }\end{array}$ \\
\hline${ }^{234} \mathrm{Th}$ & 63.3 & 28 & 59 & 204 \\
${ }^{75 \mathrm{~m}} \mathrm{Ge}$ & 139.7 & 32 & 66 & 251 \\
${ }^{71 \mathrm{~m}} \mathrm{Ge}$ & 198.3 & 41 & 85 & 397 \\
${ }^{40} \mathrm{~K}$ & 1460.8 & 30 & 63 & 232 \\
${ }^{214} \mathrm{Bi}$ & 1764.5 & 22 & 47 & 137 \\
${ }^{2} \mathrm{H}$ & 2223.3 & 15 & 33 & 76 \\
${ }^{208} \mathrm{Tl}$ & 2614.5 & 26 & 54 & 176 \\
\hline
\end{tabular}


From Table 4-2, the critical level $\left(\mathrm{L}_{\mathrm{c}}\right)$, the lower limit of detection (LLD) above background for this counting system lies at 15 to 41 counts and 33 to 85 counts for ${ }^{2} \mathrm{H}$ $(2223.3 \mathrm{keV})$ and ${ }^{71 \mathrm{~m}} \mathrm{Ge}(198.3 \mathrm{keV})$ respectively. This means that if the number of the net counts recorded with the sand samples is less than the critical level $\left(\mathrm{L}_{\mathrm{c}}\right)$, it can be concluded that the samples do not contain any measureable activity with the current experimental set up. In terms of statistics, under this condition (at the $95 \%$ confidence level) there is a $5 \%$ chance that an excess activity is measured when there actually none really present (a so-called 'false positive'). If the number of the net counts recorded from the sand samples exceeds the critical level (Lc), it is assumed that some level of real excess activity is present. Any conclusions that no activity is present are based on a $5 \%$ false negative chance. Whereas the critical levels represent the significant of the net counts, the lower limit of detection (LLD) is interpreted as the minimum number of counts needed from the source to ensure detection.

\subsubsection{Minimum Detectable Activity (MDA)}

The minimum detectable activity (MDA) for each radionuclide was determined from the background radiation spectrum for the same counting time as for the sand samples. The values were calculated using equation 2.81 and are summarized in Table 4-3. The minimum detectable activity (MDA) depends on the counting efficiency of the detector and the emission probability per disintegration of the selected gamma line.

Table 4-3 The minimum detectable activity (MDA) for the counting system.

\begin{tabular}{|c|c|c|c|c|c|}
\hline $\begin{array}{l}\text { Radio- } \\
\text { nuclide }\end{array}$ & $\begin{array}{l}\text { Energy } \\
(\mathrm{keV})\end{array}$ & $\begin{array}{c}\text { \%Emission } \\
\text { Probability }^{[\text {[WH07] }}\end{array}$ & $\begin{array}{l}\text { Measured absolute full- } \\
\text { energy peak efficiency }\end{array}$ & $\begin{array}{c}\text { MDA above } \\
\text { background }(B q)\end{array}$ & $\begin{array}{l}\text { MDA gross net } \\
\text { count }(\mathbf{B q})\end{array}$ \\
\hline${ }^{234} \mathrm{Th}$ & 63.3 & $4.1 \pm 0.7$ & $0.0064 \pm 0.0005$ & $1.30 \pm 0.24$ & $4.49 \pm 0.84$ \\
\hline${ }^{75 \mathrm{~m}} \mathrm{Ge}$ & 139.7 & $\operatorname{IT}(47.7 \mathrm{~s})$ & - & - & - \\
\hline${ }^{7 \mathrm{Im}} \mathrm{Ge}$ & $198.4 \sum \mathrm{E}$ & 2. $\rightarrow 1 . \rightarrow 0$. & - & - & - \\
\hline${ }^{40} \mathrm{~K}$ & 1460.8 & $10.67 \pm 0.13$ & $0.0051 \pm 0.0005$ & $1.56 \pm 0.05$ & $5.75 \pm 0.19$ \\
\hline${ }^{214} \mathrm{Bi}$ & 1764.5 & $15.1 \pm 0.2$ & $0.0052 \pm 0.0002$ & $0.96 \pm 0.03$ & $2.81 \pm 0.09$ \\
\hline${ }^{2} \mathrm{H}$ & 2223.3 & - & - & - & - \\
\hline${ }^{208} \mathrm{Tl}$ & 2614.5 & $35.64 \pm 0.06$ & $0.0035 \pm 0.0002$ & $0.76 \pm 0.02$ & $2.48 \pm 0.07$ \\
\hline
\end{tabular}


From Table 4-3, the minimum detectable activity (MDA) above background for the counting system ranged from $0.76 \pm 0.02 \mathrm{~Bq}$ for ${ }^{208} \mathrm{Tl}$ to $1.56 \pm 0.05 \mathrm{~Bq}$ for ${ }^{40} \mathrm{~K}$. These values show the smallest amount of radioactivity that can be detected and distinguished from the blank.

\subsection{Secular Equilibrium in Beach Sand Samples}

Natural disturbance, sample collection and preparation may all cause disequilibrium in beach sand samples; therefore the prepared samples were sealed and stored in Marinelli beakers for one month to allow secqular equilibrium. To avoid any mis-estimation of ${ }^{226} \mathrm{Ra}$ and ${ }^{232} \mathrm{Th}$ due to radon escape from the sand samples, this study also measured whether the radioactive equilibrium of radium precursors and their radon progeny and associated decay products had been established in the sand samples.

The sand sample was used to investigate radioactive equilibrium collected from Hat Sai $\mathrm{Ri}$ beach (CPHSR-1) in Chumporn province on the east coast of Thailand as seen in Figure 4-5.

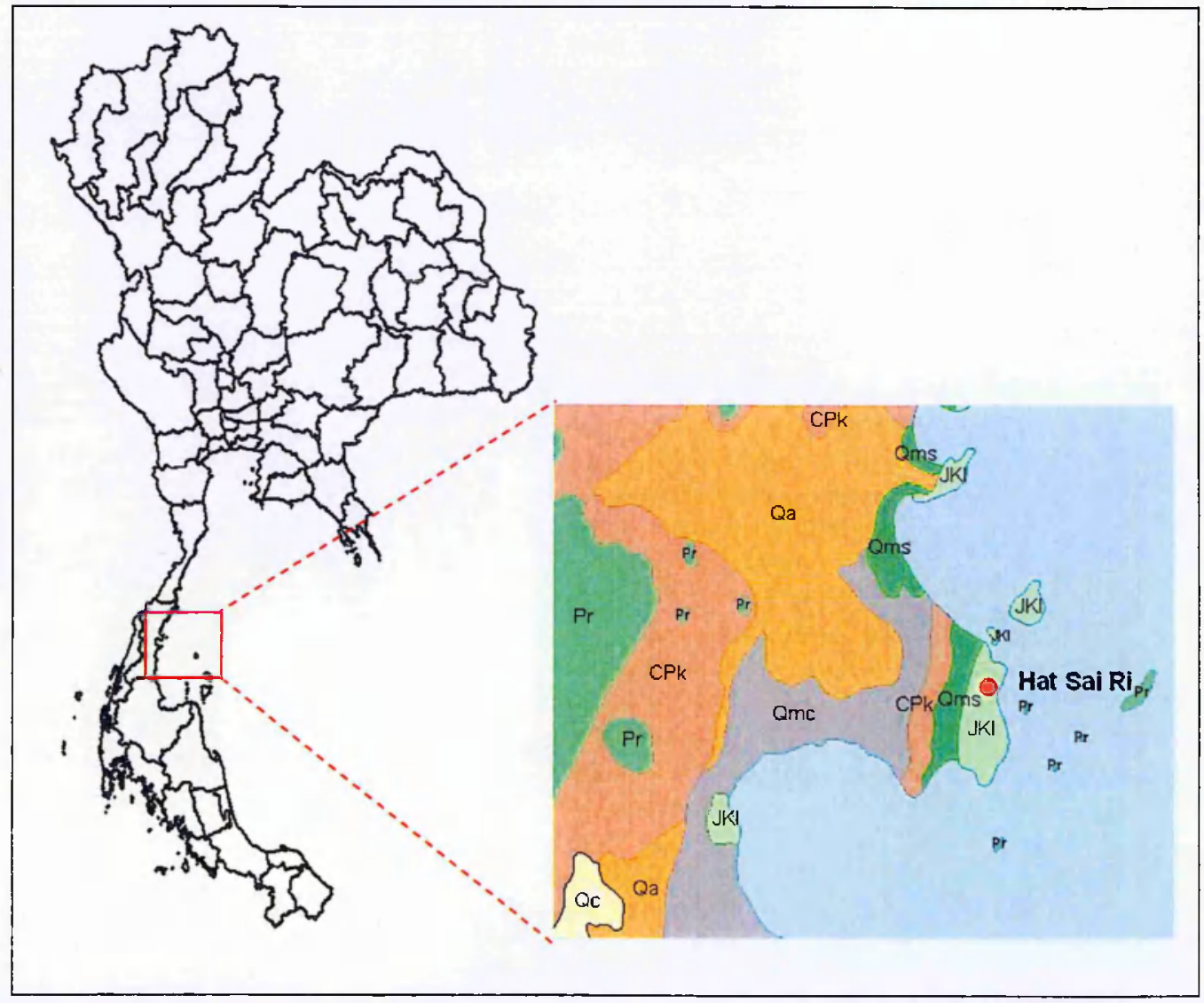

Figure 4-5: Map showing sampling point from Hat Sai Ri beach in Chumporn province. 
The sampling point is located at latitude $10^{\circ} 23^{\prime} 51.5^{\prime \prime} \mathrm{N}$ and longitude $99^{\circ} 16^{\prime} 47.9^{\prime \prime} \mathrm{E}$ recorded by Global Positioning System (GPS). The study area consists of arkosic and lithic sandstone, mudstone, siltstone, cross-bedded, conglomerate and sandstone affected by the Jurassic formations.

The sample was then prepared following the stages of sample preparation. Use was made of the hyper-pure germanium coaxial detector-based gamma-ray spectroscopy low background counting system with the set up as described in section 3.2. After an energy calibration was performed, the CPHSR-1 sample collected at the beach front was then measured every day for eight days and then every week for one month to investigate growth curves of total activity in the uranium and thorium chains. The growth in curves of gamma-ray energies in ${ }^{232} \mathrm{Th}$ and ${ }^{238} \mathrm{U}$ decay series from studied sand sample as a function of time are also shown in Figure 4-6 followed by the spectrum of the 'Sai Ri' beach sand sample collected for 172,800s and background subtracted in Figure 4-7.

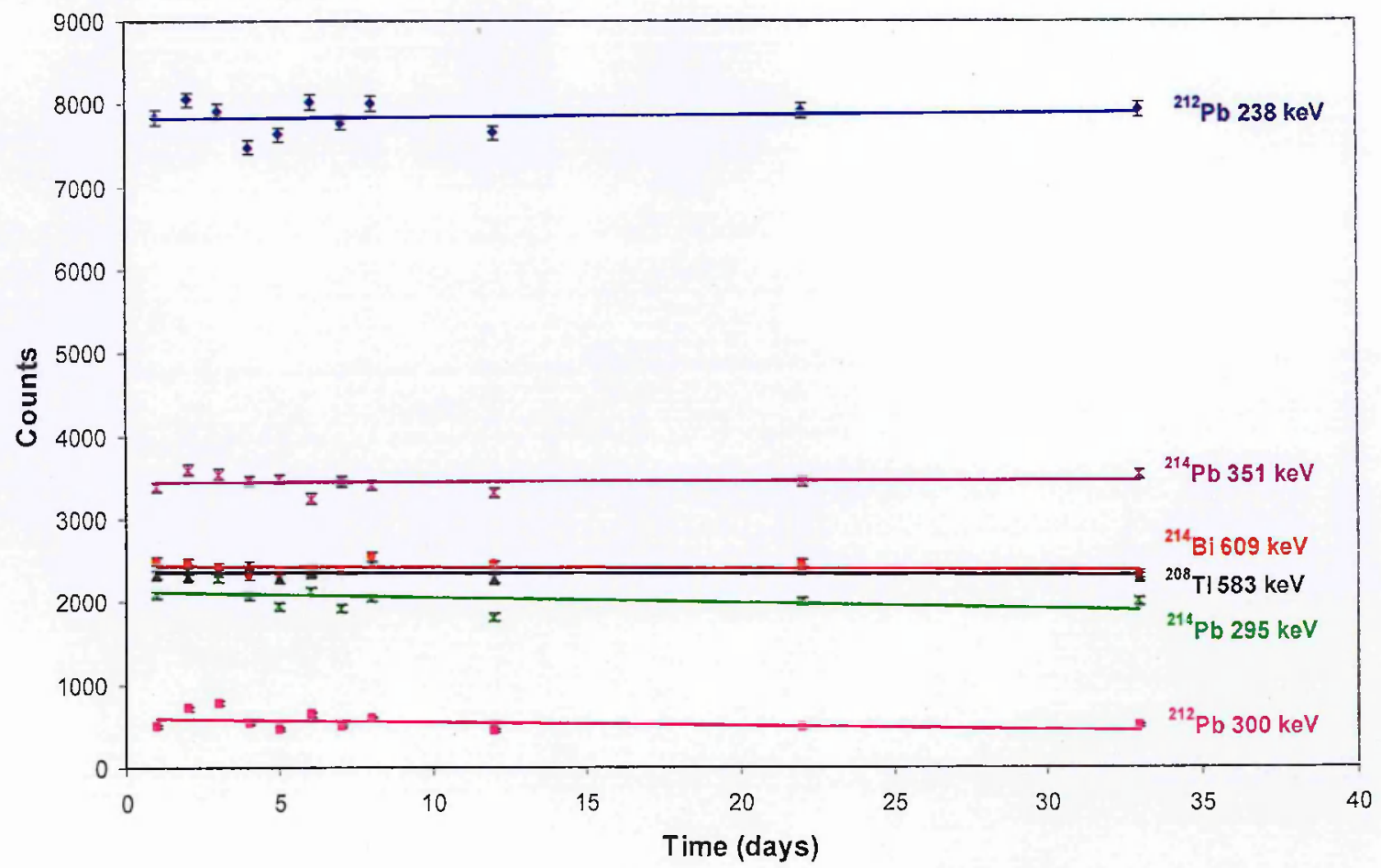

Figure 4-6: Growth in curves of some gamma-ray energies associated with the ${ }^{232} \mathrm{Th}$ and ${ }^{238} \mathrm{U}$ decay series from studied sand sample as a function of time. 


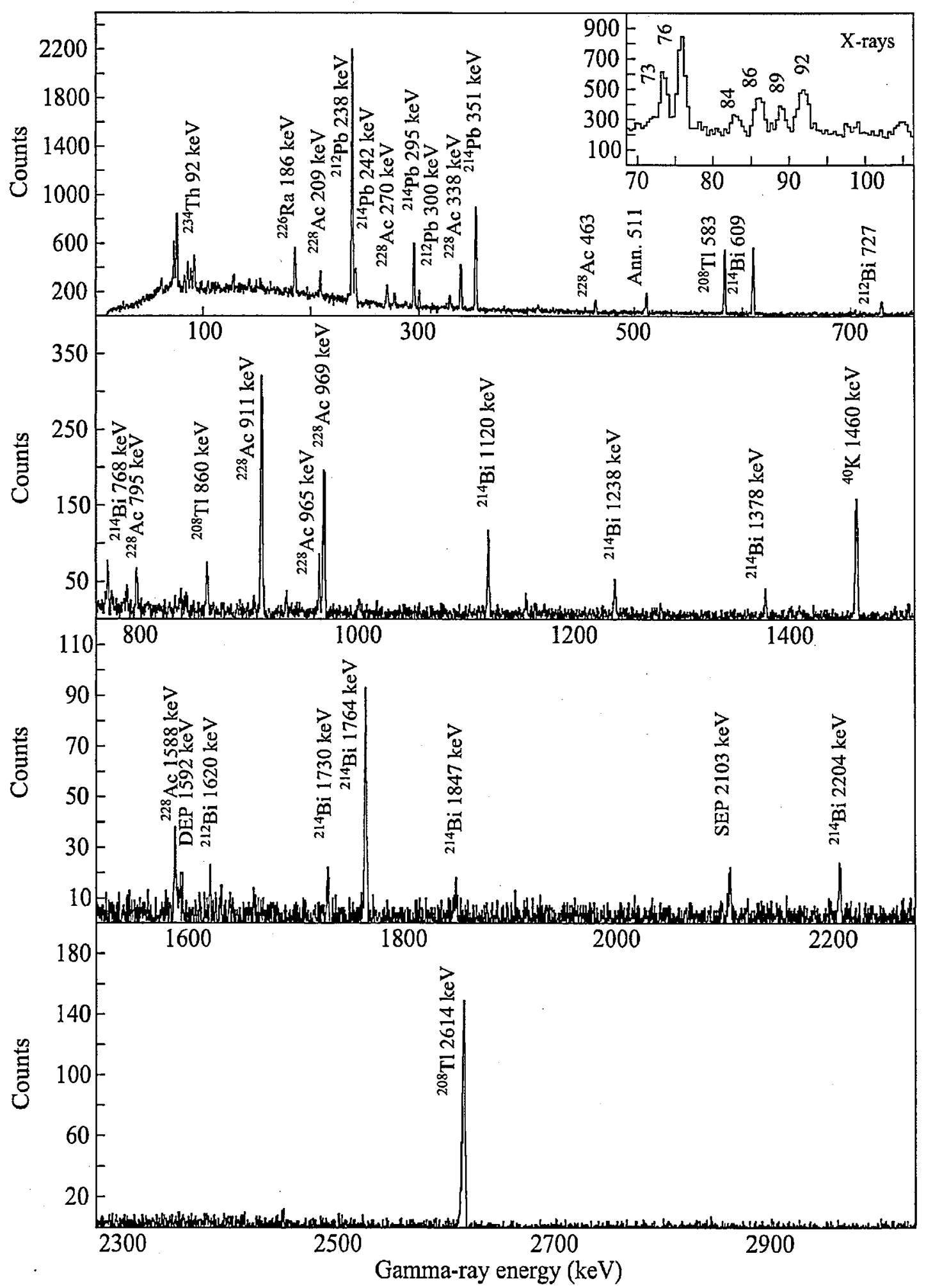

Figure 4-7: Gamma-ray spectrum of the 'Sai Ri' beach sand sample subtracted background collected for 172,800 s (i.e. 48 hours). 
With regard to radon loss, ${ }^{222} \mathrm{Rn}$ which has a 3.8 day half-life should take approximately 27 days to reach equilibrium with its parent $\left({ }^{226} \mathrm{Ra}\right)$ in the uranium chain while ${ }^{220} \mathrm{Rn}$ has only a 55.6 second half-life and would rapidly grow into its parent $\left({ }^{224} \mathrm{Ra}\right)$ in the thorium chain. Any radon loss would underestimate the interpreted ${ }^{226} \mathrm{Ra}$ content. As such, in the present study, the samples were sealed with PVC tape. In-growth of the short-lived progeny ${ }^{212} \mathrm{~Pb}(238 \mathrm{keV}$ and $300 \mathrm{keV}),{ }^{208} \mathrm{Tl}(583 \mathrm{keV})$ in the thorium chain and ${ }^{214} \mathrm{~Pb}(295 \mathrm{keV}$ and $351 \mathrm{keV})$ and ${ }^{214} \mathrm{Bi}(609 \mathrm{keV})$ in the uranium chain, from the first to eighth day and over periods of 12, 22 and 33 days after sample preparation, are shown in Figure 4-7. The small differences in the activity of each growth curve as a function of time may result from accumulation of bismuth and lead in natural sand samples leading to rapid approach to activity equilibrium with the respective parents. In addition, it might be expected that the only appreciable radon loss would be from the surfaces of a sand sample, the bulk being retained within the body of the sample. Comparison of the activity of ${ }^{212} \mathrm{~Pb}$ and ${ }^{212} \mathrm{Bi}$ from the thorium chain and ${ }^{214} \mathrm{~Pb}$ and ${ }^{214} \mathrm{Bi}$ in the uranium chain, 33 days after sample preparation, indicates that the radioactive equilibrium was maintained and that there was no significant, measureable loss of any the decay products during sample storage. The decay progeny that follow ${ }^{226} \mathrm{Ra}$ and ${ }^{224} \mathrm{Ra}$ in the decay chains would therefore also achieve this equilibrium.

It can be noted that although it would take about 27 days for ${ }^{222} \mathrm{Rn}$ to achieve equilibrium with its parent, only ${ }^{222} \mathrm{Rn}$ decay products were measured and thus radioactive equilibrium can be approached in about 2 hours under normal circumstances [EIS97]. As the longest half-life of radionuclides prior to ${ }^{210} \mathrm{~Pb}$ in the uranium chain is ${ }^{214} \mathrm{~Pb}$ which has a half-life of 26.8 minutes, radioactive equilibrium was achieved in a short period of time, of the order of a few hours. The presence of ${ }^{210} \mathrm{~Pb}\left(t_{1 / 2}=22\right.$ years $)$ resulting in the further growth is relatively slow and difficult to observe. In the thorium decay chain, there are no long-lived radionuclides after ${ }^{220} \mathrm{Rn}$. Therefore, reaching equilibrium of ${ }^{220} \mathrm{Rn}$ and its decay products only influenced by the time required for the build-up of ${ }^{212} \mathrm{~Pb}\left(t_{1 / 2}=10.6\right.$ hours $)$. 


\subsection{Radioactivity Distribution}

Beach sand samples were collected from 10 different beaches along the east and the west coast of Thailand at the following locations; (i) Hat Khoa Lak in Phang-Nga province (PNKL), (ii) Hat Nai Ton (PKNT), (iii) Hat Patong (PKPT), (iv) Hat Kata Noi (PKKT) in Phuket province, (v) Hat Chaweng in Samui Island (SMCW), (vi) Hat Kho Ma (KPNKM), (vii) Hat Rinnok (KPNRN) in Phangan Island, Suratthani province, (viii) Hat Laem Son (CPLS), (ix) Hat Sai Ri (CPHSR) in Chumporn province, and (x) Hat Khanom in Nakornsrithammarat province (NSKN) (see Figures 3-2 \& 3-3). Three sand samples were collected from each beach at the different distances from the seashore i.e. at the beachfront, 10 and 20 metres. After the samples were prepared and sealed by PVC tape for one month, each sand sample was then counted for 178,200 s (i.e. 2 days). The activity concentrations of ${ }^{226} \mathrm{Ra},{ }^{232} \mathrm{Th}$ and ${ }^{40} \mathrm{~K}$ in beach sand samples were determined to investigate the radioactivity distribution in beach sand samples as a function of the distance from the seashore, as shown in Figure 4-8, 4-9 and 4-10 respectively.

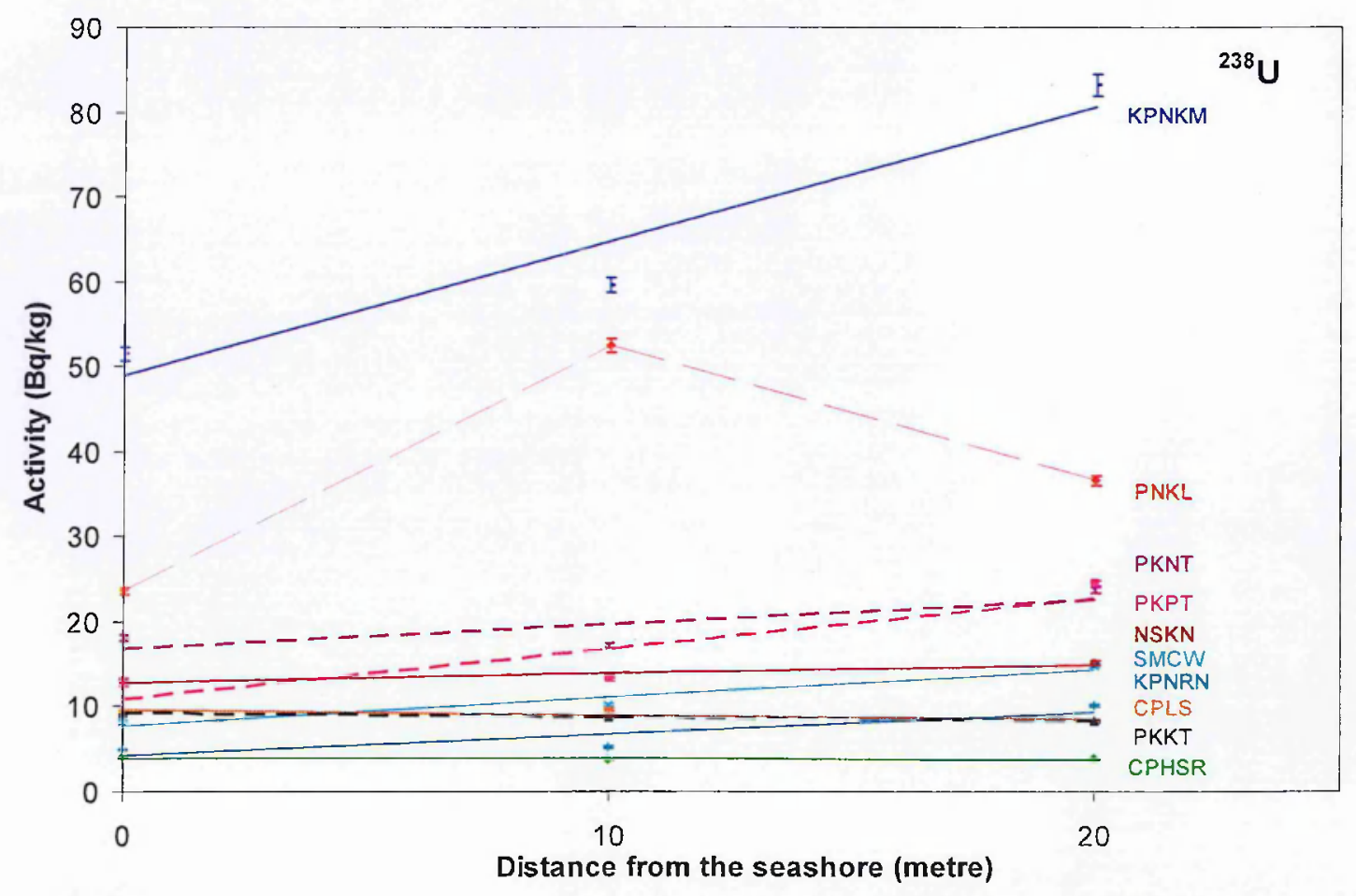

Figure 4-8: Radioactivity distribution in ${ }^{238} \mathrm{U}$ decay series nuclei from studied sand samples as a function of distance from the seashore. 


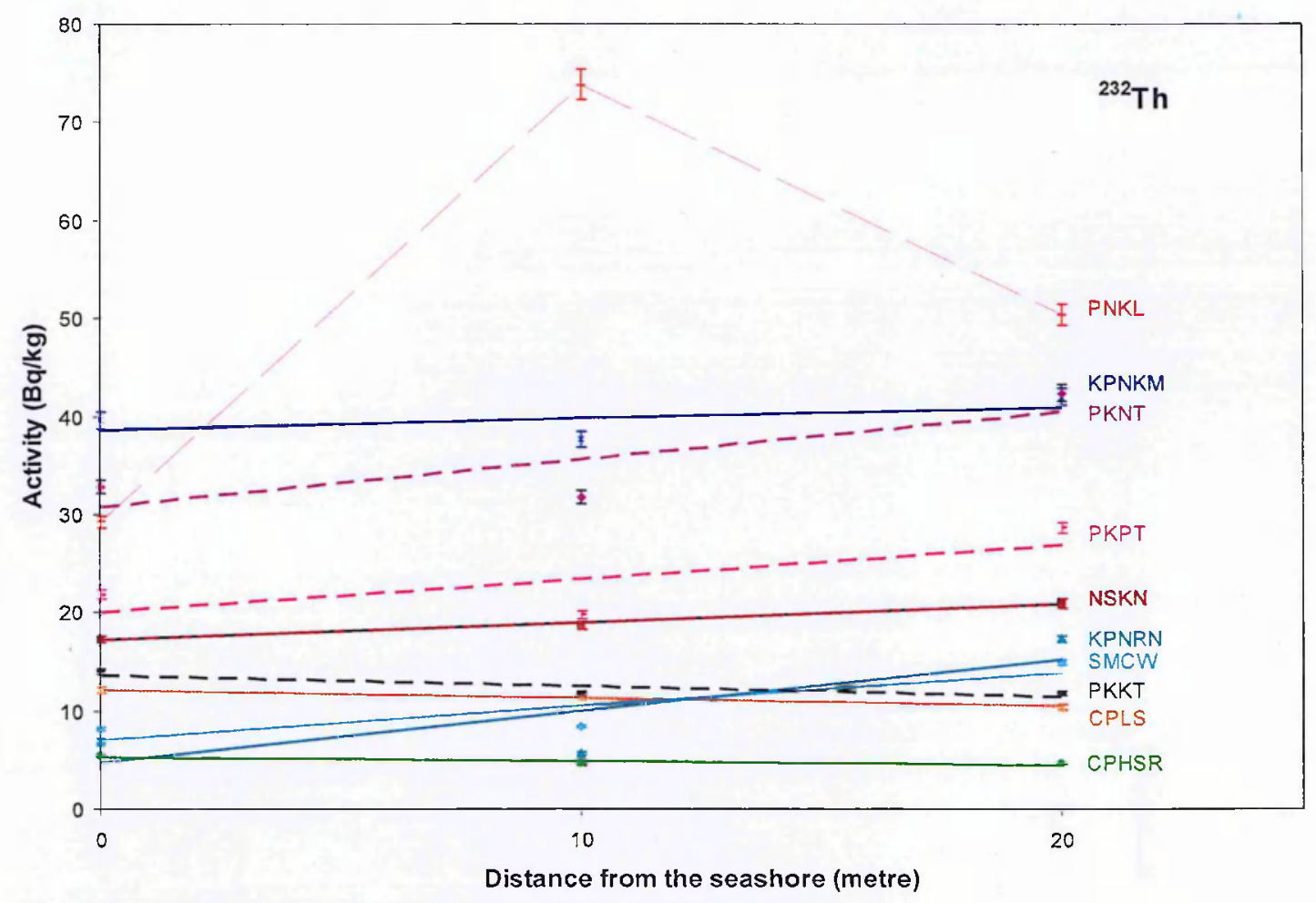

Figure 4-9: Radioactivity distribution in ${ }^{232}$ Th decay series nuclei from studied sand samples as a function of distance from the seashore.

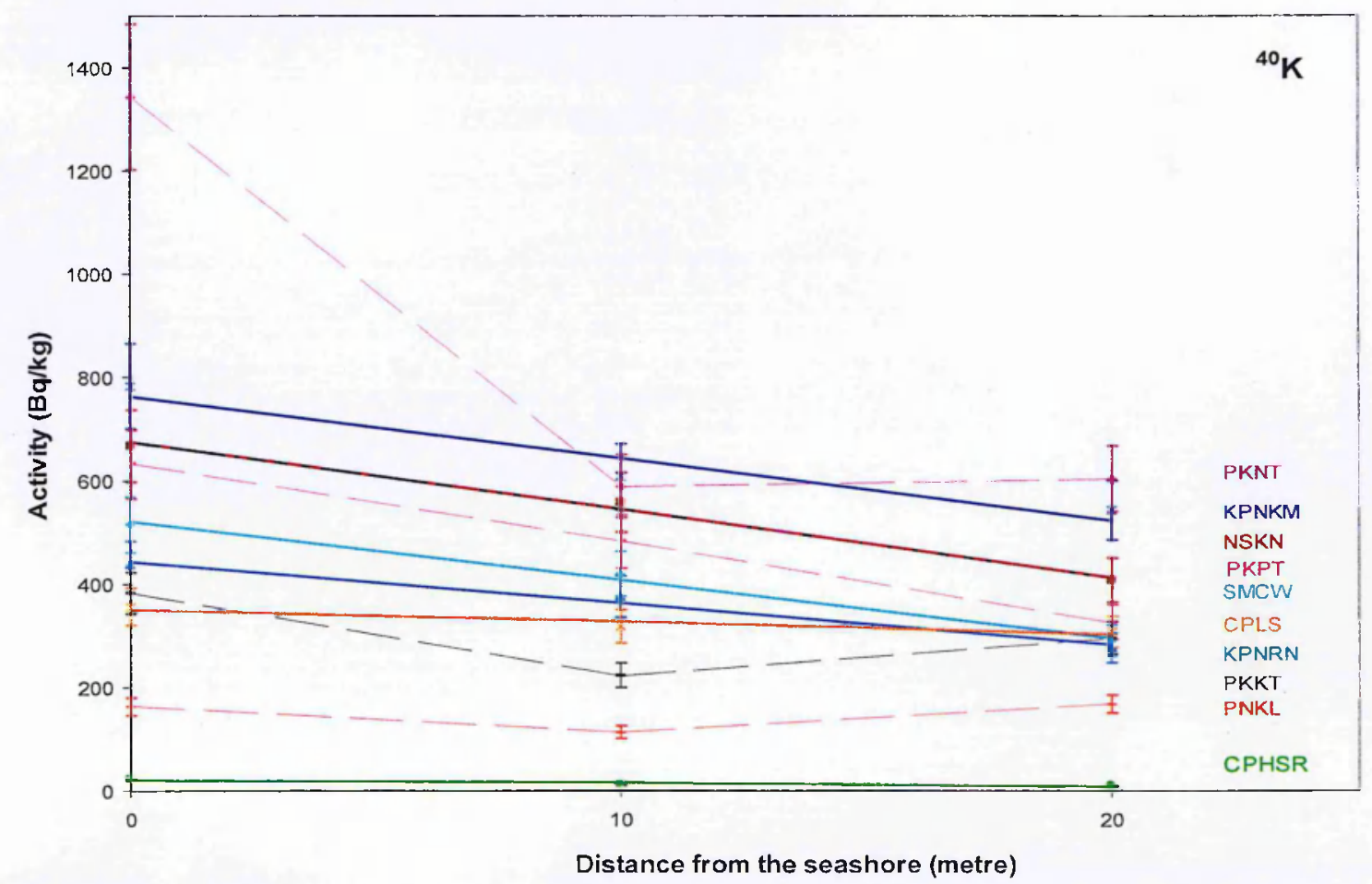

Figure 4-10: Radioactivity distribution in ${ }^{40} \mathrm{~K}$ decay from studied sand samples as a function of distance from the seashore. 
Figure 4.8 and 4.9 show that the activity concentrations of ${ }^{226} \mathrm{Ra},{ }^{232} \mathrm{Th}$ at the beachfront are comparable to that at 10 and 20 metre distances from the seashore. However, the difference of the activity in 'Khoa Lak' samples (PNKL) at each distance is somewhat higher than in others. The activities of ${ }^{226} \mathrm{Ra}$ and ${ }^{232} \mathrm{Th}$ at 10 metres are twice than that at the beachfront and 20 metres from the seashore. Since the sample was collected from the surface, some organic matter such as crushed seashells or wood sticks could have a significant impact to the level of radioactivity in the studied samples.

A relative high activity associated with the ${ }^{238} \mathrm{U}$ decay chain is obtained in the 'Kho Ma' sample (KPNKM) collected 20 metres from the beachfront. This might be explained by the fact that the position used to collect the sample was close to soil. Therefore, the composition of this sample had more beach soil sand than others. Figure 4.10 shows that the activity concentration of ${ }^{40} \mathrm{~K}$ from the beach sand collected at 10 metres is the same as that at 20 metres, while the activity concentration of ${ }^{40} \mathrm{~K}$ at the beach front is significantly higher, particularly in the "Nai Thon" sample (PKNT). This may be because at the beachfront was 'washed-out' by potassium contained in the ocean waters which was then deposited on the sand surface at the seashore.

The variation radioactivity in samples also depends on the grain size of the samples, the mineral composition of the original material and the combined processes of solution and adsorption during the process of sedimentation [HOO47].

\subsection{Phuket Island}

Phuket is the biggest island in Thailand and is located in the Andaman Sea off southern Thailand (see Figure 3-2). It is one of the most popular tourist areas because of white beach sand, long and wide beaches, with a very well known beach among Thai and foreign tourists known as 'Patong' beach. The west side of Phuket Island was hit by a tsunami in December 2004 causing a severe damage in many areas and bringing sediment from the sea floor onto the beaches of western Phuket. In the current study, eight beach sand samples were collected from the beachfronts from different beaches around the island namely; Hat Mai Kao, Hat Nai Thon, Hat Surin, Hat Patong, Hat Kata Noi, Hat Rawai, Hat Chalaong, and Hat Ao Po (see Figure 4-11). The radioactivity levels of ${ }^{226} \mathrm{Ra}$, ${ }^{232} \mathrm{Th}$ and ${ }^{40} \mathrm{~K}$ from the west side of the island (which was hit by tsunami) were then compared to the measurements to the east side of Phuket (which was not exposed in 
tsunami). The spectra of beach sand samples from eight different locations are shown in Figure 4-12 to Figure 4-19.

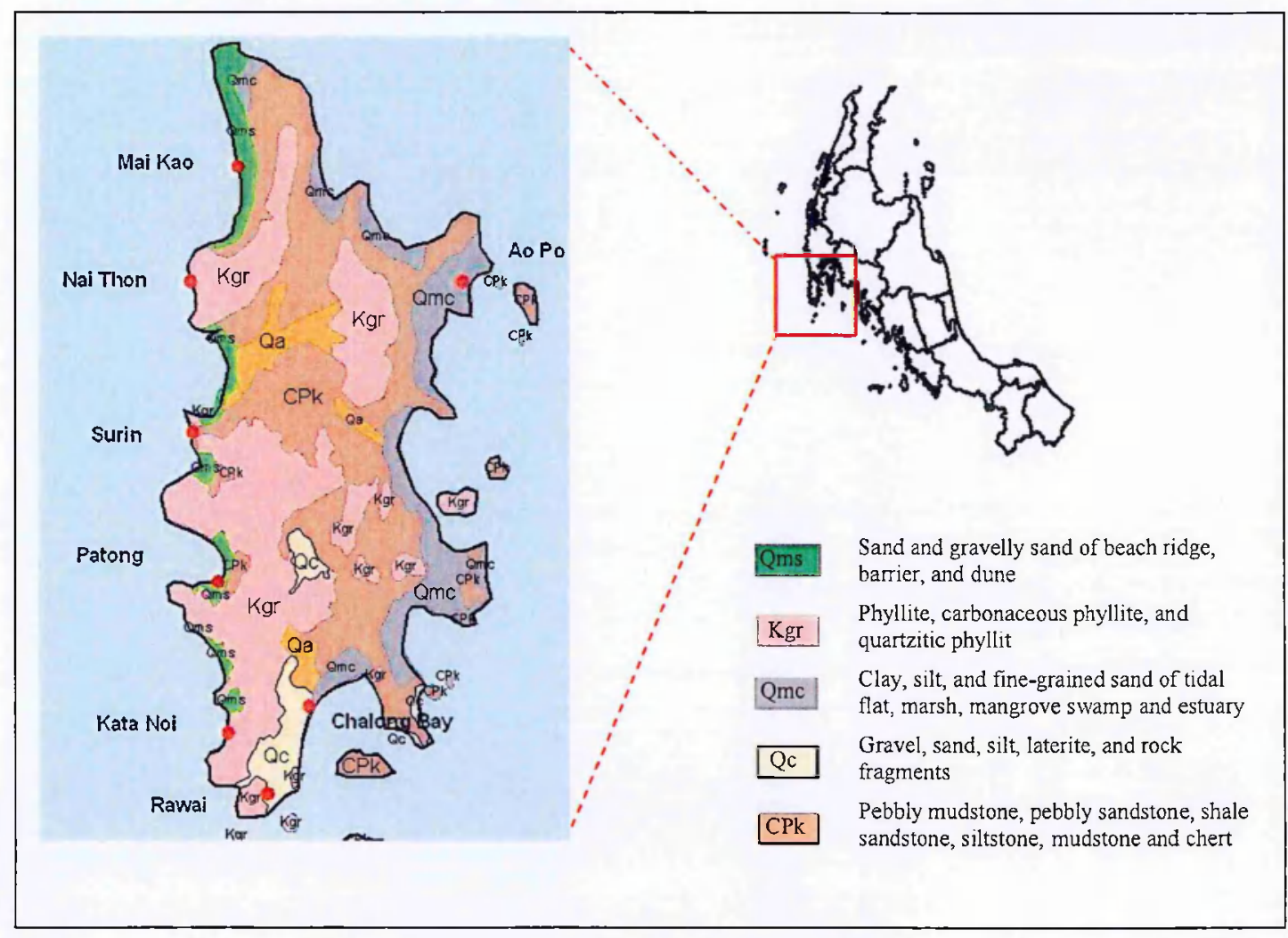

Figure 4-11: Geological map showing sampling points around Phuket Island.

\subsubsection{Sample Spectrum}

Figure 4-12 to 4-19 show the spectra of the radionuclides observed in the beach sand samples. The radioactivity in the sand samples comes from naturally occurring isotopes of uranium and thorium and their daughter products, plus ${ }^{40} \mathrm{~K}$. The decay from the radionuclides ${ }^{234} \mathrm{Th},{ }^{226} \mathrm{Ra},{ }^{214} \mathrm{~Pb}$ and ${ }^{214} \mathrm{Bi}$ identified in these spectra are the progeny in uranium decay chain headed by ${ }^{238} \mathrm{U}$, while ${ }^{212} \mathrm{~Pb},{ }^{228} \mathrm{Ac}$ and ${ }^{208} \mathrm{Tl}$ are the progeny in thorium decay chain headed by ${ }^{232} \mathrm{Th}$. No evidence for artificial radionuclides above the MDA was found in these sand samples (i.e. ${ }^{137} \mathrm{Cs}$ ). Note that the single-escape peak and double escape peaks associated with the $2,614 \mathrm{keV}$ decay associated with ${ }^{208} \mathrm{Tl}$ are also evident in the spectrum at energies of 2,103 and $1,592 \mathrm{keV}$ respectively. 


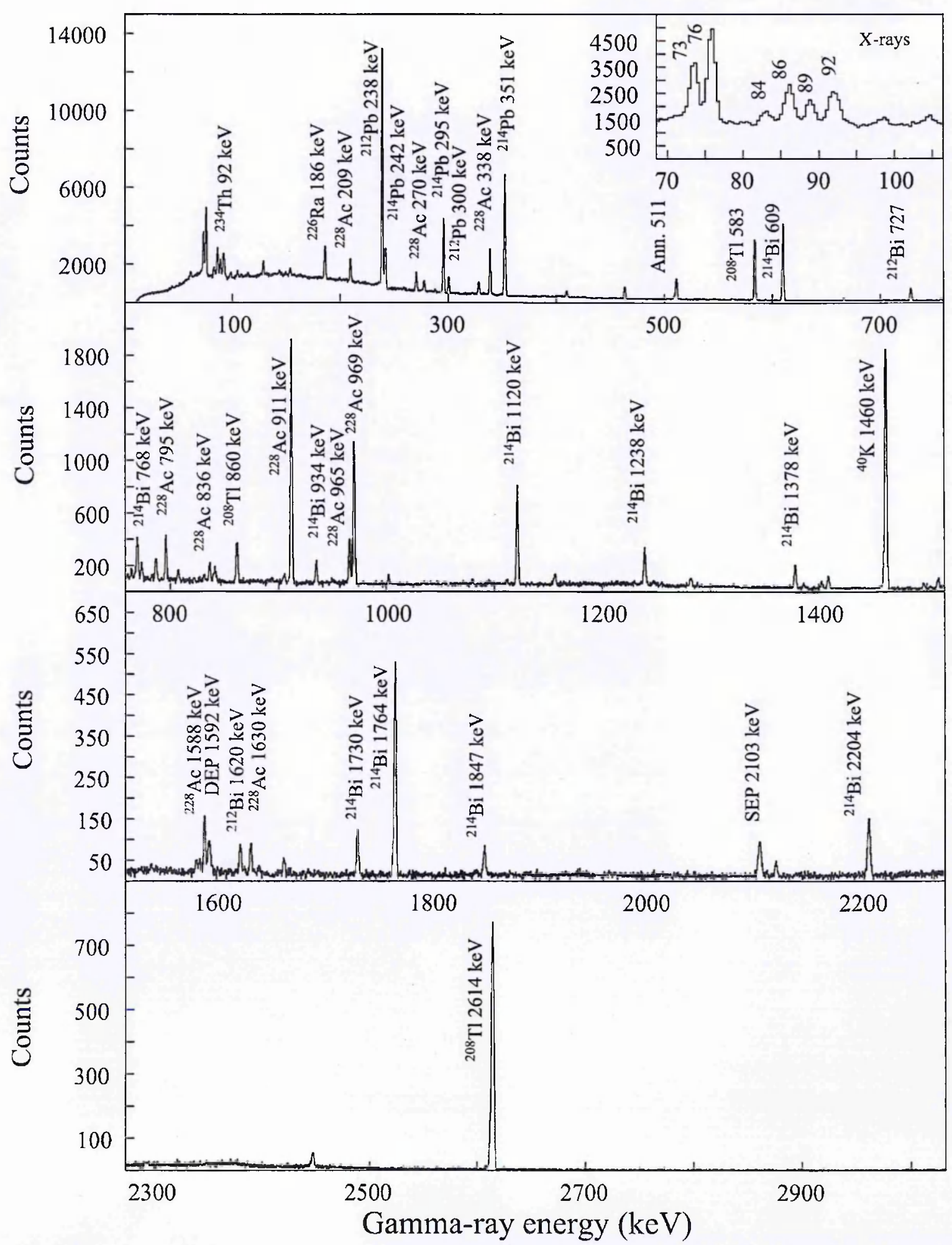

Figure 4-12: Gamma-ray spectrum of the 'Mai Kao' beach sand sample subtracted background collected for 172,800 s (i.e. 48 hours). 


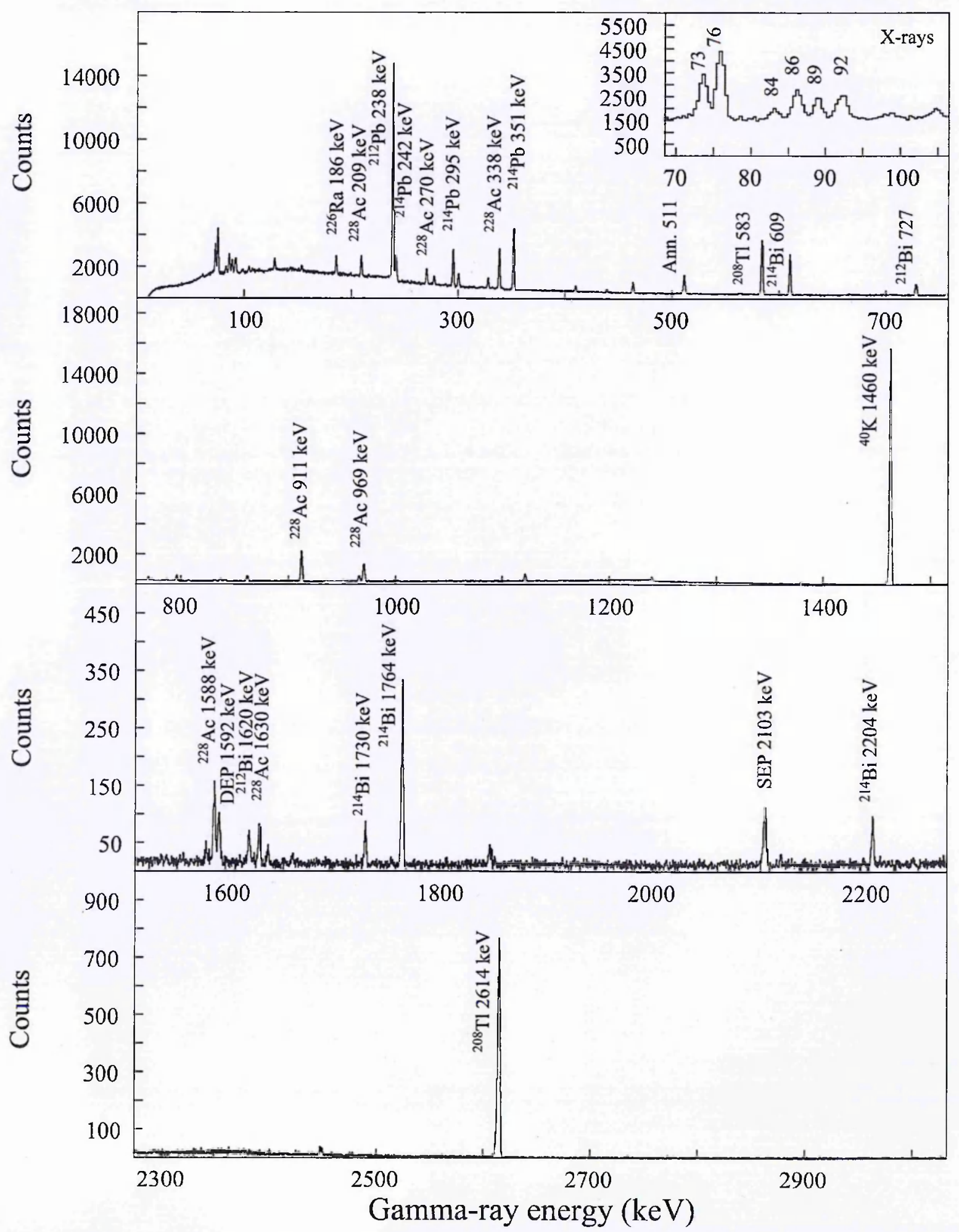

Figure 4-13: Gamma-ray spectrum of the 'Nai Ton' beach sand sample subtracted background collected for 172,800 s (i.e. 48 hours). 


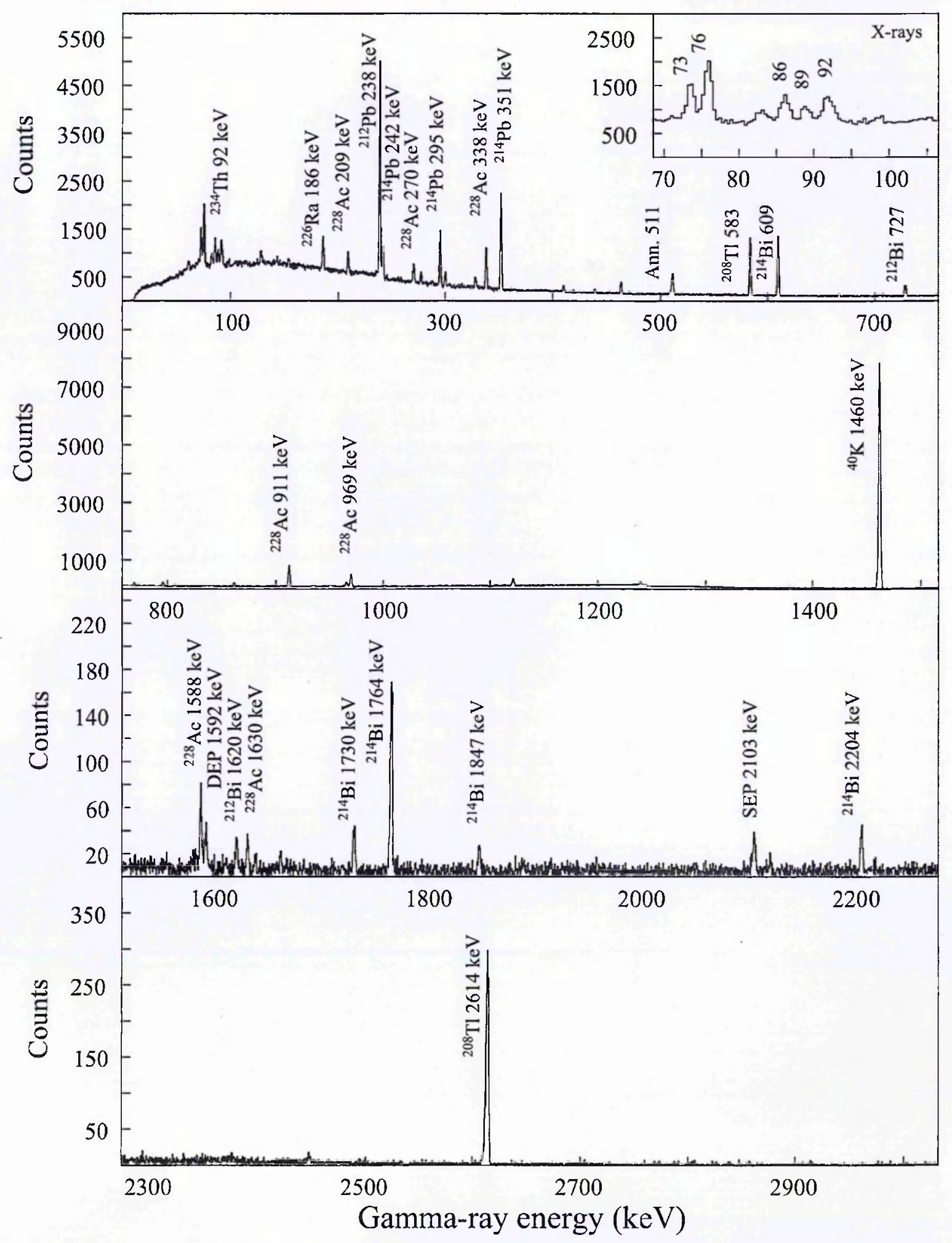

Figure 4-14: Gamma-ray spectrum of the 'Surin' beach sand sample subtracted background collected for 172,800 s (i.e. 48 hours). 


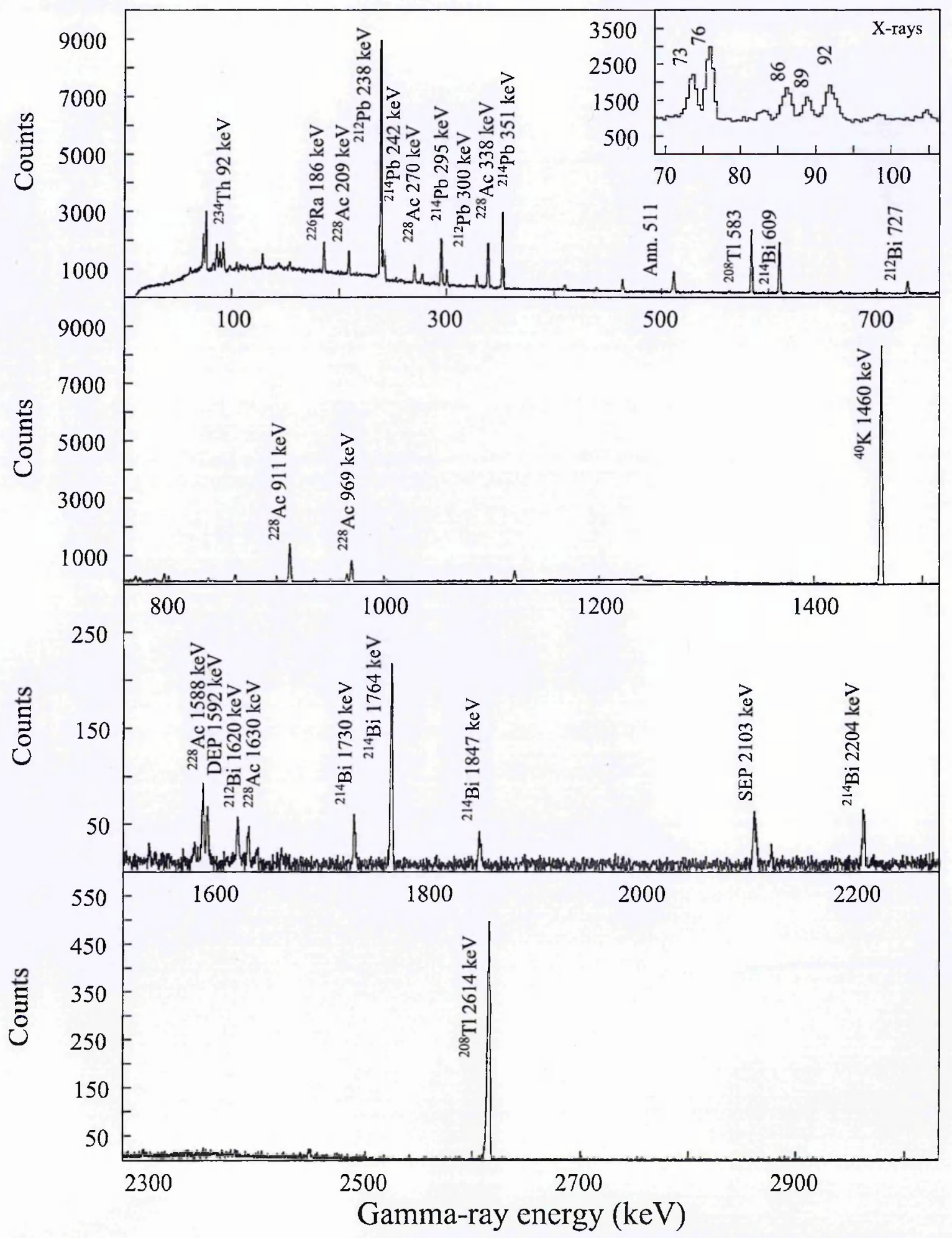

Figure 4-15: Gamma-ray spectrum of the 'Patong' beach sand sample subtracted background collected for 172,800 s (i.e. 48 hours) 


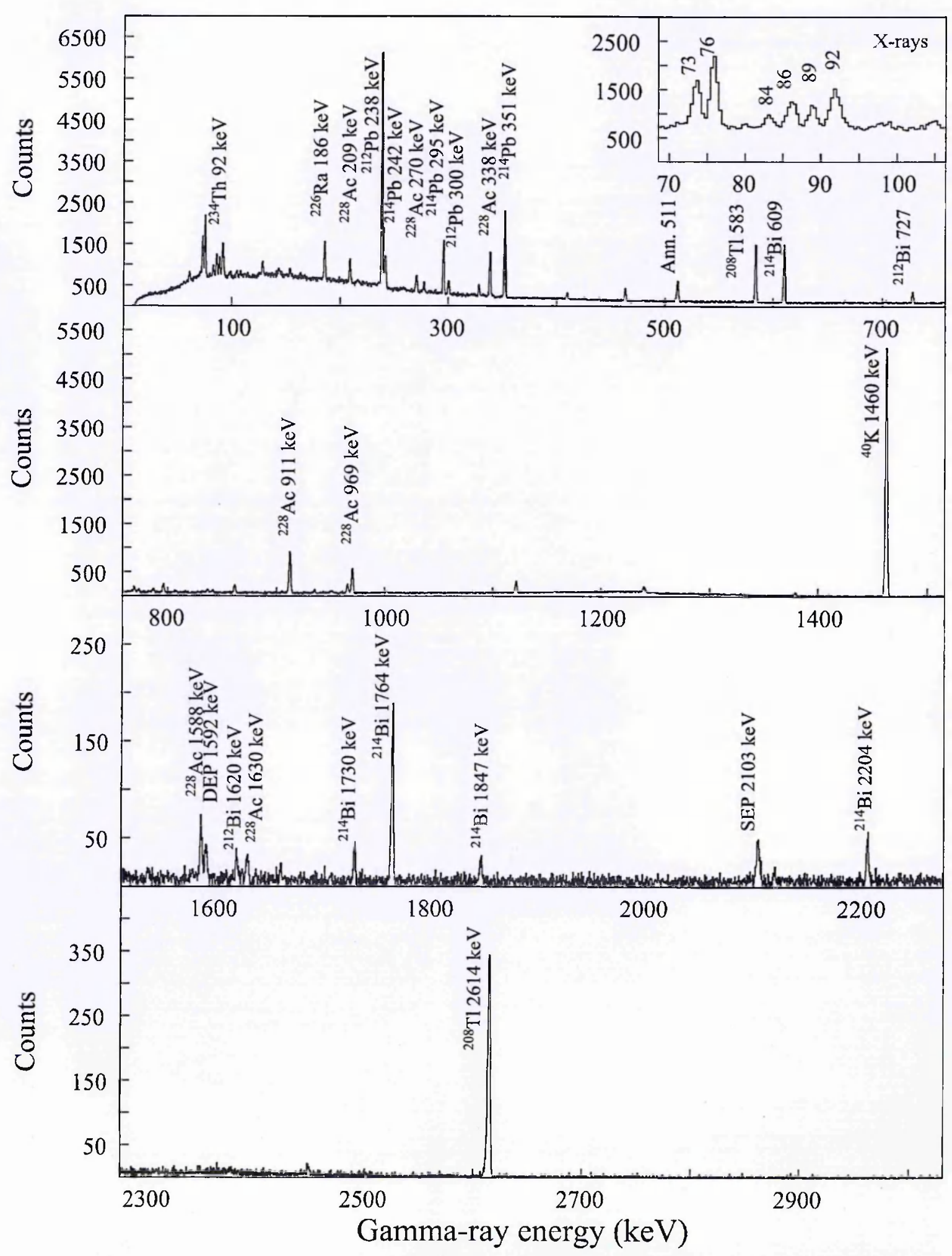

Figure 4-16: Gamma-ray spectrum of the 'Kata Noi' beach sand sample subtracted background collected for 172,800 s (i.e. 48 hours). 


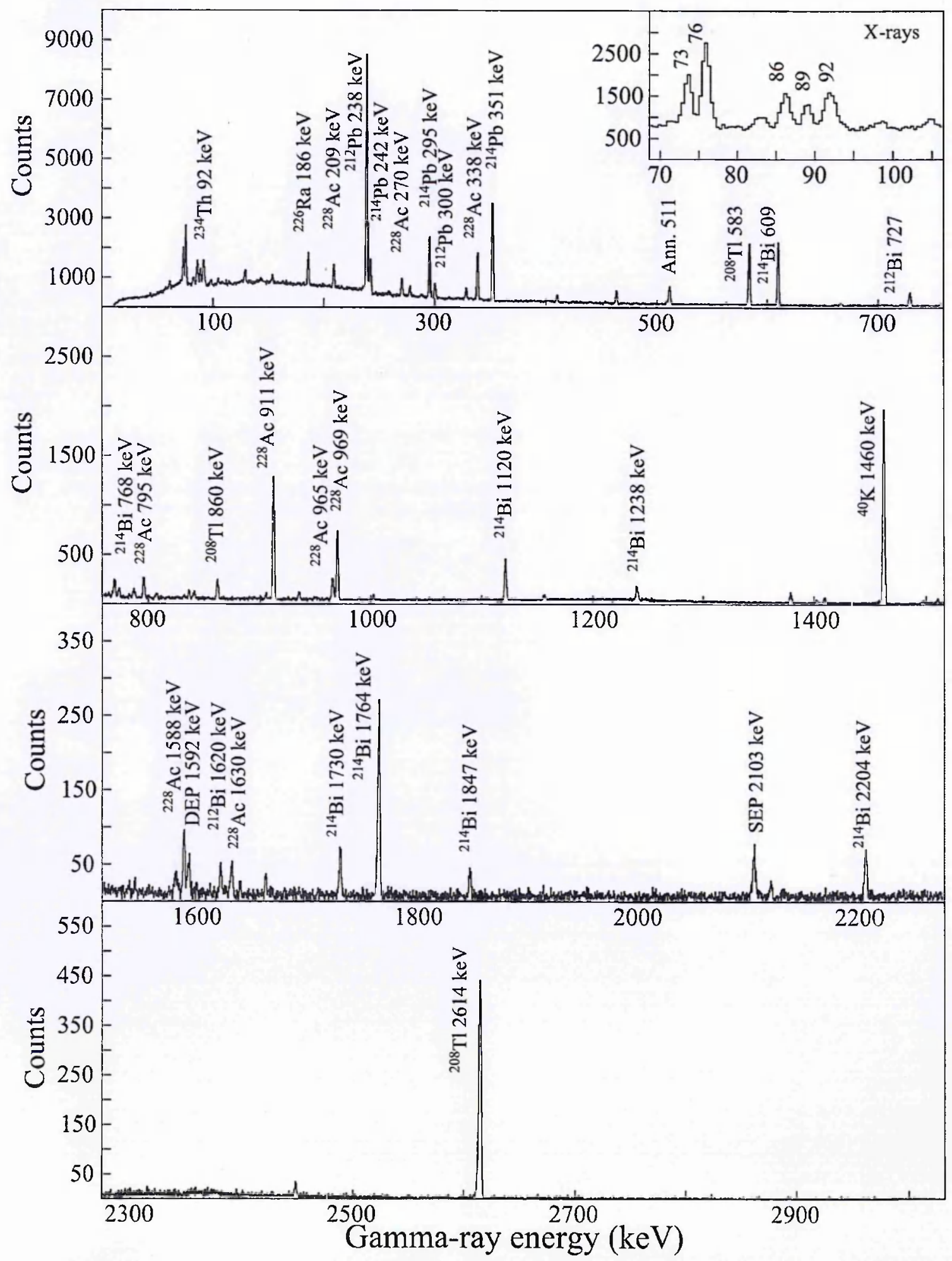

Figure 4-17: Gamma-ray spectrum of the 'Rawai' beach sand sample subtracted background collected for 172,800 s (i.e. 48 hours). 


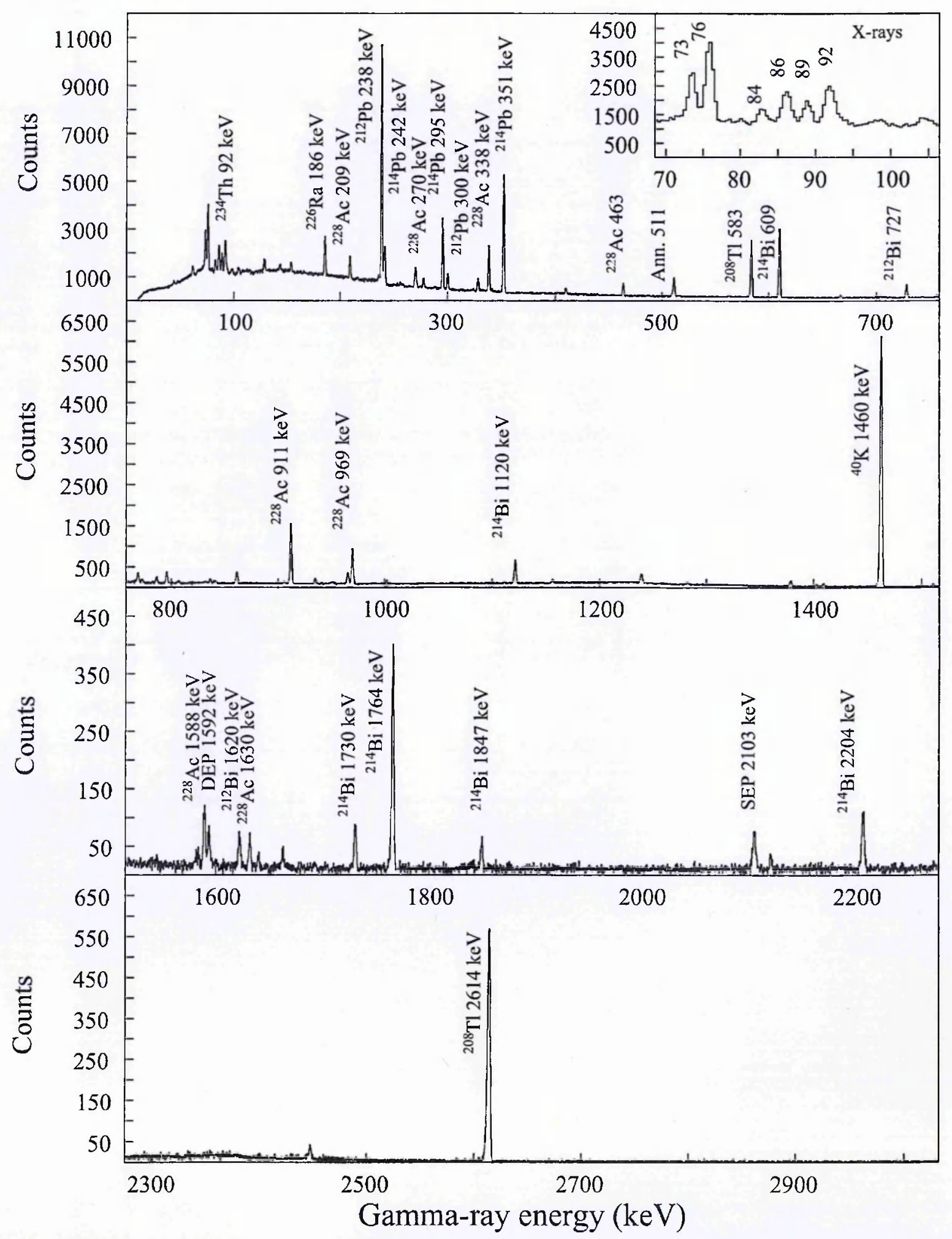

Figure 4-18: Gamma-ray spectrum of the 'Chalong Bay' beach sand sample subtracted background collected for 172,800 s (i.e. 48 hours). 


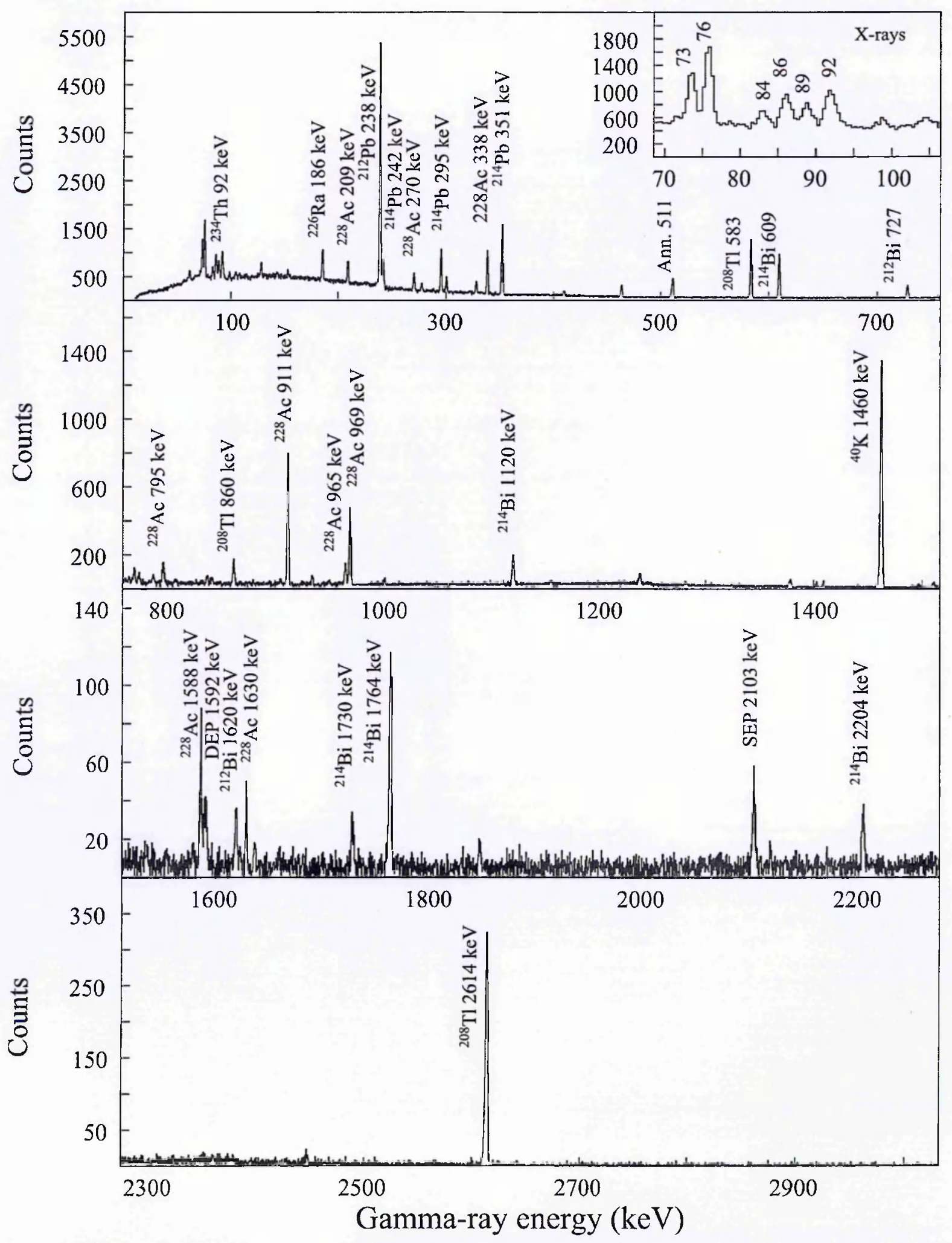

Figure 4-19: Gamma-ray spectrum of the 'Ao Po' beach sand sample subtracted background collected for 172,800 s (i.e. 48 hours). 


\subsubsection{Specific Activity}

Determination of activity concentrations also requires knowledge of specific correction factors including, a self-attenuation corrections, decay- and life-time corrections and coincidence corrections. These have been applied to the analysis where appropriate. With only a small difference in the density between the reference sources and sand samples, the self-attenuation correction factor was not taken into account in this study. The weighted means for the activity was also applied in order to achieve the best estimate of the activity concentrations for given chains. The use of independent measurements of multiple, discrete gamma-ray lines from the same decay chains allows a signficant reduction in the statistical uncertainty of the derived activity concentrations compared to the use of a single transition. The more-precise measurements for each sand sample were weighted more heavily than the less- precise measurements. This procedure is called a 'weighted mean analysis' and is illustrated in more detail in Appendix B.

By using eq. 2.85, the activity of each radionuclide in the ${ }^{232} \mathrm{Th},{ }^{238} \mathrm{U}$ series and ${ }^{40} \mathrm{~K}$ is shown in Figures 4-20 to Figure 4-27. An example of the activity calculation associated with the decay of ${ }^{40} \mathrm{~K}$ is given in Appendix B. The activities from eight different samples are summarised in Table 4-4. The weighted mean values with uncertainties are represented as dotted lines in the figures. 


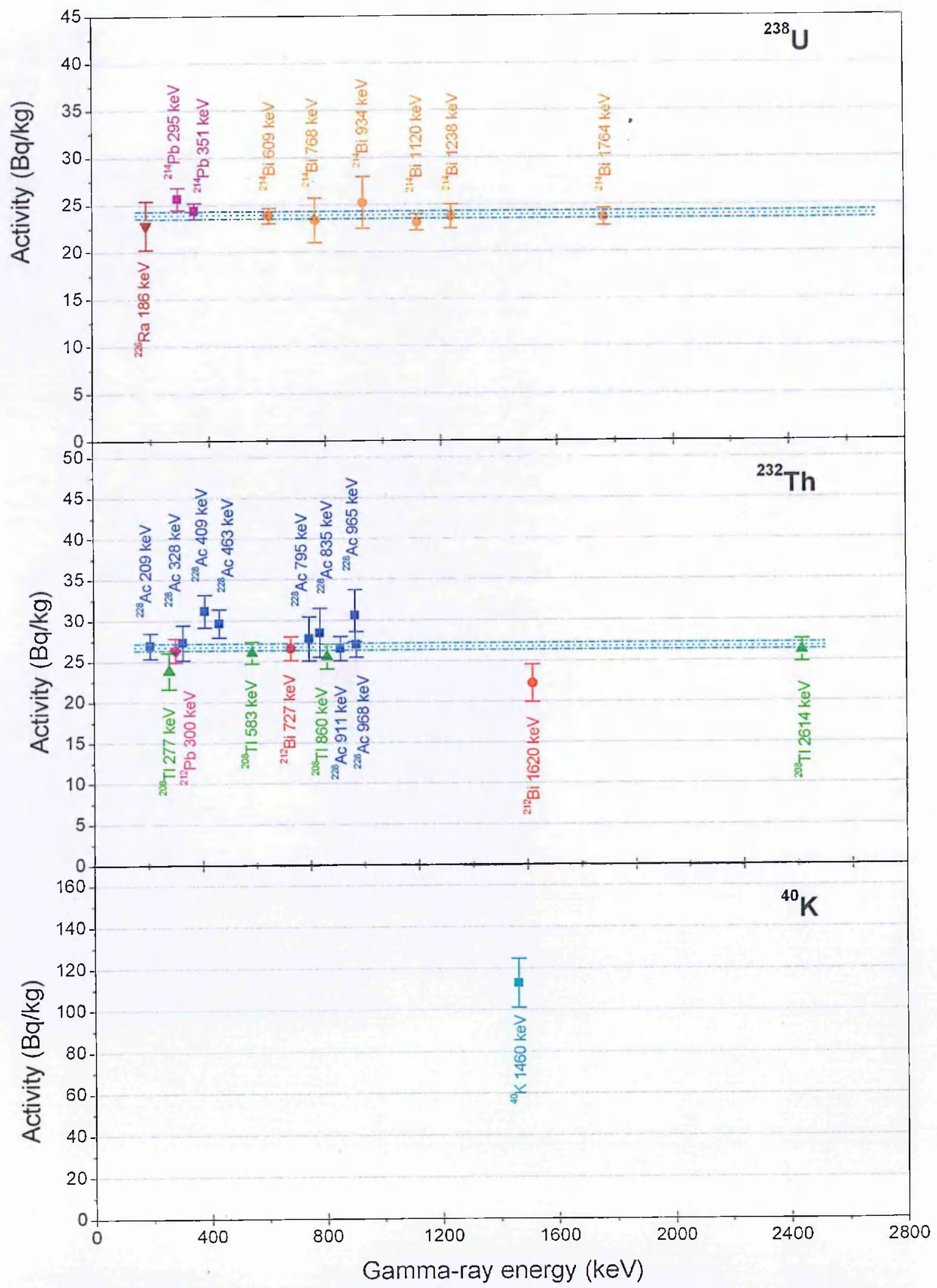

Figure 4-20: Radionuclide activity for the 'Mai Kao' beach sand sample. The dotted lines represent the weighted mean values of $23.9 \pm 0.4$ and $26.7 \pm 0.4 \mathrm{~Bq} \cdot \mathrm{kg}^{-1}$ for the ${ }^{238} \mathrm{U}$ and ${ }^{232} \mathrm{Th}$ series respectively. 


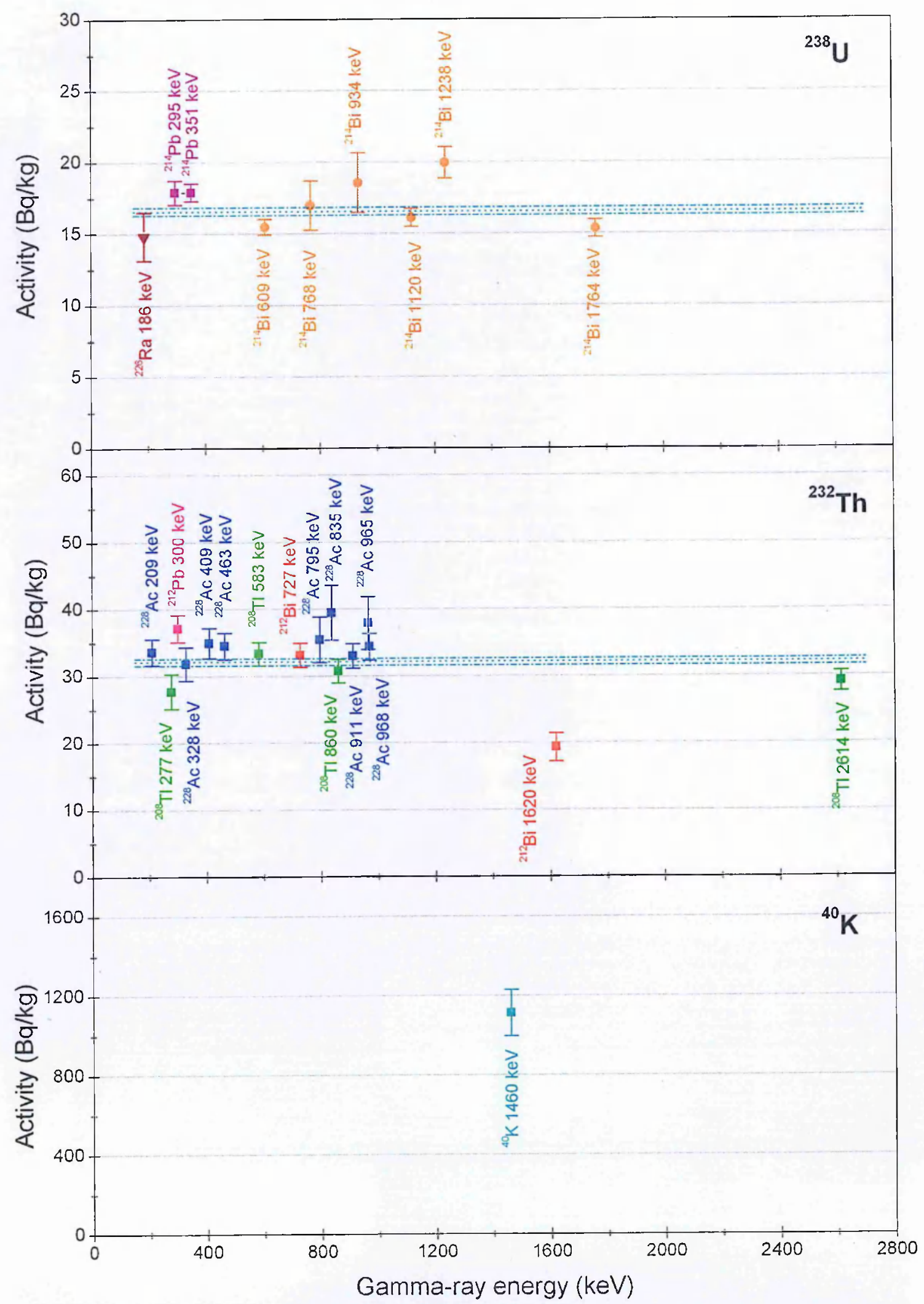

Figure 4-21: Radionuclide activity for the 'Nai Ton' beach sand sample. The dotted lines represent the weighted mean values of $16.6 \pm 0.3$ and $32.1 \pm 0.5 \mathrm{~Bq} . \mathrm{kg}^{-1}$ for the ${ }^{238} \mathrm{U}$ and ${ }^{232} \mathrm{Th}$ series respectively. 


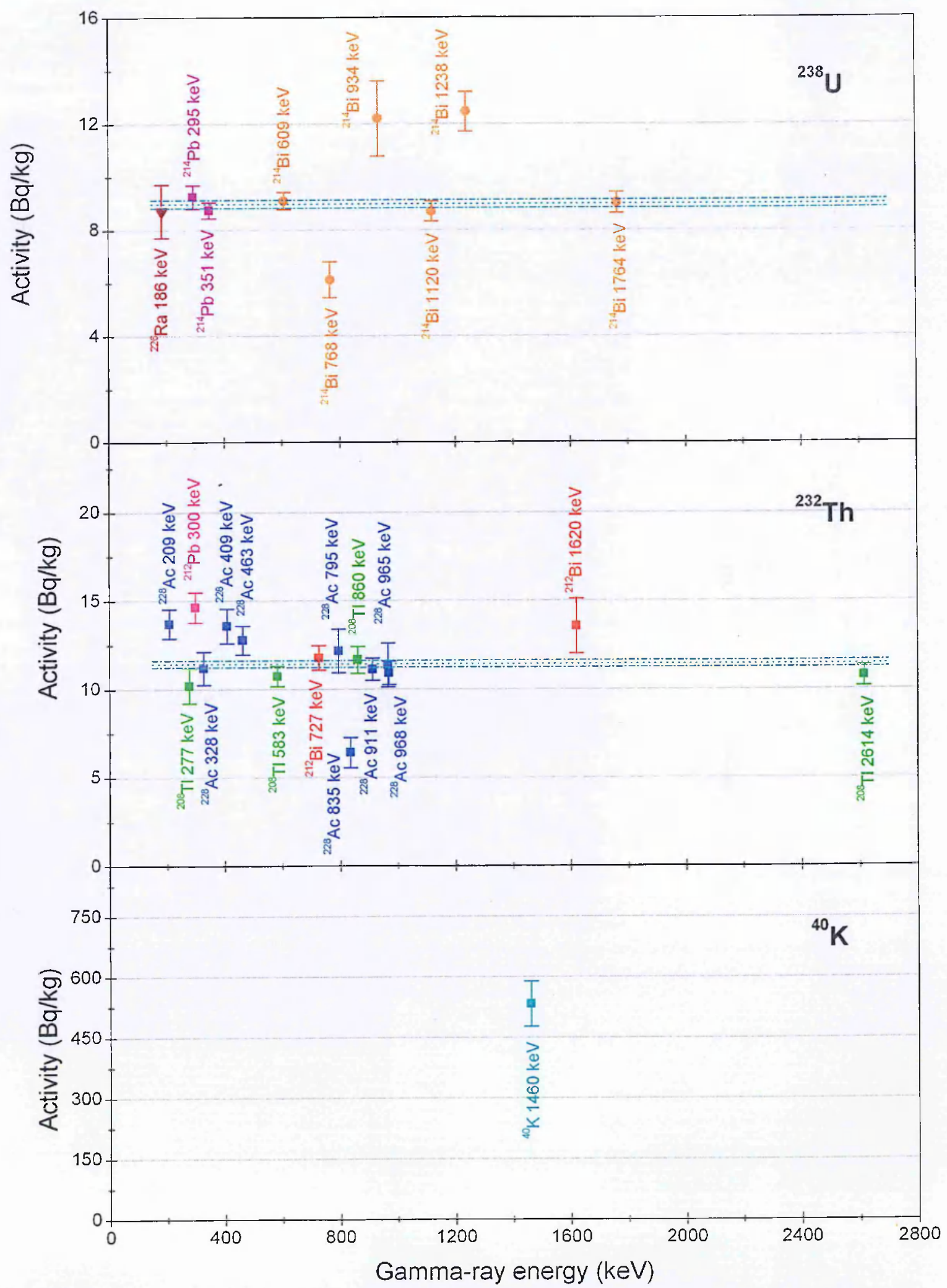

Figure 4-22: Radionuclide activity for the 'Surin' beach sand sample. The dotted lines represent the weighted mean values of $9.0 \pm 0.1$ and $11.4 \pm 0.2 \mathrm{~Bq} \cdot \mathrm{kg}^{-1}$ for the ${ }^{238} \mathrm{U}$ and ${ }^{232} \mathrm{Th}$ series respectively. 


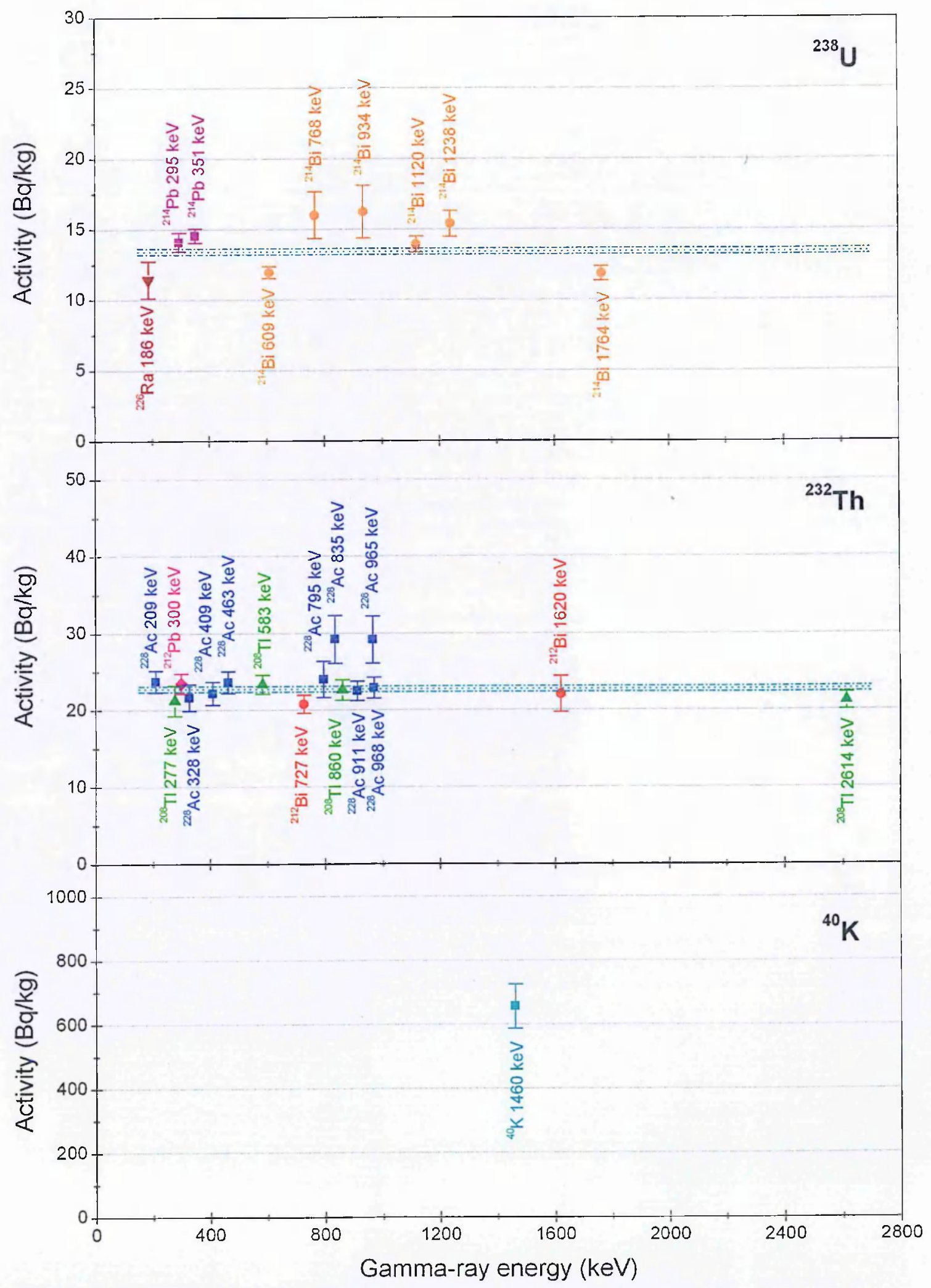

Figure 4-23: Radionuclide activity for the 'Patong' beach sand sample. The dotted line represents the weighted mean values of $13.4 \pm 0.2$ and $22.6 \pm 0.4 \mathrm{~Bq} \cdot \mathrm{kg}^{-1}$ for the ${ }^{232} \mathrm{Th}$ and ${ }^{238} \mathrm{U}$ series respectively. 


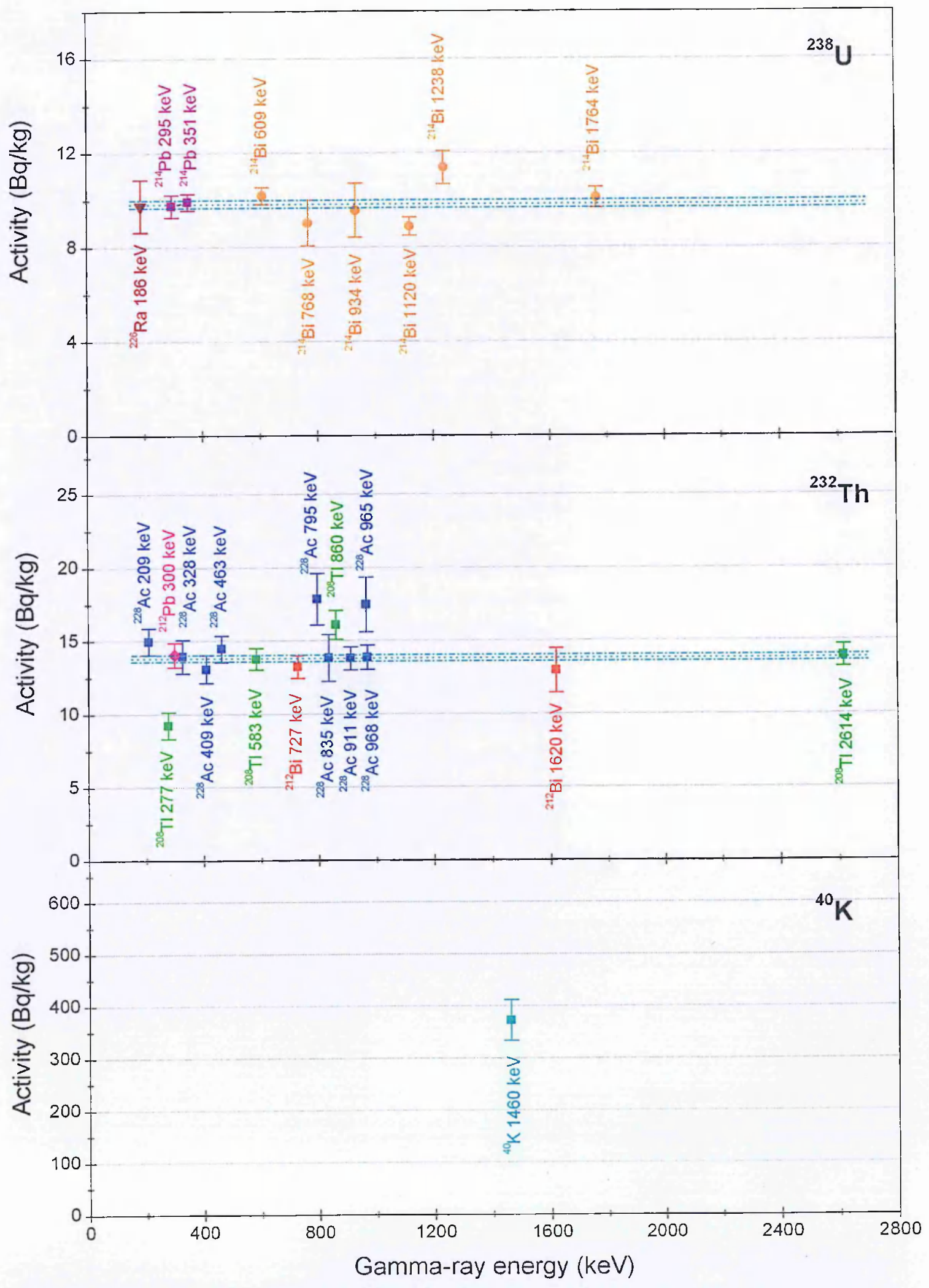

Figure 4-24: Radionuclide activity for the 'Kata Noi' beach sand sample. The dotted lines represent the weighted mean values of $9.8 \pm 0.2$ and $13.8 \pm 0.2 \mathrm{~Bq} \cdot \mathrm{kg}^{-1}$ for the ${ }^{238} \mathrm{U}$ and ${ }^{232} \mathrm{Th}$ series respectively. 


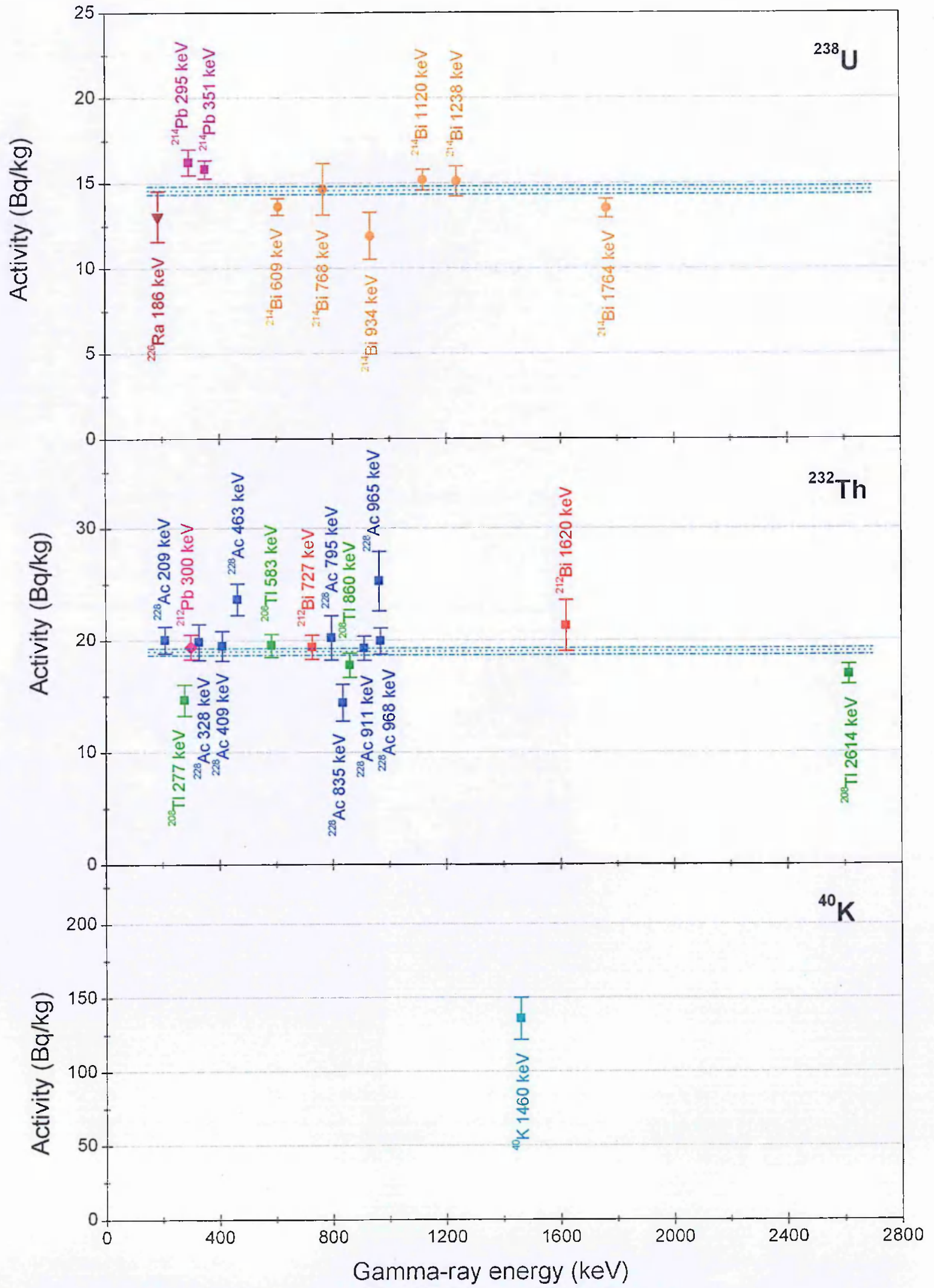

Figure 4-25: Radionuclide activity for the 'Rawai' beach sand sample. The dotted lines represent the weighted mean values of $14.6 \pm 0.2$ and $19.0 \pm 0.3 \mathrm{~Bq} \cdot \mathrm{kg}^{-1}$ for the ${ }^{238} \mathrm{U}$ and ${ }^{232} \mathrm{Th}$ series respectively. 


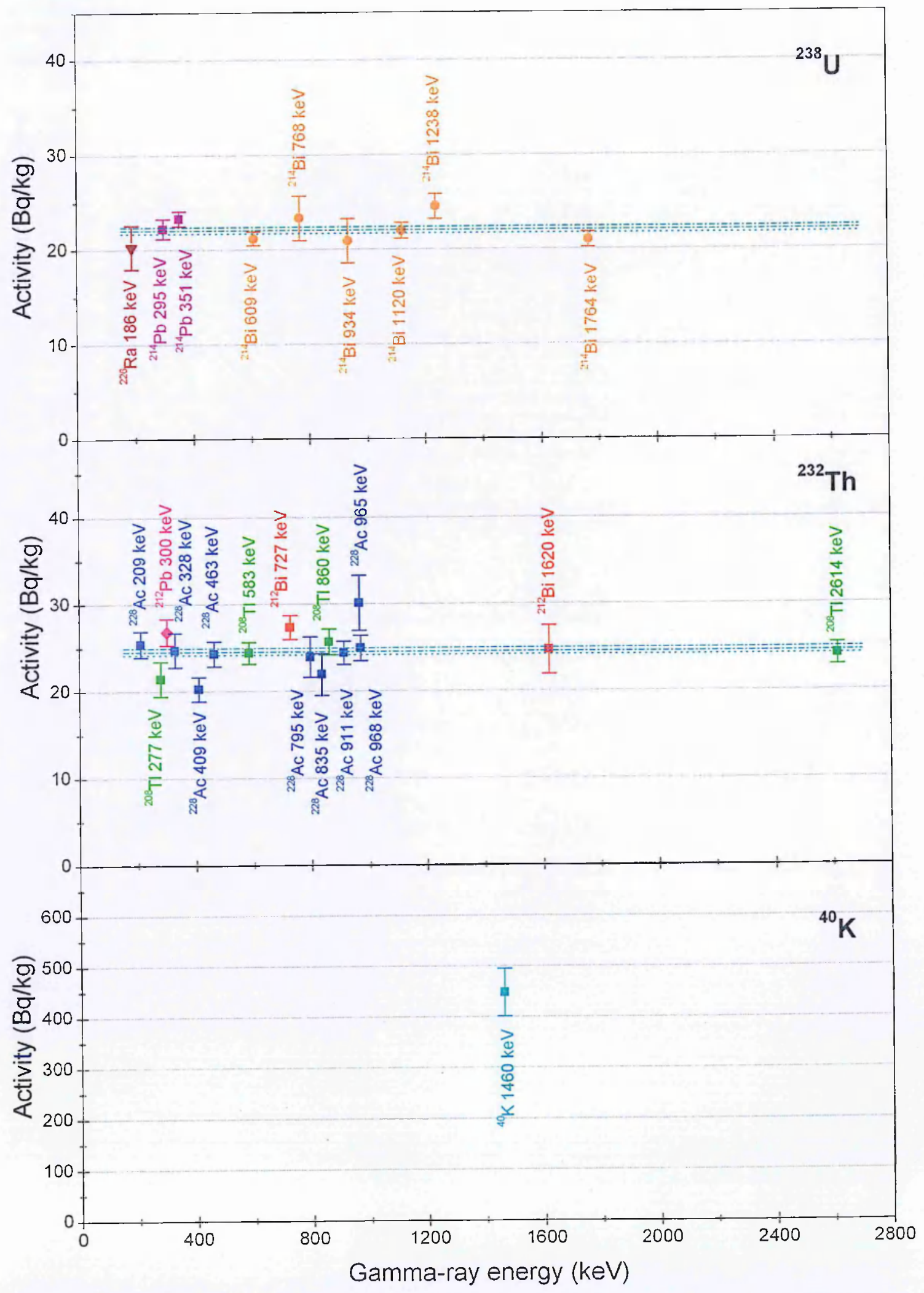

Figure 4-26: Radionuclide activity for the 'Chalong Bay' beach sand sample. The dotted lines represent the weighted mean values of $22.0 \pm 0.3$ and $24.5 \pm 0.4 \mathrm{~Bq} \cdot \mathrm{kg}^{-1}$ for the ${ }^{238} \mathrm{U}$ and ${ }^{232} \mathrm{Th}$ series respectively. 


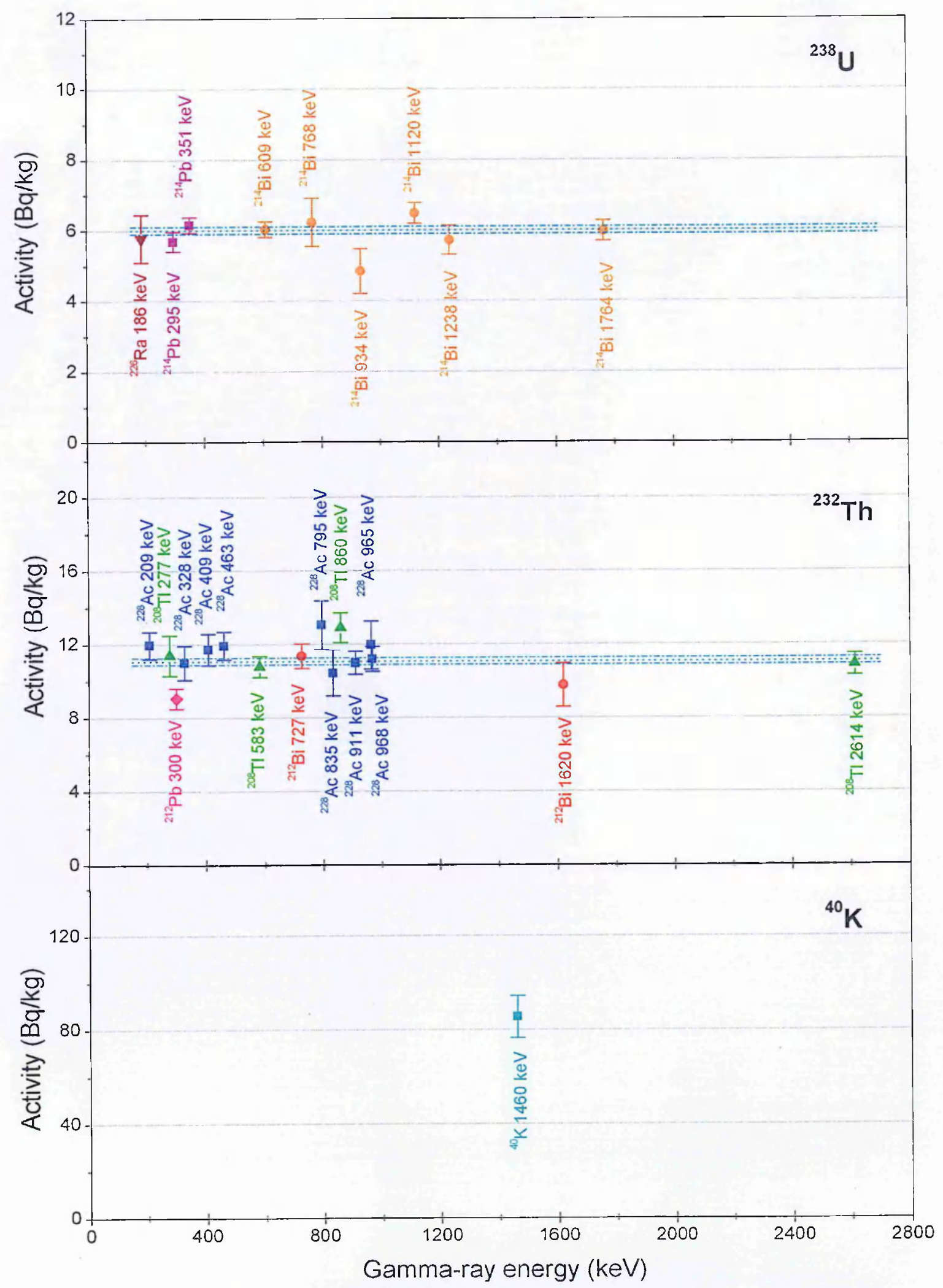

Figure 4-27: Radionuclide activity for the 'Ao Po' beach sand sample. The dotted lines represent the weighted mean values of $6.0 \pm 0.1$ and $11.1 \pm 0.2 \mathrm{~Bq} \cdot \mathrm{kg}^{-1}$ for the ${ }^{238} \mathrm{U}$ and ${ }^{232} \mathrm{Th}$ series respectively. 


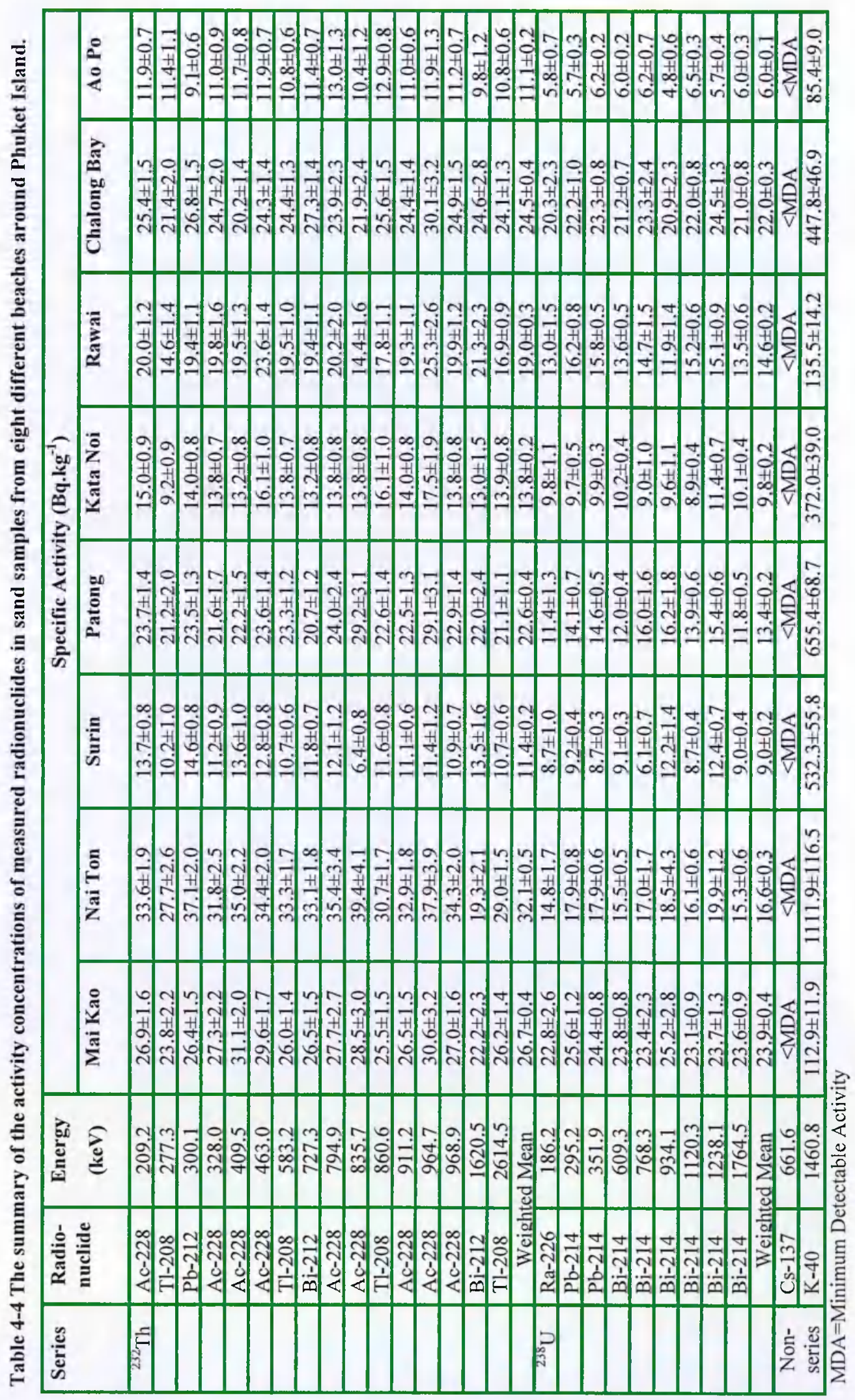


The efficiency corrected intensities of the measured discrete gamma-ray lines of energies $209.2,328.0,409.5,463.0,794.9,835.7,911.2,964.7,968.9 \mathrm{keV}\left({ }^{228} \mathrm{Ac}\right), 727.3,1620.5$ $\mathrm{keV}\left({ }^{212} \mathrm{Bi}\right), 300.1 \mathrm{keV}\left({ }^{212} \mathrm{~Pb}\right), 277.3,583.2,860.6$ and $2614.5 \mathrm{keV}\left({ }^{208} \mathrm{Tl}\right)$ were used to determine the activity concentrations of ${ }^{232} \mathrm{Th}$; the gamma-ray lines at $186.2 \mathrm{keV}\left({ }^{226} \mathrm{Ra}\right)$, $295.2,351.9 \mathrm{keV}\left({ }^{214} \mathrm{~Pb}\right), 609.3,768.3,934.1,1120.3,1238.1$ and $1764.5 \mathrm{keV}\left({ }^{214} \mathrm{Bi}\right)$ were used to determine the activity concentrations of ${ }^{226} \mathrm{Ra}$; while the 1460.8 and 661.6 $\mathrm{keV}$ transitions were used to determine the activity concentrations of ${ }^{40} \mathrm{~K}$ and ${ }^{137} \mathrm{Cs}$, respectively.

The activity concentrations of ${ }^{226} \mathrm{Ra},{ }^{232} \mathrm{Th}$ and ${ }^{40} \mathrm{~K}$ were found to lie in the range of $4.8 \pm 0.6 \leftrightarrow 25.6 \pm 1.2, \quad 6.4 \pm 0.8 \leftrightarrow 39.4 \pm 4.1, \quad 85.4 \pm 9.0 \leftrightarrow 1,112 \pm 117 \quad \mathrm{~Bq} . \mathrm{kg}^{-1}$ with the average mean values of $14.4 \pm 0.1,20.2 \pm 0.1,431.6 \pm 20.0 \mathrm{~Bq} \cdot \mathrm{kg}^{-1}$ respectively. The activity concentration of ${ }^{137} \mathrm{Cs}(661.6 \mathrm{keV})$ is below the minimum detectable activity in the current work, meaning that effectively no measurable amount of artificial radionuclide is present in the sand samples in the current study. The obtained results from beach sand samples are lower than the worldwide average concentrations for ${ }^{226} \mathrm{Ra}$ and ${ }^{232} \mathrm{Th}$ in soil as reported by the UNSCEAR (2000) of 17-60 and 11-64 Bq. $\mathrm{kg}^{-1}$ with the mean values of 35 and $30 \mathrm{~Bq} \cdot \mathrm{kg}^{-1}$ respectively. The activity concentration of ${ }^{40} \mathrm{~K}$ in the studied samples is higher than the worldwide average concentration which is $140-850 \mathrm{~Bq} \cdot \mathrm{kg}^{-1}$ with the mean values of $400 \mathrm{~Bq} \cdot \mathrm{kg}^{-1}$ due to relatively high concentration of ${ }^{40} \mathrm{~K}$ in the "Nai Ton" beach sand sample. This may result from potassium in ocean water absorbing in the sand surface at the seashore. The activity concentrations of ${ }^{226} \mathrm{Ra},{ }^{232} \mathrm{Th}$ and ${ }^{40} \mathrm{~K}$ in the beach sand samples for the present work have been compared to previous studies in Thailand, including the preliminary work from this thesis reported in reference [MAL10], and works by Boonkrongcheep et al. [BOO07], Benjakul, S. et al [BEN07], and Ayusuk, W. et al. [AYU07] (see Table 4-8). The results obtained from the study are found to be comparable with these previous studies.

\subsubsection{Mutual Interferences}

$$
\text { 4.6.3.1 }{ }^{226} \mathrm{Ra}(186.21 \mathrm{keV}) \text { and }{ }^{235} \mathrm{U}(185.27 \mathrm{keV})
$$

The activity of ${ }^{226} \mathrm{Ra}$ can be overestimated because of the mutual interference which comes from the $185.27 \mathrm{keV}$ gamma ray emitted following the decay of ${ }^{235} \mathrm{U}$ into ${ }^{231} \mathrm{Th}$ 
while the ${ }^{226} \mathrm{Ra}$ to ${ }^{222} \mathrm{Rn}$ decay also emits a gamma ray with an energy of $186.21 \mathrm{keV}$. Both ${ }^{226} \mathrm{Ra}$ and ${ }^{235} \mathrm{U}$ are present in natural samples; ${ }^{226} \mathrm{Ra}$ arising from the ${ }^{238} \mathrm{U}$ decay chain while ${ }^{235} \mathrm{U}$ is the parent radionuclide in the actinium series. The contribution of counts in the $186 \mathrm{keV}$ peak can be determined by using the expected, natural ${ }^{235} \mathrm{U} /{ }^{238} \mathrm{U}$ isotopic ratio when the ${ }^{226} \mathrm{Ra}$ is in radioactive equilibrium with its parent ${ }^{238} \mathrm{U}$ [GIL08]. The actual ${ }^{226} \mathrm{Ra}$ concentration can be determined as follows:

Natural isotopic abundance's of uranium isotopes in soils [FRI86]:

$I_{U^{238}}=99.2745 \%$

$I_{U^{235}}=0.720 \%$

Half-life and gamma-ray emission probabilities [FRI86]:

$\begin{array}{ll}T_{1 / 2}\left({ }^{238} \mathrm{U}\right)=4.4683 \times 10^{9} \text { years, } & f_{R a^{226}}=0.0328 \mathrm{r} / \text { dis. } \\ T_{1 / 2}\left({ }^{235} \mathrm{U}\right)=7.038 \times 10^{8} \text { years, } & f_{U^{235}}=0.53 \mathrm{r} / \text { dis. } .\end{array}$

At equilibrium

$$
\begin{aligned}
& A_{U^{238}}=\lambda_{U^{238}} \cdot N_{U^{238}}=\frac{\ln 2}{4.4683 \times 10^{9} \times 365 \times 24 \times 60 \times 60} \cdot 99.2745 \\
& A_{U^{235}}=\lambda_{U^{235}} \cdot N_{U^{235}}=\frac{\ln 2}{0.7038 \times 10^{9} \times 365 \times 24 \times 60 \times 60} \cdot 0.720
\end{aligned}
$$

These values can be used to calculate the gamma-ray production rates from ${ }^{226} \mathrm{Ra}$ and ${ }^{235} \mathrm{U}$ in the samples assuming 100 atoms of natural Uranium:

$$
\begin{aligned}
& \gamma_{R a^{226}}=\left(4.88 \times 10^{-16} \mathrm{dis} / \mathrm{s}\right) \cdot(0.0328 \mathrm{\gamma} / \text { dis. })=1.60 \times 10^{-17} \mathrm{\gamma} / \mathrm{s} \\
& \gamma_{U^{235}}=\left(2.248 \times 10^{-17} \mathrm{dis} / \mathrm{s}\right) \cdot(0.53 \gamma / \text { dis. })=1.19 \times 10^{-17} \mathrm{\gamma} / \mathrm{s}
\end{aligned}
$$

To quantify the individual contributions of ${ }^{226} \mathrm{Ra}$ and ${ }^{235} \mathrm{U}$ to the gamma-ray energy peak at $186 \mathrm{keV}$, the ratio of the gamma-ray production rates can be expressed by:

$$
\frac{\gamma_{R a^{226}}}{\gamma_{U^{235}}}=\frac{1.60 \times 10^{-17} \mathrm{\gamma} / \mathrm{s}}{1.19 \times 10^{-17} \mathrm{\gamma} / \mathrm{s}}=1.34
$$

In relative terms, it can be written as:

$$
\frac{\gamma_{R a^{225}}}{\gamma_{\left(R a^{225}+U^{235}\right)}}=\frac{1.60 \times 10^{-17} \mathrm{\gamma} / \mathrm{s}}{(1.60+1.19) \times 10^{-17} \mathrm{\gamma} / \mathrm{s}}=0.573
$$


$\frac{\gamma_{U^{235}}}{\gamma_{\left(R q^{226}+U^{235}\right)}}=\frac{1.19 \times 10^{-17} \gamma / s}{(1.60+1.19) \times 10^{-17} \gamma / s}=0.427$

Therefore, the total contributions to the count rate at energy of $186 \mathrm{keV}$ from ${ }^{226} \mathrm{Ra}$ and ${ }^{235} \mathrm{U}$ is $57.3 \%$ and $42.7 \%$ respectively under equilibrium condition. Simply multiplying the reported ${ }^{226} \mathrm{Ra}$ concentration by 0.573 should therefore yield the correct ${ }^{226} \mathrm{Ra}$ concentration.

$$
\text { 4.6.3.2 }{ }^{40} \mathrm{~K}(1460.8 \mathrm{keV}) \text { and }{ }^{228} \mathrm{Ac}(1459.2 \mathrm{keV})
$$

The interference from the ${ }^{40} \mathrm{~K}$ comes from the $1459.2 \mathrm{keV}$ gamma-ray emitted by ${ }^{228} \mathrm{Ac}$ from the thorium decay chain, while ${ }^{40} \mathrm{~K}$ decay emits a gamma-ray at an energy of 1460.8 $\mathrm{keV}$. The contributions to the composite peak at the $1460-\mathrm{keV}$ in a gamma-ray spectrum may therefore not be negligible and can need correction. The proportion of counts from the ${ }^{228} \mathrm{Ac}$ contribution used to subtract from the experimental peak area can be calculated in a straightforward manner using the data from the prepared ${ }^{232} \mathrm{Th}$ reference source. With ${ }^{228} \mathrm{Ac}$ in equilibrium with ${ }^{232} \mathrm{Th}$, the 1459 peak can be determined directly from the ratio of counts in the $1459 \mathrm{keV}$ peak to the counts of the ${ }^{228} \mathrm{Ac}$ decay transition at $911 \mathrm{keV}$ (27.7\% yield) or at $969 \mathrm{keV}(16.6 \%$ yield $)$.

$$
\left[\frac{C_{(1459 \mathrm{keV})}}{C_{(911 \mathrm{keV})}}\right]^{232 \mathrm{Th}}=\left[\frac{C_{(1459 \mathrm{keV})}}{C_{(911 \mathrm{keV})}}\right]^{\text {PKPT }}
$$

For the ${ }^{232}$ Th standard source;

$C_{(911 \mathrm{keV})}=37,1230 \pm 609$ counts and $C_{(1459 \mathrm{keV})}=7,839 \pm 88$ counts

For the "Patong" beach sand sample (PKPT-1); $C_{(911 \mathrm{keV})}=6,363 \pm 79$ counts

Therefore, the counts in the $1459 \mathrm{keV}$ peak from the "Patong" sand sample

$$
\begin{aligned}
=\frac{7,839}{37,1230} \times 6,363= & 134 \pm 12 \text { counts } \\
{\left[C_{(1460 \mathrm{keV})}\right]^{P K P T} } & =C_{\text {total }}-\left[C_{(1459 \mathrm{keV})}\right]^{P K P T} \\
& =50,698-134 \\
& =50,396 \pm 225 \text { counts }
\end{aligned}
$$

where $C_{\text {total }}$ is the total counts in the composite peak at $1460-\mathrm{keV}$ in a gamma-ray spectrum 
After subtracting the ${ }^{228} \mathrm{Ac}$ contribution to the total counts of the composite peak at the $1460-\mathrm{keV}$, the residual counts associated with the ${ }^{40} \mathrm{~K}$ peak are $50,396 \pm 225$ for the "Patong" beach sand sample.

\subsubsection{Elemental Concentrations}

Since the activity of the samples is also associated with the number of radioactive atoms in the samples, assuming ${ }^{226} \mathrm{Ra}$ in equilibrium with ${ }^{238} \mathrm{U}$ therefore the activity concentrations of ${ }^{238} \mathrm{U},{ }^{232} \mathrm{Th}$ and ${ }^{40} \mathrm{~K}$ were then converted into the mass concentrations by the following equation:

$$
C_{E}=\frac{M_{E} \cdot A_{E} \cdot 10^{6}}{\lambda_{E} \cdot N_{A}}
$$

where $C_{E}$ is the mass concentration of the nuclide $E$ of the measured sample, in $\mu \mathrm{g} \cdot \mathrm{g}^{-1}$ or ppm (part per million),

$M_{E}$ is the atomic mass of the nuclide $E$, in $\mathrm{g} \cdot \mathrm{mol}^{-1}$,

$A_{E}$ is the activity concentration of the nuclide $E$, in Bq.g ${ }^{-1}$,

$\lambda_{E}$ is the decay constant of the nuclide $E$,

$N_{A}$ is Avogadro's number equal to $6.023 \times 10^{23}$ atoms.mol ${ }^{-1}$

The concentration of ${ }^{40} \mathrm{~K}$ presented as a percentage (\%) of the total potassium can be described by:

$\% C_{K}=\frac{M_{K} \cdot A_{K} \cdot 10^{2}}{N_{K} \cdot \lambda_{K} \cdot N_{A}}$

where $C_{K}$ is the percentage of total $\mathrm{K}$ of the measured sample,

$M_{K}$ is the atomic mass of ${ }^{40} \mathrm{~K}$, in $\mathrm{g} \cdot \mathrm{mol}^{-1}$,

$A_{K}$ is the activity concentration of ${ }^{40} \mathrm{~K}$, in $\mathrm{Bq} \cdot \mathrm{g}^{-1}$,

$\lambda_{K}$ is the decay constant of ${ }^{40} \mathrm{~K}$,

$N_{K}$ is the percent natural abundance of ${ }^{40} \mathrm{~K}$ equal to $0.0118 \%$

$N_{A}$ is Avogadro's number equal to $6.023 \times 10^{23}$ atoms.mol ${ }^{-1}$ 
A summary of the concentrations of ${ }^{238} \mathrm{U},{ }^{232} \mathrm{Th}$ in part per million and $\%$ total $\mathrm{K}$ for the sand samples collected around Phuket Island in the current work are shown in Figure 4-28.

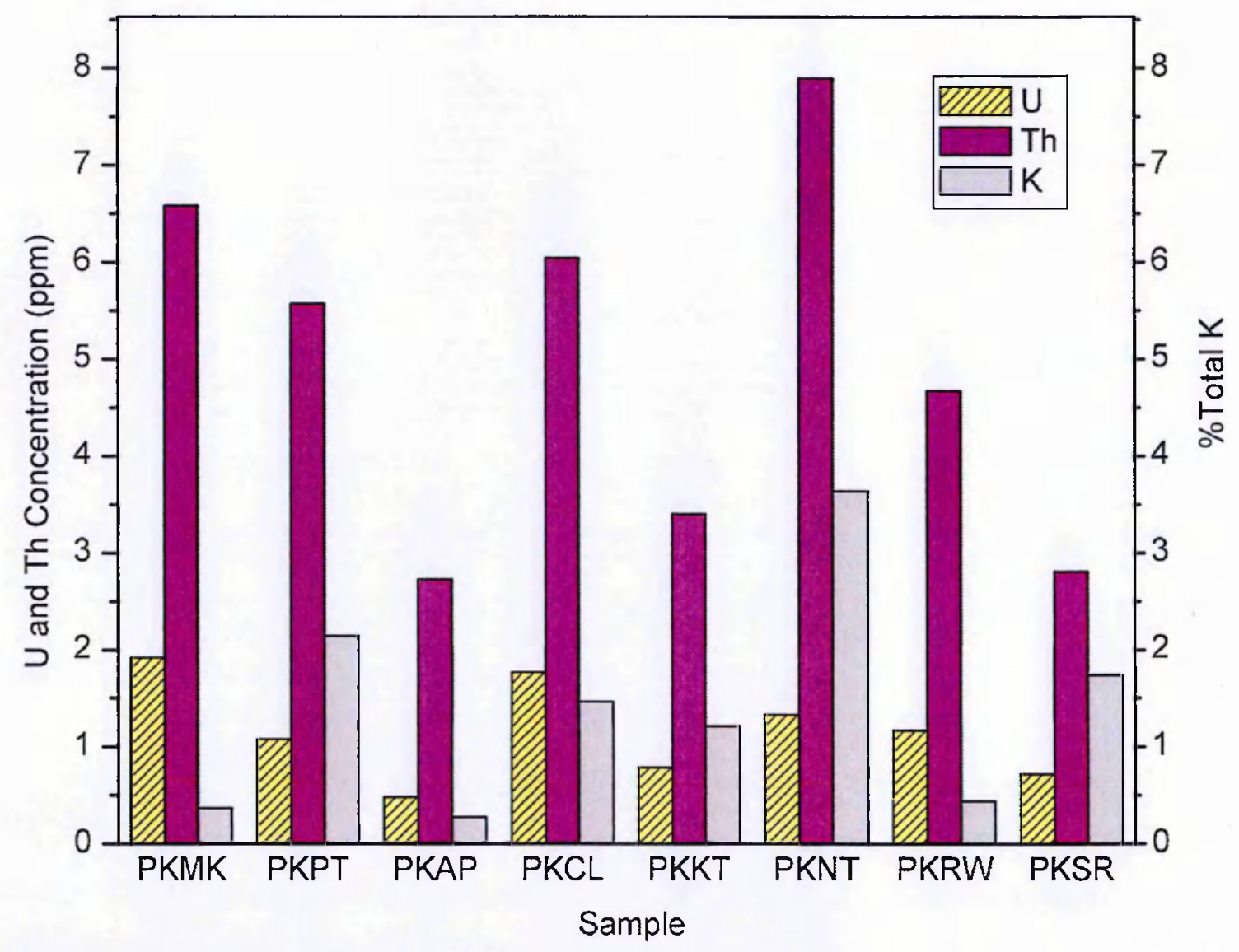

Figure 4-28: The concentrations of ${ }^{238} \mathrm{U},{ }^{232} \mathrm{Th}$ in ppm and \% total $\mathrm{K}$ in beach sand samples collected from eight different beaches around Phuket Island.

The elemental concentrations of ${ }^{238} \mathrm{U},{ }^{232} \mathrm{Th}$ and ${ }^{40} \mathrm{~K}$ were found to lie in the range of $0.48 \pm 0.01 \leftrightarrow 1.92 \pm 0.03, \quad 2.72 \pm 0.05 \leftrightarrow 7.90 \pm 0.13 \mathrm{ppm}$, and $0.28 \pm 0.03 \leftrightarrow 3.64 \pm 0.38 \%$ with the average mean values of $1.16 \pm 0.01,4.96 \pm 0.03 \mathrm{ppm}$, and $1.41 \pm 0.06 \%$ respectively. The results obtained are in the range of the typical rocks reported by [NCRP87] which are 0.54.7, 1.6-20 ppm and 0.3-4.5\% for ${ }^{238} \mathrm{U},{ }^{232} \mathrm{Th}$ and ${ }^{40} \mathrm{~K}$ respectively.

The reported uncertainty in this study takes into account only the counting statistics which results in a relatively small (Poisson) uncertainty. In practice, additional uncertainties can be produced from other sources such as sample preparation, energy and efficiency calibration, sample measurements and variations in the published nuclear data literature. Taking into consideration all possible sources of uncertainty appropriately enables a complete evaluation of the true uncertainty in the final activity concentration value obtained. 


\subsection{The West and the East Coast of Thailand}

In the present work, 60 beach sand samples collected along the west and the east coast of Thailand have been first measured to establish whether the radioactive equilibrium of ${ }^{222} \mathrm{Rn}$ with its parent $\left({ }^{226} \mathrm{Ra}\right)$ in the uranium chain had been established. This was followed by the determination of the concentrations of ${ }^{238} \mathrm{U},{ }^{232} \mathrm{Th}$ and ${ }^{40} \mathrm{~K}$ in Bq.kg ${ }^{-1}$ and in ppm. The radium equivalent activity, together with the external $\left(H_{\mathrm{ex}}\right)$ and internal $\left(H_{\text {in }}\right)$ hazard indices of ${ }^{238} \mathrm{U},{ }^{232} \mathrm{Th}$ and ${ }^{40} \mathrm{~K}$ are also discussed including the total gamma dose rate and the annual effective dose rate established using these sand samples.

\subsubsection{Sample Spectrum}

Six beach sand samples collected from six provinces namely; (i) Hat Thai Mueng in Phangnga province, (ii) Hat Mai Kao in Phuket province, (iii) Hat Nopparattara in Krabi province, (iv) Hat Leam Son in Chumporn province, (v) Hat Chaiya in Suratthani province, and (vi) Hat Khanom in Nakornsrithammarat province are representative of all sand samples collected along the west and the east coast of Thailand, as shown from Figure 4-29 to Figure 4-35.The geological properties underlying the studied areas are shown in Figure 3-2 and 3-3 for the west and the east coast of Thailand respectively.

The radionuclides found in these beach sand samples are natural radioisotopes from the uranium, thorium and actinium decay chains plus the non-series radionuclide, ${ }^{40} \mathrm{~K}$. Transitions signifying decays from ${ }^{212} \mathrm{~Pb},{ }^{212} \mathrm{Bi},{ }^{228} \mathrm{Ac}$ and ${ }^{208} \mathrm{Tl}$ are the daughter products in thorium decay chain headed by ${ }^{232} \mathrm{Th}$, while transitions following decays of ${ }^{234} \mathrm{Th}$, ${ }^{226} \mathrm{Ra},{ }^{214} \mathrm{~Pb}$ and ${ }^{214} \mathrm{Bi}$ are from decay products in uranium decay chain headed by ${ }^{238} \mathrm{U}$. Although ${ }^{235} \mathrm{U}$ can not be detected clearly in the samples in the current work, peaks at gamma-ray energies of 143 and $163 \mathrm{keV}$ from the decay of ${ }^{235} \mathrm{U}$ could be used to prove and measure its presence. Gamma-ray energies below $90 \mathrm{keV}$ were not fully analysed in this study due to the interference with characteristic $x$-rays and other difficulties in identification. No evidence of ${ }^{7} \mathrm{Be}(477 \mathrm{keV})$ which is present in the gamma spectra of some natural waters and from environmental air filters (from ${ }^{7} \mathrm{Be}$ ) was observed in the sand samples studied in the current work. The artificial radionuclides (i.e. ${ }^{137} \mathrm{Cs}$ ) were also not found above the MDA. The single-escape peak (SEP) at 2,103 keV and double escape peaks (DEP) at $1,592 \mathrm{keV}$ from ${ }^{208} \mathrm{Tl}$ do appear in the spectrum. 


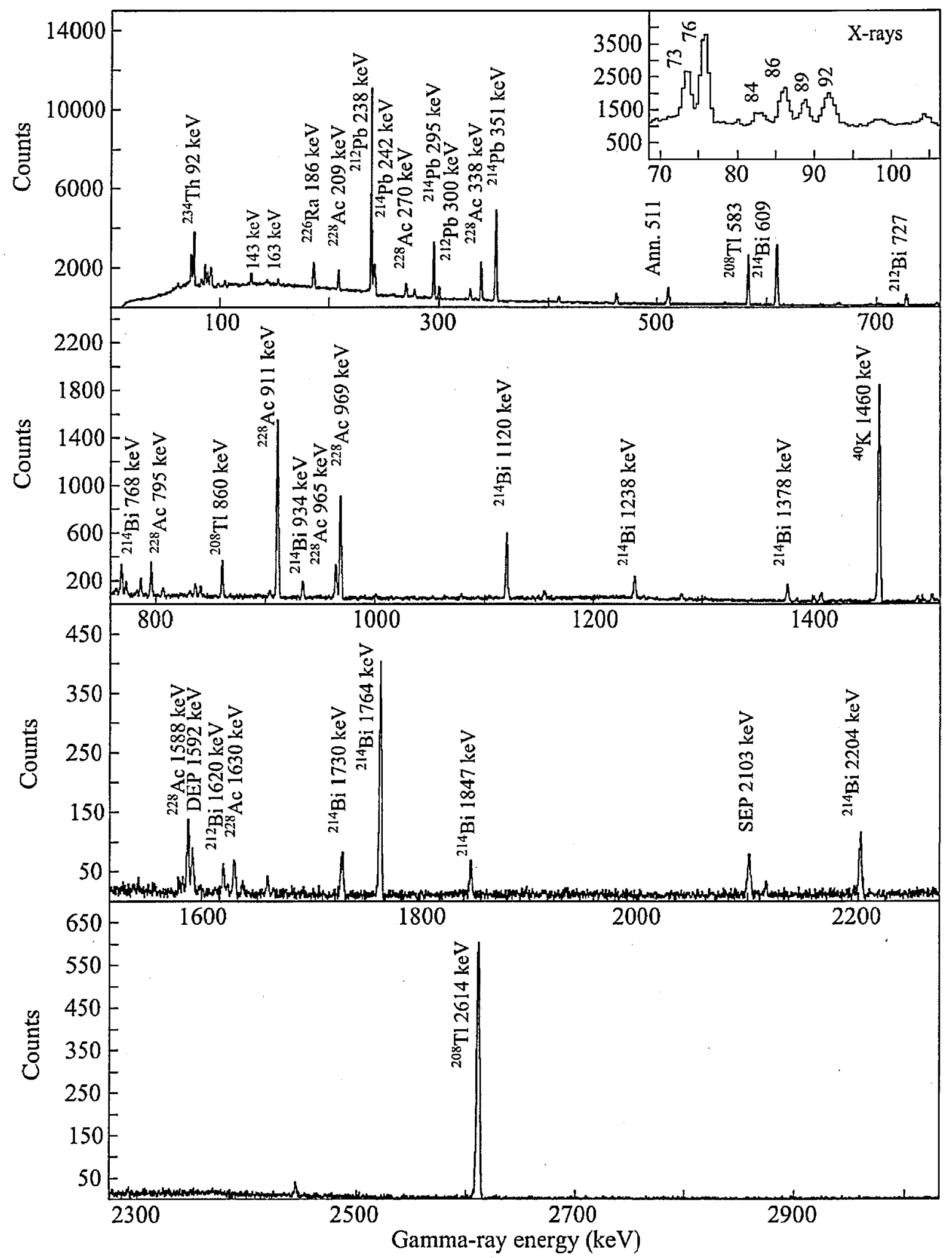

Figure 4-29: Gamma-ray spectrum of the 'Mai Kao' beach sand sample (subtracted background) collected for 172,800 s (i.e. 48 hours). 


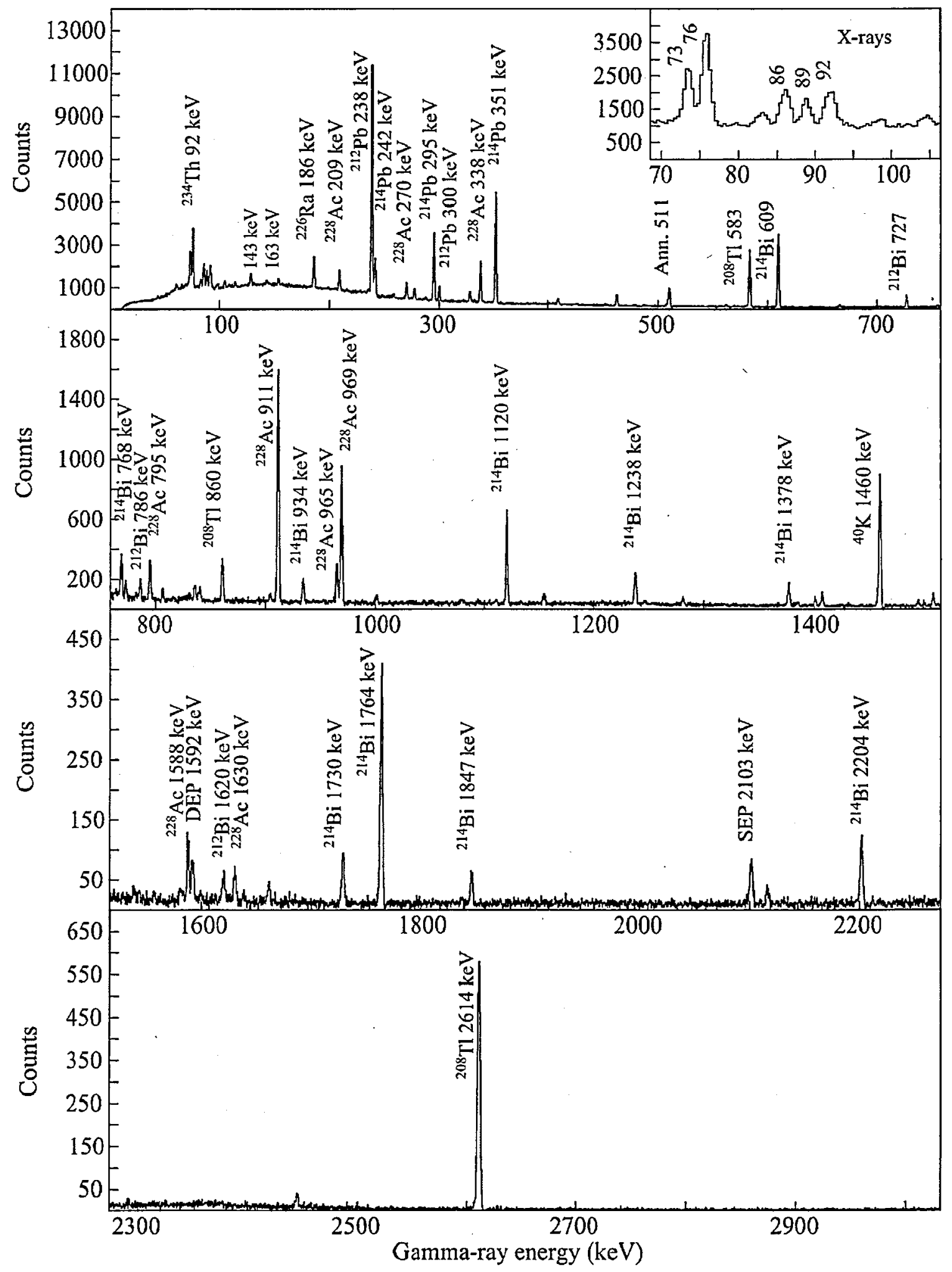

Figure 4-30: Gamma-ray spectrum of the 'Thai Mueng' beach sand sample (background subtracted) collected for 172,800 s (i.e. 48 hours). 


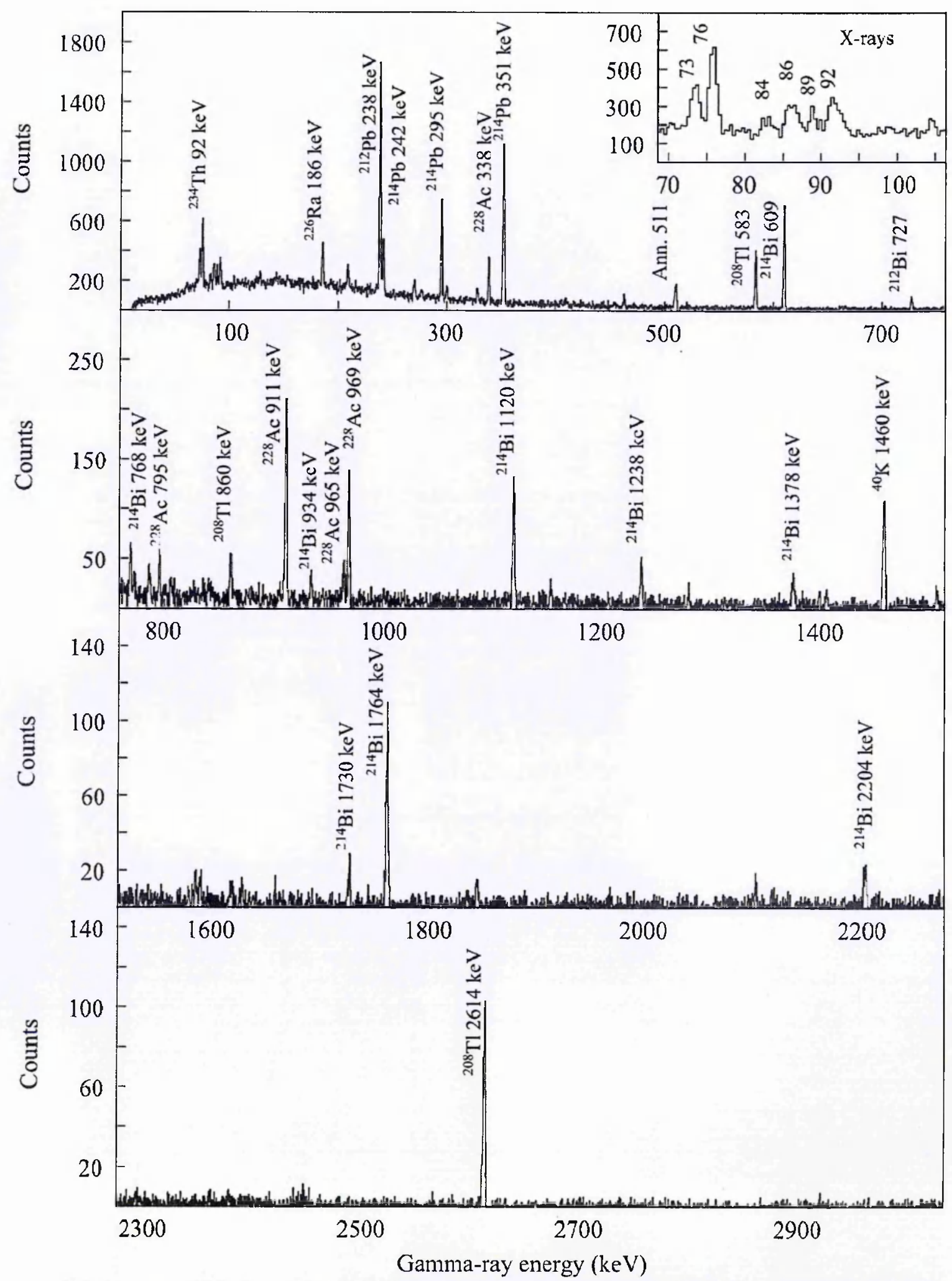

Figure 4-31: Gamma-ray spectrum of the 'Nopparat Thara' beach sand sample (background subtracted) and collected for 172,800 s (i.e. 48 hours). 


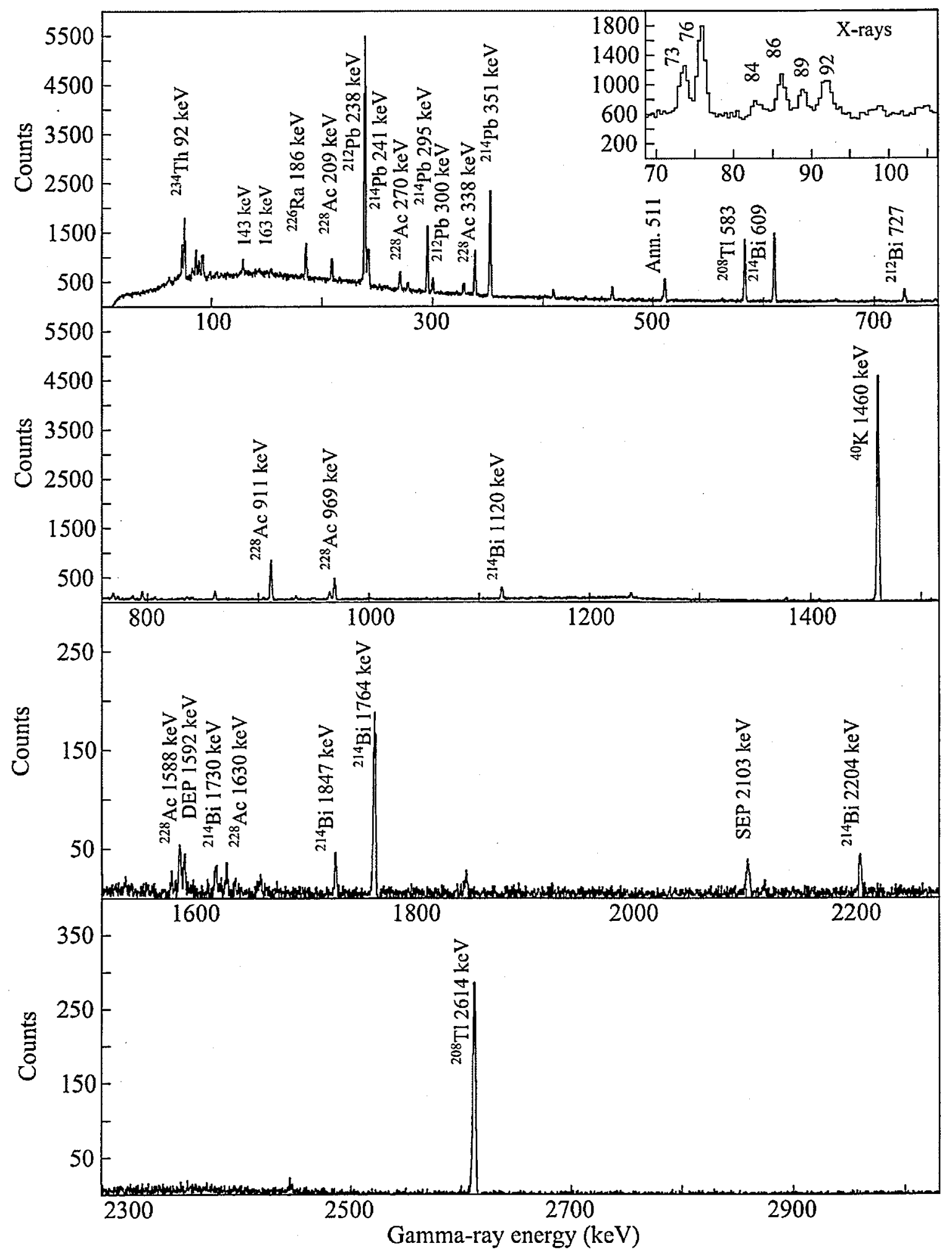

Figure 4-32: Gamma-ray spectrum of the 'Laem Son' beach sand sample (background subtracted) and collected for 172,800 s (i.e. 48 hours). 


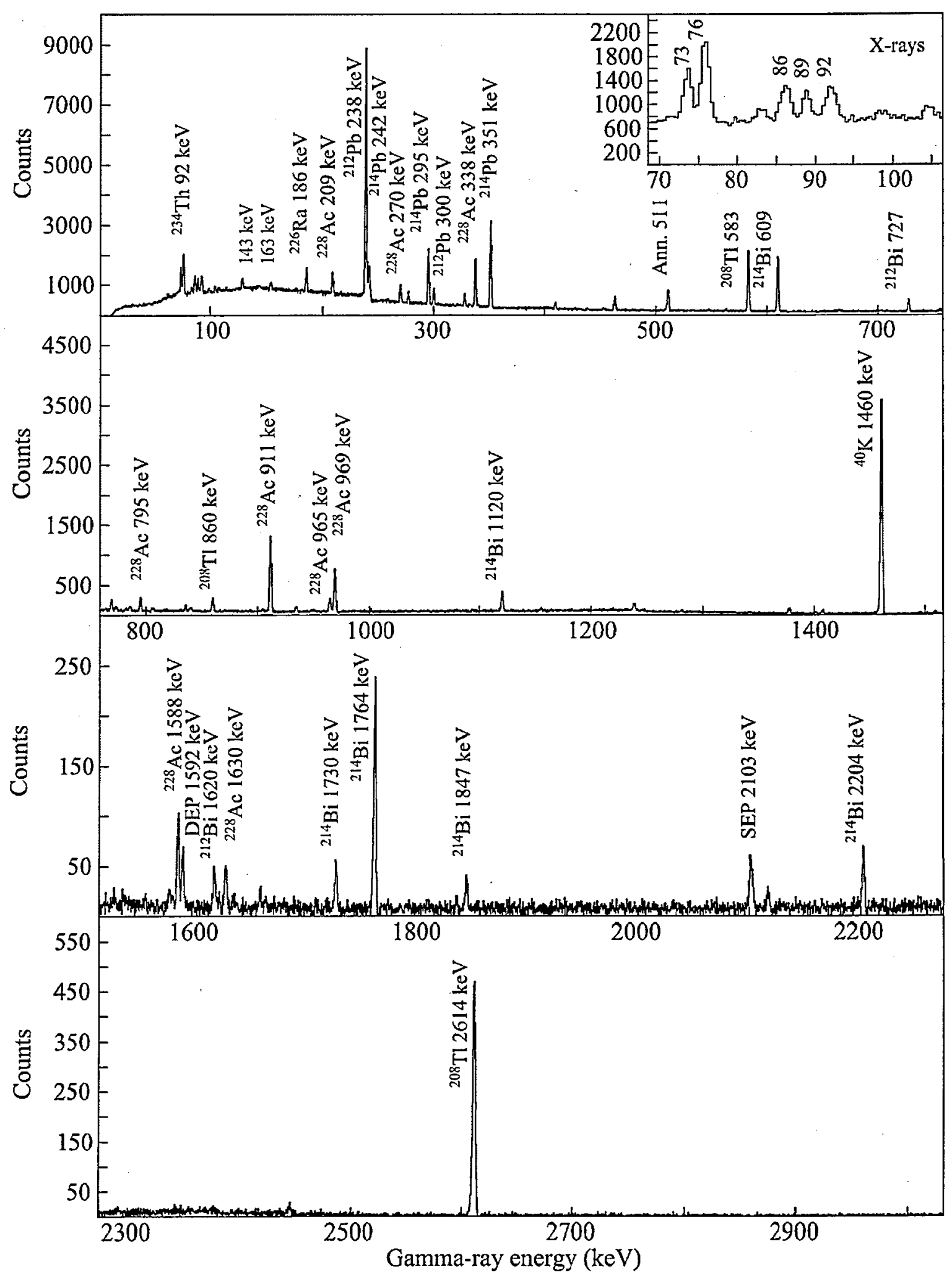

Figure 4-33: Gamma-ray spectrum of the 'Chaiya' beach sand sample (background subtracted) and collected for 172,800 s (i.e. 48 hours). 


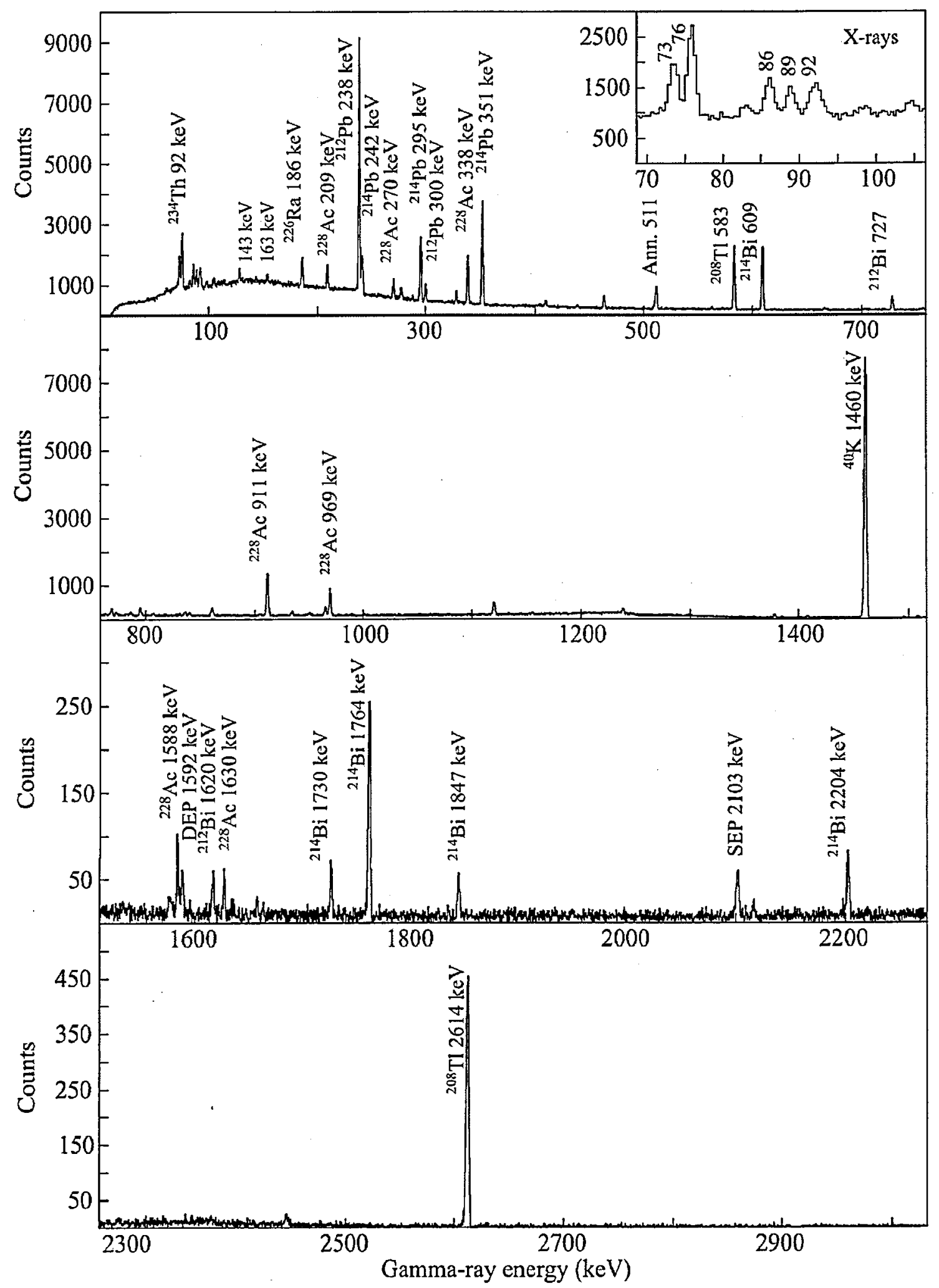

Figure 4-34: Gamma-ray spectrum of the 'Khanom' beach sand sample (background subtracted) and collected for 172,800 s (i.e. 48 hours). 


\subsubsection{The ${ }^{226} \mathrm{Ra} /{ }^{214} \mathrm{~Pb}$ and ${ }^{214} \mathrm{~Pb} /{ }^{214} \mathrm{Bi}$ Ratios}

The activity ratios of ${ }^{226} \mathrm{Ra} /{ }^{214} \mathrm{~Pb}$ and ${ }^{214} \mathrm{~Pb} /{ }^{214} \mathrm{Bi}$ were measured and summarised in Table 4-5.

Table 4-5 The activity ratios of ${ }^{226} \mathrm{Ra} /{ }^{214} \mathrm{~Pb}$ and ${ }^{214} \mathrm{~Pb} /{ }^{214} \mathrm{Bi}$ in beach sand samples.

\begin{tabular}{|c|c|c|c|}
\hline $\begin{array}{c}\text { Sample } \\
\text { no. }\end{array}$ & $\begin{array}{c}\text { Sample } \\
\text { Code }\end{array}$ & $\left.{ }^{226} \mathbf{R a}\right|^{214} \mathbf{P b}$ & ${ }^{214} \mathbf{P b} /{ }^{214} \mathbf{B i}$ \\
\hline 1 & PKMK-1 & 0.92 & 1.05 \\
2 & PKMK-2 & 0.93 & 1.04 \\
3 & PKMK-3 & 0.90 & 1.07 \\
4 & PNKL-1 & 0.87 & 1.09 \\
5 & PNKL-2 & 0.88 & 1.08 \\
6 & PNKL-3 & 0.94 & 1.04 \\
7 & PPBB-1 & 1.09 & 0.93 \\
8 & PPBB-2 & 0.83 & 1.10 \\
9 & PKPT-1 & 0.80 & 1.11 \\
10 & PKPT-2 & 0.81 & 1.13 \\
11 & PKPT-3 & 0.96 & 1.04 \\
12 & PKAP-1 & 1.01 & 0.92 \\
13 & PKCL-1 & 0.93 & 1.02 \\
14 & PKKT-1 & 1.00 & 1.02 \\
15 & PKKT-2 & 1.00 & 0.99 \\
16 & PKKT-3 & 0.92 & 1.08 \\
17 & PKNT-1 & 0.88 & 1.09 \\
18 & PKNT-2 & 0.93 & 1.03 \\
19 & PKNT-3 & 0.96 & 1.00 \\
20 & PKRW-1 & 0.84 & 1.09 \\
21 & PKRW-2 & 0.97 & 0.96 \\
22 & PKRW-3 & 0.91 & 1.06 \\
23 & PKSR-1 & 0.95 & 1.03 \\
24 & PKSR-2 & 1.00 & 0.94 \\
25 & PPTS-1 & 1.05 & 0.98 \\
26 & PPDI-2 & 1.04 & 0.92 \\
27 & PPLD-3 & 1.18 & 0.82 \\
28 & KBNT-1 & 1.09 & 0.98 \\
29 & KBNT-2 & 0.77 & 1.20 \\
30 & PNTM-1 & 0.91 & 1.06 \\
\hline
\end{tabular}

\begin{tabular}{|c|l|c|c|}
\hline $\begin{array}{c}\text { Sample } \\
\text { no. }\end{array}$ & \multicolumn{1}{|c|}{$\begin{array}{c}\text { Sample } \\
\text { Code }\end{array}$} & ${ }^{226} \mathbf{R a} /{ }^{214} \mathbf{P b}$ & ${ }^{214} \mathbf{P b}{ }^{214} \mathbf{B i}$ \\
\hline 31 & PNTM-2 & 0.91 & 1.04 \\
32 & SMTNG-1 & 0.92 & 1.06 \\
33 & SMTNG-2 & 0.89 & 1.11 \\
34 & SMLN-1 & 0.95 & 1.04 \\
35 & SMLN-2 & 0.79 & 1.18 \\
36 & SMLM-1 & 0.89 & 1.11 \\
37 & SMLM-2 & 0.89 & 1.06 \\
38 & SMLM-3 & 0.85 & 1.12 \\
39 & SMCW-1 & 0.78 & 1.14 \\
40 & SMCW-2 & 1.10 & 0.85 \\
41 & SMCW-3 & 0.88 & 1.08 \\
42 & SMBP-1 & 0.85 & 1.10 \\
43 & SMBP-2 & 0.83 & 1.12 \\
44 & STCY-1 & 1.01 & 0.99 \\
45 & STCY-2 & 0.96 & 1.00 \\
46 & NSKN-1 & 0.93 & 1.03 \\
47 & NSKN-2 & 0.82 & 1.15 \\
48 & NSKN-3 & 0.79 & 1.16 \\
49 & KPNRN-1 & 0.86 & 1.02 \\
50 & KPNRN-2 & 0.84 & 1.06 \\
51 & KPNRN-3 & 0.86 & 1.09 \\
52 & KPNKM-1 & 0.80 & 1.14 \\
53 & KPNKM-2 & 0.86 & 1.11 \\
54 & KPNKM-3 & 0.89 & 1.07 \\
55 & CPLS-1 & 0.84 & 1.09 \\
56 & CPLS-2 & 0.97 & 1.03 \\
57 & CPLS-3 & 0.98 & 0.97 \\
58 & CPHSR-1 & 1.13 & 0.91 \\
59 & CPHSR-2 & 0.86 & 1.07 \\
60 & CPHSR-3 & 1.10 & 0.91 \\
\hline
\end{tabular}

Since the activity of each radionuclide in the chain should be the same if radioactive equilibrium is achieved, the activity ratio of ${ }^{226} \mathrm{Ra}$ with its decay products and between its daughters can be used as an indicator for the radioactive equilibrium. From Table 4-5, it can be seen that the activity ratios of ${ }^{226} \mathrm{Ra} /{ }^{214} \mathrm{~Pb}$ and ${ }^{214} \mathrm{~Pb} /{ }^{214} \mathrm{Bi}$ are all close to unity. This means that the activity of ${ }^{226} \mathrm{Ra},{ }^{214} \mathrm{~Pb}$, and ${ }^{214} \mathrm{Bi}$ are similar and the assumption of radioactive equilibrium being established in the studied sand samples is valid. 


\subsubsection{The Concentrations of ${ }^{238} \mathrm{U},{ }^{232} \mathrm{Th}, \%$ Total $\mathrm{K}$ and the ${ }^{232} \mathrm{Th} /{ }^{238} \mathrm{U}$}

\section{Ratio}

The concentrations of ${ }^{238} \mathrm{U},{ }^{232} \mathrm{Th}$, and ${ }^{40} \mathrm{~K}$ were found lie in the range of $0.12-6.68,0.19$ $18.24 \mathrm{ppm}$ and $0.01-4.50 \%$ with the average mean values of $1.28,4.40 \mathrm{ppm}$ and $1.19 \%$ respectively, as illustrated in Figure 4-35. The highest $U$ concentration (6.68 ppm) was measured in the KPNKM sample corresponding to the formation of the granite rock, with and lower values found in other sedimentary rocks. The lowest $\mathrm{U}, \mathrm{Th}$ and $\mathrm{K}$ concentrations are present in the PPBB sample with values of $0.12,0.19$ and $0.01 \%$ respectively. These values are associated with limestone formations in the samples because the radionuclide contents cannot enter the carbonate lattices easily. The variation of the concentrations of ${ }^{238} \mathrm{U},{ }^{232} \mathrm{Th}$ and ${ }^{40} \mathrm{~K}$ are not only influenced by the geological feature underlying the studied area but also the geochemical properties of the different rock type.

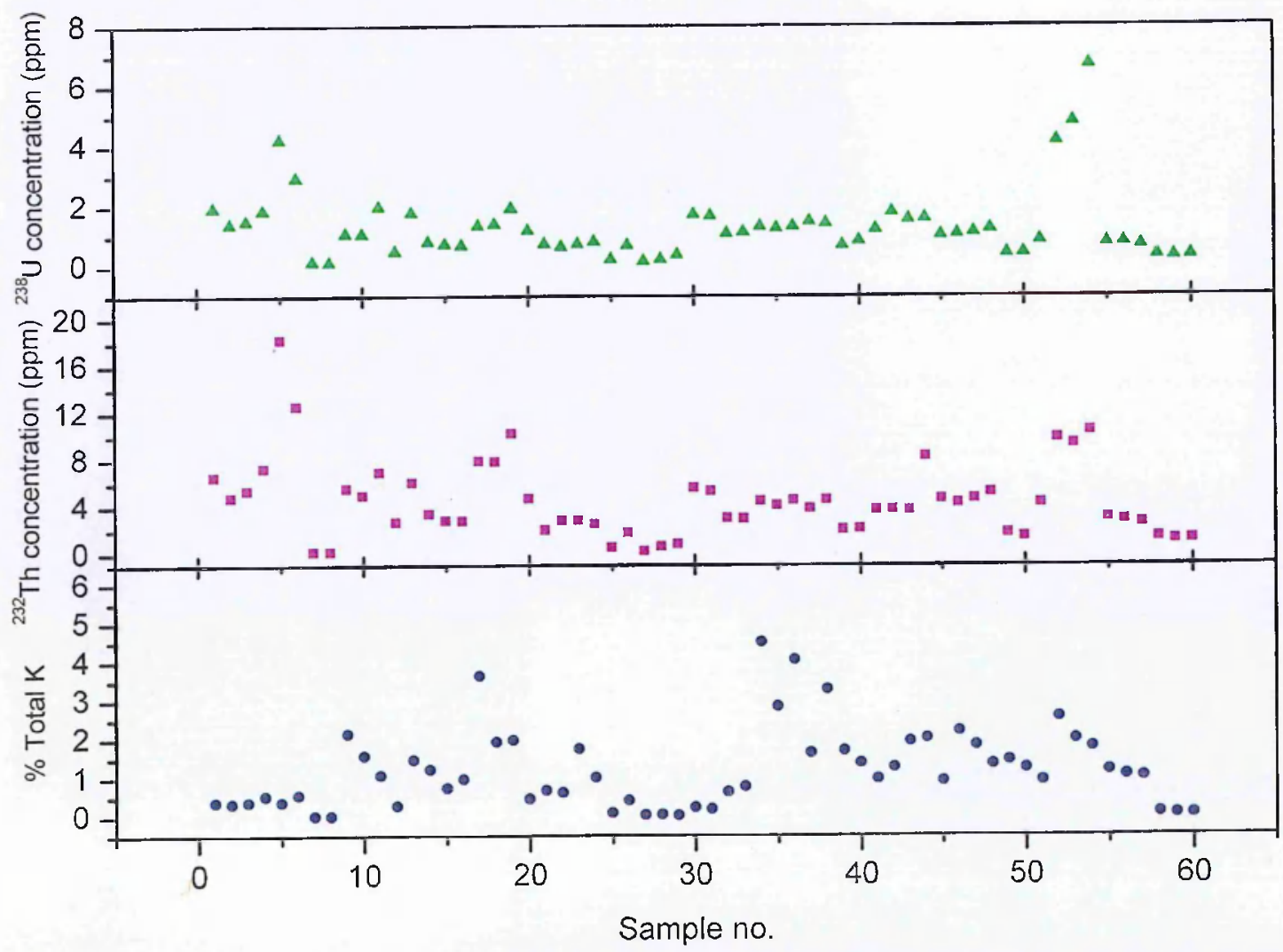

Figure 4-35: The concentrations of ${ }^{238} \mathrm{U},{ }^{232} \mathrm{Th}(\mathrm{ppm})$ and \% Total $K$ from all of the beach sand samples measured in the current study. 
Table 4-6 Elemental concentrations of the ${ }^{238} \mathrm{U},{ }^{232} \mathrm{Th}$ in ppm and the ratio of ${ }^{232} \mathrm{Th} /{ }^{238} \mathrm{U}$.

\begin{tabular}{|c|c|c|c|}
\hline $\begin{array}{c}\text { Sample } \\
\text { no. }\end{array}$ & $\begin{array}{c}{ }^{238} \mathrm{U} \\
(\mathrm{ppm})\end{array}$ & $\begin{array}{l}{ }^{232} \mathrm{Th} \\
\text { (ppm) }\end{array}$ & ${ }^{232} \mathrm{Th} /{ }^{238} \mathrm{U}$ \\
\hline 1 & 1.92 & 6.58 & 3.43 \\
\hline 2 & 1.37 & 4.81 & 3.50 \\
\hline 3 & 1.48 & 5.40 & 3.65 \\
\hline 4 & 1.84 & 7.30 & 3.97 \\
\hline 5 & 4.20 & 18.24 & 4.34 \\
\hline 6 & 2.93 & 12.61 & 4.31 \\
\hline 7 & 0.13 & 0.21 & 1.57 \\
\hline 8 & 0.12 & 0.19 & 1.59 \\
\hline 9 & 1.08 & 5.57 & 5.17 \\
\hline 10 & 1.06 & 4.96 & 4.67 \\
\hline 11 & 1.96 & 6.97 & 3.55 \\
\hline 12 & 0.48 & 2.72 & 5.65 \\
\hline 13 & 1.77 & 6.04 & 3.41 \\
\hline 14 & 0.79 & 3.40 & 4.30 \\
\hline 15 & 0.72 & 2.82 & 3.92 \\
\hline 16 & 0.68 & 2.78 & 4.09 \\
\hline 17 & 1.33 & 7.90 & 5.94 \\
\hline 18 & 1.38 & 7.81 & 5.68 \\
\hline 19 & 1.91 & 10.22 & 5.36 \\
\hline 20 & 1.17 & 4.67 & 3.99 \\
\hline 21 & 0.72 & 2.02 & 2.80 \\
\hline 22 & 0.63 & 2.84 & 4.48 \\
\hline 23 & 0.72 & 2.81 & 3.90 \\
\hline 24 & 0.79 & 2.53 & 3.23 \\
\hline 25 & 0.21 & 0.51 & 2.43 \\
\hline 26 & 0.68 & 1.77 & 2.60 \\
\hline 27 & 0.14 & 0.20 & 1.38 \\
\hline 28 & 0.20 & 0.60 & 3.02 \\
\hline 29 & 0.35 & 0.78 & 2.26 \\
\hline 30 & 1.68 & 5.58 & 3.31 \\
\hline
\end{tabular}

\begin{tabular}{|c|c|c|c|}
\hline $\begin{array}{c}\text { Sample } \\
\text { no. }\end{array}$ & $\begin{array}{c}{ }^{238} \mathrm{U} \\
(\mathrm{ppm})\end{array}$ & $\begin{array}{l}{ }^{232} \mathrm{Th} \\
\text { (ppm) }\end{array}$ & ${ }^{232} \mathrm{Th} /{ }^{238} \mathrm{U}$ \\
\hline 31 & 1.64 & 5.26 & 3.20 \\
\hline 32 & 1.05 & 2.98 & 2.84 \\
\hline 33 & 1.11 & 2.94 & 2.66 \\
\hline 34 & 1.29 & 4.45 & 3.45 \\
\hline 35 & 1.23 & 4.07 & 3.30 \\
\hline 36 & 1.30 & 4.49 & 3.47 \\
\hline 37 & 1.45 & 3.79 & 2.61 \\
\hline 38 & 1.40 & 4.54 & 3.25 \\
\hline 39 & 0.66 & 2.00 & 3.05 \\
\hline 40 & 0.81 & 2.06 & 2.54 \\
\hline 41 & 1.19 & 3.69 & 3.11 \\
\hline 42 & 1.76 & 3.72 & 2.11 \\
\hline 43 & 1.53 & 3.64 & 2.38 \\
\hline 44 & 1.55 & 8.19 & 5.27 \\
\hline 45 & 0.99 & 4.59 & 4.63 \\
\hline 46 & 1.04 & 4.27 & 4.09 \\
\hline 47 & 1.08 & 4.63 & 4.28 \\
\hline 48 & 1.21 & 5.16 & 4.27 \\
\hline 49 & 0.40 & 1.71 & 4.31 \\
\hline 50 & 0.41 & 1.39 & 3.39 \\
\hline 51 & 0.81 & 4.27 & 5.25 \\
\hline 52 & 4.14 & 9.79 & 2.37 \\
\hline 53 & 4.78 & 9.31 & 1.95 \\
\hline 54 & 6.68 & 10.37 & 1.55 \\
\hline 55 & 0.75 & 2.98 & 3.96 \\
\hline 56 & 0.76 & 2.82 & 3.69 \\
\hline 57 & 0.66 & 2.56 & 3.90 \\
\hline 58 & 0.32 & 1.34 & 4.23 \\
\hline 59 & 0.28 & 1.10 & 3.88 \\
\hline 60 & 0.30 & 1.14 & 3.78 \\
\hline
\end{tabular}

Table 4-6 gives the ratio of ${ }^{232} \mathrm{Th} /{ }^{238} \mathrm{U}$ for the 60 beach sand samples collected along the west and the east coast of Thai peninsular. The ratio was found to lie in the range from 1.38 to 5.94 with the mean value of 3.57 . The results show that the areas under investigation have uranium and thorium contents in the typical rock range with a ${ }^{232} \mathrm{Th} /{ }^{238} \mathrm{U}$ ratio close to the continental crustal average concentration of 3.82 , as reported by the NCRP (1987) (see Table 2-3). Chiozzi et al. [CHI02] state that the agreement of these two values suggests that there is no significant fractionation during weathering or associated with the metasomatic activity in the monitored area. 


\subsubsection{Correlation Between ${ }^{238} \mathrm{U}$ and ${ }^{232} \mathrm{Th}$ Concentrations}

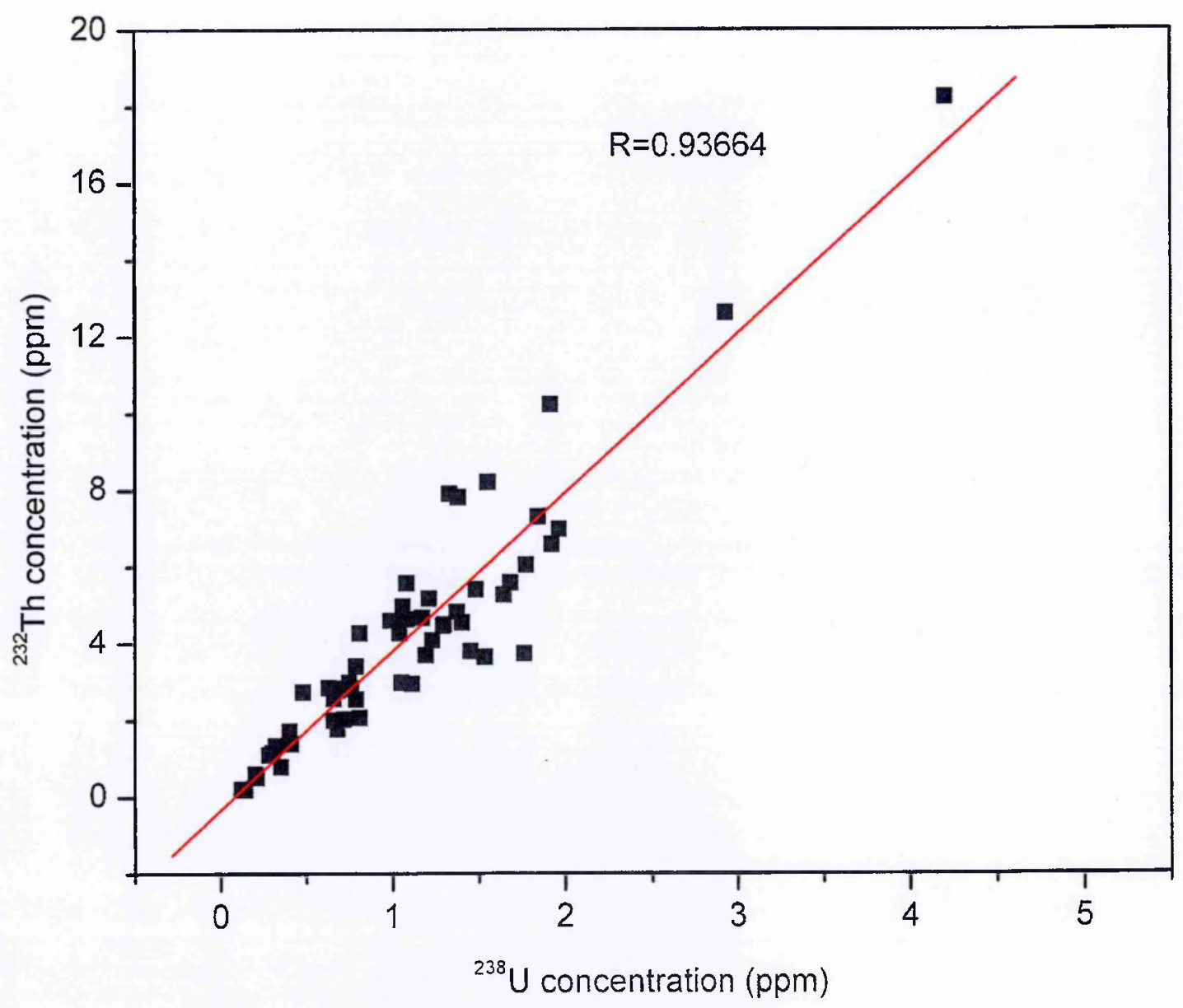

Figure 4-36: Correlation between ${ }^{238} \mathrm{U}$ and ${ }^{232} \mathrm{Th}$ in beach sand samples.

The correlation between ${ }^{238} \mathrm{U}$ and ${ }^{232} \mathrm{Th}$ concentrations in beach sand samples is shown in Figure 4-36. The solid line in the figure represents the best-fit between the ${ }^{238} \mathrm{U}$ and ${ }^{232} \mathrm{Th}$ concentrations is approximately a linear relationship with a correlation coefficient of 0.93. The ${ }^{238} \mathrm{U}$ and ${ }^{232} \mathrm{Th}$ concentrations from the KPNKM-1, KPNKM-2, and KPNKM-3 samples collected from Hat Koh Ma in Phangan island show an anomalous uranium enrichment reflected by the occurrence of granite rock and were excluded from this plot. The activity concentrations of ${ }^{238} \mathrm{U},{ }^{232} \mathrm{Th}$ and ${ }^{40} \mathrm{~K}$ with the radium equivalent activity $\left(R a_{e q}\right)$, the external $\left(H_{\mathrm{ex}}\right)$ and internal $\left(H_{\mathrm{in}}\right)$ hazard indicies estimated using equations (2.92), (2.93) and (2.94) respectively, for all beach sand samples are shown in Table 4-7. 


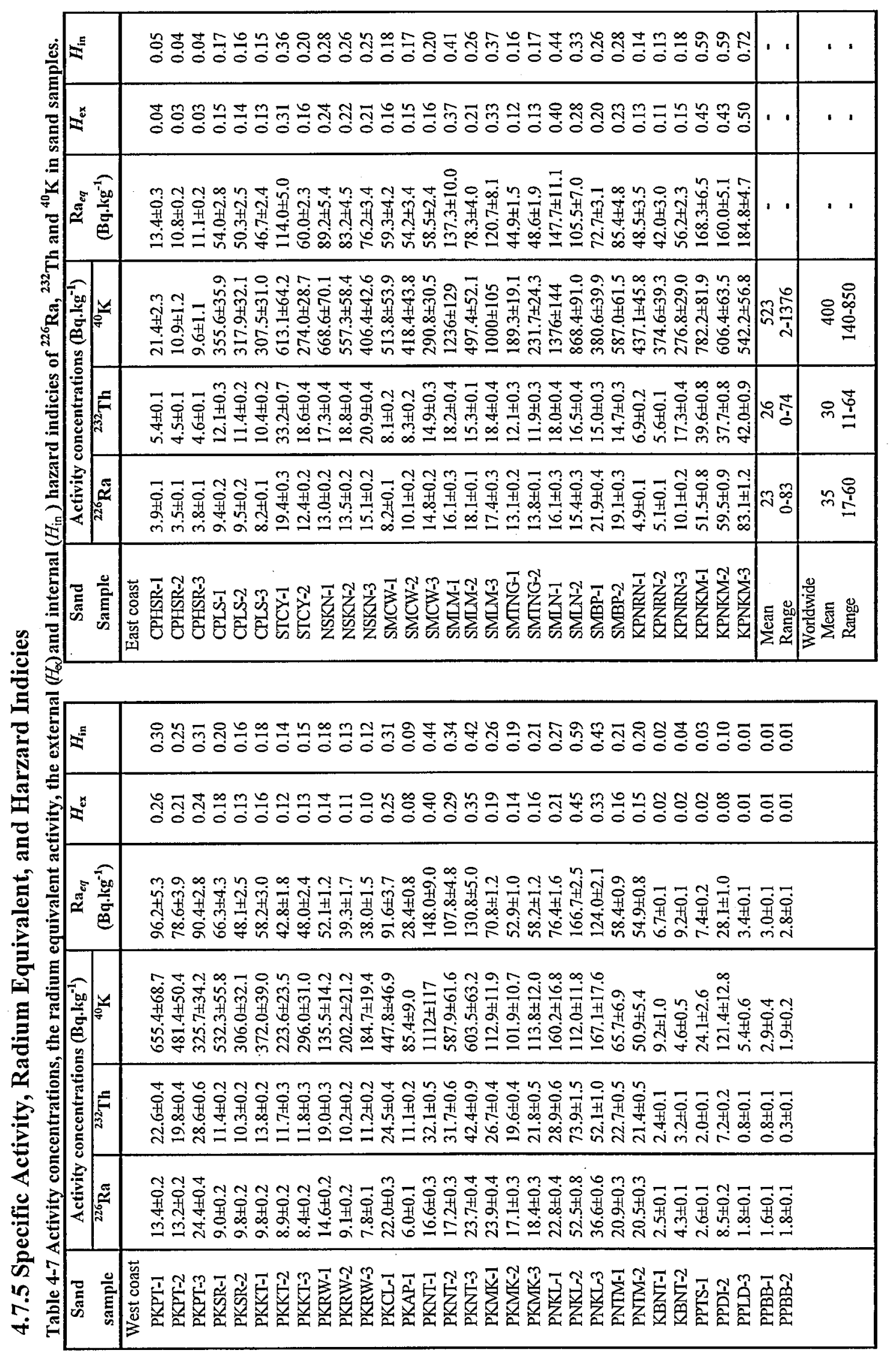


The acivity concentrations of ${ }^{226} \mathrm{Ra},{ }^{232} \mathrm{Th}$ and ${ }^{40} \mathrm{~K}$ for sand samples from the west coast lie in the range of $1.6 \pm 0.1 \leftrightarrow 52.5 \pm 0.8,0.3 \pm 0.1 \leftrightarrow 73.9 \pm 1.5$, and $2.8 \pm 0.1 \leftrightarrow 1112 \pm 117 \mathrm{~Bq}$. $\mathrm{kg}^{-1}$ respectively. By contrast, the activity concentrations of ${ }^{226} \mathrm{Ra},{ }^{232} \mathrm{Th}$ and ${ }^{40} \mathrm{~K}$ for sand samples from the east coast lie in the range of $3.5 \pm 0.1 \leftrightarrow 83.1 \pm 1.2,4.5 \pm 0.1 \leftrightarrow 42.0 \pm 0.9$, and $9.6 \pm 1.1 \leftrightarrow 1,376 \pm 144 \mathrm{~Bq} \cdot \mathrm{kg}^{-1}$ respectively. It can be thus seen that the difference of radioactivity from sand samples between the west and the east coast of Thailand is insignificant. The activity concentrations of ${ }^{226} \mathrm{Ra},{ }^{232} \mathrm{Th}$ and ${ }^{40} \mathrm{~K}$ for all sand samples were found to lie in the range of $1.6 \pm 0.1 \leftrightarrow 83.1 \pm 1.2, \quad 0.3 \pm 0.1 \leftrightarrow 73.9 \pm 1.5$, $1.9 \pm 0.2 \leftrightarrow 1,376 \pm 144 \mathrm{~Bq} \mathrm{~kg}^{-1}$ with the average mean value of $22.6 \pm 0.1,26.4 \pm 0.1$ and $523.0 \pm 6.6 \mathrm{~Bq} \cdot \mathrm{kg}^{-1}$ respectively. The results obtained from the beach sand are higher than the range for ${ }^{226} \mathrm{Ra}$ and ${ }^{232} \mathrm{Th}$ in soil as reported by the UNSCEAR (2000) which are 1760 and 11-64 Bq. $\mathrm{kg}^{-1}$. However, the mean values of ${ }^{226} \mathrm{Ra}$ and ${ }^{232} \mathrm{Th}$ are still lower than that of worldwide average values which are 35 and $30 \mathrm{~Bq} \cdot \mathrm{kg}^{-1}$ respectively. The activity concentration of ${ }^{40} \mathrm{~K}$ in the studied samples is higher than the worldwide average concentration which is $140-850 \mathrm{~Bq} \cdot \mathrm{kg}^{-1}$ with the mean values of $400 \mathrm{~Bq} \cdot \mathrm{kg}^{-1}$. This may be because all measured samples are beach sands which can be washed out by potassium in the ocean waters and more potassium was then absorbed into the sand surface. The acivity concentrations of ${ }^{226} \mathrm{Ra},{ }^{232} \mathrm{Th}$ and ${ }^{40} \mathrm{~K}$ from the current work are consistent with the values reported by others in sand as shown in Table 4-8.

The calculated external and internal hazard indices for sand samples obtained in this study ranges from $0.01-0.50$ and $0.01-0.72$ respectively while the radium equivalent activity varied from $2.8-184.8 \mathrm{~Bq} \cdot \mathrm{kg}^{-1}$ which are lower than the internationally approved values ( $<1$ for $H_{\text {ex }}$ and $H_{\text {in }}$, and $<370 \mathrm{~Bq} \cdot \mathrm{kg}^{-1}$ for $\mathrm{Ra}_{e q}$ ) [UNSCEAR00]. The indication from the current work is that none of beach sand samples studied could be considered as a radiological hazard to people who were exposed to these sand samples on the beaches and the monitored areas are at the typical local level of radioactivity from natural background radiation. It is also noted that the small variation in the radioactivity content of sand samples can be observed due to the geographical and geomorphologic conditions such as sand type, mineral make-up, density and sand transport process. 
Table 4-8 The specific activities of ${ }^{238} \mathrm{U},{ }^{226} \mathrm{Ra},{ }^{232} \mathrm{Th},{ }^{40} \mathrm{~K}$ and ${ }^{137} \mathrm{Cs}$ in the beach sand and soil samples measured in the current work and compared with previous reported values world wide.

\begin{tabular}{|c|c|c|c|c|c|}
\hline \multirow[t]{2}{*}{ Location } & \multicolumn{5}{|c|}{ Activity concentration (Bq. $\mathrm{kg}^{-1}$ dry) } \\
\hline & ${ }^{238} \mathrm{U}$ & ${ }^{226} \mathrm{Ra}$ & ${ }^{232} \mathrm{Th}$ & ${ }^{40} \mathrm{~K}$ & ${ }^{137} \mathrm{Cs}$ \\
\hline \multicolumn{6}{|l|}{ Beach sand } \\
\hline \multirow{2}{*}{$\begin{array}{l}\text { Patong Beach, Phuket, } \\
\text { Thailand [B0007] }\end{array}$} & \multirow[t]{2}{*}{ - } & \multirow{2}{*}{$\begin{array}{c}0 \leftrightarrow 67.8 \\
(8.9)\end{array}$} & \multirow{2}{*}{$\begin{array}{c}0 \leftrightarrow 335.3 \\
(42.4)\end{array}$} & \multirow{2}{*}{$\begin{array}{c}0 \leftrightarrow 4330.9 \\
(963.1)\end{array}$} & \multirow[t]{2}{*}{$0 \leftrightarrow 1.6$} \\
\hline & & & & & \\
\hline Chalatat and Samila Beach & \multirow[t]{2}{*}{-} & \multirow{2}{*}{$\begin{array}{c}0 \leftrightarrow 210.8 \\
(41.4)\end{array}$} & \multirow{2}{*}{$\begin{array}{c}0 \leftrightarrow 318.8 \\
(63.8)\end{array}$} & \multirow{2}{*}{$\begin{array}{c}89.2 \leftrightarrow 963.4 \\
(247.8)\end{array}$} & \multirow{2}{*}{$\begin{array}{c}0 \leftrightarrow 9.4 \\
(1.0)\end{array}$} \\
\hline Songkhal, Thailand [BEN07] & & & & & \\
\hline Pakmeng Beach, Trang, & \multirow[t]{2}{*}{-} & \multirow{2}{*}{$\begin{array}{c}3.9 x \rightarrow 27.4 \\
(13.1)\end{array}$} & \multirow{2}{*}{$\begin{array}{c}2.3 \leftrightarrow 15.4 \\
(6.9)\end{array}$} & \multirow{2}{*}{$\begin{array}{c}33.3 \leftrightarrow 85.2 \\
(57.3)\end{array}$} & \multirow[t]{2}{*}{-} \\
\hline Thailand [AYU07] & & & & & \\
\hline \multirow[t]{2}{*}{ Kalpakkam, India [KAN02] } & $36 \leftrightarrow 258$ & \multirow[t]{2}{*}{ - } & $352 \leftrightarrow 3872$ & \multirow{2}{*}{$\begin{array}{c}324 \leftrightarrow 405 \\
(358)\end{array}$} & \multirow[t]{2}{*}{-} \\
\hline & (124) & & (1613) & & \\
\hline \multirow{2}{*}{$\begin{array}{l}\text { Balochistan coast, Arabian sea, } \\
\text { Pakistan [AKR07] }\end{array}$} & \multirow[t]{2}{*}{-} & \multirow[t]{2}{*}{$14.4 \leftrightarrow 36.6$} & \multirow[t]{2}{*}{-} & \multirow[t]{2}{*}{$144.6 \leftrightarrow 610.5$} & - \\
\hline & & & & & \\
\hline Red Sea Coast, Egypt [ELA05] & - & $10.0 \leftrightarrow 64.0$ & $9.0 \leftrightarrow 37.4$ & $421 \leftrightarrow 969$ & - \\
\hline Ezien region, Turkey [ORG07] & 290.36 & - & 532.04 & 1160.75 & - \\
\hline Southeast coast, Brazil [VEI06] & - & $5 \leftrightarrow 4043$ & $7 \leftrightarrow 55537$ & $25 \leftrightarrow 888$ & - \\
\hline $\begin{array}{l}\text { Northeast Coast, Spain } \\
\text { [ROS91] }\end{array}$ & $5 \leftrightarrow 19$ & - & $5 \leftrightarrow 44$ & $136 \leftrightarrow 1087$ & $\leq 0.1 \leftrightarrow 1.0$ \\
\hline $\begin{array}{l}\text { West coast, South Africa } \\
\text { [NEW08] }\end{array}$ & 4.0 & - & 4.8 & 33.5 & - \\
\hline Present work, West and east & - & $1.6 \leftrightarrow 83.1$ & $0.3 \leftrightarrow 73.9$ & $1.9 \leftrightarrow 1375.6$ & - \\
\hline coast, Thailand & & $(22.6)$ & $(26.4)$ & $(523.0)$ & \\
\hline Soil & & & & & \\
\hline Songkhla, Thailand [OAP02] ${ }^{a}$ & $97.3 \leftrightarrow 721.3$ & $37.1 \leftrightarrow 471.0$ & $36.1 \leftrightarrow 676.9$ & $43.4 \leftrightarrow 816.1$ & $0.8 \leftrightarrow 1.4$ \\
\hline & & $(171.6)$ & $(211.2)$ & $(511.0)$ & $(1.1)$ \\
\hline Hatyai District, Songkhla, & - & $25.7 \leftrightarrow 156.1$ & $6.8 \leftrightarrow 91.3$ & $62.4 \leftrightarrow 949.4$ & - \\
\hline Thailand [KES08] & & $(67.7)$ & $(45.0)$ & $(213.0)$ & \\
\hline Kalpakkam, India [KAN02] & $5 \leftrightarrow 71$ & - & $15 \leftrightarrow 776$ & $200 \leftrightarrow 854$ & $\leq 1.0 \leftrightarrow 2.8$ \\
\hline & (16) & & $(119)$ & $(406)$ & \\
\hline $\begin{array}{l}\text { Qena governorate, Egypt } \\
\text { [AHM05] }\end{array}$ & - & $\begin{array}{l}7.7 \leftrightarrow 16.9 \\
(13.7)\end{array}$ & $\begin{array}{c}10.0 \leftrightarrow 16.1 \\
(12.3)\end{array}$ & $\begin{array}{l}838 \leftrightarrow 1692 \\
\quad(1233)\end{array}$ & - \\
\hline Cox’s Bazar, Bangladesh & - & $10.8 \leftrightarrow 27.3$ & $27.4 \leftrightarrow 49.4$ & $117 \leftrightarrow 688$ & - \\
\hline [ALA99] & & (19) & $(36.7)$ & $(458.2)$ & \\
\hline Byers Peninsula, Western & $5 \leftrightarrow 36$ & $3 \leftrightarrow 14$ & $4 \leftrightarrow 31$ & $125 \leftrightarrow 810$ & $0.5 \leftrightarrow 4$ \\
\hline Antarctica [NAV05] & $(16.2)$ & $(8.0)$ & $(13.1)$ & $(317.1)$ & $(1.2)$ \\
\hline Araba Valley, Jordan [ABU08] & $19 \leftrightarrow 38.7$ & - & $14.3 \leftrightarrow 35$ & $94 \leftrightarrow 762$ & - \\
\hline Tripoli, Libya [SHE97] & 10.5 & - & 9.5 & 270 & - \\
\hline Firtina Valley, Turkey[KUR07] & $11 \leftrightarrow 188$ & - & $10 \leftrightarrow 105$ & $105 \leftrightarrow 1235$ & $19 \leftrightarrow 232$ \\
\hline Faisalabad, Pakistan [TUF06] & - & $24 \leftrightarrow 33$ & $46 \leftrightarrow 62$ & $499 \leftrightarrow 629$ & - \\
\hline
\end{tabular}

a Data collected and analysed by Office of Atoms for Peace(OAP) in Thailand during 1994-2002[OAP02]

Values in parentheses represent an average of the activity concentration. 


\subsubsection{External Gamma Dose Rate}

The gamma dose rate $(D)$ in $\mathrm{nGy} \cdot \mathrm{h}^{-1}$ in the outdoor air at $1 \mathrm{~m}$ above the ground is calculated using the following equation [UNSCEAR00].

$D=0.462 A_{R a}+0.604 A_{T h}+0.0417 A_{K}$

where $D$ is the dose rate in $\mathrm{nGy} \cdot \mathrm{h}^{-1}$ and $A_{\mathrm{Ra}}, A_{\mathrm{Th}}$ and $A_{\mathrm{K}}$ are the specific activities (in units of Bq. $\mathrm{kg}^{-1}$ ) of ${ }^{226} \mathrm{Ra},{ }^{232} \mathrm{Th}$ and ${ }^{40} \mathrm{~K}$, respectively.

For the 'Patong' beach sand sample collected from the beach front (PKPT-1) the extracted values were; $A_{\mathrm{Ra}}=13.4 \pm 0.2 \mathrm{~Bq} . \mathrm{kg}^{-1}, A_{\mathrm{Th}}=22.6 \pm 0.4 \mathrm{~Bq} \cdot \mathrm{kg}^{-1}$, and $A_{\mathrm{K}}=655.4 \pm 68.7$ Bq. $\mathrm{kg}^{-1}$

Therefore, the air-absorbed dose rate due to the gamma-ray emission from the "Patong" sand samples is external dose rate $=(0.462 \times 13.4)+(0.604 \times 22.6)+(0.0417 \times 655.4)=$ $47.2 \pm 2.9 \mathrm{nGy} \cdot \mathrm{h}^{-1}$

To estimate the annual effective dose rate; the conversion factor of $0.7 S v \cdot G y^{-1}$ [UNSCEAR00] from the absorbed dose in air to the effective dose received by adults and outdoor occupancy factor, assuming that people in Thailand spend approximately $20 \%$ of their time outdoors, have been applied. Under these assumptions, the annual effective dose was calculated using the following relation [DRA06]

Annual effective dose $\left(\mathrm{mSv} \cdot \mathrm{y}^{-1}\right)=D\left(\frac{10^{-9} G y}{h}\right) \times 24 \frac{h}{d a y} \times 365 \frac{d a y}{y} \times \frac{10^{-6} m G y}{10^{-9} G y} \times 0.7 \frac{S v}{G y} \times 0.2$

$$
=D \times 1.23 \times 10^{-3} \mathrm{mSv} \cdot \mathrm{y}^{-1}
$$

Therefore, the annual effective dose from the "Patong" beach sand sample (PKPT-1D) $=47.2 \times 1.23 \times 10^{-3}=0.058 \mathrm{mSv} \cdot \mathrm{y}^{-1}=58.0 \mu \mathrm{Sv} \cdot \mathrm{y}^{-1}$ 
Table 4-9 The absorbed dose rate and annual effective dose rate caused by ${ }^{226} \mathrm{Ra},{ }^{232} \mathrm{Th},{ }^{40} \mathrm{~K}$ from the sand samples in the current study.

\begin{tabular}{|c|c|c|c|c|c|}
\hline $\begin{array}{c}\text { Beach sand } \\
\text { sample }\end{array}$ & $\begin{array}{l}\text { Absorbed dose } \\
\text { rate }\left(\mathrm{nGy} \cdot \mathrm{h}^{-1}\right)\end{array}$ & $\begin{array}{l}\text { Effective dose } \\
\text { rate }\left(\mu S v \cdot y^{-1}\right)\end{array}$ & $\begin{array}{c}\text { Beach sand } \\
\text { sample }\end{array}$ & $\begin{array}{l}\text { Absorbed dose } \\
\text { rate }\left(n G y \cdot h^{-1}\right)\end{array}$ & $\begin{array}{l}\text { Effective dose } \\
\text { rate }\left(\mu S v \cdot y^{-1}\right)\end{array}$ \\
\hline $\begin{array}{c}\text { West coast } \\
\text { PKPT- } 1\end{array}$ & $47.2 \pm 2.9$ & $57.9 \pm 3.5$ & $\begin{array}{r}\text { East coast } \\
\text { CPHSR-1 }\end{array}$ & $6.0 \pm 0.1$ & $7.4 \pm 0.2$ \\
\hline PKPT-2 & $38.2 \pm 2.1$ & $46.8 \pm 2.6$ & CPHSR-2 & $4.8 \pm 0.1$ & $5.9 \pm 0.1$ \\
\hline PKPT-3 & $42.2 \pm 1.5$ & $51.2 \pm 1.8$ & CPHSR-3 & $4.9 \pm 0.1$ & $6.0 \pm 0.1$ \\
\hline PKSR-1 & $33.2 \pm 2.3$ & $40.8 \pm 2.9$ & CPLS-1 & $26.4 \pm 1.5$ & $32.4 \pm 1.8$ \\
\hline PKSR-2 & $23.5 \pm 1.4$ & $28.8 \pm 1.6$ & CPLS-2 & $24.6 \pm 1.4$ & $30.1 \pm 1.6$ \\
\hline PKKT-1 & $28.4 \pm 1.6$ & $34.8 \pm 2.0$ & CPLS-3 & $22.9 \pm 1.3$ & $28.0 \pm 1.6$ \\
\hline PKKT-2 & $20.5 \pm 1.0$ & $25.1 \pm 1.2$ & STCY-1 & $54.5 \pm 2.7$ & $66.9 \pm 3.3$ \\
\hline PKKT-3 & $23.3 \pm 1.3$ & $28.6 \pm 1.6$ & STCY-2 & $28.4 \pm 1.2$ & $34.7 \pm 1.5$ \\
\hline PKRW-1 & $23.8 \pm 0.6$ & $29.2 \pm 0.8$ & NSKN-1 & $44.3 \pm 2.9$ & $54.4 \pm 3.6$ \\
\hline PKRW-2 & $18.8 \pm 0.9$ & $23.1 \pm 1.1$ & NSKN-2 & $40.8 \pm 2.4$ & $50.0 \pm 3.0$ \\
\hline PKRW-3 & $18.1 \pm 0.8$ & $22.1 \pm 1.0$ & NSKN-3 & $36.5 \pm 1.8$ & $44.8 \pm 2.2$ \\
\hline PKCL-1 & $43.7 \pm 2.0$ & $53.6 \pm 2.4$ & SMCW-1 & $30.1 \pm 2.2$ & $36.9 \pm 2.8$ \\
\hline PKAP-1 & $13.0 \pm 0.4$ & $16.0 \pm 0.5$ & SMCW-2 & $27.2 \pm 1.8$ & $33.3 \pm 2.2$ \\
\hline PKNT-1 & $73.4 \pm 4.9$ & $90.0 \pm 6.0$ & SMCW-3 & $28.0 \pm 1.3$ & $34.3 \pm 1.6$ \\
\hline PKNT-2 & $51.6 \pm 2.6$ & $63.3 \pm 3.2$ & SMLM-1 & $70.0 \pm 5.4$ & $85.8 \pm 6.6$ \\
\hline PKNT-3 & $61.7 \pm 2.7$ & $75.7 \pm 3.3$ & SMLM-2 & $38.4 \pm 2.2$ & $47.0 \pm 2.7$ \\
\hline PKMK-1 & $31.9 \pm 0.6$ & $39.1 \pm 0.7$ & SMLM-3 & $60.8 \pm 4.4$ & $74.6 \pm 5.4$ \\
\hline PKMK-2 & $23.9 \pm 0.5$ & $29.4 \pm 0.6$ & SMTNG-1 & $21.2 \pm 0.8$ & $26.0 \pm 1.0$ \\
\hline PKMK-3 & $26.4 \pm 0.6$ & $32.4 \pm 0.7$ & SMTNG-2 & $23.2 \pm 1.0$ & $28.5 \pm 1.3$ \\
\hline PNKL-1 & $34.7 \pm 0.8$ & $42.5 \pm 1.0$ & SMLN-1 & $75.7 \pm 6.0$ & $92.8 \pm 7.4$ \\
\hline PNKL-2 & $73.5 \pm 1.1$ & $90.2 \pm 1.3$ & SMLN-2 & $53.1 \pm 3.8$ & $65.2 \pm 4.6$ \\
\hline PNKL-3 & $55.4 \pm 1.0$ & $67.9 \pm 1.2$ & SMBP-1 & $35.1 \pm 1.7$ & $43.0 \pm 2.1$ \\
\hline PNTM-1 & $26.1 \pm 0.4$ & $32.0 \pm 0.5$ & SMBP-2 & $42.2 \pm 2.6$ & $51.8 \pm 3.2$ \\
\hline PNTM-2 & $24.5 \pm 0.4$ & $30.0 \pm 0.5$ & KPNRN-1 & $24.7 \pm 1.9$ & $30.2 \pm 2.3$ \\
\hline KBNT-1 & $3.0 \pm 0.1$ & $3.7 \pm 0.1$ & KPNRN-2 & $21.4 \pm 1.6$ & $26.2 \pm 2.0$ \\
\hline KBNT-2 & $4.1 \pm 0.1$ & $5.1 \pm 0.1$ & KPNRN-3 & $26.7 \pm 1.2$ & $32.7 \pm 1.5$ \\
\hline PPTS-1 & $3.4 \pm 0.1$ & $4.2 \pm 0.1$ & KPNKM-1 & $80.3 \pm 3.5$ & $98.5 \pm 4.3$ \\
\hline PPDI-2 & $13.3 \pm 0.5$ & $16.3 \pm 0.7$ & KPNKM-2 & $75.5 \pm 2.7$ & $92.6 \pm 3.3$ \\
\hline PPLD-3 & $1.5 \pm 0.1$ & $1.9 \pm 0.1$ & KPNKM-3 & $86.4 \pm 2.5$ & $105.9 \pm 3.1$ \\
\hline PPBB-1 & $1.4 \pm 0.1$ & $1.7 \pm 0.1$ & & & \\
\hline PPBB-2 & $1.3 \pm 0.1$ & $1.6 \pm 0.1$ & & & \\
\hline
\end{tabular}

The gamma absorbed dose rates due to ${ }^{226} \mathrm{Ra},{ }^{232} \mathrm{Th}$ and ${ }^{40} \mathrm{~K}$ in sand samples varied in the range $1.3 \pm 0.1$ to $86.4 \pm 2.5 \mathrm{nGy} \cdot \mathrm{h}^{-1}$ with an average value of $48 \pm 1 \mathrm{nGy} \cdot \mathrm{h}^{-1}$. Assuming a $20 \%$ outdoor occupancy factor, the corresponding annual effective dose varied from $1.6 \pm 0.1$ to $105.9 \pm 3.1 \mu \mathrm{Sv}$ with mean of $59.1 \pm 0.3 \mu \mathrm{Sv}$ or $0.059 \mathrm{mSv} \cdot \mathrm{y}^{-1}$ which was found to be significantly lower than the worldwide average value of $0.07 \mathrm{mSv}^{-1} \mathrm{y}^{-1}$ for the annual outdoor effective dose as reported by [UNSCEAR00]. 
The similar measured activity concentrations for ${ }^{226} \mathrm{Ra},{ }^{214} \mathrm{~Pb}$, and ${ }^{214} \mathrm{Bi}$ in the uranium chain verify that ${ }^{226} \mathrm{Ra}$ decay products are in radioactive equilibrium with their parent in the sand samples. However, for the radium precursors (from ${ }^{238} \mathrm{U}$ to ${ }^{230} \mathrm{Th}$ ) this equilibrium could not be uniquely established in the current work. Therefore, in the present work three possible assumptions of the behaviour of ${ }^{238} \mathrm{U}$ decay chain in the studied sand samples are suggested:

(i) The whole chain of ${ }^{238} \mathrm{U}$ is in equilibrium. Natural disturbances or sample preparation could not interrupt the radioactive equilibrium in the samples resulting in the small differences in the activity of ${ }^{214} \mathrm{~Pb}$ and ${ }^{214} \mathrm{Bi}$ growth curves as a function of time in Figure 4-6.

(ii) The radioactive equilibrium had been established only in part of the decay chain in the sand samples, starting from ${ }^{226} \mathrm{Ra}$ prior to ${ }^{210} \mathrm{~Pb}$. Daughter isotopes of ${ }^{226} \mathrm{Ra}$ grow in rapidly and approach activity equilibrium with their parents in about 2 hours. Beyond that time the growth curve is relatively slow since ${ }^{210} \mathrm{~Pb}$ which has a 22.3 year half-life had been created [EIS97]. It would take about 150 years to reach equilibrium with the ${ }^{226} \mathrm{Ra}$. Therefore, significant amounts of ${ }^{210} \mathrm{~Pb}$ are assumed not to be present in the samples.

(iii) The radium activity in the decay chain can arise from the parent decay of ${ }^{238} \mathrm{U}$ and/or from ${ }^{226} \mathrm{Ra}$ itself. Since compounds of ${ }^{226} \mathrm{Ra}$ are soluble in water, radium nuclides are mobile and may be introduced along with any water, precipitate and leached out due to chemical pressure and temperature changes [WIL94].

As an unpredictable manner of radionuclides in the uranium chain as mentioned above may cause disequilibrium between ${ }^{226} \mathrm{Ra}$ and its parent, ${ }^{238} \mathrm{U}$, it might be suggested that discussion on ${ }^{226} \mathrm{Ra}$ activity would be more correct (rather than ${ }^{238} \mathrm{U}$ activity). In addition to measuring the ${ }^{235} \mathrm{U}$ content from the contribution to the gamma-ray energy at the 186 $\mathrm{keV},{ }^{235} \mathrm{U}$ can also be estimated from other gamma transitions at 144,163 and $205 \mathrm{keV}$ with branching ratios of $10.96,5.08$, and $5.01 \%$ respectively. The uranium isotopic abundance could be, in turn, calculated using the ${ }^{238} \mathrm{U}$ results from the $1001 \mathrm{keV}$ $(0.837 \%)$ transition energy of ${ }^{234 \mathrm{~m}} \mathrm{~Pa}$ [EBA09] and ${ }^{235} \mathrm{U}$ results which are averaged from the three gamma-ray energies as previously mentioned. However, since those gamma-ray energies subject to low emission probabilities, measurements of such energies are likely to suffer from high uncertainties and summing possibilities that would have to be corrected. 


\section{Chapter 5}

\section{Conclusions}

Growth curves of total activity in the uranium and thorium chains have been investigated to study radioactive equilibrium phenomena in the studied sand samples (CPHSR-1). The small differences in the activity of each growth curve as a function of time indicate that the radioactive equilibrium was been maintained in the studied samples and no significant loss of any of the (gaseous) radon decay products occurred during sample storage. The rapid growth curves to the activity equilibrium of daughter isotopes with the respective parents may have resulted from; (i) accumulation of bismuth and lead in natural sand samples, (ii) any appreciable radon loss would be from the surfaces of a sand sample while the bulk being retained within the body of the sample, and (iii) the longest half-life of radionuclides prior to ${ }^{210} \mathrm{~Pb}$ in the uranium chain is ${ }^{214} \mathrm{~Pb}$ with the half-life of 26.8 minutes, therefore the radioactive equilibrium would be achieved in about 2 hours. The radioactivity distribution in beach sand samples was measured at different distances from the seashore. The activity concentrations of ${ }^{238} \mathrm{U}$ and ${ }^{232} \mathrm{Th}$ at the beachfront are comparable to that at 10 and 20 metre distances from the seashore except in KPNKM samples which contain relatively high activity associated with the ${ }^{238} \mathrm{U}$ decay chain. The activity concentration of ${ }^{40} \mathrm{~K}$ at the beachfront was significantly higher than that at 10 and 20 metres from the beach. This may be because at the beachfront was 'washed-out' by potassium contained in the ocean waters which was then deposited on the sand surface at the seashore. It should be noted that the variation in radioactivity in samples also depended on the grain size of the samples, the mineral composition of the original material and the combined processes of solution and adsorption during the process of sedimentation [HOO47].

The activity ratios of ${ }^{226} \mathrm{Ra} /{ }^{214} \mathrm{~Pb}$ and ${ }^{214} \mathrm{~Pb} /{ }^{214} \mathrm{Bi}$ for all the sand samples are close to unity. This means that the activity of ${ }^{226} \mathrm{Ra},{ }^{214} \mathrm{~Pb}$, and ${ }^{214} \mathrm{Bi}$ are approximately equal and that radioactive equilibrium had been established in the sand samples under study. The 
concentrations of ${ }^{238} \mathrm{U},{ }^{232} \mathrm{Th}$, and ${ }^{40} \mathrm{~K}$ were found lie in the ranges $0.12-6.68,0.19-18.24$ ppm and $0.01-4.50 \%$ with mean values of $1.28,4.40 \mathrm{ppm}$ and $1.19 \%$ respectively. The highest $U$ concentration $(6.68 \mathrm{ppm})$ was measured in the KPNKM sample which corresponds to the formation of the granite rock. Lower values are found in other sedimentary rocks. The lowest $\mathrm{U}, \mathrm{Th}$ and $\mathrm{K}$ concentrations were present in the PPBB sample with values of $0.12 \mathrm{ppm}, 0.19 \mathrm{ppm}$ and $0.01 \%$ respectively. These values are associated with limestone formations in the samples because the radionuclide contents cannot easily enter the carbonate lattices. The variation of the concentrations of ${ }^{238} \mathrm{U}$, ${ }^{232} \mathrm{Th}$, and ${ }^{40} \mathrm{~K}$ are not only influenced by the geological features underlying the studied area but also the geochemical properties of the different rock types. The ${ }^{232} \mathrm{Th} /{ }^{238} \mathrm{U}$ ratio was found line in the range from 1.38 to 5.94 with the mean value of 3.57 . The results show that the area under investigation have uranium and thorium contents in the typical rock range with the ${ }^{232} \mathrm{Th} /{ }^{238} \mathrm{U}$ ratio close to the continental crustal average concentration of 3.82 reported by the NCRP (1987). Chiozzi et al. [CHI02] state that the agreement of these two values suggests that there is no significant fractionation during weathering or associated with the metasomatic activity in the monitored area. The correlation between ${ }^{238} \mathrm{U}$ and ${ }^{232} \mathrm{Th}$ concentrations approximately in linear relatinoship with a good correlation coefficient of 0.93 excluding the data from the KPNKM samples which contain anomaly in uranium enrichment reflected from the occurrence of granite rock.

The activity concentrations of ${ }^{226} \mathrm{Ra},{ }^{232} \mathrm{Th}$ and ${ }^{40} \mathrm{~K}$ for sand samples from the west coast lie in the range of $1.6 \pm 0.1 \leftrightarrow 52.5 \pm 0.8,0.3 \pm 0.1 \leftrightarrow 73.9 \pm 1.5$, and $2.8 \pm 0.1 \leftrightarrow 1112 \pm 117 \mathrm{~Bq} \cdot \mathrm{kg}^{-1}$ respectively. By contrast, the activity concentrations of ${ }^{226} \mathrm{Ra},{ }^{232} \mathrm{Th}$ and ${ }^{40} \mathrm{~K}$ for sand samples from the east coast lie in the range of $3.5 \pm 0.1 \leftrightarrow 83.1 \pm 1.2,4.5 \pm 0.1 \leftrightarrow 42.0 \pm 0.9$, and $9.6 \pm 1.1 \leftrightarrow 1376 \pm 144 \mathrm{~Bq} \cdot \mathrm{kg}^{-1}$ respectively. It can be seen that the difference in radioactivity levels between sand samples from the west and the east coast of Thailand is insignificant. The activity concentrations of ${ }^{226} \mathrm{Ra},{ }^{232} \mathrm{Th}$ and ${ }^{40} \mathrm{~K}$ for all sand samples were found to lie in the range of $1.6 \pm 0.1 \leftrightarrow 83.1 \pm 1.2, \quad 0.3 \pm 0.1 \leftrightarrow 73.9 \pm 1.5$, $1.9 \pm 0.2 \leftrightarrow 1376 \pm 144 \mathrm{~Bq} \cdot \mathrm{kg}^{-1}$ with the average mean value of $22.6 \pm 0.1,26.4 \pm 0.1$ and $523.0 \pm 6.6 \mathrm{~Bq} . \mathrm{kg}^{-1}$ respectively. The results obtained from the beach sand are higher than the range for ${ }^{226} \mathrm{Ra}$ and ${ }^{232} \mathrm{Th}$ in soil as reported by the UNSCEAR (2000) which are 17-60 and 11-64 Bq. $\mathrm{kg}^{-1}$. However, the mean values of ${ }^{226} \mathrm{Ra}$ and ${ }^{232} \mathrm{Th}$ are still lower than that of worldwide average values which are 35 and $30 \mathrm{~Bq} \cdot \mathrm{kg}^{-1}$ respectively. The activity 
concentration of ${ }^{40} \mathrm{~K}$ in the studied samples is higher than the worldwide average concentration of $140-850 \mathrm{~Bq} \cdot \mathrm{kg}^{-1}$ with the mean values of $400 \mathrm{~Bq} \cdot \mathrm{kg}^{-1}$. This may be because all measured samples are beach sands and could be washed out by potassium in the ocean waters with the result of more potassium then being absorbed into the sand surface. The activity concentrations of ${ }^{226} \mathrm{Ra},{ }^{232} \mathrm{Th}$ and ${ }^{40} \mathrm{~K}$ from the current work are consistent with the values reported by previous studied for sand in Thailand and other countries.

The calculated external and internal hazard indices for sand samples obtained in this study range from $0.01-0.50$ and $0.01-0.72$ respectively while the radium equivalent activity varied from $2.8-184.8 \mathrm{~Bq} \cdot \mathrm{kg}^{-1}$ which are lower than the internationally approved values ( $<1$ for $H_{\mathrm{ex}}$ and $H_{\text {in }}$, and $<370 \mathrm{~Bq} \cdot \mathrm{kg}^{-1}$ for $\mathrm{Ra}_{e q}$ ) [UNSCEAR00]. The indication from the current work is that none of the beach sand samples studied could be considered as a radiological hazard to people who were exposed to these sand samples on the beaches and the monitored areas are at the typical local level of radioactivity from natural background radiation. It is also noted that the small variation in the radioactivity content of sand samples can be observed due to the geographical and geomorphologic conditions such as sand type, mineral make-up, density and sand transport process. The gamma absorbed dose rates due to ${ }^{226} \mathrm{Ra},{ }^{232} \mathrm{Th}$ and ${ }^{40} \mathrm{~K}$ in sand samples varied in the range $1.3 \pm 0.1$ to $86.4 \pm 2.5 \mathrm{nGy} \cdot \mathrm{h}^{-1}$ with an average value of $48 \pm 1 \mathrm{nGy} \cdot \mathrm{h}^{-1}$. Assuming a $20 \%$ outdoor occupancy factor, the corresponding annual effective dose varied from $1.6 \pm 0.1$ to $105.9 \pm 3.1 \mu \mathrm{Sv}$ with mean of $59.1 \pm 0.3 \mu \mathrm{Sv}$ or $0.059 \mathrm{mSv} \cdot \mathrm{y}^{-1}$ which compares to the worldwide average value of $0.07 \mathrm{mSv} \cdot \mathrm{y}^{-1}$ for the annual outdoor effective dose as reported by [UNSCEAR00].

Since ${ }^{235} U$ could be estimated from other gamma transitions which are 143.76, 163.33 and $205.31 \mathrm{keV}$ gamma-ray energies, it would be suggested to determine the contribution of ${ }^{235} \mathrm{U}$ to the $186 \mathrm{keV}$ from those energies and estimate the ${ }^{238} \mathrm{U}$ activity from gamma-ray energy at $1001 \mathrm{keV}$ of ${ }^{234 \mathrm{~m}} \mathrm{~Pa}$. However, low emission probabilities and summing possibilities in gamma-ray energies including inconsistencies in the nuclear data may cause the unexpected results. Thus low-level radioactivity measurements in environmental samples could be more complicated and should be made with care. 


\section{References}

[ABU08] Abusini, M. and Al-Ayasreh, K. etc., 'Determination of Uranium, Thorium and Potassium Activity Concentrations in Soil Cores in Araba Valley, Jordan', Radiation Protection Dosimetry, vol. 128, no. 2, 2008, pp. 213-216.

[AHM05] Ahmed, N. K. and Mohamed El-Arabi, A. G., 'Natural Radioactivity in Farm Soil and Phosphate Fertilizer and Its Environmental Implications in Qena Governorate, Upper Egypt', Journal of Environmental Radioactivity, vol.84, no. 1, 2005, pp. 51-64.

[AKR07] Akram, M. et. al., 'Determination of Gamma-Emitting Radionuclides in the Inter-Tidal Sediments off Balochistan (Pakistan) Coast, Arabian Sea', Radiation Protection Dosimetry, vol.123, no.2, 2007, pp. 268-273.

[ALA99] Alam, M. N. et. al., 'The ${ }^{226} \mathrm{Ra},{ }^{232} \mathrm{Th}$ and ${ }^{40} \mathrm{~K}$ Activities in Beach Sand Minerals and Beach Soils of Cox's Bazar, Bangladesh', Journal of Environmental Radioactivity, vol. 46, 1999, pp. 243-250.

[ANSI99] American National Standard for Calibration and Use of Germanium Spectrometers for the Measurement of Gamma-Ray Emission Rates of Radionuclides, ANSI N42.14, The Institute of Electrical and Electronics Engineers (IEEE), New York, 1999.

[AVI05] Department of Civil Aviation, 'Earthquake and Tsunami: Maps, charts and sequence events', DCA website, 15 February 2005, accessed 11 Dec 2008, $<\mathrm{http}: / /$ www.aviation.go.th/rbm/tsunami_files/tsunami.htm\#3>.

[AYU07] Ayusuk, W. and Kessaratikoon, P., Quantitative Measurement of Natural Radioactivity in Beach Sand Samples from the Pakmeng Beach in Trang Province, Undergraduate Project in Science, Thaksin University, Thailand, 2007.

[BAT10] Bateman, H., 'Solution of a System of Differential Equations Occurring in the Theory of Radioactive Transformations', Proceedings of the Cambridge Philosophical Society, vol. 15, 1910, pp. 423-427.

[BEN07] Benjakul, S. and Kessaratikoon, P. etc., Natural Radionuclide Distribution in Soil from Muang District in Songkhla Province, Msc. Thesis, Thaksin University, Thailand, 2007. 
[BER95] Bernard, Z., Tracers in the Oil Field, Elsevier, 1995. ISBN: 044488968X, 9780444889683.

[BO007] Boonkrongcheep, R. and Kessaratikoon, P., Quantitative and Qualitative Measurement of Radioactivity in Beach Sand from Patong Beach in Phuket Province, The $10^{\text {th }}$ Conference on Nuclear Science and Technology, Thailand, 2007.

[BOU78] Bouwer, F. J. and Meklveen, J. W. etc., 'Uranium Assay of Phosphate Fertilizers and Other Phosphatic Materials', Health Physics 34, 1978, pp. 345-352.

[CAN04] Canberra Industries, Inc., Genie 2000 Spectroscopy System: Customization Tool Manual, USA, Canberra, 2004.

[CEM09] Cember, H. and Johnson, T. E., Introduction to Health Physics, $4^{\text {th }}$ ed., London, McGraw-Hill, 2009. ISBN: 978-0-07-142308-3.

[CET06] Cetnar, J., 'General Solution of Bateman Equation for Nuclear Transmutations', Annals of Nuclear Energy, vol. 33, no. 7, May 2006, pp. 640-645.

[CHI02] Chiozzi, P. and Pasquale, V. etc., 'Naturally Occurring Radioactivity at the Alps-Apennines Transition', Radiation Measurements, vol. 35, no. 2, April 2002, pp. 147-154.

[CHO02] Choppin, G. and Liljenzin, J. etc., Radiochemistry and Nuclear Chemistry, $3^{\text {rd }}$ ed., USA, Butterworth-Heinemann, 2002. ISBN: 978-0-7506-7463-8.

[CUR68] Currie, L. A., 'Limits for Qualitative Detection and Quantitative Determination', Analytical Chemistry, vol. 40, no. 3, 1968, pp. 586-593.

[DEB88] Debertin, K. and Helmer, R. G., Gamma- and X-Ray Spectroscopy with Semiconductor Detectors, Elsevier Science, 1988.

[DEB79] Debertin, K., 'International Intercomparison of Gamma-Ray Emission-Rate Measurements by Means of Germanium Spectrometer and 152Eu Source', Nuclear Instruments and Methods, North-Holland Publishing, vol. 158, 1979, pp. 479-486.

[DHE92] Dheeradilok, P., an Introduction to Geology of Thailand, National Conference on Geologic Resources of Thailand: Potential for Future Development, Department of Mineral Resources, 1992. 
[DHE95] Dheeradilok, P., 'Quaternary Coastal Morphology and Deposition in Thailand', Quaternary International, vol. 26, 1995, pp. 49-54.

[DMRA05] Department of Mineral Resources, 'Areas Affected by Tsunami', accessed 16 December 2008, < http://www.dmr.go.th/tsunami/report/009.pdf $>$.

[DMRT05] Department of Mineral Resources (DMR), Tsunami, Ministry of Natural Resources and Environment, Thailand, 2005.

[DRA06] Dragovic, S. and Jankovic, L. etc., 'Assessment of Gamma Dose Rate from Terrestrial Exposure in Serbia and Montenegro', Radiation Protection Dosimetry, vol. 121, no. 3, 2006, pp. 297-302.

[DOV04] Dovlet, C. and Povierec, P. P., 'Quantification of Uncertainty in Gamma Spectrometric Analysis of Environmental Samples', Quantifying Uncertainty in Nuclear Analytical Measurements, IAEA-TECDOC-1401, 2004, pp. 103-126, ISBN: 92-0108404-8.

[EBA09] Ebaid, Y. Y., 'Use of Gamma-Ray Spectrometry for Uranium Isotopic Analysis in Environmental Samples', Romanian Journal of Physics, 2010, vol. 55, no. 1-2, pp. 6874.

[EGG99] EG\&G Ortec., Gamma Vision for Window, Handbook Manual Version 5.10, 288, 1999.

[EIS97] Eisenbud, M. and Gesell, T., Environmental Radioactivity from Natural, Industrial, and Military Sources, $4^{\text {th }}$ ed., USA, Academic Press Ltd., 1997, ISBN: 978-012-235154-9.

[ELA05] El-Arbi A. M., 'Natural Radioactivity in Sand Used in Thermal Therapy at the Red Sea Coast', Journal of Environmental Radioactivity, vol. 81, 2005, pp. 11-19.

[ELB03] El-Baradei, M. M. and Burkart, W., Handbook of Radioactivity Analysis, $2^{\text {nd }}$ ed., USA, Academic Press Ltd., 2003, ISBN: 0-12-436603-1.

[ELE08] Electronics Tutorials, 'Semiconductor Basics', Basic Electronics Tutorial and Revision website, accessed 16 Dec 2008, $<$ http://www.electronicstutorials.ws/diode/diode7.gif $>$. 
[FIR98] Firestone, R. B., Table of Isotope, $8^{\text {th }}$ ed., California, John Wiley $\&$ Sons Ltd., 1998, ISBN: 978-0471330561.

[FRI81] Friedlander, G. and Kennedy, J. W. etc., Nuclear and Radiochemistry, $3^{\text {rd }}$ ed., USA, John Wiley \& Sons Ltd., 1981, ISBN: 0-471-86255-X.

[GEH05] Gehrke, R. J. and Davidson, J. R., 'Acquisition of Quality $\gamma$-Ray Spectra with HPGe Spectrometers', Applied Radiation and Isotopes, vol. 62, 2005, pp. 479-499.

[GON00] Gonzalez, A. G., 'The Safety of Radioactive Waste Management: Achieving Internationally Acceptable Solutions', The IAEA Bulletin, vol. 42, no.3, 2000, pp. 5-18.

[GIL08] Gilmore, G., Practical Gamma-ray Spectrometry, $2^{\text {nd }}$ ed., England, John Wiley \& Sons Ltd, 2008, ISBN: 978-0-470-86196-7.

[GRA85] Gray, P. W. and Ahmed A., 'Linear Classes of Ge(Li) Detector Efficiency Functions', Nuclear Instruments and Methods in Physics Research A, vol. 237, 1985, pp.577-589.

[HEA98] Health, R. L., Gamma-Ray Spectrum Catalogue: Ge and Si Detector Spectra, $4^{\text {th }}$ ed., Idaho National Engineering \& Environmental Laboratory, 1998.

[IAEA06] International Atomic Energy Agency, Review of Radiation Oncology Physics: A Handbook for Teachers and Students, 1.2.7 -1.2.8, 2006.

[ICRP06] International Commission on Radiological Protection (ICRP), the ICRP 2006 Draft Recommendations, ICRP Publication XX, 2006.

[KAN02] Kannan, V. et al., ' Distribution of Natural and Antropogenic Radionuclides in Soil and Beach Sand Samples of Kalpakkam (India) using Hyper Pure Germanium (HPGe) Gamma Rays Spectroscopy', Applied Radiation and Isotopes, vol. 57, 2002, pp. 109-119.

[KES05] Kessaratikoon, P. and Udomsomporn, S. etc., Radioactivity of Sand Samples from the Chalatat and Samila Beaches in Songkhla Province, The $33^{\text {rd }}$ Congress on Science and Technology of Thailand, 2005.

[KES08] Kessaratikoon, P. and Awaekechi, S., 'Natural Radioactivity Measurement in Soil Samples Collected from Municipal Area of Hat Yai District in Songkhla Province, Thailand', KMITL Science Journal section A, vol. 8, no. 2, 2008, pp.52-58. 
[KNO00] Knoll, G. F., Radiation Detection and Measurement, $3^{\text {rd }}$ ed., New York, John Wiley \& Sons Ltd., 2000, ISBN: 0-471-07338-5.

[KRA88] Krane, K. S., Introductory Nuclear Physics, $2^{\text {nd }}$ ed., USA, John Wiley \& Sons Inc., 1988, ISBN: 978-0-471-80553-3.

[KUR07] Kurnaz, A. et al., 'Determianation of Radioactivity levels and Hazards of Soil and Sediment Samples in Firtinia Valley (Rize, Turkey)', Applied Radiation and Isotopes, vol. 65, 2007, pp. 1281-1239.

[LER09] Leroy, C. and Rancoita, Pier-G., Principles of Radiation Interaction in Matter and Detection, $2^{\text {nd }}$ ed., Singapore, World Scientific Publishing, 2009, ISBN-13: 978-981281-828-7(pbk), ISBN-10: 981-281-828-6 (pbk).

[LIL01] Lilley, J. S., Nuclear Physics, New York, John Wiley \& Sons Ltd., 2001, ISBN: 0-471-97936-8.

[LIN90] Lindstrom, R. M. et al., 'A Low-Background Gamma-Ray Assay Laboratory for Activation Analysis', Nuclear Instrument and Methods in Physics Research Section A, vol. 299, no.1-3, 1990, pp.425-429.

[MAL10] Malain, D. et al., 'Measurements of NORM in Beach Sand Samples along the Andaman Coast of Thailand after the 2004 Tsunami', Nuclear Instrument and Methods in Physics Research Section A, vol. 619, 2010, pp. 441-445.

[NAV05] Navas, A. and Soto, J. etc., 'Radionuclides in soils of Byers Peninsula, South Shetland Islands, Western Antarctica', Applied Radiation and Isotopes, vol. 62, no. 5, May 2005, pp. 809-816.

[NEA40] Neary, G. J., 'The Beta-Ray Spectrum of Radium E', Proceedings of the Royal Society of London Series A, Mathematics and Physical Science, vol. 175, March 1940, pp. 71-87.

[NCRP87] National Council on Radiation Protection and Measurements (NCRP), Exposure of the Population in the United States and Canada from Natural Background Radiation, NCRP Report no. 94, Maryland, 1987, ISBN: 0913392936.

[NCRP07] National Council on Radiation Protection and Measurements (NCRP), Cesium-137 in the environment: radioecology and approaches to assessment and management: recommendations of the National Council on Radiation Protection and 
Measurements, November 21, 2006, NCRP Report no.154, Bethesda, Md., 2007, ISBN: 9780929600918 .

[NEW08] Newman, R. T, et al., 'Determination of Soil, Sand and Ore Primordial Radionuclide Concentrations by Full-Spectrum Analyses of High-Purity Germanium Detector Spectra', Applied Radiation and Isotopes, vol. 66, Jun-Jul 2008, pp. 855-859.

[OAP02] Office of Atoms for Peace (OAP), Annual Report 1994-2002, Ministry of Science, Technology and Environment, Thailand, 2002.

[ONJ06] Onjia, A. and Jankovic, L. etc., 'Assessment of Gamma Dose Rate from Terrestrial Exposure in Serbia and Montenegro', Radiation Protection Dosimetry, vol. 121, no. 3, 2006, pp. 297-302.

[ORG07] Orgun, Y. et al., 'Natural and Antropogenic Radionuclides in Rocks and Beach Sands from Ezine Region(Canakkale), Western Anatolia, Turkey', Applied Radiation and Isotopes, vol. 65, no. 6, Jun 2007, pp. 739-747.

[PHY09] National Institute of Standards and Technology, 'X-Com: Photon Cross

Sections Database', NIST website, accessed 20 October 2009, $<$ http://physics.nist.gov/PhysRefData/Xcom/Text/XCOM.html $>$.

[PPR08] University of London, 'PH2510 - Nuclear Physics Laboratory High-Resolution Gamma Spectroscopy (NP2)', accessed 11 Dec 2008, $<$ http://www.pp.rhul.ac.uk/ ptd/TEACHING/PH2510/np2.pdf $>$.

[QU106] Quindós, L. S., 'Correction by Self-Attenuation in Gamma-ray Spectrometry for Environmental Samples', Journal of Radioanalytical and Nuclear Chemistry, vol. 270, no. 2,2006, pp.339-343.

[RON84] Ronald, L. K., Radioactivity in the Environment: Sources, Distribution, and Surveillance, USA, Harwood Academic Publishers, 1984.

[ROS91] Rosell, J. R. and Ortega, X. etc., 'Natural and Artificial Radionuclides on the Northeast Coast of Spain', Health Physics, vol. 60, no. 5, May 1991, pp. 709-712.

[SAK94] Sakanoue, M., 'Determination of Very Low Levels of Radioactivity', International Union of Pure and Applied Chemistry, vol. 66, no. 12, 1994, pp. 2537-2586. 
[SAR00] Saradi, D. and MacMahon, T. D., 'Gamma-Ray Emission Probabilities in the Decay of ${ }^{226} \mathrm{Ra}$ and Its Daughters', Journal of Radioanalytical and Nuclear Chemistry, vol. 244, no.2, 2000, pp.463-469.

[SAT84] Satoh, K. et al., 'Determination of Attenuation Coefficient for Self-Absorption Correction in Routine Gamma Ray Spectroscopy of Environment Bulk Sample', Journal of Radioanalytical and Nuclear Chemistry, vol. 84, no. 2, 1984, pp. 431-440.

[SHE97] Shenber, M. A., 'Measurement of Natural Radioactivity Levels in Soil in Tripoli', Applied Radiation and Isotopes, vol. 48, no. 1, 1997, pp. 147-148.

[SPA72] Spalding, R. F. and Sacket, W. M., 'Uranium in Runoff from the Gulf of Mexico Distribution Province: Anomalous Concentration', Science, vol. 175, 1972, pp. 629-631.

[THA11] Sawadee Public Company, 'A Guide to Southern Thailand', Sawadee website, accessed 19 March 2011, <http://thailand.sawadee.com/south_of_thailand/>.

[THE96] Theodorsson, P., Measurement of Weak Radioactivity, London, World Scientific, 1996, ISBN: 978-981-02-2315-1.

[THO98] Thompson, A. et al., Environmental Geology in Land Use Planning: A Guide to Good Practice, Report to the Department of the Environment, Transport and the Regions, Symonds Travers Morgan, East Grinstead, 1998, pp. 80.

[TOI00] Toivonen, I. K. and Nikkinen, M. T., Gamma-Spectrometry, High-Resolution for Radionuclide Determination, New York, John Wiley \& Sons Ltd., 2000.

[TSO95] Tsoulfanidis, N., Measurement and Detection of Radiation, $2^{\text {nd }}$ Ed., London, Taylor \& Francis Ltd., 1995, ISBN: 1560323175.

[TRA07] TRACERCO, Module 14: Naturally Occuring Radioactive Material in Oil Production, Radiological Safety Course, 2007, pp. 1-11.

[TUF06] Tufail, M., 'Measurement of Terrestrial Radiation for Assessment of Gamma Dose from Cultivated and Barren Saline Soils of Faisalabad in Pakistan', Radiation Measurements, vol. 41, 2006, pp. 443-451.

[UND96] Underhill, T. P., Naturally Occurring Radioactive Material: Principles and Practices, USA, St. Lucie Press, 1996, ISBN: 1-57444-009-8. 
[UNSCEAR93] United Nations Scientific Committee on the Effects of Atomic Radiation (UNSCEAR), Sources and effects of ionizing radiation, Report to General Assembly, with Scientific Annexes, New York, 1993.

[UNSCEAR00] United Nations Scientific Committee on the Effects of Atomic Radiation (UNSCEAR), Sources and effects of ionizing radiation, Report to General Assembly, with Scientific Annexes, New York, 2000.

[VAN01] Van der Stritch, E. and Kirchmann, R., Radioecology:Radioactivity \& Ecosystems, Belgium, Fortemps, 2001.

[VEI06] Veiga, R. et al., 'Measurement of Natural Radioactivity in Brazilian Beach Sands', Health Physics, vol. 41, no. 2, February 2006, pp. 189-196.

[VER01] Verdoya, M. and Chiozzi, P. etc., 'Heat Producing Radionuclides in Metamorphic Rocks of the Brainconnais-Piendmont Zone (Maritime Alps)', Eclogae Geologicae Heletiaev, vol. 94, 2001, pp. 1-7.

[VET07] Vetter, K., 'Recent Developments in the Fabrication and Operation of Germanium Detector', Annual Review of Nuclear and Particle Science, vol. 57, 2007, pp. $363-404$

[WAH07] Wahl, W., Radionuclide Handbook for Laboratory Workers in Spectrometry, Radiation Protection, and Medicine, Institute for Spectrometry and Radiation Protection (ISuS), Germany, 2007.

[WIL94] Wilson, W. F., A Guide to Naturally Occurring Radioactive Material (NORM), USA, PennWell Publishing Company, 1994, ISBN: 9780878144075.

[YUA07] Yuan, D. and Kernan, W., 'Explicit Solutions for Exit-Only Radioactive Decay Chains', Journal of Applied Physics, vol. 101, 2007, pp. 1-12. 


\section{Appendix A}

\section{List of Presentations \& Publications}

\section{- Poster Presentations}

'Measurements of NORM in beach sand samples along the Andaman coast of Thailand after the 2004 tsunami' presented at the $11^{\text {th }}$ International Symposium on Radiation Physics (ISRP11) $20^{\text {th }}-25^{\text {th }}$ September 2009, in Melbourne, Australia.

'An evaluation of the natural radioactivity in Andaman beach sand samples of Thailand and radioactive equilibrium in the U-Th series decay chains' presented at the Symposium on Radiation Measurements and Applications (SORMA XII) $24^{\text {th }}-27^{\text {th }}$ May 2010, in Ann Arbor, Michigan, USA.

\section{- Peer Reviewed Paper Publications}

Malain, D., Regan, P., Bradley, D.A., Matthews, M., Santawamaitre, T. and Al-Sulaiti, H.A., 'Measurements of NORM in beach sand samples along the Andaman coast of Thailand after the 2004 tsunami', Nuclear Instrument and Methods in Physics Research Section A, vol. 619, 2010, pp. 441-445.

Al-Sulaiti, H.A., Regan, P., Bradley, D.A., Malain, D., Santawamaitre, T. Habib, A., Matthews, M., Bukhari, S., and Al-Dosari M. 'A preliminary report on the determination of natural radioactivity levels of the State of Qatar using high-resolution gamma-ray spectrometry' Nuclear Instrument and Methods in Physics Research Section A, vol. 619, 2010, pp. 427-431.

Santawamaitre, T., Regan, P., Bradley, D.A., Matthews, M., Malain, D., and Al-Sulaiti, H.A., 'An evaluation of the level of naturally occurring radioactive material in soil samples along the Chao Phraya River basin', Nuclear Instrument and Methods in Physics Research Section A, vol. 619, 2010, pp. 453-456.

Santawamaitre, T., Malain, D., Al-Sulaiti, H.A., Matthews, M., Bradley, D.A., and Regan, P., 'Study of natural radioactivity in riverbank soils along the Chao Phraya river basin in Thailand', Nuclear Instruments and Methods in Physics Research Section A, 2010, doi:10.1016/j.nima.

2010.10 .057 


\section{Appendix B}

\section{Example of Calculation}

\section{- Determination of the Source Activity}

The present activity of the ${ }^{152} \mathrm{Eu}$ source used in this experiment to be a gamma reference source was calculated based on the experiment date $\left(30^{\text {th }}\right.$ March 2009) is shown below.

${ }^{152} \mathrm{Eu}$ source in marinelli beaker (Serial no. S313.PH); Original activity $3.02 \mathrm{kBq}$; Activity Date. $1^{\text {st }}$ Febuary 2009 and Half life 13.51 years

$$
A=\frac{A_{0}}{2^{1 / t_{1} / 2}}
$$

$$
\text { Where: } \begin{aligned}
\mathrm{A} & =\text { Current activity } \\
\mathrm{A}_{0} & =\text { Original activity } \\
t & =\text { Time difference } \\
t_{1 / 2} & =\text { Half lifei }
\end{aligned}
$$

The activity on $30^{\text {th }}$ March 2009 is:

$$
\text { Current activity }=\frac{3.02 k B q}{2^{(1 / 02 / 2009-30 / 03 / 2009) / 13.51 y r}}
$$

$\therefore$ The activity of the ${ }^{152} \mathrm{Eu}$ source is $=2.996 \mathrm{kBq}$ 
- Determination of the best estimate of weighted mean from the "Patong" beach sand sample in ${ }^{232} \mathrm{Th}$ decay series

\begin{tabular}{cc}
\hline Energy $(\mathrm{keV})$ & Activity $\left(\mathrm{Bq} \mathrm{kg}^{-1}\right)$ \\
\hline 911.2 & $23.4 \pm 0.9$ \\
968.9 & $24.9 \pm 1.1$ \\
583.2 & $21.6 \pm 0.7$ \\
860.5 & $24.6 \pm 1.3$ \\
2614.5 & $22.8 \pm 1.0$ \\
\hline
\end{tabular}

A weighting factor can be defined as

$$
w_{i}=\frac{1}{\sigma_{i}^{2}}
$$

The weighted mean is given by

$$
M_{w}=\frac{\sum_{i} w_{i} M_{i}}{\sum_{i} w_{i}}
$$

And the standard error of the weighted mean is given by

$$
\sigma_{M_{w}}=\sqrt{\frac{1}{w_{1}+w_{2}+\ldots . .+w_{n}}}
$$

For the data in this example:

\begin{tabular}{cccc}
\hline$M_{i} \pm \sigma_{i}$ & $\sigma_{i}^{2}$ & $w_{i}=1 / \sigma_{i}^{2}$ & $w_{i} \times M_{i}$ \\
\hline $23.4 \pm 0.9$ & 0.81 & 1.2345 & 28.89 \\
$24.9 \pm 1.1$ & 1.21 & 0.8264 & 20.58 \\
$21.6 \pm 0.7$ & 0.49 & 2.0408 & 44.08 \\
$24.6 \pm 1.3$ & 1.69 & 0.5917 & 14.55 \\
$22.8 \pm 1.0$ & 1.0 & 1.0000 & 22.80 \\
\hline$\sum_{w}=\frac{\sum w_{i}=5.6934}{\sum_{i} w_{i}}=\frac{130.90}{5.6934}=23.0$ & & \\
$\sigma_{M_{w}}=\sqrt{\frac{1}{w_{1}+w_{2}+\ldots . .+w_{n}}}=\sqrt{\frac{1}{5.6934}}=0.4$
\end{tabular}

Therefore, the best estimate of the true mean is $23.0 \pm 0.4$ 


\section{- Determination of the activity concentration of ${ }^{40} K$}

Determination of activity concentration of ${ }^{40} \mathrm{~K}$ in a sand sample is performed on the basis of identification of a peak in the spectrum at $1460.8 \mathrm{keV}$.

The corresponding activity concentration of ${ }^{40} \mathrm{~K}$ in the sample is calculated as:

$$
A=\frac{N}{\varepsilon f t_{s} m K_{1} K_{2} K_{3} K_{4} K_{5}}
$$

with:

$$
N=N_{S}-\frac{t_{s}}{t_{b}} N_{b}
$$

using the following experimental values:

$N_{S}=48,574$ (the net peak area in the sample spectrum)

$N_{b}=167$ (the net peak area in the background spectrum)

$t_{s}=172,800 \mathrm{sec}$ (sample live counting time)

$t_{b}=172,800 \mathrm{sec}$ (background live counting time)

$N=48,574-\frac{172,800}{172,800} \times 167=48,407$

$\mathrm{M}=0.824 \mathrm{~kg}$ (sample mass)

$\varepsilon=0.00506$ (detection efficiency at $1460.7 \mathrm{keV}$ )

$T_{1 / 2}=1.277 \times 10^{9}$ years

$f=0.1067$ is the emission probability of the $1460.7 \mathrm{keV}$ gamma line

$K_{1}$ is the decay correction factor. In this study, the period $(\Delta t)$ between sampling date and measuring date is 210 days, $\left(\Delta t<<T_{1 / 2}=1.277 \times 10^{9}\right.$ years $)$ then:

$$
K_{1}=\exp \left(-\frac{\ln 2 \cdot \Delta t}{T_{1 / 2}}\right)=1.0
$$


$K_{2}$ is the correction factor for the nuclide decay during counting. Because $t_{r}=172,800$ $\sec <<T_{1 / 2}=1.277 \times 10^{9}$ years, this correction factor is:

$$
K_{2}=\frac{T_{1 / 2}}{\ln (2) \cdot t_{r}}\left(1-\exp \left(-\frac{\ln (2) \cdot t_{r}}{T_{1 / 2}}\right)\right)=1.0
$$

$K_{3}$ is the correction factor for self-attenuation in the measured sample compared with the calibration sample. This correction factor must be taken into account when matrix of calibration sample and measured sample is not the same. For this sample, the correction factor is:

$$
K_{3}=\frac{1-e^{-\mu x}}{\mu x}=1
$$

$K_{4}$ is the correction factor for loss due to random summing. If we assume that resolution time $(\tau)$ of system is $\tau=4 \mu \mathrm{s}$ and the mean total count rate $R=1 p / \mathrm{sec}$ then this correction factor is:

$$
K_{4}=\exp (-2 R \tau)=0.9999
$$

For radionuclide ${ }^{40} \mathrm{~K}$ the coincidence correction factor $K_{5}=1.0$ because this radionuclide has no cascade of successive photon emission.

Finally we get for activity concentration of ${ }^{40} \mathrm{~K}$ in the sample:

$$
\begin{aligned}
& A=\frac{N}{\varepsilon t_{s} m K_{1} K_{2} K_{3} K_{4} K_{5}}=\frac{48,407}{0.00506 \cdot 0.1067 \cdot 172,800 \cdot 0.824 \cdot 1.0 \cdot 1.0 \cdot 1.0 \cdot 0.9999 \cdot 1.0} \\
& A=630 \mathrm{~Bq} \cdot \mathrm{kg}^{-1}
\end{aligned}
$$




\section{Appendix C}

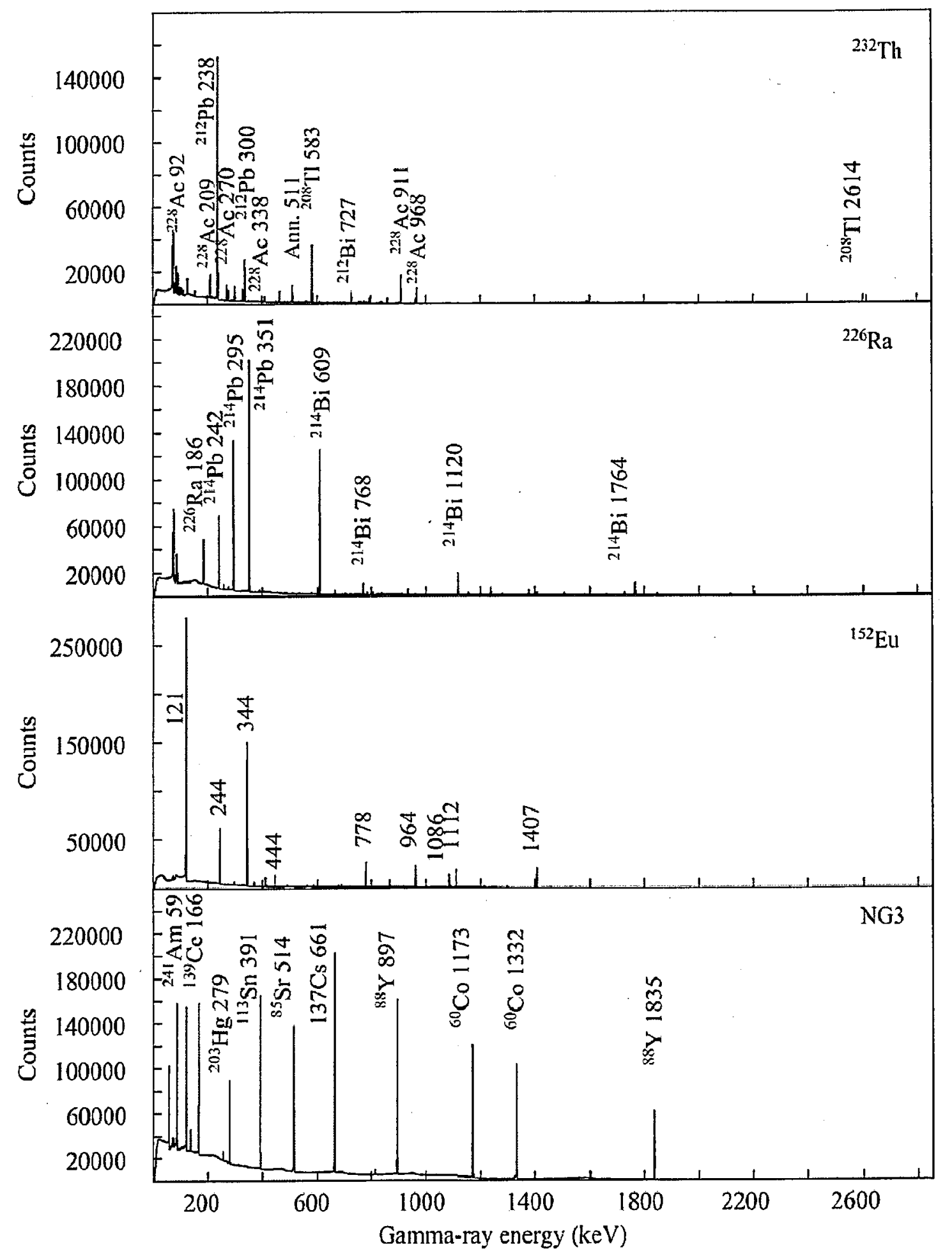

Figure 1: Efficiency spectra collected from 4 standard sources for 86400 s (i.e one day) 


\section{Appendix D}

Table 1 Geographical locations and identification of sand samples collected from west and east coast of Thailand

\begin{tabular}{|c|c|c|c|c|}
\hline \multirow{2}{*}{ Sample code } & \multirow{2}{*}{$\begin{array}{l}\text { Sample location/Distance } \\
\text { form the seashore }\end{array}$} & \multirow{2}{*}{ Weight +0.01 (g) } & \multicolumn{2}{|c|}{ Geographical location } \\
\hline & & & Longitude $(\mathrm{E})$ & Latitude $\left({ }^{\circ} \mathrm{N}\right)$ \\
\hline West coast & & & & \\
\hline PKPT & Hat Patong, Phuket & & & \\
\hline PKPT-1 & $0 \mathrm{~m}$ & 824.03 & $98^{\circ} 17^{\prime} 35.5^{\prime \prime}$ & $7^{\circ} 53^{\prime} 27.6^{\prime \prime}$ \\
\hline PKPT-2 & $10 \mathrm{~m}$ & 920.93 & $98^{\circ} 17^{\prime} 35.6^{\prime \prime}$ & $7^{\circ} 53^{\prime} 27.5^{\prime \prime}$ \\
\hline PKPT-3 & $20 \mathrm{~m}$ & 983.72 & $98^{\circ} 17^{\prime} 36.1^{\prime \prime}$ & $7^{\circ} 53^{\prime} 27.3^{\prime \prime}$ \\
\hline PKSR & Hat Surin, Phuket & & & \\
\hline PKSR-1 & $0 \mathrm{~m}$ & 940.96 & $98^{\circ} 16^{\prime} 42.5^{\prime \prime}$ & $7^{\circ} 58^{\prime} 31.2^{\prime \prime}$ \\
\hline PKSR-2 & $10 \mathrm{~m}$ & 1024.16 & $98^{\circ} 16^{\prime} 42.7^{\prime \prime}$ & $7^{\circ} 58^{\prime} 31.2^{\prime \prime}$ \\
\hline PKKT & Hat Kata Noi, Phuket & & & \\
\hline PKKT-1 & $0 \mathrm{~m}$ & 908.47 & $98^{\circ} 17^{\prime} 56.2^{\prime \prime}$ & $7^{\circ} 48^{\prime} 20.5^{\prime \prime}$ \\
\hline PKKT-2 & $10 \mathrm{~m}$ & 1010.36 & $98^{\circ} 17^{\prime} 56.5^{\prime \prime}$ & $7^{\circ} 48^{\prime} 20.5^{\prime \prime}$ \\
\hline PKKT-3 & $20 \mathrm{~m}$ & 945.35 & $98^{\circ} 17^{\prime} 56.7^{\prime \prime}$ & $7^{\circ} 48^{\prime} 20.5^{\prime \prime}$ \\
\hline PKRW & Hat Rawai, Phuket & & & \\
\hline PKRW-1 & $0 \mathrm{~m}$ & 928.00 & $98^{\circ} 19^{\prime} 17.4^{\prime \prime}$ & $7^{\circ} 46^{\prime} 18.2^{\prime \prime}$ \\
\hline PKRW-2 & $10 \mathrm{~m}$ & 927.09 & $98^{\circ} 19^{\prime} 17.2^{\prime \prime}$ & $7^{\circ} 46^{\prime} 18.2^{\prime \prime}$ \\
\hline PKRW-3 & $20 \mathrm{~m}$ & 908.21 & $98^{\circ} 19^{\prime} 17.2^{\prime \prime}$ & $7^{\circ} 46^{\prime} 18.6^{\prime \prime}$ \\
\hline PKCL-1 & Chalong Bay, Phuket & 876.69 & $98^{\circ} 20^{\prime} 41.1^{\prime \prime}$ & $7^{\circ} 49^{\prime} 14.4^{\prime \prime}$ \\
\hline PKAP-1 & Aoa Po, Phuket & 1005.34 & $98^{\circ} 25^{\prime} 55.3^{\prime \prime}$ & $8^{\circ} 3^{\prime} 39.8^{\prime \prime}$ \\
\hline PKNT & Hat Nai Ton, Phuket & & & \\
\hline PKNT-1 & $0 \mathrm{~m}$ & 922.50 & $98^{\circ} 16^{\prime} 38.4^{\prime \prime}$ & $8^{\circ} 3^{\prime} 37.0^{\prime \prime}$ \\
\hline PKNT-2 & $10 \mathrm{~m}$ & 1026.52 & $98^{\circ} 16^{\prime} 38.7^{\prime \prime}$ & $8^{\circ} 3^{\prime} 36.9^{\prime \prime}$ \\
\hline PKNT-3 & $20 \mathrm{~m}$ & 1008.78 & $98^{\circ} 16^{\prime} 39.3^{\prime \prime}$ & $8^{\circ} 3^{\prime} 37.2^{\prime \prime}$ \\
\hline PKMK & Hat Mai Khao, Phuket & & & \\
\hline PKMK-1 & $0 \mathrm{~m}$ & 1044.47 & $98^{\circ} 18^{\prime} 2.19^{\prime \prime}$ & $8^{\circ} 7^{\prime} 32.90^{\prime \prime}$ \\
\hline PKMK-2 & $10 \mathrm{~m}$ & 1073.65 & $98^{\circ} 18^{\prime} 2.86^{\prime \prime}$ & $8^{\circ} 7^{\prime} 32.99^{\prime \prime}$ \\
\hline PKMK-3 & $20 \mathrm{~m}$ & 1052.28 & $98^{\circ} 18^{\prime} 3.34^{\prime \prime}$ & $8^{\circ} 7^{\prime} 33.01^{\prime \prime}$ \\
\hline PNKL & Hat Kho Lak, Phang-Nga & & & \\
\hline PNKL-1 & $0 \mathrm{~m}$ & 979.78 & $98^{\circ} 14^{\prime} 47.4^{\prime \prime}$ & $8^{\circ} 38^{\prime} 29.8^{\prime \prime}$ \\
\hline PNKL-2 & $10 \mathrm{~m}$ & 1007.34 & $98^{\circ} 14^{\prime} 47.9^{\prime \prime}$ & $8^{\circ} 38^{\prime} 29.7^{\prime \prime}$ \\
\hline PNKL-3 & $20 \mathrm{~m}$ & 988.41 & $98^{\circ} 14^{\prime} 48.2^{\prime \prime}$ & $8^{\circ} 38^{\prime} 29.5^{\prime \prime}$ \\
\hline PNTM & Hat Tai Mueng, Phang-Nga & & & \\
\hline PNTM-1 & $0 \mathrm{~m}$ & 1044.16 & $98^{\circ} 14^{\prime} 48.1^{\prime \prime}$ & $8^{\circ} 24^{\prime} 1.7^{\prime \prime}$ \\
\hline PNTM-2 & $10 \mathrm{~m}$ & 1044.68 & $98^{\circ} 14^{\prime} 48.2^{\prime \prime}$ & $8^{\circ} 24^{\prime} 1.9^{\prime \prime}$ \\
\hline KBNT & Hat Nopparat Thara, Krabi & & & \\
\hline KBNT-1 & $0 \mathrm{~m}$ & 926.66 & $98^{\circ} 48^{\prime} 31.2^{\prime \prime}$ & $8^{\circ} 2^{\prime} 35.8^{\prime \prime}$ \\
\hline KBNT-2 & $10 \mathrm{~m}$ & 1030.66 & $98^{\circ} 48^{\prime} 31.1^{\prime \prime}$ & $8^{\circ} 2^{\prime} 36.2^{\prime \prime}$ \\
\hline PPTS-1 & Tonsai Bay, Phi Phi Island, & 921.89 & $98^{\circ} 46^{\prime} 12.8^{\prime \prime}$ & $7^{\circ} 44^{\prime} 19.2^{\prime \prime}$ \\
\hline PPDI-2 & Phi Phi Don, Phi Phi Island, & 997.72 & $98^{\circ} 46^{\prime} 12.6^{\prime \prime}$ & $7^{\circ} 44^{\prime} 22.2^{\prime \prime}$ \\
\hline PPLD-3 & Lohdalam Bay, Phi Phi & 932.42 & $98^{\circ} 46^{\prime} 13.3^{\prime \prime}$ & $7^{\circ} 44^{\prime} 24.7^{\prime \prime}$ \\
\hline PPBB & Bamboo Island, Krabi & & & \\
\hline PPBB-1 & $0 \mathrm{~m}$ & 889.68 & $98^{\circ} 47^{\prime} 51.7^{\prime \prime}$ & $7^{\circ} 49^{\prime} 5.5^{\prime \prime}$ \\
\hline
\end{tabular}




\begin{tabular}{|c|c|c|c|c|}
\hline PPBB-2 & $10 \mathrm{~m}$ & 930.00 & $98^{\circ} 47^{\prime} 50.9^{\prime \prime}$ & $7^{\circ} 48^{\prime} 56.6^{\prime \prime}$ \\
\hline CPHSR & Hat Sai Ri, Chumporn & & & \\
\hline CPHSR-1 & $0 \mathrm{~m}$ & 968.80 & $99^{\circ} 16^{\prime} 47.9^{\prime \prime}$ & $10^{\circ} 23^{\prime} 51.5^{\prime \prime}$ \\
\hline CPHSR-2 & $10 \mathrm{~m}$ & 1004.26 & $99^{\circ} 16^{\prime} 47.5^{\prime \prime}$ & $10^{\circ} 23^{\prime} 51.5^{\prime \prime}$ \\
\hline CPHSR-3 & $20 \mathrm{~m}$ & 1004.75 & $99^{\circ} 16^{\prime} 47.0^{\prime \prime}$ & $10^{\circ} 23^{\prime} 51.4^{\prime \prime}$ \\
\hline CPLS & Hat Lame Son, Chumpom & & & \\
\hline CPLS-1 & $0 \mathrm{~m}$ & 870.20 & $99^{\circ} 9^{\prime} 4.1^{\prime \prime}$ & $9^{\circ} 58^{\prime} 40.6^{\prime \prime}$ \\
\hline CPLS-2 & $10 \mathrm{~m}$ & 937.21 & $99^{\circ} 9^{\prime} 3.8^{\prime \prime}$ & $9^{\circ} 58^{\prime} 40.5^{\prime \prime}$ \\
\hline CPLS-3 & $20 \mathrm{~m}$ & 964.11 & $99^{\circ} 9^{\prime} 2.9^{\prime \prime}$ & $9^{\circ} 58^{\prime} 40.5^{\prime \prime}$ \\
\hline STCY & Hat Chaiya, Suratthani & & & \\
\hline STCY-1 & $0 \mathrm{~m}$ & 956.83 & $99^{\circ} 16^{\prime} 13.4^{\prime \prime}$ & $9^{\circ} 22^{\prime \prime} 28.0^{\prime \prime}$ \\
\hline STCY-2 & $10 \mathrm{~m}$ & 994.09 & $99^{\circ} 16^{\prime} 13.3^{\prime \prime}$ & $9^{\circ} 22^{\prime} 28.4^{\prime \prime}$ \\
\hline NSKN & Hat Khonom, & & & \\
\hline NSKN-1 & $0 \mathrm{~m}$ & 974.85 & $99^{\circ} 52^{\prime} 27.7^{\prime \prime}$ & $9^{\circ} 10^{\prime} 35.0^{\prime \prime}$ \\
\hline NSKN-2 & $10 \mathrm{~m}$ & 991.54 & $99^{\circ} 52^{\prime} 27.2^{\prime \prime}$ & $9^{\circ} 10^{\prime} 35.1^{\prime \prime}$ \\
\hline NSKN-3 & $20 \mathrm{~m}$ & 1017.17 & $99^{\circ} 52^{\prime} 27.0^{\prime \prime}$ & $9^{\circ} 10^{\prime} 35.1^{\prime \prime}$ \\
\hline SMCW & $\begin{array}{l}\text { Hat Chaweng, Koh Samui, } \\
\text { Suratthani }\end{array}$ & & & \\
\hline SMCW-1 & $0 \mathrm{~m}$ & 985.70 & $100^{\circ} 3^{\prime} 33.7^{\prime \prime}$ & $9^{\circ} 31^{\prime} 19.2^{\prime \prime}$ \\
\hline SMCW-2 & $10 \mathrm{~m}$ & 1001.53 & $100^{\circ} 3^{\prime} 33.5^{\prime \prime}$ & $9^{\circ} 31^{\prime} 19.5^{\prime \prime}$ \\
\hline SMCW-3 & $20 \mathrm{~m}$ & 1010.01 & $100^{\circ} 3^{\prime} 33.2^{\prime \prime}$ & $9^{\circ} 31^{\prime} 19.6^{\prime \prime}$ \\
\hline SMLM & $\begin{array}{l}\text { Hat Lamai, Koh Samui, } \\
\text { Suratthani }\end{array}$ & & & \\
\hline SMLM-1 & $0 \mathrm{~m}$ & 981.90 & $100^{\circ} 2^{\prime} 46.0^{\prime \prime}$ & $9^{\circ} 27^{\prime} 50.5^{\prime \prime}$ \\
\hline SMLM-2 & $10 \mathrm{~m}$ & 1026.58 & $100^{\circ} 2^{\prime} 45.9^{\prime \prime}$ & $9^{\circ} 27^{\prime} 50.6^{\prime \prime}$ \\
\hline SMLM-3 & $20 \mathrm{~m}$ & 1024.22 & $100^{\circ} 2^{\prime} 45.2^{\prime \prime}$ & $9^{\circ} 27^{\prime} 50.9^{\prime \prime}$ \\
\hline SMTNG & $\begin{array}{l}\text { Hat Taling Ngam, Koh } \\
\text { Suratthani }\end{array}$ & & & \\
\hline SMTNG-1 & $0 \mathrm{~m}$ & 981.68 & $99^{\circ} 55^{\prime} 58.2^{\prime \prime}$ & $9^{\circ} 27^{\prime} 59.6^{\prime \prime}$ \\
\hline SMTNG-2 & $10 \mathrm{~m}$ & 961.63 & $99^{\circ} 55^{\prime} 58.6^{\prime \prime}$ & $9^{\circ} 27^{\prime} 59.6^{\prime \prime}$ \\
\hline SMLN & $\begin{array}{l}\text { Hat Lipa Noi, Koh Samui, } \\
\text { Suratthani }\end{array}$ & & & \\
\hline SMLN-1 & $0 \mathrm{~m}$ & 961.49 & $99^{\circ} 56^{\prime} 4.2^{\prime \prime}$ & $9^{\circ} 30^{\prime \prime} 2.6^{\prime \prime}$ \\
\hline SMLN-2 & $10 \mathrm{~m}$ & 959.25 & $99^{\circ} 56^{\prime} 4.4^{\prime \prime}$ & $9^{\circ} 30^{\prime} 2.7^{\prime \prime}$ \\
\hline SMBP & $\begin{array}{l}\text { Aao Bo Phut, Koh Samui, } \\
\text { Suratthani }\end{array}$ & & & \\
\hline SMBP-1 & $0 \mathrm{~m}$ & 1001.72 & $100^{\circ} 19.0^{\prime \prime}$ & $9^{\circ} 33^{\prime} 58.0^{\prime \prime}$ \\
\hline SMBP-2 & $10 \mathrm{~m}$ & 976.53 & $100^{\circ} 1^{\prime} 8.6^{\prime \prime}$ & $9^{\circ} 33^{\prime} 57.7^{\prime \prime}$ \\
\hline KPNRN & $\begin{array}{l}\text { Hat Rin Nok, Koh Phangan, } \\
\text { Suratthani }\end{array}$ & & & \\
\hline KPNRN-1 & $0 \mathrm{~m}$ & 929.24 & $100^{\circ} 4^{\prime} 5.2^{\prime \prime}$ & $9^{\circ} 40^{\prime} 37.5^{\prime \prime}$ \\
\hline KPNRN-2 & $10 \mathrm{~m}$ & 938.02 & $100^{\circ} 4^{\prime} 5.4^{\prime \prime}$ & $9^{\circ} 40^{\prime} 37.8^{\prime \prime}$ \\
\hline KPNRN-3 & $20 \mathrm{~m}$ & 986.35 & $100^{\circ} 4^{\prime} 4.8^{\prime \prime}$ & $9^{\circ} 40^{\prime} 37.9^{\prime \prime}$ \\
\hline KPNKM & $\begin{array}{l}\text { Hat Koh Ma, Koh Phangan, } \\
\text { Suratthani }\end{array}$ & & & \\
\hline KPNKM-1 & $0 \mathrm{~m}$ & 944.60 & $99^{\circ} 58^{\prime} 48.6^{\prime \prime}$ & $9^{\circ} 47^{\prime} 48.3^{\prime \prime}$ \\
\hline
\end{tabular}


Appendix E

Paper Publication 


\title{
Nuclear Instruments and Methods in Physics Research A
}

\author{
journal homepage: www.elsevier.com/locate/nima
}

\section{Measurements of NORM in beach sand samples along the Andaman coast of Thailand after the 2004 tsunami}

\author{
D. Malain ${ }^{\text {a } *}$, P.H. Regan ${ }^{a}$, D.A. Bradley ${ }^{a}$, M. Matthews ${ }^{b}$, T. Santawamaitre ${ }^{a}$, H.A. Al-Sulaiti ${ }^{a}$ \\ a Centre for Nuclear and Radiation Physics, Department of Physics, University of Surrey, Guildford, CU2 7XH. UK \\ b Centre of Environmental Health Engineering, Department of Civil Engineering, University of Surrey, Guildford, GU2 7XH, UK
}

\section{A R T I C LE I N F O}

\section{Available online 1 December 2009}

\section{Keywords:}

Gamma-ray spectroscopy

Hyper-pure germaniun detector

Naturally occuring radioactive materials Gamma-ray intensities

\begin{abstract}
A B S T R A C T
A hyper-pure gernianium detector-based gamma-ray spectroscopy low background counting system was used to determine the levels of natural radioactivity from beach sand samples along the Andaman coast of Thailand following the 2004 tsunami. The activity concentrations of ${ }^{226} \mathrm{Ra},{ }^{232} \mathrm{Th}$ and ${ }^{40} \mathrm{~K}$ were found to lie in the range of $2.7 \pm 0.1 \leftrightarrow 23.5 \pm 0.4,3.0 \pm 0.1 \leftrightarrow 34.6 \pm 0.6,10.7 \pm 0.9 \leftrightarrow 654.3 \pm 21.6 \mathrm{~Bq}$ $\mathrm{kg}^{-1}$ respectively. The total gamma absorbed dose rate in air at $1 \mathrm{~m}$ above the ground surface ranges from $3.5 \pm 0.1$ to $52.8 \pm 0.9 \mathrm{nGy} \mathrm{h}^{-1}$ with an average value of $31 \pm 1 \mathrm{nGy} \mathrm{h}^{-1}$ corresponding to annual effective dose of $0.038 \mathrm{mSv}$. The latter was found to be significantly lower than the world average value of $0.07 \mathrm{mSvy}^{-1}$ for outdoor annual effective dose, as reported by UNSCEAR(2000) but consistent with values for sand found by others. The results from this study will be used to establish a radiological baseline map in Thailand and used as reference information to assess any alterations in the radioactivity background level due to the changes in the topography of the location, other developments around the area or any artficial influences on the environment.
\end{abstract}

2009 Elsevier B.V. All rights reserved.

\section{Introduction}

Human beings are exposed to low levels of ionizing radiation from natural sources during their daily lives. Naturally occurring radioactive materials (NORM) are present in the wider environment such as foods, soil, water, air, building materials, including the human body itself (such as ${ }^{40} \mathrm{~K}$ and ${ }^{14} \mathrm{C}$ in bones) [1]. Since the largest contribution (about $87 \%$ ) of the radiation dose received by the world's population is due to natural radiation sources, it is important to assess the radiation doses in order to limit possible health effects on humans from such natural sources.

Primordjal radionuclides are typically long lived, with half-lives at least comparable to the estimated age of the earth $\left(4.5 \times 10^{9} \mathrm{yr}\right)$ [2] and are distributed widely throughout the earth and oceans. The most important primordial radionuclides are ${ }^{40} \mathrm{~K}$ (half-life $1.28 \times 10^{9} \mathrm{yr}$ ), ${ }^{238} \mathrm{U}$ (half-life $4.47 \times 10^{9} \mathrm{yr}$ ) and ${ }^{232} \mathrm{Th}$ (half-life $1.41 \times 10^{10} \mathrm{yr}$ ) [3]. Some other terrestrial radionuclides including those of the ${ }^{235} \mathrm{U}$ series, ${ }^{87} \mathrm{Rb},{ }^{138} \mathrm{La},{ }^{147} \mathrm{Sm}$ and ${ }^{176} \mathrm{Lu}$ are also known but their effects are typically neglected as they contribute such low levels to the total dose from natural background [4].

According to Gonzalez [5], some natural processes such as volcanic eruptions, mineral water springs, erosion and movements of sand can bring fractions of this huge radioactive inventory into the human habitat. An Indian Ocean earthquake

\footnotetext{
* Corresponding author.

E-mail address: d.malain@surrey.ac.uk (D. Malain).
}

on 26th December 2004 below Sumatra, measuring approximately 9.3 on the Richter scale attacked the 17 countries of Sri Lanka, India, Indonesia, Thailand, Malaysia, Myanmar, Maldives, Bangladesh, Somalia, Seychelles, Madagascar, Mozambique, Mauritius, Sauth Africa, Australia, Tanzania and Kenya [6]. A sudden displacement of a large volume of water due to a massive rise or drop in sea level caused by this earthquake generated destructive tsunami waves. In Thailand, a series of large waves hir the Andaman coast impacted severely on the six coastal provinces along the Andaman Sea, namely: Ranong, Phang-Nga, Phuket, Krabi, Trang and Satun. The movement of sea water and sand caused by the tsunami may have transferred radioactivity from other areas (for example, the ocean floors) onto the beaches, increasing the environmental dose rate due to NORM. Therefore, this study is an attempt to determine the activity concentrations of ${ }^{226} \mathrm{Ra},{ }^{232} \mathrm{Th},{ }^{40} \mathrm{~K}$ including estimates of the equivalent dose rate in air at $1 \mathrm{~m}$ above the ground surface presented along the Andaman coast of Thailand following the tsunami. These will be compared to measurements on the eastern coast of Thailand which was not exposed in the tsunami.

\section{Materials and methods}

\subsection{Sampling and sample preparation}

Beach sand samples were collected by a random choice from six different locations along the west and east coast of Thailand 
during August 2008 as shown in Fig. 1 covering six provinces: (1) Phang-Nga; (2) Phuket; (3) Krabi; (4) Chumporn; (5) Suratthani; and (6) Nakornsrithammarat. About $2 \mathrm{~kg}$ of sand was collected for each sample from the ground surface (down to a depth of $5 \mathrm{~cm}$ ). After collection, sand samples were first dried at room temperature to remove moisture and then oven dried at a temperature of $50 \mathrm{C}$ for $24 \mathrm{~h}$ to obtain a constant weight, crushed and passed through a $500 \mu \mathrm{m}$ sieve to ensure homogeneity of the sample. Samples of approximate mass $900 \mathrm{~g}$ each were placed in $550 \mathrm{ml}$ Marinelli beakers (made from polyethylene plastic) which were sealed with a PVC tape, dry weighed and stored for about four weeks to allow radioactive equilibrium of ${ }^{222} \mathrm{Rn}$ with its parent $\left({ }^{226} \mathrm{Ra}\right)$ in an uranium chain.

\subsection{Gamma-ray spectrometry}

A high-resolution, low background gamma-ray spectroscopy system, based on a passively shielded hyper-pure germanium detector was used to measure the gamma-ray spectra emitted from the prepared samples. The HPGe coaxial detector used had a measured energy resolution of $2.08 \mathrm{keV}$ (FWHM) and an absolute photopeak gamma-ray efficiency of approximately $0.2 \%$ at $1332 \mathrm{keV}$. The detector was shielded by a $10 \mathrm{~cm}$ thick lead wall internally lined with $1 \mathrm{~mm}$ copper sheet for additional absorption of lead $\mathrm{K} \mathrm{X}$-rays. A pre-prepared source standard of ${ }^{232} \mathrm{Th}$ and its decay chain members, with energies up to $2.6 \mathrm{MeV}$ was used to perform an energy calibration which covered the entire range over which the spectrometer was used. Reference sources made from ${ }^{232} \mathrm{Th},{ }^{226} \mathrm{Ra},{ }^{152} \mathrm{Eu}$ and $\mathrm{NG} 3$ (a mixed radionuclide source containing ${ }^{241} \mathrm{Am},{ }^{109} \mathrm{Cd},{ }^{139} \mathrm{Ce},{ }^{137} \mathrm{Cs},{ }^{60} \mathrm{Co},{ }^{57} \mathrm{Co},{ }^{203} \mathrm{Hg},{ }^{13} \mathrm{Sn},{ }^{85} \mathrm{Sr}$ and ${ }^{88} Y$ ) in the same Marinelli beaker geometry as used for the samples were employed for the absolute efficiency calibration of the system. The spectrum analysis was performed by the computer software Genie2000 obtained from CANBERRA. The measurement time for both background and samples was 172,800 s (i.e. 48 h) in order to gain a good counting statistics for each sample. Background spectra, collected with de-ionised, water filled blanks, were also collected and used to correct the net peak area of gamma rays of the measured isotopes. The shape of Patong sand sample spectrum with radionuclide identification is shown in Fig. 2.

The absolute efficiency curve (see Fig. 3) of the detector used in the current work was fitted using the following polynomial described by Gray and Ahmed [7]

$\varepsilon(E, p)=\left[p_{1}+p_{2} \ln (E)+p_{3} \ln ^{2}(E)+p_{4} \ln ^{3}(E)+p_{5} \ln ^{5}(E)+p_{6} \ln ^{7}(E)\right] / E$

where $:$ is the absolure photopeak efficiency and $E$ represents energy in MeV.

\subsection{Calculations}

The efficiency correct intensities of the measured discrete gamma-ray lines of energies $911.2,968.9\left({ }^{228} \mathrm{Ac}\right), 583.2,860.5$ and $2614.5 \mathrm{keV}\left({ }^{208} \mathrm{Tl}\right)$ were used to determine the activity concentrations of ${ }^{232} \mathrm{Th}$; the gamma-ray lines at 351.9 ( $\left.^{214} \mathrm{~Pb}\right), 609.3$ 1120.3. 1238.1 and $1764.5 \mathrm{keV}\left({ }^{214} \mathrm{Bi}\right)$ were used to determine the activity concentrations of ${ }^{226} \mathrm{Ra}$ (from the ${ }^{238} \mathrm{U}$ decay chain); while the 1460.8 and $661.6 \mathrm{keV}$ transitions were used to determine the activity concentrations of ${ }^{40} \mathrm{~K}$ and ${ }^{137} \mathrm{Cs}$, respectively. The weighted means for the activity was also taken into account in order to achieve the best estimate of these values. The use of independent measurements multiple discrete gamma-ray lines from the same decay chains allows a signficant reduction in the statistical uncertainty of the derived activity concentrations

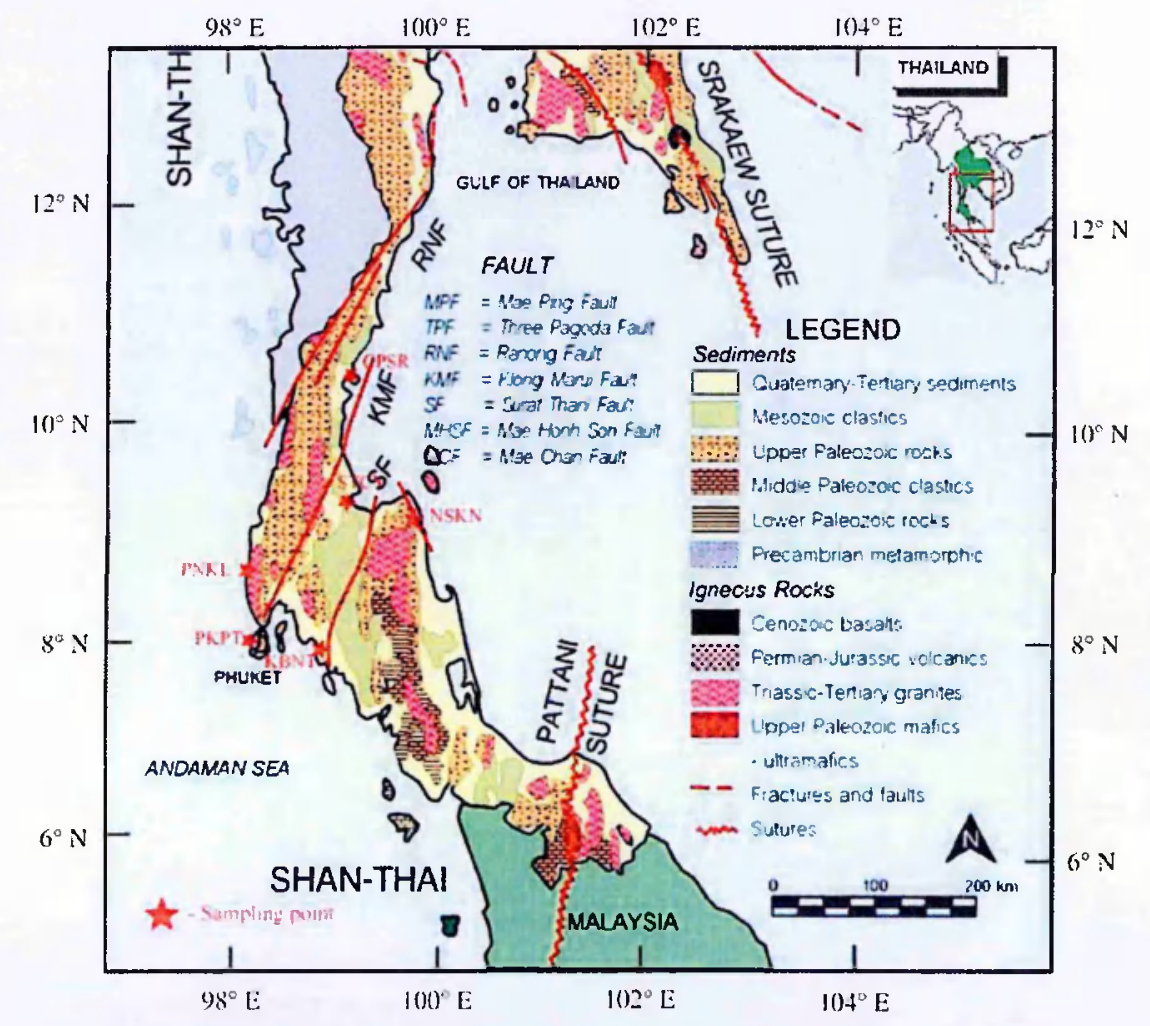

Fig. 1. Geological map and sampling points along the western and eastern coast of Thailand. 


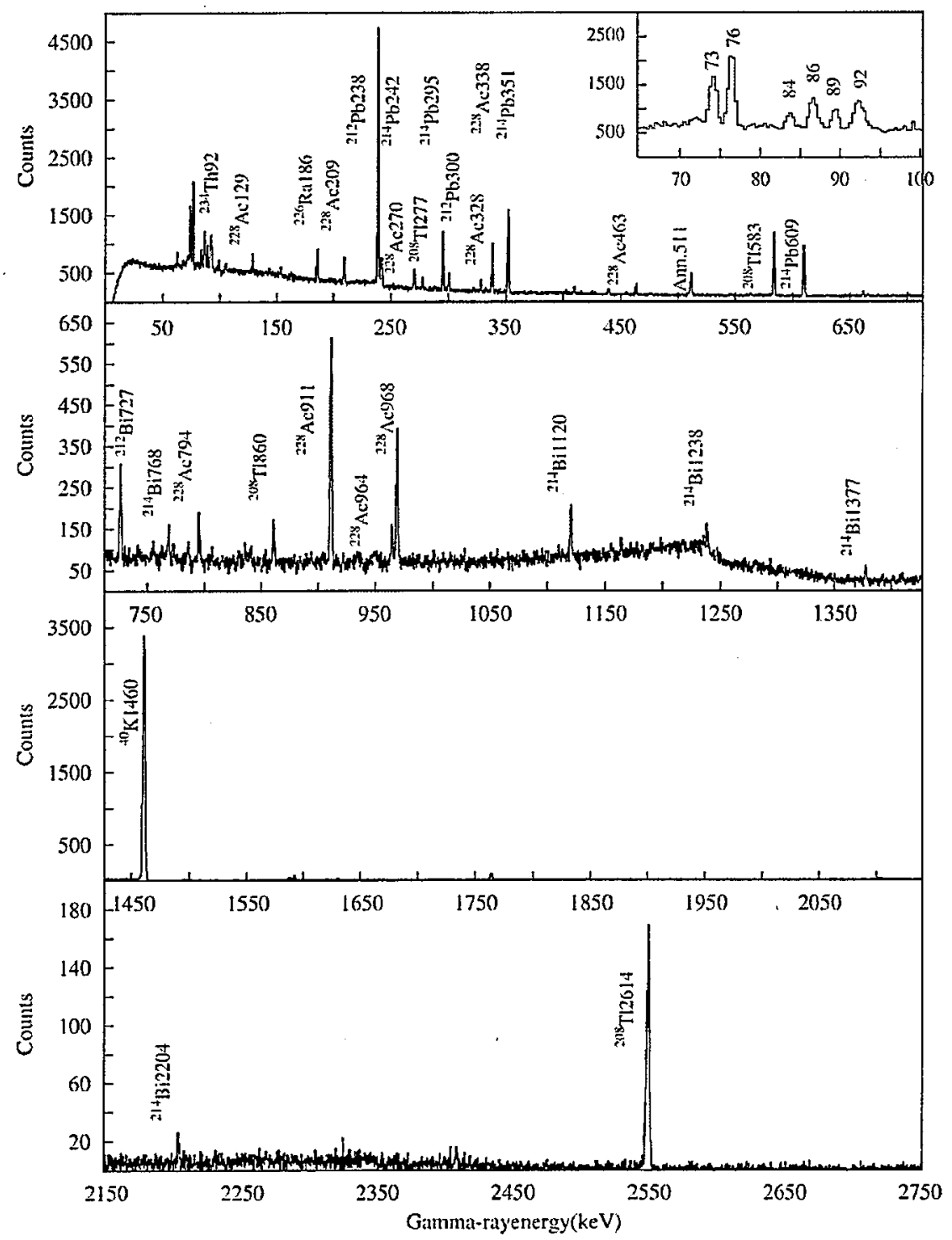

Fig. 2. Gamma-ray spectrum of 'Patong' beach sand sample subtracted background collected for 172,800 s (i.e. 48 h).

compared to the use of a single transition [8]. The activity levels for radionuclides of interest in the measured samples were then computed by using the following equation [9]

$A=\frac{C}{E P_{;} m}$

where $A$ is the activity level of a certain radionuclide in $\mathrm{Bq} \mathrm{kg}^{-1}, C$ is the net counting rate of the corresponding photopeak, in count per second, $\varepsilon$ is the efficiency at photopeak energy, $P_{i}$ is the emission probability of the gamma line corresponding to the peak energy $m$ is the mass of the measured sample, in $\mathrm{kg}$.

Determination of activity concentrations also requires knowledge of specific correction factors including, a self-attenuation correction, decay- and life-time correction and coincidence correction. These have been applied to the analysis where appropriate.

The minimum detectable activity (MDA) for the gammaray measurements was calculated according to the Currie formula $[10]$

$M D A=\frac{4.653 \sigma_{N_{n}}+2.706}{\varepsilon P_{r} T}$

where $\sigma_{N_{B}}$ is the standard deviation of the background and $T$ is the sample counting time

The gamma dose rate $(D)$ in $n G y h^{-1}$ in the outdoor air can be calculated using the following equation reported by $U N$ $\operatorname{SCEAR}(2000)$

$\mathrm{D}=0.462 A_{R a}+0.604 A_{T ! 1}+0.0417 A_{K}$

where $A_{R a}, A_{T h}$ and $A_{K}$ are the specific activities in $B q ~ k g^{-1}$ of $^{226} \mathrm{Ra}$, ${ }^{232} \mathrm{Th}$ and ${ }^{40} \mathrm{~K}$, respectively.

To estimate the annual effective dose rate, use has been made of the conversion factor of $0.7 \mathrm{SvG} \mathrm{yr}^{-1}$ [4] from the absorbed dose in air to effective dose received by adults and an outdoor occupancy factor of $20 \%$, this being the average worldwide value reported in [3]. Under these assumptions, the annual effective 


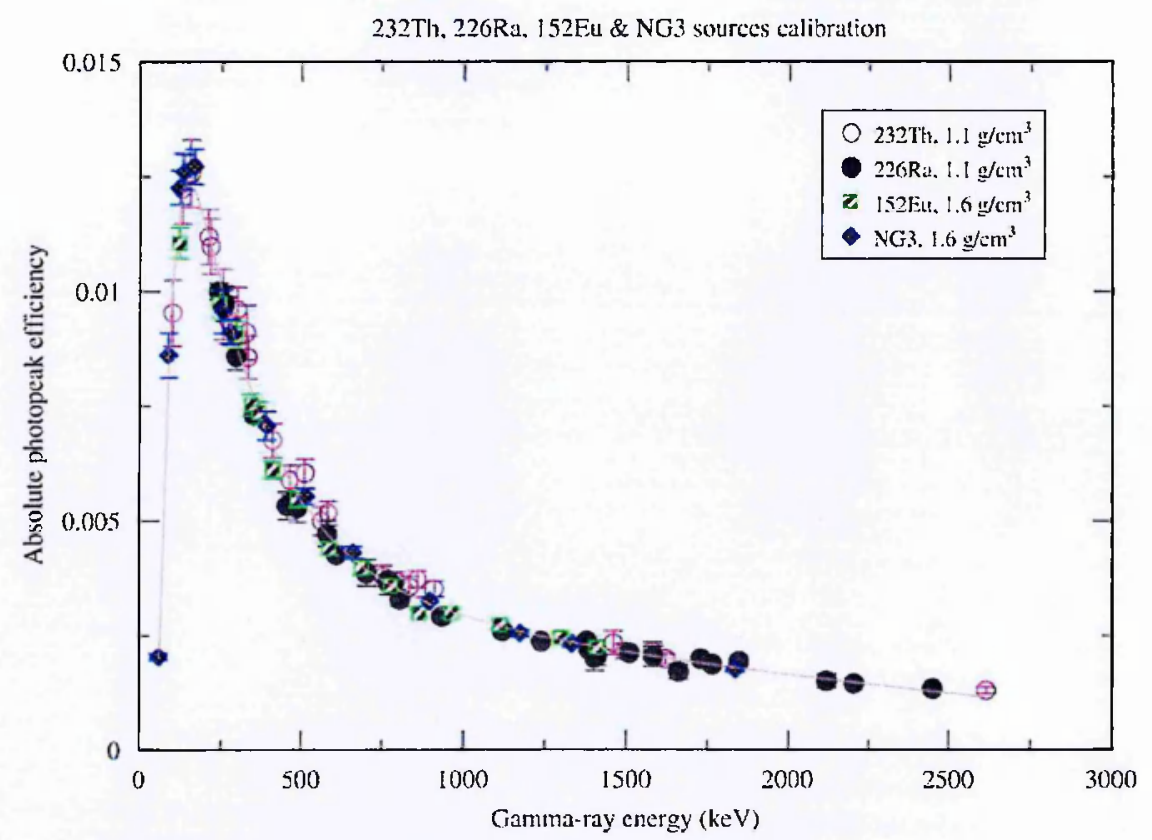

Fig. 3. Absolute efficiency curve of detector used in current work.

Table 1

The activity concentrations, the total absorbed dose and annual effective tose rate caused by ${ }^{226} \mathrm{Ra},{ }^{232} \mathrm{Th}$ and ${ }^{40} \mathrm{~K}$ from the sand samples in the current study.

\begin{tabular}{|c|c|c|c|c|c|c|}
\hline \multirow[t]{2}{*}{ Sample code } & \multirow[t]{2}{*}{ Location/site } & \multicolumn{3}{|c|}{ Activity concentrations $\left\langle\mathbf{B q} \mathbf{k g}^{-1}\right.$, } & \multirow{2}{*}{$\begin{array}{l}\text { Alusorbed dose rate } \\
\left(n G y h^{-1}\right)\end{array}$} & \multirow{2}{*}{$\begin{array}{l}\text { Effective dose rate } \\
\left(\mathrm{mSv} \mathrm{y}^{-1}\right)\end{array}$} \\
\hline & & ${ }^{226} \mathrm{Ra}$ & ${ }^{232} \mathrm{Tl}$ & ${ }^{40} \mathrm{~K}$ & & \\
\hline \multicolumn{7}{|l|}{ West coast } \\
\hline PKPT & Hat Patong. Phuket & $12.7 \doteqdot 0.3$ & $23.0 \div 0.4$ & $654.3 \pm 21.7$ & $46.7 \pm 0.9$ & $0.057 \div 0.001$ \\
\hline PNKL & Hat Khod Lak, Phangnga & $23.5 \div 0.4$ & $31.2 \pm 0.5$ & $155.6 \pm 5.5$ & $35.1 \pm 0.4$ & $0.044 \div 0.001$ \\
\hline KBNT & Hat Nopparattlaara. Krabi & $2.7 \pm 0.1$ & $3.0 \pm 0.1$ & $10.7 \pm 0.9$ & $3.5 \pm 0.1$ & $0.004 \pm 0.001$ \\
\hline \multicolumn{7}{|l|}{ East coust } \\
\hline CPSR & Hat Sai Ri. Chumporn & $3.2=0.1$ & $5.1 \pm 0.1$ & $182.4 \pm 8.6$ & $12.3 \pm 0.4$ & $0.015 \pm 0.001$ \\
\hline STCY & Hat Chaiya. Suratthani & $18.6=0.3$ & $34.5 \div 0.6$ & $559.7 \pm 18.6$ & $51.7 \pm 0.8$ & $0.063 \pm 0.001$ \\
\hline KNSN & Hat Khanom, Nakorn srithammarat & $11.6=0.1$ & $16.9 \pm 0.2$ & $500.9 \pm 6.9$ & $36.5 \pm 0.3$ & $0.045 \pm 0.001$ \\
\hline
\end{tabular}

NB. the reported uncertainty takes into ascount the statistics of counting only and does not seek to estimate error in conversion factor and outcioor occupancy factor.

close was calculated by the following equation [11]:

Annual effective dose $\left(m S v y r^{-1}\right)$

$$
\begin{aligned}
& =D\left(\frac{10^{9} G y}{h}\right) \times 24 \frac{h}{d a y} \times 365 \frac{\text { day }}{y} \times \frac{10^{-6} \mathrm{mGy}}{10^{9} \mathrm{~Gy}} \times 0.7 \frac{S y}{\overline{G y}} \times 0.2 \\
& =D \times 1.23 \times 10^{-3} \mathrm{mSvyr}^{-1}
\end{aligned}
$$

\section{Results and discussions}

Although there are hundreds of gamma rays emitted by ${ }^{226} \mathrm{Ra}$ and ${ }^{232} \mathrm{Th}$ decay daughters, the choice of gamma rays to be measured was made with care. For example, it is better to accept a peak free of summing and mutual spectral interferences, even its lower intensity decay branch compared to a contaminated line of higher-intensity [12]. One of the major interferences in the gamma spectrometry of NORM is the mutual interference between decays from ${ }^{226} \mathrm{Ra}(186.21 \mathrm{keV})$ and ${ }^{235} \mathrm{U}(185.27 \mathrm{keV})$. The contribution of counts in the $186 \mathrm{keV}$ peak can be mathematically calculated by using the ${ }^{235} \mathrm{U} /{ }^{238} \mathrm{U}$ isotopic ratio when the ${ }^{226} \mathrm{Ra}$ is in radioactive equilibrium with its parent ${ }^{238} \mathrm{U}$. However, the proportion in peak will give misleading results, if the ${ }^{226} \mathrm{Ra}$ is not in equilibrium with ${ }^{238} \mathrm{U}$. In this study, the activity of ${ }^{226} \mathrm{Ra}$ is not taken into account and only the ${ }^{214} \mathrm{~Pb}$ or ${ }^{214} \mathrm{Bi}$ activities will be used because of association with peak interferences and natura! disturbances that may cause disequilibrium between ${ }^{226} \mathrm{Ra}$ and its parent ${ }^{238} \mathrm{U}$. Therefore we discuss ${ }^{226} \mathrm{Ra}$ activity rather than ${ }^{238} \mathrm{U}$.

Table 1 represents the activity concentrations obtained following the gamma-ray spectrometry measurements of the sand samples. The preliminary analysis from six samples is presented in the current work. The activity concentrations of ${ }^{226} \mathrm{Ra},{ }^{232} \mathrm{Th}$ and ${ }^{40} \mathrm{~K}$ for sand samples from the west coast lie in the ranges $2.7 \pm 0.1 \leftrightarrow 23.5 \pm 0.4,3.0 \pm 0.1 \leftrightarrow 31.2 \pm 0.5$ and $10.7 \pm 0.9 \leftrightarrow 654.3 \pm 21.6 \mathrm{~Bq} \mathrm{~kg}^{-1}$ respectively. By contrast, the acivity concentrations of ${ }^{226} \mathrm{Ra},{ }^{232} \mathrm{Th}$ and ${ }^{40} \mathrm{~K}$ for sand samples from the east coast lie in the range of $3.2 \pm 0.1 \leftrightarrow 18.6 \pm 0.3$, $5.1 \pm 0.1 \leftrightarrow 34.5 \pm 0.6$ and $182.4 \pm 8.6 \leftrightarrow 559.7 \pm 18.6 \mathrm{~Bq} \mathrm{~kg}^{-1}$ respectively. It can be seen that the difference of radioactivity from sand samples between the west and east coast of Thailand is insignificant. The activity concentration of ${ }^{137} \mathrm{Cs}$ is under the minimum detectable activity meaning that effectively no measurable amount of artificial radionuclide is present in the sand samples in the current study. The total gamma absorbed 
Table 2

Activities results of ${ }^{238} \mathrm{U},{ }^{226} \mathrm{Ra}_{4}{ }^{232} \mathrm{Th},{ }^{10} \mathrm{~K}$ and ${ }^{137} \mathrm{Cs}$ obtained by gamma-ray spectrometry in beach sand samples. compared with previously reported data from Thailand and other countries.

\begin{tabular}{|c|c|c|c|c|c|}
\hline \multirow[t]{2}{*}{ Location } & \multicolumn{5}{|c|}{ Activity concentration ( $\mathrm{Bq} \mathrm{kg}{ }^{-1}$ dry) } \\
\hline & ${ }^{238} \mathrm{U}$ & ${ }^{226} \mathrm{Ra}$ & ${ }^{232} \mathrm{Th}$ & ${ }^{40} \mathrm{~K}$ & ${ }^{137} \mathrm{Cs}$ \\
\hline \multicolumn{6}{|l|}{ Present work Thailand } \\
\hline - West coast & - & $2.7 \leftrightarrow 23.5$ & $3.0 \leftrightarrow 31.2$ & $10.7 \nrightarrow 654.3$ & $<0.5$ \\
\hline - East coast & - & $3.2 \leftrightarrow 18.6$ & $5.1 \rightarrow 34.5$ & $182.4 \leftrightarrow 559.7$ & \\
\hline Songkhla. Thailand [14] & - & $0 \leftrightarrow 211(41)$ & $0 \leftrightarrow 319(64)$ & $89 \leftrightarrow 963(248)$ & $0-9(1)$ \\
\hline Trang, Thailand $|15|$ & - & $3.9 \curvearrowleft 27.4(13.1)$ & $2.3 \ldots 15.4(6.9)$ & $33.3 \leftrightarrow 85.2(57.3)$ & - \\
\hline Kalpakkam, Indial 16$]$ & $36 \leftrightarrow 258(124)$ & - & $352 \leftrightarrow 3872(1613)$ & $324 \leftrightarrow 405(358)$ & - \\
\hline Red Sea coast, Egypt ${ }^{\mid 17}$ & - & $10.0 \leftrightarrow 64.0$ & $9.0 \leftrightarrow 37.4$ & $421 \rightarrow 969$ & - \\
\hline Ezien region, Turkey ${ }^{|18|}$ & 290.4 & - & 532.0 & 1160.8 & - \\
\hline Southeast coast, Brazil $\mid 19\}$ & - & $5 \leftrightarrow 4043$ & $7 \leftrightarrow 55537$ & $25 \leftrightarrow 888$ & - \\
\hline Northeast coast, Spain ${ }^{|20|}$ & $5 \leftrightarrow 19$ & - & $5 \leftarrow 44$ & $136 \leftrightarrow 1087$ & $\leq 0.1-1.0$ \\
\hline West coast, South Africa $|21|$ & 4.0 & - & 4.8 & 33.5 & - \\
\hline
\end{tabular}

dose rate in air at $1 \mathrm{~m}$ above the ground surface ranges from $3.5 \pm 0.1$ to $52.8 \pm 0.9 \mathrm{nGyh}^{-1}$ with an average value of $31 \pm$ $1 \mathrm{nGy} \mathrm{h}-1$. The corresponding annual effective dose of $0.038 \mathrm{mSv}$ was found to be significantly lower than the world average value of $0.07 \mathrm{mSv} \mathrm{yr}^{-1}$ for the annual outdoor effective dose as reported by UNSCEAR(2000). The activity concentrations of ${ }^{226} \mathrm{Ra},{ }^{232} \mathrm{Th}$ and ${ }^{40} \mathrm{~K}$ in the beach sand samples from the present work have been compared with previous studies in Thailand and other countries, as shown in Table 2 . The activity concentration obtained in this study are found to be comparable with this previous data.

It should be noted that to ensure that there has been no ${ }^{222} \mathrm{Rn}$ loss from the samples, sample containers should ideally be completely sealed by the use of an ' $O$ ' ring [13] and special containers constructed from specific materials to prevent the escape of gaseous radon are also recommended.

\section{Conclusions}

The average value of the total gamma absorbed dose rate from sand samples was estimated to be $31 \pm 1 \mathrm{nGy} \mathrm{h}^{-1}$ leading to a predicted annual effective dose of $0.038 \mathrm{mSv}$, lower than the world average annual outdoor effective dose value of $0.07 \mathrm{mSvyr}^{-1} \mathrm{as}$ reported by UNSCEAR(2000), but consistent with the values reported by others for sand. No artificial radionuclides were observed above the MDA limit in the sand samples studied in the current work. The indication from the current work is that the monitored areas are at the typical local level of radioactivity from natural background radiation. The radioactivity concentrations of ${ }^{226} \mathrm{Ra},{ }^{232} \mathrm{Th}$ and ${ }^{40} \mathrm{~K}$ along the Andaman coast are comparable to that of the east coast which was not exposed to the tsunami. However, since the current preliminary data concerns only six samples from the area studied, further analysis will need to take place for a greater number of samples, the data including measurements of radioactivity in beach sand samples at different distances from the seashore to establish the associated distribution.

\section{Acknowledgements}

This work was carried out under scholarships from the Royal Thai Government awarded to DM and TS. HA acknowledges support from the Ministry of Environment, Doha-Qatar. The authors would like to express their deep gratitude to University of Surrey for providing the various facilities. A special thanks to the laboratory technicians, Mr. James Wallbank and
Mr. John-William Brown for all their help, technical support and valuable hints.

\section{References}

[1] W.F. Wilson. A Guide to Naturally Occurring Radioactive Material (NORM). PennWell Publishing Company, USA, 1994.

[2] National Council on Radiation Protection and Measurements (NCRP), 1987, Exposure of the Population in the United States and Canada from Natural Background Radiation, NCRP Report no. 94. Maryland.

[3] United Nations Scientific Committee on the Effects of Atomic Radiation. Soures and effects of ionizing radiation, 1993. Report to General Assembly. with Scientific Annexes (NY: UNSCEAR).

[4] United Nations Scientific Committee on the Effects of Atonic Radiation. Sources and effects of ionizing radiation, 2000. Report to Ceneral Assembly. with Scientific Annexes (NY: UNSCEAR).

[5] A.G. Conzalez. The safety of radioactive waste management: achieving internationally acceptable solutions, The IAEA Bulletin 42 (3) (2000) 5-18.

[6] Department of Mineral Resources, Tsunami. Ministry of Natural Resources and Environment, Thailand, 2005.

[7] P.W. Gray. A. Alimed, Linear classes of $\mathrm{Ge}(\mathrm{Li})$ detector efficiency functions, Nuclear Instruments and Methods in Physics Research. A 237 (1985) 577-589.

[8] H. Cember, T.E. Johnson, Introduction to Health Physics, fourth ed., McGrawHill, London, 2008.

[9] N.M. Ibrahim, Natural activities of $U$, Th and $K$ in building materials, Journal of Environmental Radioactivity 43 (1999) 255-258.

[10] L.A. Currie, Limits for qualitative detection and quantitative determination. Analytical Chemistry 40 (3) (1968) 586-593.

[11] S. Dragovic, et al., Assessment of gamma dose rate from terrestrial exposure in Serbia and Montenegro. Radiation Protection Dosimetry 121 (3) (2006) 297-302.

[12] G. Gordon, Practical Gamma-ray Spectrometry, second ed., John Wiley \& Sons Lid., England, 2008.

[13] B. Heaton, Field survey instrumentation and radioanalytical procedures for NORM. Applied Radiation and Isotopes 49 (1998) 197-204.

114] S. Benjakul, et al. Natural Radionuclide Distribution in Soil from Muang District in Songkhla Province, M. Sc. Thesis, Thaksin University, 2007.

[15] W. Ayusuk, et al., Quantitative Measurement of Natural Radioactivity in Beach Sand Samples from the Pakmeng Beach in Trang Province. Undergraduate Project in Science, Thaksin University. 2007.

[16] V. Kannan, et al., Distribution of natural and antropogenic radionuclides in soil and beach sand samples of Kalpakkam (India) using hyper pure germanium (HPGe) gamma rays spectroscopy. Applied Radiation and Isotopes 57 (2002) 109-119.

[17] A.M. El-Arabi, Natural radioactivity in sand used in thermal therapy at the Red Sea coast. Journal of Environmental Radioactivity 81 (2005) 11-19.

[18] Y. Orgun, et al., Natural and antropogenic radionuclides in rocks and beach sands from Ezine Region Western Anatolia, Turkey, Applied Radiation and Isotopes 65 (2007) 739-747.

[19] R. Veiga, et al.. Measurement of naturai radioactivity in Brazilian beach sands, Radiation Measurements 41 (2006) 189-196.

[20] J.R. Rosell, et al., Natural and artificial radionuclides on the Northeast coast of Spain, Health Physics 60 (1991) 709-712.

[21) R.T. Newman, et al., Determination of soil sand and ore primordial radionuclide concentrations by full-spectrum analyses of high-purity germanium detector spectra, Applied Radiation and Isotopes 66 (2008) 855-859. 